\title{
MPRA
}

Munich Personal RePEc Archive

\section{A Comparison Between Direct and Indirect Seasonal Adjustment of the Chilean GDP 1986-2009 with X-12-ARIMA}

Medel, Carlos A.

7 July 2014

Online at https://mpra.ub.uni-muenchen.de/57053/

MPRA Paper No. 57053, posted 03 Jul 2014 05:45 UTC 


\title{
A Comparison Between Direct and Indirect Seasonal Adjustment of the Chilean GDP 1986-2009 with X-12-ARIMA*
}

\author{
Carlos A. Medel ${ }^{\dagger}$
}

May 1, 2014

\begin{abstract}
It is well known among practitioners that the seasonal adjustment applied to economic time series could involve several decisions to be made by the econometrician. In this paper, I assess which aggregation strategy delivers the best results for the case of the Chilean GDP 1986-2009 quarterly dataset (base year: 2003). This is done by performing an aggregate-by-disaggregate analysis under different schemes, as the fixed base year dataset allows this fair comparison. The analysis is based exclusively on seasonal adjustment diagnostics contained in X-12-ARIMA program. A detailed description of the program and its quality assessment are also provided. The results show that it is preferred, in terms of stability, to use the first block of supply-side disaggregation as well as the direct mode.
\end{abstract}

JEL-Codes: C14, C18, C49, C65, C87.

Keywords: Seasonal adjustment, univariate time-series models, ARMA, X-12-ARIMA.

\section{Resumen}

Es bien sabido que el ajuste estacional aplicado a series de tiempo económicas puede significar la toma de varias decisiones por parte de quién realiza el ajuste. Así, en este trabajo se analiza qué estrategia de agregación entrega los mejores resultados para el caso del PIB chileno 1986-2009 trimestral (año base: 2003). Lo anterior se realiza mediante comparaciones de las series agregadas a través de sus componentes bajo distintos esquemas de agregación, dado que los datos de año base fijo permiten una comparación justa. El análisis se basa exclusivamente en las herramientas de diagnóstico de estacionalidad contenidos en el programa X-12-ARIMA. También se describe detalladamente el programa y sus herramientas de análisis de la calidad del ajuste. Los resultados indican que es preferible, en términos de estabilidad, el uso del primer bloque de desagregación por el lado de la actividad, así como también del PIB ajustado como tal.

Códigos JEL: C14, C18, C49, C65, C87.

Palabras clave: Ajuste estacional, modelos de series de tiempo univariados, ARMA, X-12-ARIMA.

*I thank Rodrigo Alfaro, Carlos Alvarado, Consuelo Edwards, Mario Giarda, Carlos P. Medel, Michael Pedersen, Pablo Pincheira, and Damián Romero for comments and suggestions. I also thank Applied Econometrics II students at University of Chile. X-12-ARIMA is a product of US Census Bureau and is freely available at http://www. census.gov/srd/www/x12a/. The version used in this paper is the 0.2.10.

†E-mail: carlos_medel@yahoo.com. 


\section{Resumen no técnico}

Es bien sabido que el ajuste de remoción de la estacionalidad-movimientos intraanuales sistemáticos-aplicado a series de tiempo económicas puede significar la toma de varias decisiones por parte de quién realiza el ajuste, sobre algunos parámetros que gobiernan el proceso. Así, en este trabajo se analiza qué estrategia de agregación entrega los mejores resultados para el caso del PIB chileno 1986-2009 de frecuencia trimestral (año base: 2003). De esta forma, se cuenta con una apreciación adecuada sobre qué conjunto de series, que componen el PIB chileno bajo la metodología de año base fijo, entregan un resultado más estable que otros conjuntos de series que también originan el PIB chileno.

El análisis se realiza mediante comparaciones de las series agregadas resultantes ajustadas por estacionalidad a través de sus componentes, bajo distintos esquemas de agregación tradicionalmente utilizados con este tipo de datos. Esta comparación es justa, en parte, debido a que los datos construidos bajo la metodología de año base fijo aseguran la aditividad exacta de las series originales. La respuesta se basa exclusivamente en las herramientas de diagnóstico de estacionalidad contenidos en el programa X-12-ARIMA, desarrollado por el US Census Bureau, y de amplia utilización en oficinas estadísticas internacionales. En el trabajo también se describe detalladamente el programa y sus herramientas de análisis de la calidad del ajuste.

Los resultados indican que es preferible en términos de estabilidad, es decir, los resultados de menor variación promedio mientras nuevas observaciones se agregan al análisis, el uso del primer bloque de desagregación por el lado de la actividad, así como también del PIB ajustado como tal sin desagregar. 


\section{Introduction}

It is well known among practitioners that seasonal adjustment applied to economic time series could involve several decisions to be made by the econometrician. Many of these decisions concern parameters to be fixed prior to the adjustment process and are included in traditional programs such as X-12-ARIMA or TRAMOSEATS. ${ }^{1}$ In spite of these advances, there is no consensus about a particular method to obtain robust results. Specifically, the decisions to be made by the econometrician seem to be case dependent and based merely on empirics. ${ }^{2}$ In the case of an aggregate series-that already is a weighted sum of disaggregates-, there are several strategies to perform a seasonal adjustment, for instance, by: (i) adjusting an aggregate series by itself, (ii) adjusting components of the aggregate with the same methodology and then aggregate to the original, and (iii) adjusting components with a different methodology and adding up to the original. These strategies could deliver results that strongly differ from each other. Some reasons for this difference are nonlinearities in the components, different seasonal patterns through themselves, and difficulties in identifying the trading day effect.

In this paper, I assess the question of which of these strategies performs the most stable results for the case of the Chilean Gross Domestic Product (GDP) 1986-2009 quarterly dataset (base year: 2003). I perform an aggregate-by-disaggregate analysis under different schemes, based exclusively on the diagnostics for seasonal adjustment contained in the X-12-ARIMA program (hereafter, X12). These capabilities include spectral plots, sliding-spans-based diagnostics and revision history diagnostics, all of them simple checks that cast for both quality and stability of results. ${ }^{3}$ By performing this exercise, I will be able to provide an informed opinion about which scheme provides the most stable seasonal adjustment for the mentioned Chilean GDP vintage. Obviously, the same strategy can be applied to another dataset to investigate the same problem. However, notice that since 2009 the GDP dataset is released under the linked-chain methodology, losing its additive property. Hence, this exercise should be read as a benchmark for future research in this matter.

Note that as seasonal adjustment does not have an objective definition, the term "accurate" cannot operate under these circumstances. Instead, I considered the more stable as the best result. The exercise is carried out on the automatic program default mode, according to the suggestions presented in Maravall (2002). Then, if a component does not fulfill the statistical criteria of an acceptable result, minimal interventions are made one-by-one until all test are fulfilled.

The question about how we know if it is better to use direct or indirect adjustment is similar to that treated in Astolfi, Ladiray, and Mazzi (2001), Hood and Findley (2001), Otranto and Triacca (2002), among other papers. Nevertheless, to the author's knowledge, no similar study has been carried out with Chilean GDP data. It is worth mentioning that despite several testing procedures contained in X12, choosing between direct and indirect adjustment constitutes a different, separate question. This is because the challenge consists of choosing appropriate diagnostics to compare between several adjustments applied to the same variable. Some diagnostics would be replicated while others, as those of stability and quality, need more attention and careful treatment. This would lead to proceed without, for instance, the $M 1-M 11$ and $Q$ statistics (described later) integrated in X12, or a deviation measure from direct approach. Moreover, as Hood and Findley (2001) suggest, the ratio of one adjustment to another is also not valid, because spurious seasonality emerges. These and many other examples remark the importance of a tailored quality assessment: different users would weigh different diagnostic outputs pursuing their own objectives. Take the case, for instance, of an adjuster that will make use of seasonally adjusted series in a turning point detection analysis. The smoothness in the resulting series will likely be a desirable outcome. For these and other reasons to be discussed later, I make use of diagnostics that allow a quality and stability assessment for indirect adjustment, namely, spectral analysis in the frequency domain, sliding spans and revision history. The key is to have always in mind the goal of the absence of residual seasonality; that is, absence of seasonality in series that theoretically should not have it.

\footnotetext{
${ }^{1}$ See Findley et al. (1998) and Gómez and Maravall (1997) for details.

${ }^{2}$ Astolfi, Ladiray, and Mazzi (2001).

${ }^{3}$ See Findley et al. (1998) and US Census Bureau (2011) for a full description and analysis of the new capabilities with respect to previous version of the program, the X-11-ARIMA (Dagum, 1980).
} 
The results show that in terms of stability it is recommended to use the direct-the GDP by itself-as well as the first stage of disaggregation by supply-side. This result relies on the output of the three diagnostics tools used by X12, and exploiting the additive characteristic of the dataset. Therefore, I take into account just a stability criterion to discriminate between aggregations. Moreover, the results for the second and third stage of disaggregation by demand-side are very poor, according to the standard automatic setup described later. Particularly powerful tools to discriminate are spectral plots and sliding spans, both estimated to the final seasonally adjusted series.

The paper proceeds as follows. In section 2, I describe the program. Then, I review the diagnostics contained in X12. In section 3 I provide some intuition about why both kinds of adjustments may differ, along with some elements to consider to revert poor results. ${ }^{4}$ In section 4 I apply these procedures to the Chilean GDP obtained by five different aggregation schemes-by supply- and demand-side-plus the GDP by itself. I conclude in section 5 .

\section{The X-12-ARIMA program}

The X12 program is developed by the US Census Bureau (http://www.census.gov/) and is based in the well-known X-11 program introduced in 1965 (Shiskin, Young, and Musgrave, 1967), and the Statistics Canada's X-11-ARIMA program (Dagum, 1980). X12 enhances its previous versions by including more filters and automatic modeling techniques that improve the quality of adjustment. It also offers a user-friendly customization of the process, especially useful for batch mode. Recall that the purpose of the program is to decompose a time series $\left(y_{t}\right)$ into a trend-cycle component $\left(y_{t}^{\tau}\right)$ plus (or times, depending on the kind of seasonality) a seasonally adjusted component $\left(y_{t}^{s a}\right)$, plus (or times) a residual irregular component $\left(y_{t}^{i r}\right.$; then $y_{t}=y_{t}^{\tau}+y_{t}^{s a}+y_{t}^{i r}$, or $\left.y_{t}=y_{t}^{\tau} \times y_{t}^{s a} \times y_{t}^{i r}\right)$. Hence, the two latter components, $y_{t}^{s a}$ and $y_{t}^{i r}$, should not exhibit a cyclical behavior. Furthermore, trends and seasonally adjusted series (the log-difference) tend to attract a lot of attention, which redound on the importance of stability as a measure of economic diagnostic reliability. As Granger (1979) pointed out, this decomposition is relevant because seasonality explains most of the variance of a series, being economically insignificant.

The description of the adjustment proposed by the X12 program lies in the description of the X-11 program, which is fully developed in Ladiray and Quenneville (2001). According to figure 1, the chronological sequence of a typical adjustment begins with preadjustments (the RegARIMA module) prior to entering the seasonal adjustment itself, made with X-11-based tools. Note that series of these blocks are tested with a battery of specific diagnostics, iterating until the required statistical characteristics are fulfilled.

The RegARIMA module, one of the major enhancements with respect to X-11, ${ }^{5}$ works basically as follows. The objective is to prepare the series prior to the adjustment, by controlling for several undesirable effects. These corrections are made with a regression with ARIMA noise (which takes the name RegARIMA) that includes a control set $X=\left[\begin{array}{lll}x_{1} & \ldots & x_{I}\end{array}\right]$ :

$$
\phi(L) \Phi\left(L^{s}\right)(1-L)^{d}\left(1-L^{s}\right)^{D}\left(y_{t}-\sum_{i} \beta_{i} x_{i t}\right)=\theta(L) \Theta\left(L^{s}\right) z_{t},
$$

where $L$ is the backshift operator $\left(L^{p} y_{t}=y_{t-p}\right), s$ is the seasonal period, $\phi(L)$ is the nonseasonal autoregressive (AR) operator, $\Phi\left(L^{s}\right)$ is the seasonal AR operator, $\theta(L)$ is the nonseasonal moving average (MA) operator, $\Theta\left(L^{s}\right)$ is the seasonal MA operator, and $z_{t}$ is iid with zero mean and variance equal to $\sigma_{z}^{2}$ (white noise). Note that $z_{t}$ is modeled with an ARIMA process as the series $y_{t}$ after these controls commonly exhibits autocorrelation.

\footnotetext{
${ }^{4}$ Readers already familiarized with the program can skip sections 2 and 3 without losing information or structure.

${ }^{5}$ A complete list of these enhancements is: (i) the inclusion of sliding spans as a tool for testing stability, (ii) revision history diagnostics also for stability, (iii) new Henderson trend filter routine, (iv) new options for seasonal filters, (v) new outlier detection options, (vi) a new table to analyze pertinence of trading-day effects, and (vii) a pseudo-additive decomposition (US Census Bureau, 2011).
} 
Figure 1: Flow diagram for seasonal adjustment with X12

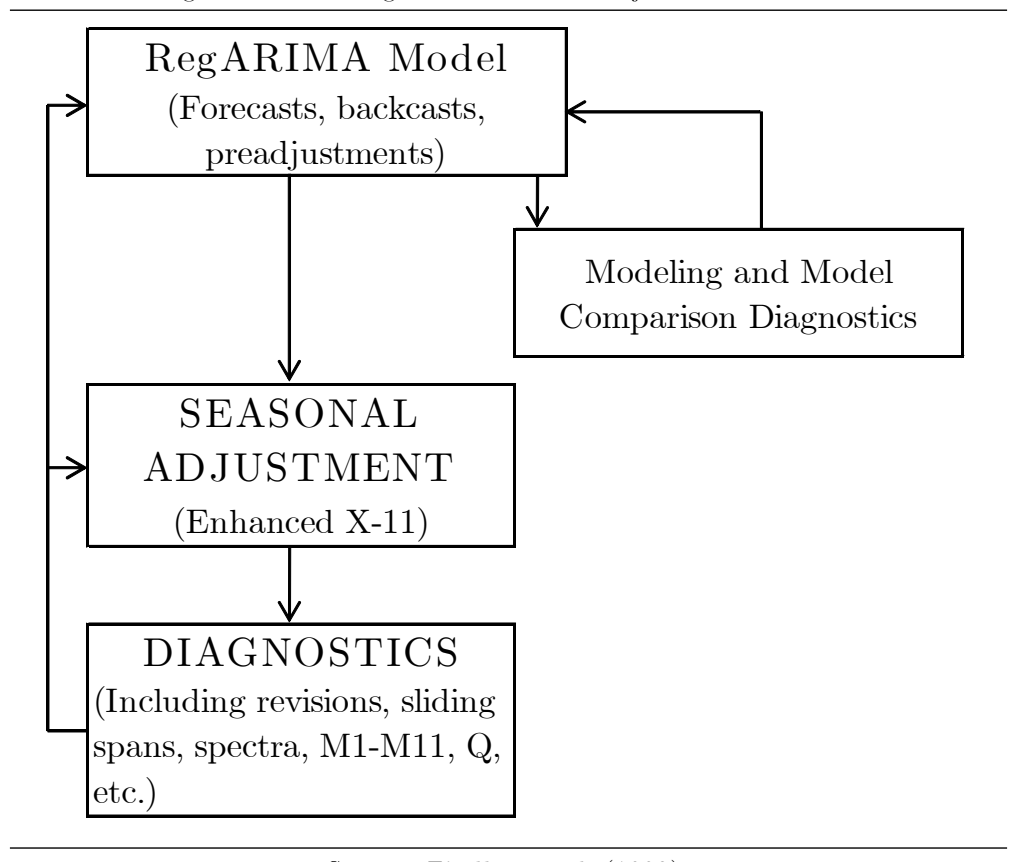

Source: Findley et al. (1998)

This representation states for a time-varying mean for $y_{t}$ while including controls; otherwise, $y_{t}$ has a constant mean. In X12, $x_{i}$ controls are optional, and some of them have options as well. These controls are the following (the option used by the original program is presented in [ ]; US Census Bureau, 2011, Table 4.1 , pp. 36-38):

- Trend constant [const]:

$$
(1-L)^{-d}\left(1-L^{s}\right)^{-D} I(t \geq 1), \text { where } I(t \geq 1)= \begin{cases}1 & \text { for } t \geq 0 \\ 0 & \text { for } t<1\end{cases}
$$

- Fixed seasonal [seasonal]:

$$
M_{1, t}=\left\{\begin{array}{cc}
1 & \text { in January } \\
-1 & \text { in December } \\
0 & \text { otherwise }
\end{array}, \ldots, M_{11, t}=\left\{\begin{array}{cc}
1 & \text { in November } \\
-1 & \text { in December } \\
0 & \text { otherwise }
\end{array}\right.\right.
$$

In series with frequency equal to $s$ per year, it can be modeled with $s$ variables. While the sum of those $s$ variables adds to one, perfect collinearity problem arises with constant term-typically to control for measuring units. To overcome this shortcoming, X12 includes $s-1$ regressors with appropriate specification.

- Fixed seasonal $[\sin \cos []]$ :

$$
\sin \left(\omega_{j} t\right), \cos \left(\omega_{j} t\right), \text { where } \omega_{j}=2 \pi j / 12,1 \leq j \leq 6\left(\text { drop } \sin \left(\omega_{6} t\right) \equiv 0\right) .
$$

- Trading day (monthly or quarterly flow) [tdnolpyear, td]:

$$
T_{1, t}=(\# \text { of Mondays })-(\# \text { of Sundays }), \ldots, T_{6, t}=(\# \text { of Saturdays })-(\# \text { of Sundays }) .
$$

- One Coefficient Trading Day (monthly or quarterly flow) [td1nolpyear, td1coef]:

$$
\text { (\# of weekdays) }-\frac{5}{2} \text { (\# of Saturdays and Sundays). }
$$


- Length-of-Month (monthly flow) [lom]:

$m_{t}-\bar{m}$, where $m_{t}=$ length of month $t$ (in days) and $\bar{m}=30.4375$ (average length of month).

- Length-of-Quarter (quarterly flow) [1oq]:

$q_{t}-\bar{q}$, where $q_{t}=$ length of quarter $t$ (in days) and $\bar{q}=91.3125$ (average length of quarter).

- Leap Year (monthly or quarterly flow) [lpyear]:

$$
L Y t=\left\{\begin{array}{cc}
0.75 & \text { in leap year February (first quarter) } \\
-0.25 & \text { in other Februaries (first quarter) } \\
0 & \text { otherwise }
\end{array}\right.
$$

- Stock Trading Day (monthly stock) [tdstock $[w]]$ :

$$
\begin{aligned}
D_{1, t} & =\left\{\begin{array}{cc}
1 & \widetilde{w}^{t h} \text { day of the month } t \text { is a Monday } \\
-1 & \widetilde{w}^{t h} \text { day of the month } t \text { is a Sunday } \\
0 & \text { otherwise }
\end{array},\right. \\
D_{6, t} & =\left\{\begin{array}{cc}
1 & \widetilde{w}^{t h} \text { day of the month } t \text { is a Saturday } \\
-1 & \widetilde{w}^{t h} \text { day of the month } t \text { is a Sunday } \\
0 & \text { otherwise. }
\end{array}\right.
\end{aligned}
$$

- Statistics Canada Easter (monthly or quarterly flow) [sceaster [w]]:

$$
E(w, t)=\left\{\begin{array}{cc}
n_{E / w} & \text { in March } \\
-n_{E / w} & \text { in April } \\
0 & \text { otherwise }
\end{array}\right.
$$

- Easter Holiday (monthly or quarterly flow) [easter $[w]]$ :

$$
E(w, t)=\frac{1}{w} \times[\# \text { of the } w \text { days before Easter falling in month (or quarter) } t] .
$$

- Labor Day (monthly flow) [labor $[w]]$ :

$$
L(w, t)=\frac{1}{w} \times[\# \text { of the } w \text { days before Labor Day falling month } t] .
$$

- Thanksgiving (monthly flow) $[\operatorname{thank}[w]]$ :

$$
\begin{aligned}
T h C(w, t)= & \text { proportion of days from } w \text { days before Thanksgiving through } \\
& \text { December } 24 \text { that fall in month } t .
\end{aligned}
$$

- Additive Outlier at $\mathbf{t}_{\mathbf{0}}\left[\right.$ aodate $e_{0}$ :

$$
A O_{t}^{\left(t_{0}\right)}= \begin{cases}1 & \text { for } t \neq t_{0} \\ 0 & \text { for } t=t_{0}\end{cases}
$$

- Level Shift at $\mathbf{t}_{0}\left[1 \mathrm{~s} d a t e_{0}\right]$ :

$$
L S_{t}^{\left(t_{0}\right)}=\left\{\begin{array}{cc}
-1 & \text { for } t<t_{0} \\
0 & \text { for } t \geq t_{0}
\end{array}\right.
$$

- Temporary Change at $\mathbf{t}_{0}\left[\right.$ tcdate $\left._{0}\right]$ :

$$
T C_{t}^{\left(t_{0}\right)}=\left\{\begin{array}{cc}
0 & \text { for } t<t_{0} \\
\alpha^{t-t_{0}} & \text { for } t \geq t_{0}
\end{array}\right.
$$


- Ramp, $\mathbf{t}_{\mathbf{0}}$ to $\mathbf{t}_{\mathbf{1}}\left[\right.$ [rpdate $e_{0}-$ date $\left._{1}\right]$ :

$$
R P_{t}^{\left(t_{0}, t_{1}\right)}=\left\{\begin{array}{cc}
-1 & \text { for } t \leq t_{0} \\
\frac{t-t_{0}}{t_{1}-t_{0}}-1 & \text { for } t_{0}<t<t_{1} \\
0 & \text { for } t \geq t_{1}
\end{array}\right.
$$

Note that some of these controls are stocks, while others are flows. Fuzzy special cases are those related to trading days, such as the moving (nonfixed) holidays. These are all those holidays defined as a rule, not falling on a specific calendar day, for instance, every first Thursday of every September. In the Chilean case, these cases would be all those affected by a bill passed some years ago that consists in moving particular holidays falling on a working day (different to Monday) to the nearest Monday of that week.

RegARIMA completes three substeps concerning identification, estimation and diagnostic checking. The identification of the ARIMA model is based on partial autocorrelation and sample autocorrelation techniques. It also includes an automatic algorithm of model selection similar to that proposed by Víctor Gómez and Agustín Maravall (the TRAMO procedure; 1997). For specific user-defined regressors, the program makes use of traditional information criteria to assess adequacy (AIC, AICC, BIC and Hannan-Quinn). However, traditional $t$-Statistics for individual parameter testing, and $\chi^{2}$ for a group of variables, are also reported. The module also forecasts and backcasts the original series based on estimated ARIMA models with predefined $(p, d, q)$ combinations. Forecasts are traditionally used in this context to reduce changes in the adjusted series as new observations become available, often referred to as revisions (Bobbitt and Otto, 1990). The criterion that casts best for a forecasting model used in X12 is the root mean squared error.

The estimation is made via maximum likelihood using the Iterated Generalized Least Squared method (IGLS; see Otto, Bell, and Burman, 1987). The first battery of diagnostics is applied next. These checks are used to assess the overall adequacy of controls and user-defined regressors as well as forecast and backcast accuracy. They are based mainly on the AR spectrum diagnostics similar to that contained in the BAYSEA program (Bayesian Seasonal Adjustment; Akaike and Ishiguro, 1980), by examining the RegARIMA resulting residuals in search for additive outliers, level shifts, among other anomalies. More details can be found in Findley et al. (1998) and US Census Bureau (2011).

The remaining seasonal adjustment process continues with the fitted value of the RegARIMA model. At the end of the process, the excluded controls are added to the irregular component to then sum up all the components to conform the original series.

Once all diagnostics are passed, the resultant series enters the seasonal adjustment module. This module is based on the X-11 iterative algorithm, which makes use of successive estimates of MAs. The goal of this module is to separate-with all diagnostics approved-the series into the following components: trend-cycle $\left(y_{t}^{\tau}\right)$, seasonal adjusted series $\left(y_{t}^{s a}\right)$, trading-day component $\left(y_{t}^{t d}\right)$, Easter holiday $\left(y_{t}^{E}\right)$, and an irregular component $\left(y_{t}^{i r}\right)$. Note that X-11 does not distinguish between trend and cycle, basically because the series traditionally analyzed does not provide enough sample span to determine whether it is trend or cycle. ${ }^{6}$ The seasonal component represents intra-year fluctuations, that is, regularities that are repeated more or less year after year. This implies that the method is built to deal exclusively with monthly or quarterly series. The trading day component measures the different composition of days of the week in a month or quarter. The Easter holiday measures this specific effect in the same spirit of the trading day effect. Finally, the irregular component combines all the remaining effects not covered by the abovementioned components, and exhibits an erratic behavior hard to associate with specific clearly identified intra-year fluctuations. So, X-11 proposes two decompositions:

1. Additive: $y_{t}=y_{t}^{\tau}+y_{t}^{s a}+y_{t}^{t d}+y_{t}^{E}+y_{t}^{i r}$, and

2. Multiplicative: $y_{t}=y_{t}^{\tau} \times y_{t}^{s a} \times y_{t}^{t d} \times y_{t}^{E} \times y_{t}^{i r}$.

\footnotetext{
${ }^{6}$ Note that this component, despite its name, does not necessarily match the concept of trend in the traditional economics usage.
} 
In addition, X12 includes two more decompositions:

1. Log-additive: $\log \left(y_{t}\right)=\log \left(y_{t}^{\tau}\right)+\log \left(y_{t}^{s a}\right)+\log \left(y_{t}^{t d}\right)+\log \left(y_{t}^{E}\right)+\log \left(y_{t}^{i r}\right)$, and

2. Pseudo-additive: $y_{t}=y_{t}^{\tau} \times\left(y_{t}^{s a}+y_{t}^{t d}+y_{t}^{E}+y_{t}^{i r}-1\right)$.

The identification of each component is made one by one, based on MAs. ${ }^{7}$ A simple algorithm of two stages-noted with super indices-as Ladiray and Quenneville (2001) show, is presented in table 1.

Table 1: The X-11 basic algorithm

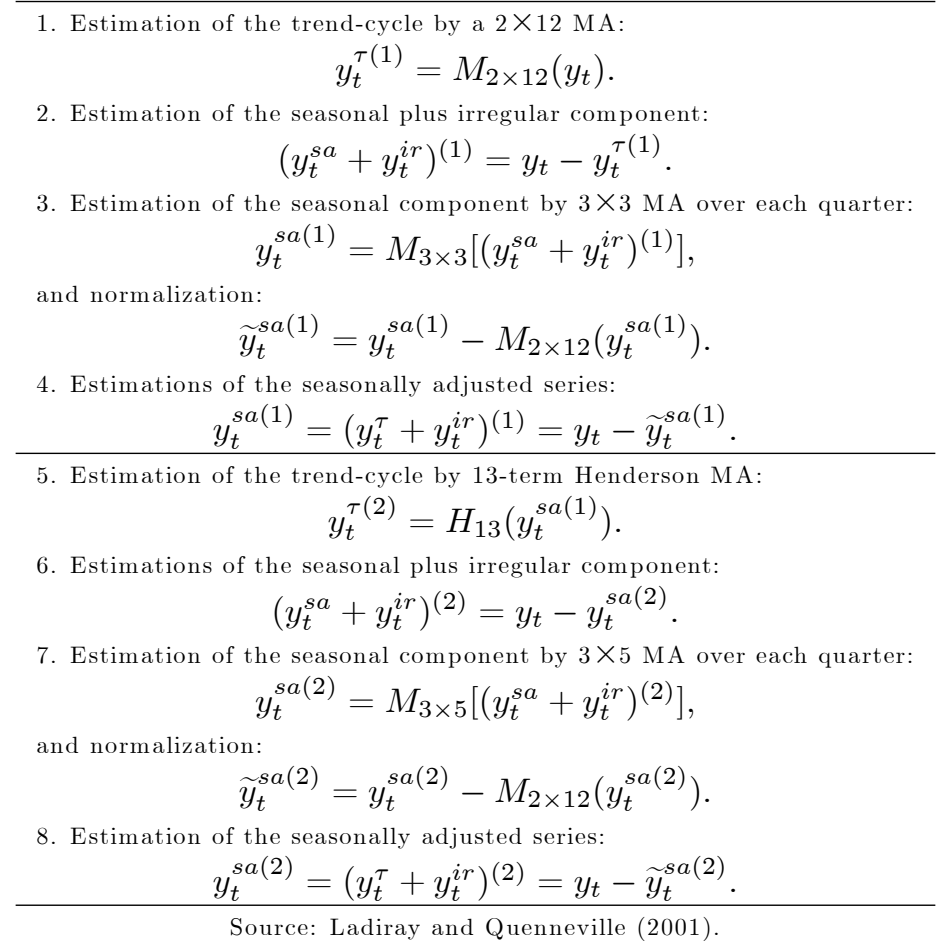

Note that in the X-11 program the outliers, level shift, and other effects are identified after the application of the algorithm of table 1, to then iterate until all undesirable effects are disseminated off the adjusted series. In $\mathrm{X} 12$, this identification is made within the RegARIMA module, prior to the adjustment. The outlier detection-for-correction process is a key element for MA stability, along with forecasts to reduce revision changes as new data becomes available.

The final module of X12 is an overall diagnostics checking. It is based on several tables-for analyzing intraannual movements of series with ease- provided by X-11-ARIMA as well as the M1-M11 quality-control statistics, summarized in annex A. These eleven $M$ statistics, discussed in Lothian and Morry (1978), is a set of controls with an intuitive and easy interpretation: values above 1 -ranging from 0 to 3 -redound in a poor adjustment for a particular reason. All of them are constructed with the purpose of checking the contribution of trend-cycle, seasonally adjusted and irregular component to changes of the original series. A weighted average of all of them constitutes another couple of statistics, $Q 1$ and $Q 2$, both F distributed, pertaining to

\footnotetext{
${ }^{7} \mathrm{An}$ MA of coefficients $\left\{\theta_{i}\right\}$ is defined as $M\left(y_{t}\right)=\sum_{i=-p}^{f} \theta_{i} y_{t+i}$, where $p$ represents past values and $f$ future values of $y_{t}$ series. So, the problem is reduced to finding a set of coefficients $\left\{\theta_{i}\right\}$ with $p$ and $f$ fixed, that works for identification purposes. Several "known" distributions of $\theta_{i}$ are proposed. See, for instance, Koyck (1954) and Almon (1965). Note that a compact notations $m \times n$ or $M_{m \times n}$ are also used. For instance, a $3 \times 4$ moving average is the average of 4 consecutive $\gamma_{t}$ terms (from $t$ to $t+4$ ), where each $\gamma_{t}$ is composed by 3 consecutive terms centered-equally weighted when MA is symmetric-at $t$ : $\gamma_{t}=\frac{1}{3} y_{t-1}+\frac{1}{3} y_{t}+\frac{1}{3} y_{t+1}$. Thus, the sequence of $\theta_{i}$ terms corresponds to $\frac{1}{12}\{1,2,3,3,2,1\}$. The Henderson MA-trend is also used because it has the ability to reproduce up to third-order polynomials, thereby capturing trend turning points. It consists of specific distributions of the $\theta_{i}$ values, that can be either symmetric $\left(\theta_{i}=\theta_{-i}\right)$ or asymmetric $\left(\theta_{i} \neq \theta_{-i}\right)$. See details in Henderson (1916).
} 
irregular and seasonal component, respectively. Several improvements were made in order to merge both $Q$ statistics into one (the $Q$-stat), keeping the quality signal anchored to 1 . In the same spirit, X12 reports the "Table $D 8$ " as an output that contains the result of an ANOVA. X12 reports a test based on all statistics shown in Table $D 8$ to test for stable and moving seasonality jointly, configuring a combined test for the presence of identifiable seasonality. As a set of individual significance tests in traditional econometricsglobal significance-the joint statistic is $\mathrm{F}$ distributed, and receives the denomination " $D 8 \mathrm{~F}$-test" for short.

\section{$3 \quad$ Diagnostics and results handling}

Instability of adjustment is a crucial problem recognized in X12. For that reason, user-defined regressors were included in X12, and major improvements were incorporated to assess the reliability of these interventions. Some of these are the use of spectral plots for detecting seasonality, and warnings to the user based on sliding spans and revision history diagnostics. All three will be detailed below and constitute adequate diagnostics to compare the adjustment between direct and indirect strategies-and perhaps, between a number of methods. It is common from a practitioner's point of view to see seasonal adjustment as a tool for smoothness-a filtering technique. But, as will be shown, the smoothness pursued by seasonal adjustment is in spectral plots of seasonally adjusted series and the irregular component, instead of the original series that generates those spectra.

An important remark on X12's diagnostics is provided by Hood (2007). As she explains, M7 and D8 Ftests are not designed to detect residual seasonality. Instead, they are for testing stable seasonality in the actual series-if the original series is seasonal. Note that this kind of testing is model-specific, implying that ultimately depends on user preferences of RegARIMA parameters. Rather, some model-free diagnostics as spectral plots applied to (log-differenced) original series produce better results in detecting seasonality. ${ }^{8}$ Notice that in the case of indirect adjustment it is possible to finding residual seasonality despite the quality of its disaggregates, remarking that the answer relies ultimately on empirics (Hood and Findley, 2001).

\subsection{Spectral plots}

In the context of X12, the use of spectral plots is for detecting seasonality and trading-day effects in the original series as well as residual seasonality in seasonally adjusted series, plus the irregular component. Spectral analysis was introduced firstly for economic time series analysis in the 1960s by Cunnyngham (1963), Hatanaka (1963), Granger and Morgenstern (1963), Granger and Hatanaka (1964), and Nerlove (1964), among others. ${ }^{9}$

An economic time series can be analyzed from two points of view: frequency domain and time domain. The intuition behind frequency domain lies in the useful manner in which a variable can be plotted in terms of its cycles-measuring its strength in decibels-for any given frequency, without requiring new information. Thus, spectral analysis allows analyzing the relationships between the frequencies with ease. The graph of frequencies versus decibels is called the periodogram-a special case of the spectrum. In a spectral graph, the low frequencies to the left correspond to slowly changing components-like the trend-while higher frequencies correspond to rapidly changing components-like the irregular component. Peaks in the spectral plot at certain frequencies of actual data indicate the presence of seasonality and trading day effect. The sample spectrum for a size $T$ for the series $\left\{y_{t}\right\}_{t=1}^{t=T}$, measured in decibels, corresponds to:

$$
\widehat{s}(\lambda)=10 \cdot \ln \left\{\frac{\widehat{\sigma}_{m}^{2}}{2 \pi\left|1-\sum_{j=1}^{m} \widehat{\phi}_{j} e^{i 2 \pi j \lambda}\right|^{2}}\right\},
$$

\footnotetext{
${ }^{8}$ Findley et al. (1998) agree that the spectrum and sliding-span diagnostics can be used, as well as RegARIMA model diagnostics, as a better alternative to F-test, which tends to indicate false positive cases. Also, Hood (2007) found that X12's default spectrum-built in an AR(30) model-is a better indicator to find seasonality than $D 8 \mathrm{~F}$-test, $\chi^{2}$, and an AR(10) spectrum.

${ }^{9}$ For a comprehensive use of the spectrum for economic time series analysis, see Hamilton (1994).
} 
where $0 \leq \lambda \leq \frac{1}{2}$ represents frequency measured in radians, $\lambda=\frac{k}{12}$, with $1 \leq k \leq 6$, being relevant the frequencies $\frac{1}{4}$ and $\frac{1}{2}$ cycles per quarter, for quarterly series. The $\widehat{\phi}_{j}$ coefficients are extracted from an estimated AR process of $y_{t}-\bar{y}$ regressed by $y_{t-m}-\bar{y}$, where $1 \leq j \leq m$, with $\bar{y}=\frac{1}{T} \sum_{t=1}^{T} y_{t}$, and $\widehat{\sigma}_{m}^{2}$ is the sample variance of the resulting regression residuals. This AR process is of order $30-\mathrm{AR}(30)$ or $m=30$-in the default mode. The order 30 is chosen basically because captures most of the dynamic of the series. An order $m$ chosen with information criteria, such as the AIC, tends to generate smoother spectral amplitudes. Since the $\widehat{\phi}_{j}$ parameters are variance-corrected covariances between $y_{t}$ and $y_{t-j}$, the informational content of the spectrum with respect to the time domain remains fixed (Hamilton, 1994). Note that using the De Moivre's theorem, the term $e^{-i \lambda j}$, where $i$ stands for $\sqrt{-1}$, is equal to $\cos (\lambda j)-i \cdot \sin (\lambda j)$, and using the known trigonometrical results $\cos (0) \equiv 1, \sin (0) \equiv 0, \sin (-\theta) \equiv-\sin (\theta)$, and $\cos (-\theta) \equiv \cos (\theta)$, the expression can be written in terms of the cosine function. Since $\cos (\lambda j)=\cos [(l+2 \pi k) j]$ for any integers $k$ and $j$, the spectrum is a periodic function of $\lambda$. Hence, we need to know the values of $\widehat{s}(\lambda)$ between 0 and $\pi$ to infer the periodogram value for any $\lambda$.

The decision about the quality of the adjustment in X12 consists of a "visual significance", similar to the BAYSEA program. ${ }^{10}$ The series has seasonality if the spectrum exhibits a peak at frequencies of $\frac{1}{2}$ or $\frac{1}{4}$. The trading day effect is present if a peak is observed at the frequency of 0.34821 for monthly series, and at 0.04464 for quarterly series. ${ }^{11}$ As the spectrum is used to test the quality of the adjustment, it is also estimated for the differenced final seasonal adjusted series and the final irregular component. Soukup and Findley (1999) also suggest to analyzing the resultanting RegARIMA residual spectra in cases where first two spectra do not discriminate. This can be done at the cost of hurting the rate of false discovery of seasonality as well as trading day effect. ${ }^{12}$ A peak is called significant if it is above the median of $\widehat{s}\left(\lambda_{k}\right)$ values, and must be larger than its neighboring (not including $\lambda_{60}=\frac{1}{2}$ ) values $\widehat{s}\left(\lambda_{k-1}\right)$ and $\widehat{s}\left(\lambda_{k+1}\right)$ by at least $\frac{6}{52}$ times the range $\widehat{s}^{\max }-\widehat{s}^{\min }$, where $\widehat{s}^{\max }=\max _{k} \widehat{s}\left(\lambda_{k}\right)$ and $\widehat{s}^{\min }=\min _{k} \widehat{s}\left(\lambda_{k}\right)$. X12 plots spectra with 52 frequencies. So, the unit of measure is standardized to "stars"-equivalent to $\frac{1}{52}$ unit of frequency-so a peak is (six or more stars) easy to detect visually. As not all the series have trading day effect, it is more valuable to focus only on a single frequency: there of seasonality $(0.348$ cycles/month), instead of trading day effect $(0.432)$.

A logarithmic transformation tends to found spurious seasonality, so it uses the differenced original series for testing (Soukup and Findley, 1999). Notice that the spectrum as a diagnostic is not as powerful as the likelihood-ratio is for detecting trading-day effects, but it is more versatile because it does not depend upon a correct model specification. Moreover, the F-test tends to find spurious seasonality since the irregular component exhibits a typical, but low, autocorrelation. This traditional significance test is inadequate also for a typical sample size. In X12, spectral diagnostics are computed with 96 observations in default-and desirable-mode, requiring a minimum of 60 observations to perform the routine. ${ }^{13}$

As spectral analysis allows seeing the relationships between the frequencies, I can quantify the importance of certain frequencies relative to the frequencies of other components. Thus, for a comparison between two or more adjustments for the same variable, the result is direct. A lower non-significant peak-or even better, the absence of it-in the seasonally adjusted and irregular component at specific frequencies reflects an adjustment of better quality. In annex B, I show the case of a simulated highly seasonal series. It is clear from the exercise how the spectral shape of both original and subsequent seasonally adjusted series should be.

\footnotetext{
${ }^{10}$ See Akaike and Ishiguro (1983) for a complete comparison between the two programs.

${ }^{11}$ These frequencies are obtained by considering the decimal part of the number of cycles per month. For instance, the average month of a year is $\frac{365.25}{12}=30.4375$ days. Hence, a cycle that is repeated every seven days goes through $\frac{30.4375}{7}=4.34821$. See Priestley (1981) and US Census Bureau (2011) for details. The trading day effect is relatively hard to find. Cleveland and Devlin (1980) suggest that it is present, but very weak, at the 0.432 frequency.

${ }^{12}$ The authors estimate a false discovery rate narrowly above $20 \%$ when using this criterion, by bootstrapping the irregular component of 42 macroeconomic series of the US. The acceptable rate of X12 is $10 \%$. Both results equally obtained with the "six-stars criterion", are described next.

${ }^{13}$ Ladiray (2008) recommends having more than 80 observations for useful results with quarterly series.
} 


\subsection{Sliding spans}

Sliding spans compare different estimates from seasonal adjustment from overlapping subspans of the time series data. They are fully presented and analyzed in Findley et al. (1990). As Findley et al. (1998) pointed out, sliding spans were included in X12 to enhance the diagnostics for: (i) determine whether a series is seasonally adjusted adequately, (ii) deciding between direct or indirect adjustment, and (iii) confirming option choice about filters' length. ${ }^{14}$ In default mode, X12 analyzes four overlapping spans. Each one is delayed from the other with one-year-ahead difference, data availability. ${ }^{15}$ The span begins in January of every year, by default. In cases where this is not possible, RegARIMA made forecast-or backcasts if neededof the series to balance the sample. These forecast observations fulfill several accuracy tests to be included in the routine. Battipaglia and Focarelli (1995) show a number of scenarios where sliding spans result in a better stability control than $Q$ statistic of X-11-ARIMA, a result used in this paper. These results are in line with Findley and Monsell (1986) and Findley et al. (1990).

As was mentioned, the sliding spans are computed as shown in figure 2, where spans are of four years' length. Then, the $S_{t}(k)$ values are compared-the values of observation $t$ (fixed) obtained across different $k$ (moving) spans-for all observations of the sample in which $k \geq 2$ and $k^{\max }=4$.

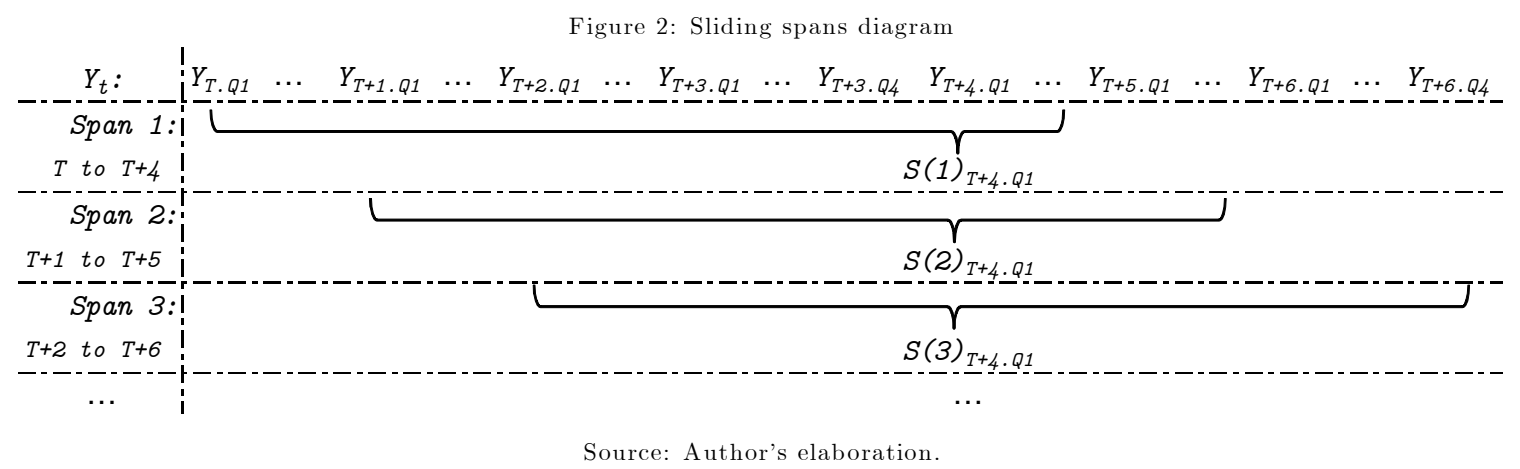

The determinacy of how well-stable-the seasonal adjustment is, is based on a double-threshold decision:

1. Compute the following quantity:

$$
S_{t}(k)=\frac{\max _{k} y_{t}(k)-\min _{k} y_{t}(k)}{\min _{k} y_{t}(k)}
$$

where $y_{t}(k)$ is the $y_{t}$ series adjusted at sliding span $k-S_{t}(k)$ is simply "the sliding span $k$ of $y_{t}$ ". The seasonally adjusted series, $y_{t}^{s a}$, is flagged as unstable if $S_{t}(k)>3 \%$. For quarter-on-quarter changes of seasonally adjusted series, this is $Q Q_{t}(k)=\left[y_{t}^{s a}(k)-y_{t-1}^{s a}(k)\right] / y_{t-1}^{s a}(k)$, they are flagged as unstable if:

$$
S_{t}(k)=\max _{k} Q Q_{t}(k)-\min _{k} Q Q_{t}(k)>3 \% .
$$

Note that $y_{t}^{i}$ is an observation belonging at least to two spans. X12 uses $k=\{2,3,4\}$, depending on data availability.

2. This leads to the second check (as X12 plots out):

\footnotetext{
${ }^{14}$ Findley et al. (1990) apply sliding-span-based diagnostics to determine empirically the choice of a seasonal filter to be used to adjust several US macroeconomic series.

${ }^{15}$ See Hood (2007) to know how long a series should be depending on filters selected. For instance, a $3 \times 5$ filter needs seven years of data, while a $3 \times 3$ filters needs just six years of observations. See also footnote 7 .
} 


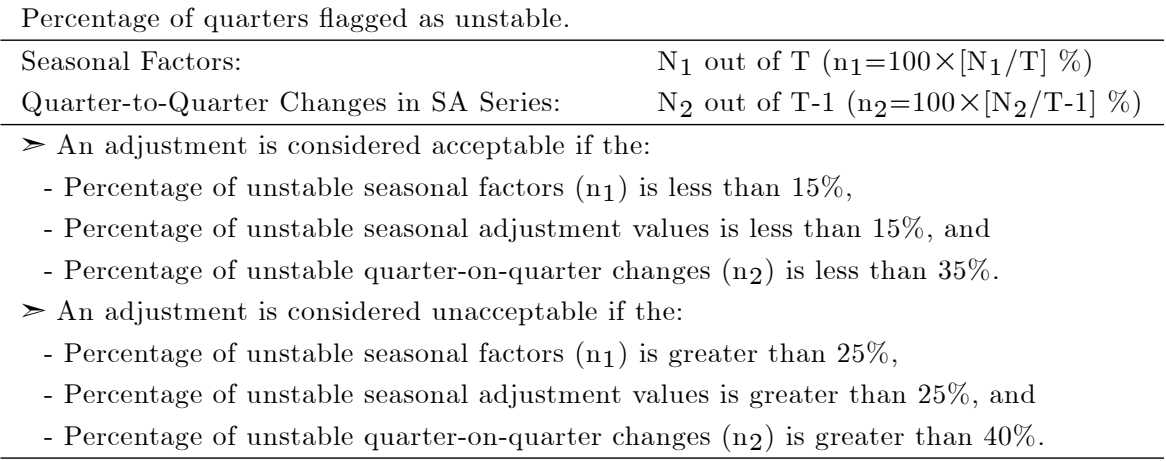

So, if the number of observations flagged as unstable exceeds the thresholds depending on the series considered, X12 warns the user on this finding. These estimates are calculated to seasonal factors, seasonally adjusted, and quarter-on-quarter changes in seasonally adjusted series. Notice that sliding spans estimates with year-on-year changes of both trend-cycle and seasonally adjusted series could be meaningless given that changes on its direction-a negative variation-may represent a genuine change in trend and so forth.

In the empirical application presented later, instead of using a threshold rule I focus on the mean of the $S_{t}(k)$ series to have a linear assessment of stability across the sample. Also because the original threshold used by X12 is set just by a particular specification. ${ }^{16}$ I make use of this diagnostics to quarter-on-quarter changes in seasonally adjusted and trend-cycle series. Obviously, determinacy of stability is reached through a minor mean of $S_{t}(k)$ of each aggregation. Nevertheless, the analysis based on quarter-on-quarter series may present shortcomings compared with the sliding span analysis in levels. These are cases where several known problems arise in the seasonal adjustment of months or quarter with fixed calendar holidays, such as Independence Day in Chile (September $18^{t h}$ and $19^{t h}$ are fixed holidays). Thus, if the two days fall on Monday and Tuesday, it is more probable that the remaining week will be composed of working days instead of the case when the two days fall on Wednesday and Thursday. The latter case suggests a major probability that Friday will be a de facto holiday. Nevertheless, it is not considered as holiday by X12. For cases like this, it is worth deviating the attention-and statistical tolerance-for a while in sliding spans estimated with quarter-on-quarter changes series.

Regarding a comparison between $M$ and $Q$ statistics, Findley et al. (1990) show that $Q$ statistics-a summary of $M 1-M 11$ statistics-is not as discriminator as a sliding span. This drawback is presented by examples, demonstrating that lower values of $Q$ are not discriminating between adjustable series and series that that cannot be reliably adjusted. Moreover, Lothian and Morry (1978) show that the $Q$-statistic by itself is not a dominant option with respect to others such as the sliding span. Related to stability, it is uncommon that a large irregular component does not compromise the stability of the whole adjustment. Thus, an integral analysis should be made using $Q$-statistic instead of specific $M$-statistics, a shortcoming overriden by sliding spans. Another advantage is the interpretation of its outcome, given that the impact of outliers and other undesirable effects can be directly evaluated numerically on quarter-on-quarter changes.

The sliding span also serves to evaluate intermediate steps of the seasonal adjustment, which can be more fruitful with indirect adjustment. As it constitutes a parameter-free computation, it can be used as a decision rule for the model's goodness of fit. This is especially relevant in cases with a marked trading day effect, which is often detected with an F-test on the irregular series. The trading day effect tends to generate autocorrelated irregular components. A major problem for diagnostics is that the irregular becomes autocorrelated. Thus, F-tabulated values are no longer correct for statistical inference. As several alternatives emerge, the sliding span is a valid candidate to handle with stability in these contexts. Finally, sliding spans also deal with the so-called "raking" technique for reconciliation in aggregate time series. This means that when the sum of disaggregates does not fit with the aggregate, the difference is prorated to disaggregates based on its weights on aggregate.

\footnotetext{
${ }^{16}$ In fact, the sliding-spans methodology and their threshold-based stability decision has been set by "asking an expert from an economic statistics division at the Census Bureau how much variability is acceptable." Findley et al. (1990), p. 347.
} 


\subsection{Revision history}

The basic revision calculated by the program is the difference between the earliest adjustment of a quarter's datum obtained when that quarter is the final quarter in the series and a later adjustment based on all future data available at the time of the diagnostic analysis (Findley et al., 1998, pp. 137). Often, the informational content of last observations is more important for users, especially for those involved with conjunctural assessment. This measure complements previous diagnostics and focuses on the effect of new information on the historical record of seasonally adjusted series to basically determine the variance contribution of each component. Thus, it clearly constitutes a stability measure. As sliding spans, they may be constructed observation by observation, or by blocks of observations separated, say, by one year. As instability constitutes a recognized problem in X12, suggestions such as that of Bobbit and Otto (1990) help to fix part of the problem. The authors show that the use of a large number of forecasts prior to the adjustment can result in a smaller average revision between concurrent and final seasonal adjustments, a characteristic typically pursued by the adjuster. This finding is also nicely presented in Findley (2005).

The revision is calculated as follows. Suppose that the series to be seasonally adjusted is $\left\{y_{t}\right\}_{t=t_{0}}^{t=T}$, and $t_{0} \leq t \leq T$. Hence, if $y^{s a}$ is the seasonally adjusted series, then $y_{t \mid t}^{s a}$ is the concurrent seasonal adjustment of observation $t$, and $y_{t \mid T}^{s a}$ is the final adjustment of observation $t$-made with the full sample, $T$. The revision is:

$$
R_{t}=\frac{y_{t \mid T}^{s a}-y_{t \mid t}^{s a}}{y_{t \mid t}^{s a}}
$$

Revisions are calculated to trend-cycle, seasonal factors, seasonally adjusted series, and optionally for outof-sample forecast errors of RegARIMA. It can also be estimated in terms of quarter-on-quarter changes, $C_{t \mid t}=\left(y_{t \mid t}^{s a}-y_{t-1 \mid t}^{s a}\right) / y_{t-1 \mid t}^{s a}$, in such case corresponding to: $R_{t}=C_{t \mid T}-C_{t \mid t}$. In general terms, the lag with which the revision can be estimated-the value of difference $(T-t)$-is a user-defined integer, where $T-t=\{4,8\}$ are the defaults with quarterly data. As a measure of instability, an opposite sign between $C_{t \mid T}$ and $C_{t \mid t}$ represents the undesirable case where the series changes its direction as a result of methodological instability. A final remark on the motivation to analyze revisions is provided by US Census Bureau (2011). As the majority of users are concerned with last observations, it is worth mentioning that many of them are based on preliminary data. Hence, if final data are issued or revised three quarters after their first release, setting $T-t=3$ (or sadjlags=3 and trendlags=3) would be appropriate to study the seasonal effect of that series.

\subsection{Why may direct and indirect adjustment results differ?}

There are several reasons why both kinds of adjustments may differ. I discuss some of these reasons next, supposing that the same methodology and sample span is applied for both adjustments. ${ }^{17} \mathrm{I}$ follow closely the discussion provided in Ladiray and Mazzi (2003), and also, but on a lesser extent, in Peronacci (2003). Firstly, note that several unrealistic conditions should fulfill the adjustments in order to deliver the same results. These include: when the combination and adjustment are linear, the series does not exhibit outliers, the same filter is applied to all series, and, if with multiplicative adjustment there is no irregular component, then it is more likely that both adjustments coincide. In the same way, similar results between both adjustments can be obtained if the statistical characteristics of the series are similar. This is a very uncommon fact with GDP datasets, but more likely with interest rates.

The adjustment made directly or by means of its disaggregation may differ because of:

- The use of a multiplicative adjustment in disaggregates. This is especially the case with an aggregate compound by an algebraic sum of components, such as GDP. Note that when components are adjusted in a multiplicative way, the original series are divided by a specific seasonal factor. Since the seasonal factors are not common across sectors, or even more, imperfectly correlated, the sum of those components should exhibit a different behavior to that of by, say, an additive adjustment of the aggregate.

\footnotetext{
${ }^{17}$ This assumption also refers to comparisons with same data vintages without revisions.
} 
- Presence of outliers and differences in the trading day effect of the disaggregation. As in the previous case, idiosyncratic effects of components could cast for different parameters in the adjustment. A rough example consists of an aggregate of two equally weighted components. Suppose that both components exhibit the typical behavior of an economic series, and also related between them, except for its outliers. Also, the first series experience several outliers across sample span, followed by outliers in the second component in the same direction. Obviously, they will be corrected separately implying that they can still share the same filter characteristics. But, the aggregate will exhibit a very noisy behavior as it adds up both kinds of outliers-or shocks. Thus, it will be hard to find a stable filter for adjusting the aggregate, implying that different estimates would emerge.

- Use of different filters. Even in a series without outliers and with the same kind of adjustment, the results may diverge. This could be the case when different filters are used. Note that sensibility of MA to its order leads to dramatically different results in cases with volatile series. Recall that the order of an MA is closely related to the independence-lower correlation-of the series observations. So, the more independent the observations are, the more sensitive to its order the MA is. In the case of seasonal adjustment, it could occur that when just one component has a different filter than the rest, the indirect adjustment result moves away from that of the direct one. This point is exaggerated when the observations of the aggregate are less independent of those of its disaggregation. ${ }^{18}$

- Different forecasting models. If disaggregation is forecast with different ARIMA models, and consequently different from that of the aggregate, it is more likely that both adjustments will not coincide. This is because different forecasting models could induce major revisions due to forecasting accuracy. Furthermore, the forecasting model can account for different MA filters between disaggregations. Hence, redound into differences between direct and indirect adjustment.

- Harshness of aggregation. Obviously, as the number of series included in the aggregation increases, its weight in the aggregate decreases. This happens in any context such as, for instance, original and seasonally adjusted series. Thus, a series composed of $n_{1}$ subseries, it is more likely to deliver more unstable results than that one built with $n_{2} \gg n_{1}$ subseries. This is not necessarily always the case as it still depends on how the aggregation is made. If the aggregation of components with erratic seasonality converges to a series with stable seasonality, it is desirable to aggregate just a little number of series in terms of stability. But, if the assumption $n_{2} \gg n_{1}$ is computed with a large enough $n_{2}$ relative to $n_{1}$, the marginal contribution of a series with erratic seasonality will not affect the result of the aggregate.

- Fading out of judgment. As will be discussed later, a way to improve poor adjustment results consists in fixing some diagnostics by means of user's judgment. This is common with series that exhibit erratic seasonal components, requiring fine expertise rather than those that exhibit stable seasonality. It could be the case that the choice based on user judgment of a specific filter, forecasting model, specific fixed effect, or any other user intervention may help to correct some diagnostics. Nevertheless, as a result of this intervention, the disaggregation becomes adjusted under a different setup of that of the aggregate. This leads to almost surely divergent results between the direct and indirect adjustments.

\subsection{How to revert poor results?}

There are several strategies to evaluate when some diagnostics fail in order to extract seasonality. These corrections arise supposing that a more stable adjustment is preferable with most recent data. All these corrections require user intervention. Expert judgment is always desirable. Manipulations can be made at any stage of the process (described in figure 1) or even prior to the analysis without affecting results' validation. Some recommendations found in the literature include the following.

- Regarding seasonality detection, spectrum diagnostics tend to fail when changing seasonality is present. Spectra work well with medium-size series. With a long series, spectral plots show little change when

\footnotetext{
${ }^{18}$ See below, in the empirical application section, the cases of the supply sectors Capture fishery and Electricity, gas and water, to name a few, with respect to the case of GDP by itself.
} 
more observations are added. This could hide most recent data seasonality (Hood and McDonaldJohnson, 2009). Hence, analysis of more recent data (latest 60 observations) leads directly to the detection of seasonality with the spectrum of original series.

- For the same abovementioned problem, a reduction of spectrum bandwidth increases the probability of detection of seasonality. As Hood (2007) finds, the use of an AR(10) model instead of an AR(30) casts for less smoother spectral plots. This change brings attached the risk of finding more false negative cases. Nevertheless, this represents a minor shortcoming when seasonality is hard to detect. This is especially the case when the $\mathrm{AR}(30)$ model cannot discriminate because of short peaks at seasonal or trading day frequencies.

- Another way to find seasonality relies on the suggestion proposed by Maravall (2005). This consists of a joint test of seasonal dummies contained in a regression of original series. The theoretical distribution is based on the nonparametric Kendall-Ord test (Kendall and Ord, 1990). As it constitutes a nonparametric test, its use with a short sample span, however, is not entirely recommended.

- The goal of seasonal adjustment is to achieve the absence of residual seasonality. This task could be eased with a series that has already been controlled for effects that facilitate residual seasonalityby removing outliers, for instance. With this purpose in mind, Soukup and Findley (1999) suggest testing residual RegARIMA series for seasonality through spectral plots. This check, as the authors suggest, improves the capacity of remaining diagnostics contained in the program to dissipate residual seasonality.

- Several rough interventions also facilitate both detection and quality improvement. This category includes fix data transformation-such as a logarithm-, change filters lengths, avoid sample span flagged as unstable-according to sliding span and revision history-, RegARIMA fixed effects manipulation and/or fix RegARIMA model, among others. Note that X12 has the option of deactivating specific stability diagnostics, such as sliding spans or RegARIMA residuals outliers' detection. An iterative process fixing one control at a time is recommended, basically to ensure consistency as new information arrives.

- A typical undesirable effect are outliers. RegARIMA specifically controls for additive outliers. Nevertheless, a second check is recommended specifically when it appears in recent observations. Taking the case of, for instance, an outlier at the last observation available. For sure, RegARIMA will replace this observation with one affine to the series prior to outlier arrival, and no further intervention will be required. But, if it is expected that few of next observations will exhibit the same value, then it is recommended to include the observation in the adjustment process. Keeping the outlier observation for processing can be managed in several ways inside the RegARIMA module. For instance, by using the span or types=(ls tc) options within outlier command. Of course, a different situation arises when the outlier is located near the half of series length. Obviously, the most ideal case with outliers is when they are at the beginning of the sample, and the sample is a long enough.

- For stability purposes, Bobbit and Otto (1990) suggest the use of long-horizon backcasts and forecasts. The authors conclude that revisions are smaller when a series is extended with enough long-horizon forecasts. This finding is achieved by comparing the stability of adjusted series with extended original series-using a symmetric filter-versus not extended or extended by just one year. It is also interesting, especially from a practitioners' point of view, that a simple automatic procedure is equally accurate as modeling individual ARIMA processes.

\section{Empirical application: The case of Chile's GDP 1986-2009}

In this section, I focus on applying the abovementioned diagnostics to determine whether is preferred a direct or indirect seasonal adjustment for the Chilean GDP 1986-2009 (base year: 2003). The diagnostics considered are all those that are robust to direct and indirect adjustment, namely spectral plots, sliding spans and revision history. The analysis is complemented with several statistics that resume part of the adjustment quality assessment as, for instance, bias in seasonally adjusted series. 
Notice that the particular vintage used has several desirable characteristics for an economic-statistical analysis, such as: (i) it does not have induced breaks or level shifts due to methodological changes, (ii) it is prepared and released on a quarterly basis, (iii) it is compounded by a number of sectors with different seasonal patterns, and (iv) it does not have any missing values, mismatches, or any other shortcoming to deal with previous to the adjustment.

The dataset corresponds to the same used in Medel (2013). In that work, a complete out-of-sample exercise is provided with the original as well as seasonally adjusted series using the same aggregation schemes. Thus, it is clear and direct the impact on the forecast accuracy of seasonality remotion. It also accounts for the impact of trading day effect on out-of-sample performance.

\subsection{Data: Descriptive statistics and aggregations}

I use the first 96 observations of the Central Bank of Chile's Quarterly National Accounts (QNA), from 1986.I to 2009.IV, starting with GDP as the most aggregated, and with three levels of disaggregation on the demand and supply sides. The construction of the dataset is made as follows. First, it is used the dataset detailed in the official volume "National Accounts of Chile 2003-2009" (Banco Central de Chile, 2010). The original series are in levels, denominated in millions of 2003 Chilean pesos. Hence, the additivity-or subtraction-is ensured as the components are denominated in the same units and constructed with the same base year. This also implies a weight equal to 1 (or -1) for an added (or subtracted) component (Ladiray and Mazzi, 2003). Second, I calculate the quarterly variation of the dataset provided in Stanger (2007). This dataset contains quarterly data from the period 1986-2002 denominated-also-in millions of 2003 Chilean pesos. Finally, the quarterly overlapping method is used backwards by fixing the base year 2003 and building the series back to 1986 with the quarterly rates calculated previously. Nevertheless, I use only the first 96 observationscounting from 1986.I onwards-as they constitute the minimum length suggested by X12 developers to stress X12 capabilities, even though the minimum length of series to perform a routine is 60 observations.

The original as well as the adjusted series compound the Chilean GDP by demand side and supply side. A scheme of demand-side aggregations of all series with acronyms used in this paper is shown in annex C, and those of supply-side in annex D. There is a total of five different aggregations plus the GDP by itself ("Aggregation 6"). All five aggregation blocks as well as aggregation 6 deliver the GDP, calculated as a sum of every corresponding component. ${ }^{19}$

Since 2008 the Central Bank of Chile has adopted the linked-chain methodology to produce the GDP dataset. This methodology-used to improve representativeness-implies that the dataset lose its additive property. Under this scheme, the disaggregation added to an aggregate does not necessarily coincide with the direct aggregate. The indirect seasonal adjustment quality-and stability-depends in this context, among others factors, on the so-called non-additive term that emerges from the difference between both aggregates. A method to adjust indirectly a linked-chain variable is presented in Scheiblecker (2014), but it has not been thoroughly examined yet. So, indirect adjustment with linked-chain data is left to further research.

\subsection{Setting up the exercise}

The exercise consists of adjusting all the components by demand side and supply side to then add up according to the aggregation schemes. Note that some parameters governing the adjustment of each component may differ between them. The exercise is carried on the automatic program default mode, according to the suggestions presented in Maravall (2002). Then, if a component does not fulfill the statistical criteria of an acceptable result, minimal interventions are made one-by-one until all test are fulfilled. The choice of these interventions is made considering stability as a criterion. It is, trying to keep the adjustment parameters fixed along the evaluation sample span-from the $60^{\text {th }}$ to the $96^{\text {th }}$ observation (2000.IV to 2009.IV). Note that this dynamic scheme is made to compute the sliding span and revision history. Oppositely, spectral plots are computed with the whole sample.

\footnotetext{
${ }^{19}$ Annex E displays the share of every sector of real GDP at 2003 prices, while annex $\mathrm{F}$ displays some typical statistics of sectors with the full sample for the transformations used in the analysis. Annex G depicts all aggregation components in log levels to provide a general overview of their shape in the time domain.
} 
The adjustment is made through Eviews 7.2 interface for X-12-ARIMA version 0.2.10. Notice that Eviews makes use of its own notation for X12 options. These options used by Eviews are the following (while the script used for the adjustment is presented in annex $\mathrm{H}$ ):

- Mode: For setting up the seasonal adjustment method: "m" for multiplicative, "a" for additive, "p" for pseudo-additive, and "1" for log-additive seasonal adjustment.

- Filter: For setting up the seasonal filter: "msr" for automatic, moving seasonality ratio, "x11" for X11 default, "stable" for stable, and "s $3 \times j "$ for $3 \times j \mathrm{MA}, j \in\{1,5,9,15\}$.

- Trans.: For setting up a transformation for RegARIMA: "logit" for logit, "auto" for automatically choose between no transformation and log transformation, number for Box-Cox power transformation using specified parameter, where "0" is for log transformation.

- SSpan: For analyzing the stability with sliding spans: "sspan".

- Check: For checking the residuals of RegARIMA: "check".

- Outlier: For analyzing the presence of outliers of RegARIMA: "outlier".

- ARIMA: For setting up the ARIMA specification of RegARIMA: " $f$ " for use forecasts from the chosen model, "b" for use forecasts and backcasts from the chosen model, " $(p, d, q)$ " for manually entering specification. When this option is used, it could also be accompanied by "oos" for use out-of-sample forecasts for automatic model selection.

The adjustment options of each component are presented in table 2. Note that a logarithmic multiplicative adjustment with automatic filter selection is the preferred specification. ${ }^{20}$ The sliding span for trend-cycle and seasonally adjusted, along with the diagnostics used for resultant RegARIMA residual series, are also selected. The trading day effect cannot be identified in these series because of sample length. All remaining parameters are left in Eviews' default mode.

Several adjustments deserve mentioning. The Change in inventories (ci) series does not show seasonality according to X12 diagnostics. When series containing this component are added up to its aggregation, $c i$ is included on its original version. The External demand (ed) series corresponds to a series in level that allows for negative and zero values. Therefore, an additive adjustment was tried but with negative outcome. As a result, is used an indirect adjustment corresponding to its definition but with seasonally adjusted series: $x_{t}^{s a}-m_{t}^{s a}$. The seasonality of the Exports of services $(x s)$ series is found with two RegARIMA specifications at two different sample spans. The first, with a $(0,0,1)$ specification is obtained through 1986.I to 2003.I, while the second, for 2003.II to 2009.IV is found using a RegARIMA specification supported by an out-ofsample criterion. In general, all those series in which the RegARIMA specification is fixed-to the $(0,0,1)$ model-or sliding span option deactivated, correspond to cases with an erratic behavior across time, with a relatively high variance (see annexes F and G), specially at the first stages of the sample.

\footnotetext{
${ }^{20}$ Common error messages in X12 by each kind of adjustment were:

Additive Adjustment:

WARNING: The program will not generate backcasts for series longer than 15 years.

ERROR: Cannot calculate X-11 holiday adjustment for a quarterly series.

ERROR: An X-11 holiday adjustment cannot be performed unless the multiplicative seasonal adjustment option

is chosen. No seasonal adjustment this run.

Pseudo Additive Adjustment:

ERROR: Cannot calculate $\mathrm{X}-11$ holiday adjustment for a quarterly series.

ERROR: Pseudo-additive seasonal adjustment cannot be performed when preadjustment factors are derived from a

REGARIMA model. No seasonal adjustment this run.

Multiplicative Adjustment:

ERROR: Cannot calculate $\mathrm{X}-11$ holiday adjustment for a quarterly series. No seasonal adjustment this run.
} 
Table 2: Seasonal adjustment options of each sector

\begin{tabular}{|c|c|c|c|c|c|c|c|c|}
\hline Sector & Agg. & Mode & Filter & Trans. & SSpan & Check & Outlier & ARIMA \\
\hline Households cons. exp.: nondurables & 1 & $m$ & $m s r$ & $\log$ & $\checkmark$ & $\checkmark$ & $\checkmark$ & $F, o o s$ \\
\hline Households cons. exp.: durables & 1 & $m$ & stable & auto & $x$ & $\checkmark$ & $\checkmark$ & $F$, oos \\
\hline Construction and works & 1 & $m$ & $m s r$ & $\log$ & $\checkmark$ & $\checkmark$ & $\checkmark$ & $F$, oos \\
\hline Changes in inventories $(*)$ & 1 & $x$ & $x$ & $x$ & $x$ & $x$ & $x$ & $x$ \\
\hline Exports of goods & 1 & $m$ & $m s r$ & $\log$ & $\checkmark$ & $\checkmark$ & $\checkmark$ & $F$, oos \\
\hline Exports of services, first sample & 1 & $m$ & $m s r$ & auto & $x$ & $\checkmark$ & $\checkmark$ & $(0,0,1)$ \\
\hline Exports of services, second sample & 1 & $m$ & $m s r$ & auto & $x$ & $\checkmark$ & $\checkmark$ & $F, o o s$ \\
\hline Imports of goods $(* *)$ & 1 & $m$ & $m s r$ & $\log$ & $\checkmark$ & $\checkmark$ & $\checkmark$ & $F$, oos \\
\hline Imports of services $(* *)$ & 1 & $m$ & $m s r$ & $\log$ & $\checkmark$ & $\checkmark$ & $\checkmark$ & $F$, oos \\
\hline Exports & 2 & $m$ & $m s r$ & $\log$ & $\checkmark$ & $\checkmark$ & $\checkmark$ & $F$, oos \\
\hline $\operatorname{Imports}(* *)$ & 2 & $m$ & $m s r$ & $\log$ & $\checkmark$ & $\checkmark$ & $\checkmark$ & $F$, oos \\
\hline Internal demand & 3 & $m$ & $m s r$ & auto & $x$ & $\checkmark$ & $\checkmark$ & $(0,0,1)$ \\
\hline External demand $(* * *)$ & 3 & $x$ & $x$ & $x$ & $x$ & $x$ & $x$ & $x$ \\
\hline Electricity, gas, and water & 5 & $m$ & $m s r$ & $\log$ & $\checkmark$ & $\checkmark$ & $\checkmark$ & $F$, oos \\
\hline Capture fishery & 5 & $m$ & $m s r$ & auto & $\checkmark$ & $\checkmark$ & $\checkmark$ & $(0,0,1)$ \\
\hline Mining & 5 & $m$ & $m s r$ & $\log$ & $\checkmark$ & $\checkmark$ & $\checkmark$ & $F$, oos \\
\hline Wholesale and retail trade & 5 & $m$ & $m s r$ & $\log$ & $\checkmark$ & $\checkmark$ & $\checkmark$ & $F$, oos \\
\hline Manufacturing & 5 & $m$ & $m s r$ & $\log$ & $\checkmark$ & $\checkmark$ & $\checkmark$ & $F$, oos \\
\hline Owner-occupied dwellings & 5 & $m$ & $m s r$ & $\log$ & $\checkmark$ & $\checkmark$ & $\checkmark$ & $F$, oos \\
\hline Public administration & 5 & $m$ & $m s r$ & $\log$ & $\checkmark$ & $\checkmark$ & $\checkmark$ & $F$, oos \\
\hline Duties + taxes $(* *)$ & 5 & $m$ & $m s r$ & $\log$ & $\checkmark$ & $\checkmark$ & $\checkmark$ & $F$, oos \\
\hline Non-deductible VAT & 5 & $m$ & $m s r$ & $\log$ & $\checkmark$ & $\checkmark$ & $\checkmark$ & $F$, oos \\
\hline Imports CIF & 5 & $m$ & $m s r$ & $\log$ & $\checkmark$ & $\checkmark$ & $\checkmark$ & $F$, oos \\
\hline GDP Natural resources & 4 & $m$ & $m s r$ & $\log$ & $\checkmark$ & $\checkmark$ & $\checkmark$ & $F$, oos \\
\hline GDP Non-natural resources & 4 & $m$ & $m s r$ & $\log$ & $\checkmark$ & $\checkmark$ & $\checkmark$ & $F$, oos \\
\hline Other sectors & 4 & $m$ & $m s r$ & $\log$ & $\checkmark$ & $\checkmark$ & $\checkmark$ & $F$, oos \\
\hline GDP & 6 & $m$ & $m s r$ & $\log$ & $\checkmark$ & $\checkmark$ & $\checkmark$ & $F$, oos \\
\hline
\end{tabular}

$\left({ }^{*}\right)$ Not considered in analysis. $\left({ }^{*}\right)$ Subtracted. $\left({ }^{* *}\right)$ Adjusted indirectly. Source: Author's elaboration. 
Figure 3: Chilean GDP - Seasonally adjusted and log-differenced series

A: Seasonally adjusted series

Aggregation 6

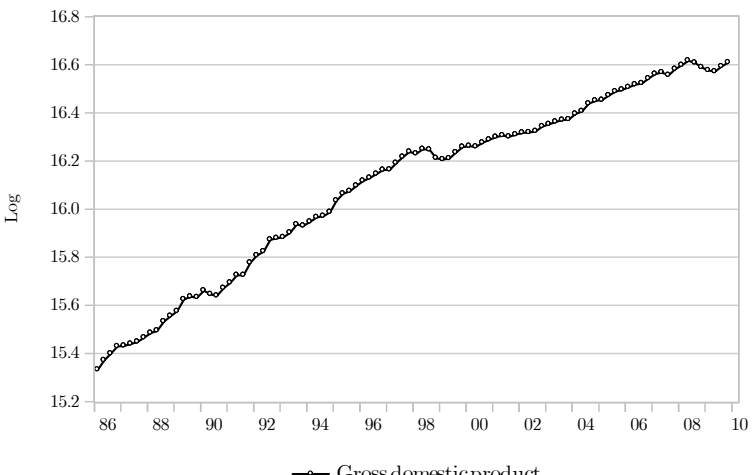

Aggregation 4

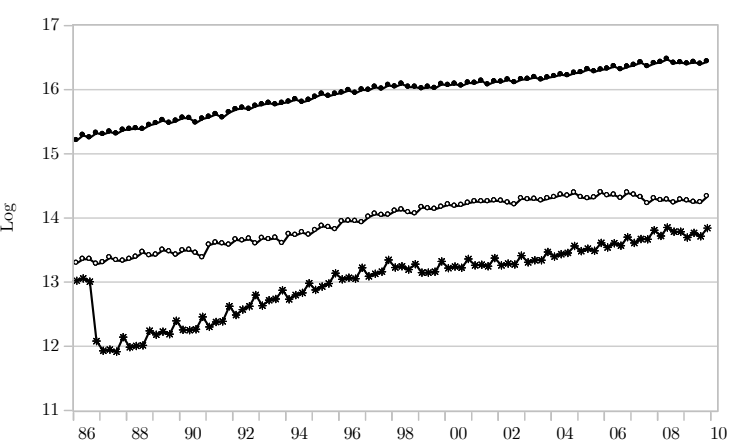

$\multimap$ GDP Ntrl. rsrcs. — GDP Nonntrl. rsres. — Others

Aggregation 5

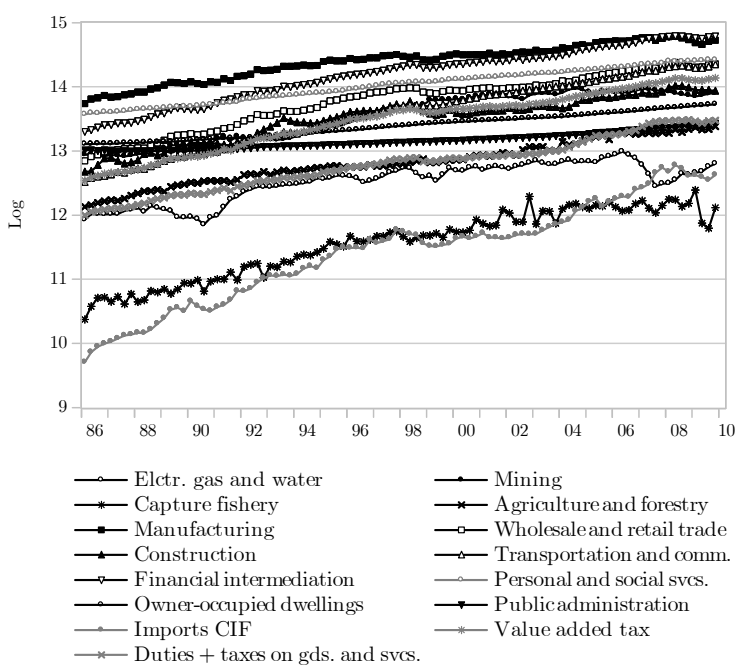

Aggregation 3

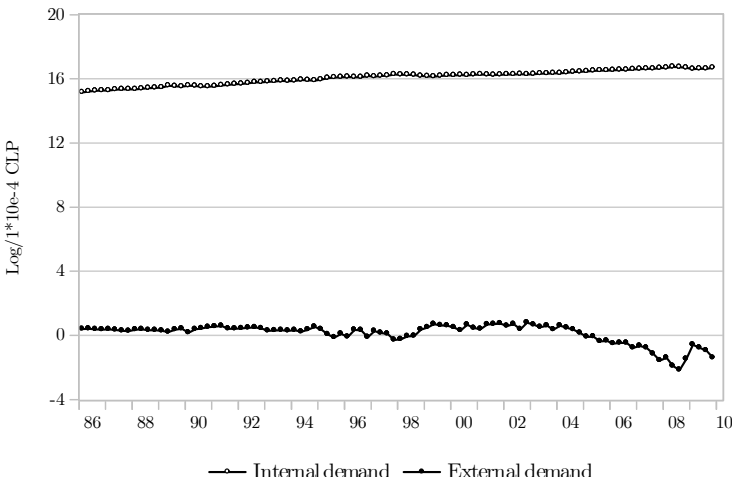

Aggregation 2

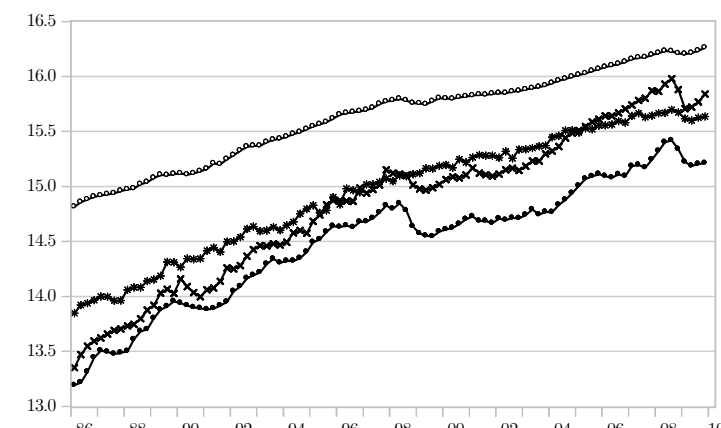

— Hhlds. cons. exp. — Investmen

Aggregation 1

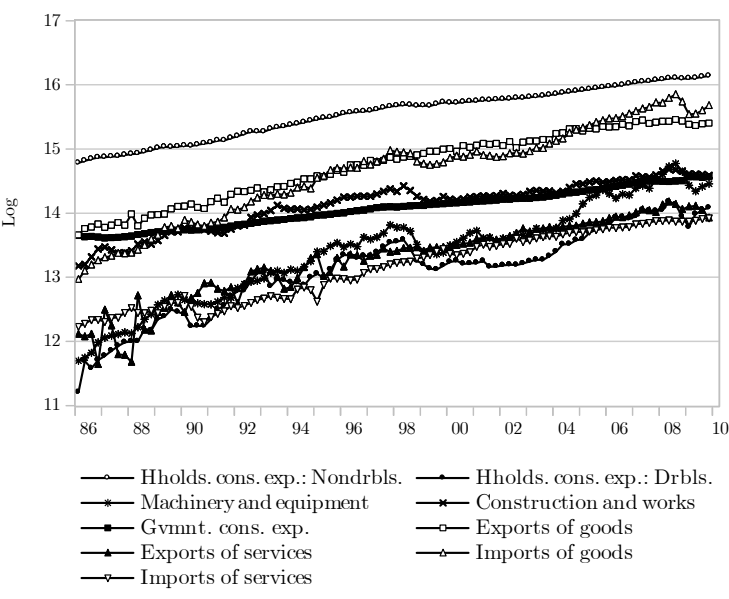

Source: Author's elaboration 
Aggregation 6

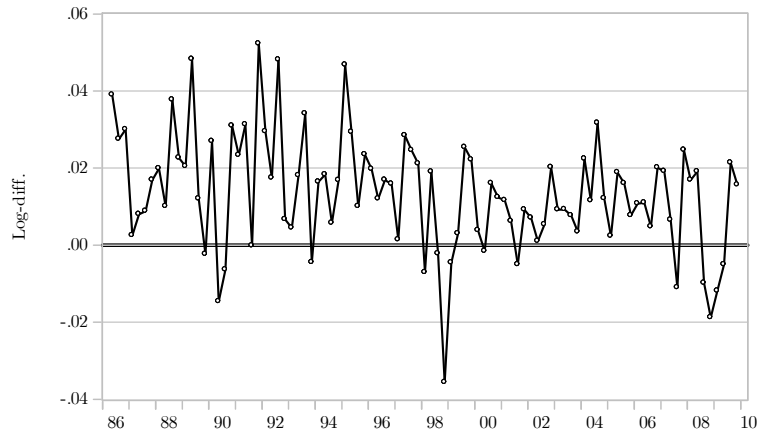

$\rightarrow$ Gross domestic product

Aggregation 4

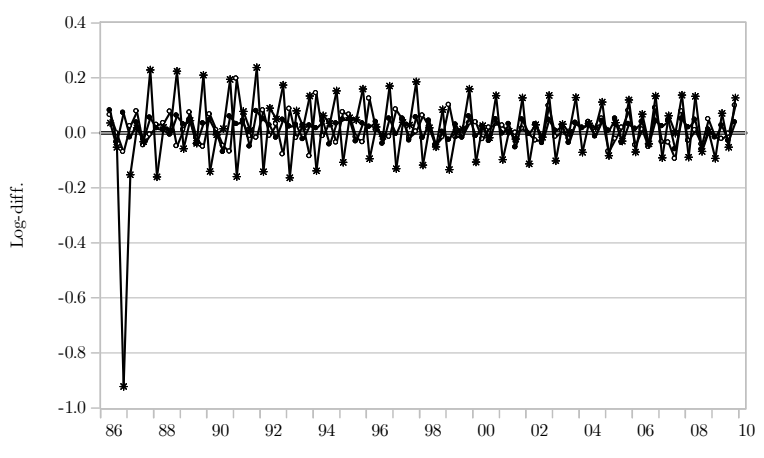

- GDP Ntrl. rsrcs. — GDP Nonntrl. rsrcs. — Others

Aggregation 5
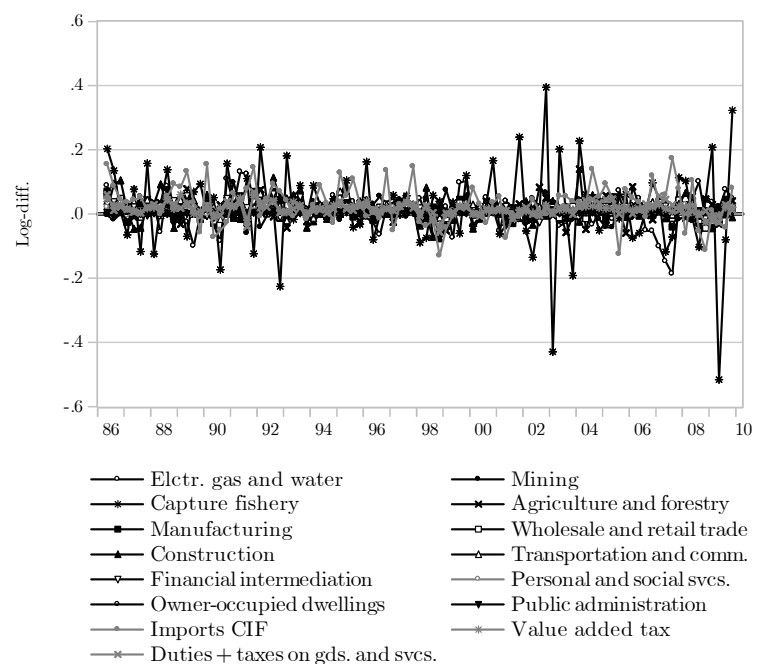

Aggregation 3

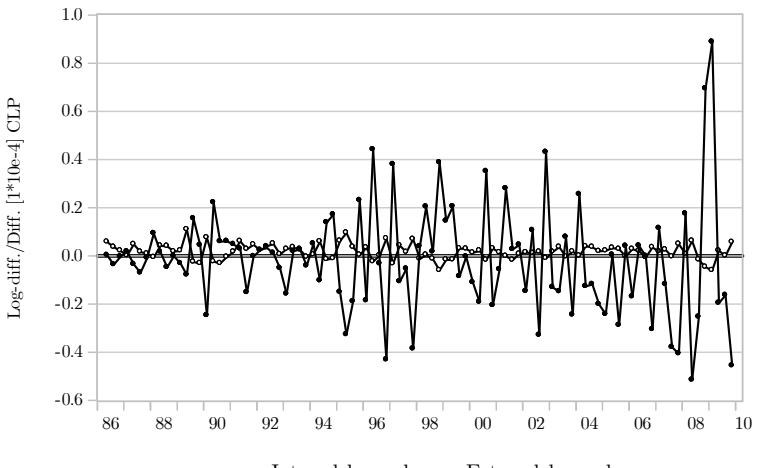

$\multimap$ Internal demand $\rightarrow$ External demand

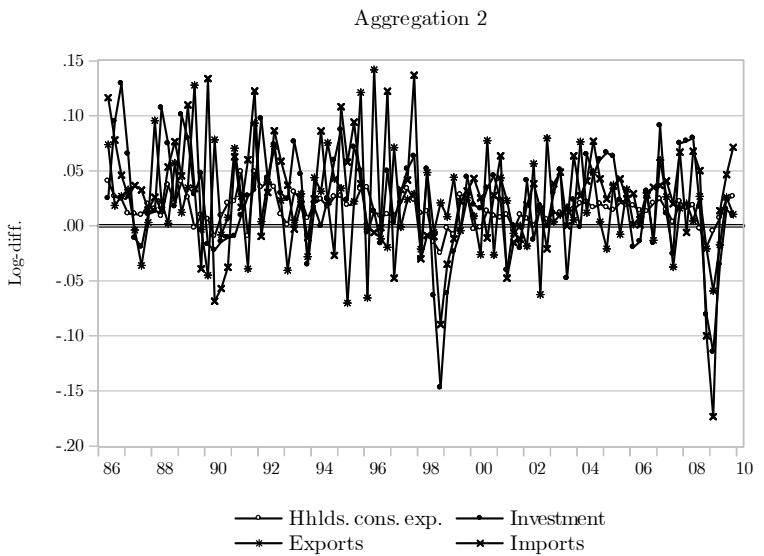

Aggregation 1

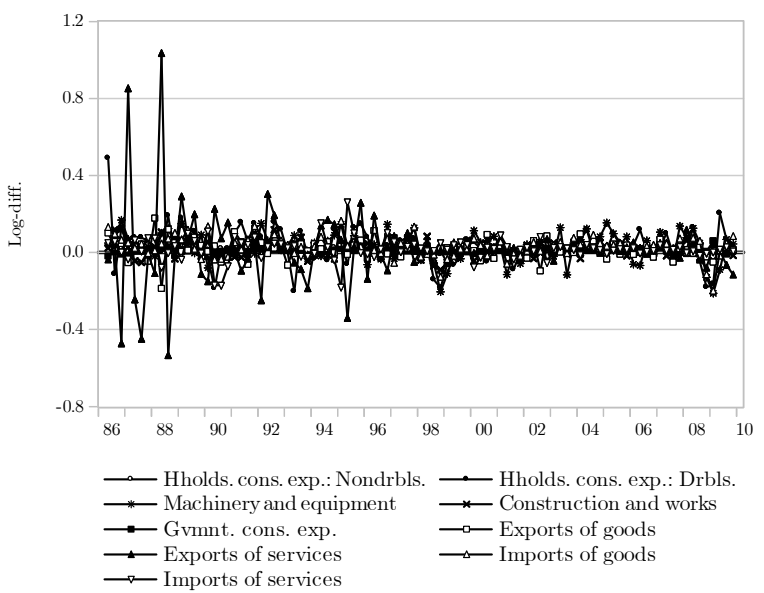




\subsection{Results}

In this subsection, I analyze the estimates of diagnostics checks for all six aggregations. Notice that, as aggregation 6 acts as a natural benchmark, deviations from seasonally adjusted series of that aggregation are considered a low quality adjustment. However, this result has to be considered just as a benchmark given the discussion of previous sections about the possibilities among which the different schemes may differ. Specifically, disaggregates can handle Easter effects and nonlinearities better, and when adding up to the original, different seasonal patterns do not cancel noisy effects at all. A corollary of this discussion is that an "actual seasonally adjusted" series does not exist, while many little changes in some parameters for the aggregate and all its diagnostics falling on the acceptance region. This implies that expert judgment plays a key role in determining which strategy is best. ${ }^{21}$

To have a general overview of the adjusted series, in figure 3 panel A, I plot the seasonally adjusted series in logarithmic levels (whole sample), while in panel B, its quarterly variation (quarter-on-quarter changes).

The first result concerns bias. As X12 adjusts the series within a year across all years of available sample, the mean of seasonally adjusted series should coincide with that of original series. Table 4 displays this result, showing a downward bias for the demand side aggregations (-1.0\% on average) and an upward bias for those of supply side (1.2\% on average). As displayed in the table, aggregations 4 and 6 are the least biased adjusted series. Regarding second moments, panel B shows the covariance of the first five aggregations with respect to adjusted GDP-aggregation 6-given that a full comparison with actual series is not possible. As in the case of mean, aggregation 4 is the closest to the benchmark, along with aggregation $3 .^{22}$

Nevertheless, the original dataset described in Stanger (2007) and Banco Central de Chile (2010) recognize that the data construction method comprises bias, but with values surrounding 0.2 to $0.0 \%$ of total GDP. Thus, the results presented in table 4 are possibly due to the nonparametric characteristic of the program, being unable to detect special data effects without user intervention, namely trading day, at sectoral level. The implications for modeling-and forecasting-, however, can be easily controlled through the use of intercept corrections as is pointed out by, for instance, Clements and Hendry (1996).

\begin{tabular}{l} 
Table 4: Bias and covariance analysis \\
\hline Mean of original series: $10,474,000$. \\
\hline Mean (\% deviation to original) of aggregation: \\
\begin{tabular}{llll}
1 & $10,399,000(-0.7 \%)$ & 4 & $10,566,000(0.9 \%)$ \\
2 & $10,349,000(-1.2 \%)$ & 5 & $10,633,000(1.5 \%)$ \\
3 & $10,350,000(-1.2 \%)$ & 6 & $10,473,000(0.0 \%)$ \\
\hline Covariance with Aggregation 6 & adjustment: \\
1 & 0.9990 & 4 & 0.9998 \\
2 & 0.9989 & 5 & 0.9996 \\
3 & 0.9998 & 6 & 1.0000 (by definition) \\
\hline
\end{tabular}
\end{tabular}

\subsubsection{Spectra-based diagnostics}

Spectral graphics are computed with (free licensed) gretl 1.9.12cvs software, available at http://gretl. sourceforge.net/. ${ }^{23}$ As mentioned, they are computed with the whole sample for the final seasonally adjusted and irregular component. The quality assessment should be easy considering pairwise comparisons of one aggregation to another. Anchoring to aggregation 6 as a benchmark is strongly recommended.

\footnotetext{
${ }^{21}$ Note that, however, the issue of robustness arises in many econometric problems with finite sample as a result of parameter uncertainty and/or misspecification.

${ }^{22}$ Nevertheless, notice that these results are not analyzed through a formal statistical test. Instead, they are provided as preliminary exploratory analysis.

${ }^{23}$ There are several (pay licensed) software alternatives to estimate the spectrum. For instance, using the command pergram in Stata, or the command periodogram in Matlab.
} 
The results are presented in annex I. From the first panel of figures, concerned with seasonally adjusted series, it is easy to be aware of the inefficiencies of aggregations 1 and 2: they exhibit clearly a peak at $\frac{\pi}{2}$ frequency-thereof seasonality-but also in the irregular component (second panel). Regarding the four remaining cases, the three first are all visually congruent with aggregation 6 . However, considering the irregular component, note that the spectrum of aggregation 4 is most alike to the benchmark. It is worth to mention that aggregation 6 positively overpass all X12 diagnostics, despite of a peak between frequencies $\left(\frac{\pi}{2}, \frac{3 \pi}{4}\right)$-associated with trading day effect; but no robust identification was possible due to sample size. As a result, aggregations 4 and 6 remain with promissory results.

\subsubsection{Sliding-span-based diagnostics}

The sliding spans are estimated with the minimum length of observations required by X12: 60 observations. As I dispose of the shortest length, the estimation of sliding spans is made in recursive scheme rather than a rolling-window alike, adding one year at a time. This treatment can be seen as a "lower bound quality" made by sliding spans, given two forces behind the dynamics that emerge while the span is increased. On the one hand, if more observations are available, they will be added while the initials will be dropped. The new data, similar to most recent dynamic, will redound in a better quality adjustment. Furthermore, with long enough series, it is possible to exclude observations that show different behavior from that of the more recent data. On the other hand, as Otto (1985) suggests, adding more observations to series-being actual as well as (back)forecasted-result in smaller revisions. To the matter of this empirical application, however, these both excluded possible improvements seem to have a minor impact. This, because the first years of data seem well behaved in most sectors.

The sliding spans are computed for final seasonally adjusted and trend-cycle series with two transformations: logarithmic and log-differenced levels. These four sets of variables are analyzed because those are the series that attract the attention of the users. The log-differentiation stands for quarter-on-quarter changes approximation. The results are provided in terms of descriptive statistics of $S_{t}(k)$ series. Recalling that for the series in logarithmic units $S_{t}(k)=\left[\max _{k} y_{t}(k)-\min _{k} y_{t}(k)\right] / \min _{k} y_{t}(k)$ for span $k$, so the mean of $S_{t}(k)$ until $K$ available spans corresponds to:

$$
\bar{S}=\sum_{t=1}^{T} \frac{\max _{k} y_{t}(k)-\min _{k} y_{t}(k)}{\min _{k} y_{t}(k)}, \forall k \in K \mid K=\left\{1, \ldots, \frac{T}{s}\right\},
$$

quantifying the average deviation from the minimum to maximum estimates of each observation. For logdifferenced series, the analyzed statistic corresponds also to the mean of $S_{t}(k)$, but defined as:

$$
\bar{S}=\sum_{t=1}^{T}\left[\max _{k} Q Q_{t}(k)-\min _{k} Q Q_{t}(k)\right], \forall k \in K \mid K=\left\{1, \ldots, \frac{T}{s}\right\},
$$

where $Q Q_{t}(k)=\left[y_{t}^{s a}(k)-y_{t-1}^{s a}(k)\right] / y_{t-1}^{s a}(k)$. Note that if $S_{t}(k)>\alpha \%$, then the observation $t$ is flagged as unstable. The value of $\alpha$ used as a threshold is $3 \%$ for seasonally adjusted series and $33.3 \%$ for trend-cycle series. This last value is considered as an approximation to the $3 \%$ threshold applied to seasonal factors. Thus, it supposed a null expectation on irregular component movements. The adjustment is considered of poor quality if the number of observations flagged as unstable exceeds $25 \%$ with logarithmic and $40 \%$ with log-differenced series.

To make a more demanding comparison, I find the maximum and minimum values of $y_{t}(k)$ through 3 to 10 spans, recalling that X12 finds from 2 to 4 spans. Thus, including a higher number of spans gives more chances to consider more distant estimates. Given the recursive scheme, available data allows to estimate 10 sliding spans. The first is estimated until 2000.IV ( $1^{\text {st }}$ to $60^{\text {th }}$ observation) while the last, until 2009.IV ( $1^{\text {st }}$ to $96^{\text {th }}$ observation). Note that the last span that allows for a joint triple comparison includes observations until 2007.IV-this is, the last span where $\# k^{\text {min }}=3$.

The results are reported for trend-cycle and seasonally adjusted series, for two transformations (log and log-differenced) in the following scheme: 


\begin{tabular}{rcc} 
& Log-differenced & Logarithms \\
\hline Seasonally adjusted series: & Annex J & Companion Tables, Section 2 \\
Trend-cycle series: & Companion Tables, Section 1 & Companion Tables, Section 3 \\
\hline
\end{tabular}

where Companion Tables refers to a separate document accompanying this work. As a summary, table 5 reports some descriptive statistics of $\bar{S}$ series.

As can be seen from table 5, most of the divergence between aggregations occurs with the log-differenced series. In the case of seasonally adjusted series, note that the benchmark achieves a $34 \%$ of unstable cases (threshold: 40\%). Recalling that the adjustment made to aggregation 6 overpass all the diagnostics in the default mode. This $34 \%$ of unstable cases is achieved with the modifications made to the sliding-span basic scheme and threshold impositions. These modifications are made basically to stress the differences between aggregations. The results with this kind of data show that two aggregations exhibit better results than the benchmark, both belong to the supply side: aggregations 4 and 5, for median, mean and times flagged as unstable. A similar result is replicated qualitatively with trend-cycle series, but excluding aggregation 5 . In this case, aggregation 4 also seems an alternative-especially given the stability of its point estimates. So, overall, aggregation 4 remains as the most stable along with aggregation 6 with both $\log$ and log-differenced data.

Table 5: Summary of sliding-span-based diagnostics

Trend-cycle series

Log-differenced Logarithmic

(threshold for \% Unstable: 40\%) (threshold for \% Unstable: 25\%)

\begin{tabular}{lrrrrrrrrrrrrr} 
Aggregation & \multicolumn{1}{c}{1} & \multicolumn{1}{c}{2} & \multicolumn{1}{c}{3} & \multicolumn{1}{c}{4} & \multicolumn{1}{c}{5} & \multicolumn{1}{c}{6} & 1 & 2 & 3 & 4 & 5 & \multicolumn{1}{c}{6} \\
\hline Median & 42.30 & 23.80 & 211.80 & 11.40 & 22.20 & 12.20 & 0.35 & 0.23 & 1.51 & 0.11 & 0.19 & 0.10 \\
Mean & 69.81 & 26.28 & 354.56 & 13.08 & 24.76 & 14.11 & 0.54 & 0.26 & 2.36 & 0.14 & 0.21 & 0.14 \\
Maximum & 316.00 & 80.40 & 1122.00 & 4610 & 83.70 & 52.70 & 3.05 & 0.70 & 7.20 & 0.56 & 1.08 & 0.52 \\
Minimum & 12.30 & 3.10 & 41.80 & 0.70 & 3.70 & 0.20 & 0.10 & 0.03 & 0.33 & 0.01 & 0.02 & 0.00 \\
\% Unstable & $71 \%$ & $27 \%$ & $100 \%$ & $5 \%$ & $34 \%$ & $11 \%$ & $2 \%$ & $0 \%$ & $33 \%$ & $0 \%$ & $0 \%$ & $0 \%$ \\
\hline
\end{tabular}

Seasonally adjusted series

Log-differenced Logarithmic

(threshold for \% Unstable: $40 \%$ )

(threshold for \% Unstable: $25 \%$ )

\begin{tabular}{lrrrrrrrrrrrrr} 
Aggregation & \multicolumn{1}{c}{1} & \multicolumn{1}{c}{2} & \multicolumn{1}{c}{3} & \multicolumn{1}{c}{4} & \multicolumn{1}{c}{5} & \multicolumn{1}{c}{6} & \multicolumn{1}{c}{1} & 2 & 3 & 4 & 5 & 6 \\
\hline Median & 78.00 & 56.20 & 243.00 & 22.10 & 27.40 & 27.40 & 0.56 & 0.49 & 1.57 & 0.14 & 0.18 & 0.19 \\
Mean & 86.20 & 75.89 & 263.20 & 26.88 & 30.34 & 32.03 & 0.58 & 0.53 & 1.72 & 0.18 & 0.21 & 0.22 \\
Maximum & 215.10 & 220.80 & 608.80 & 100.40 & 98.90 & 96.90 & 1.81 & 1.50 & 3.54 & 0.51 & 0.54 & 0.54 \\
Minimum & 25.50 & 14.60 & 87.80 & 2.20 & 5.50 & 1.40 & 0.12 & 0.03 & 0.38 & 0.02 & 0.03 & 0.02 \\
\% Unstable & $98 \%$ & $86 \%$ & $100 \%$ & $30 \%$ & $30 \%$ & $34 \%$ & $0 \%$ & $0 \%$ & $10 \%$ & $0 \%$ & $0 \%$ & $0 \%$ \\
\hline
\end{tabular}

Shaded cells indicate the minimum median and mean of each transformation, and reliable ajdustments.

Source: Author's elaboration.

In the case of logarithmic series, just little differences can be adverted. However, aggregation 4 for seasonally adjusted data and aggregation 6 for trend-cycle, provide the most stable estimates, with aggregation 4 for trend-cycle being also strongly suggested to use. Among all possibilities, undoubtedly aggregation 3 has the worst performance, representing the case where adding up components with different seasonality results in a worst aggregate performance.

\subsubsection{Revision history diagnostics}

As defined in subsection 3.3, revision history is the distance (always nonnegative) between an observation of specific component of seasonal adjustment process, made with the sample available until that observation (concurrent), and the same observation when the adjustment is made with additional data (most recent). As concerns the stability of the overall process, this measure has the advantage of quantifying, and making comparable through different methods, the dynamic effect of adding new data. Hence, it clearly exposes the 
methodological instability of the X12 program. Notice that this instability arises mainly from the sensitivity of MA estimates to change in the dynamics of the series. Furthermore, the instability has to be observed through a set of observations and not by one observation alone. In that case, RegARIMA will treat it as an outlier and exclude it from the adjustment.

The results are presented graphically in annex K. The figures show, plotted for log-differenced trend-cycle (panel A) and seasonally adjusted series (panel B), the concurrent and the most recent (marked with $\mathbf{v})$ estimates of each observation across time. Hence, two statistics are reported: (i) the absolute average change, and (ii) the number of times that the movement from concurrent to most recent (or vice versa) includes the zero. The absolute average change is the average of the distance between concurrent and most recent, across time. So, a shorter average results in better stability. The second statistic accounts for the undesirable case that is reporting firstly a decrease in the series to, quarters later, notice that the series indeed increases, or vice versa.

Table 6 reports a summary of both statistics analyzed. As shown, aggregation 4 exhibits better statistics than aggregation 6 for both trend-cycle and seasonally adjusted series jointly. In particular, the absolute change for trend-cycle reaches 0.2 with aggregation 6 , while just 0.1 with aggregation 4 . Notice that the best case of demand-side-aggregation 2-is not fully disposable. With seasonally adjusted series, the benchmark achieves an average of 0.3 , in a tie with aggregations 4 and 5 . With these series, however, demand-side aggregations exhibit a worse performance than in the previous case. Regarding the "Times equal to 0 " measure, notice that the results are not generally scattered, except with aggregation 3. Undoubtedly, aggregation 4 represents the best case where never the estimates change their direction as new data are incorporated in the adjustment. Hence, aggregation 4 come out as the most stable aggregation.

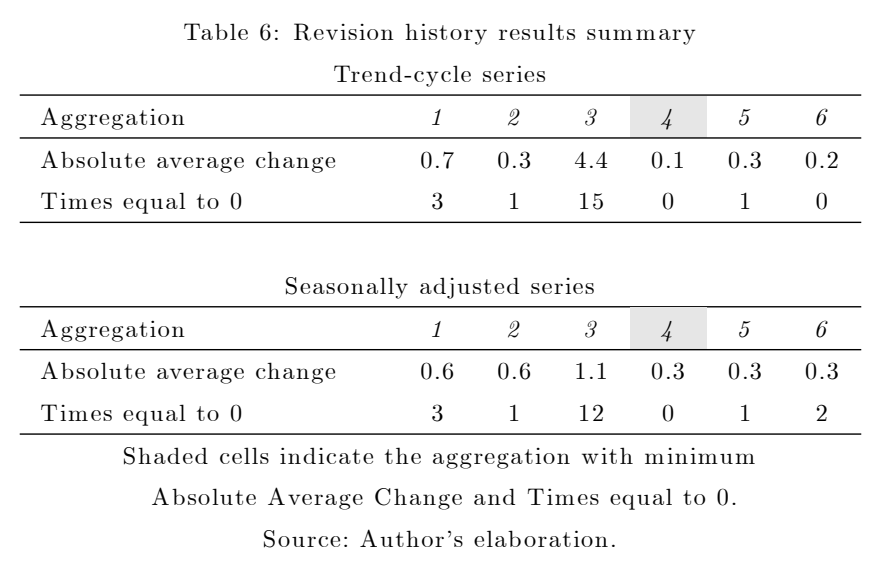

\section{Concluding remarks}

This paper addresses the question of which aggregation scheme provides the best results for an overall seasonal adjusting process for the Chilean GDP 1986-2009 (base year: 2003) using the X-12-ARIMA program version 0.2 .10 . These are understood as the best results that achieve the most stability in resultanting series. This stability is tested with specific tools contained in the X12 program; specifically, spectral plots, sliding spans and revision history. This paper provides a detailed description of these tools as well as other capabilities contained in X12.

Spectral plots are used commonly to analyze a series through its frequency domain. It is used in this context as a model-free diagnostic to associate the cycles of series with their strengths. Therefore, spectral plots for final seasonally adjusted series as well as for irregular components are especially useful to detect residual seasonality. Hence, it evaluates the quality of the overall process.

Sliding-span diagnostics and revision history can be seen as pure stability measures. Sliding spans allow the user to detect unstable passages of the sample-indicating also if a user intervention is required. Revision history quantifies how reliable the adjustment applied to certain series is as the sample is increasing in length. 
All the abovementioned diagnostics are analyzed for the case of Chilean GDP 1986-2009 (base year: 2003). The results show that in terms of stability, the use of the direct-the GDP by itself-is recommended as is the first stage of disaggregation by supply-side. Moreover, the results for the second and third stage of disaggregation by demand-side are strongly poor, according to the standard setup used for the adjustment. These results are not surprising at all, given that the aggregations made by supply side already groups components with more affine dynamics. These components are, at least, themselves more affine than the wellknown demand-side National Accounts convention. Regarding methodological issues, particularly powerful tools to discriminate between stable aggregations are spectral plots and sliding spans, both estimated to the final seasonally adjusted series.

Finally, several topics emerge for future investigations. Especially relevant are the calibration of some thresholds used by diagnostics to certain-and relevant-cases as Chilean GDP, or if there is any difference in thresholds used for real or financial variables. Also, since 2008 the Central Bank of Chile produces the GDP dataset under a linked-chain methodology. As this method makes variables grow independently, a difference between the aggregates (may) emerge. Thus, the stability, ultimately, depends on the statistical properties of this non-additive term. Nonetheless, these and other topics are left to further research.

\section{References}

1. Akaike, H. and M. Ishiguro, 1983, Comparative Study of the X-11 and BAYSEA Procedures of Seasonal Adjustment, in A. Zellner (ed.), Applied Time Series Analysis of Economic Data, Bureau of the Census, US Department of Commerce, New York, US.

2. Almon, S., 1965, "The Distributed Lag Between Capital Appropriations and Net Expenditures," Econometrica 33(1): 178-196.

3. Astolfi, R., D. Ladiray and G.L. Mazzi, 2001, Seasonal Adjustment of European Aggregates: Direct versus Indirect Approach, Working Document 14 2001, Theme 1 General Statistics, Eurostat.

4. Banco Central de Chile, 2010, Cuentas Nacionales de Chile 2003-2009, available at: http://www.bcentral.cl/publicaciones/estadisticas/actividad-economica-gasto/pdf/ccnn_2003_2009.pdf.

5. Battipaglia, P. and D. Focarelli, 1995, A Comparison of Indicators for Evaluating X-11-ARIMA Seasonal Adjustments, Technical Report, Research Department, Bank of Italy.

6. Bobbitt, L. and M.C. Otto, 1990, Effects of Forecasts on the Revisions of Seasonally Adjusted Values Using the X-11 Seasonal Adjustment Procedure, Proceedings of the Business and Economic Statistics Section, American Statistical Association, pp. 449-453.

7. Bradley, J.V., 1968, Distribution-Free Statistical Tests, Prentice Hall, Englewood Cliffs, New Jersey, US.

8. Clements, M.P. and D.F. Hendry, 1996, "Intercept Corrections and Structural Change," Journal of Applied Economics 11(5): 475-494.

9. Cleveland, W.S. and S.J. Devlin, 1980, Calendar Effects in Monthly Time Series: Detection by Spectrum Analysis and Graphical Methods, Journal of the American Statistical Association 75(371): 487496.

10. Cunnyngham, J., 1963, Spectral Analysis of Economic Time Series, Working Paper 16, Bureau of the Census, US Department of Commerce, New York, US.

11. Dagum, E.B., 1980, The X-11-ARIMA Seasonal Adjustment Method, Statistics Canada.

12. Findley, D.F., 2005, "Asymptotic Stationary Properties of the Out-of-sample Forecast Errors of Misspecified RegARIMA Models and the Optimality of GLS for One-step-ahead Forecasting," Statistica Sinica 15(2): 447-476. 
13. Findley, D.F. and B.C. Monsell, 1986, New Techniques for Determining if a Time Series can be Seasonally Adjusted Reliably, and their application to US Foreign Trade Series, in M.R. Perryman and J.R. Schmidt, Regional Econometric Modeling, Kluwer-Nijhoff, Amsterdam, The Netherlands.

14. Findley, D.F, B.C. Monsell, W.R. Bell, M.C. Otto and B.-C. Chen, 1998, "New Capabilities and Methods of the X-12-ARIMA Seasonal-Adjustment Program," Journal of Business and Economic Statistics 16(2): 127-152.

15. Findley, D.F., B.C. Monsell, H.B. Shulman and M.G. Pugh, 1990, "Sliding Spans Diagnostics for Seasonal and Related Adjustments," Journal of the American Statistical Association 85(410): 345355.

16. Gómez, V. and A. Maravall, 1997, Programs TRAMO and SEATS, Instructions for User (Beta Version: September 1996), Working Paper 9628, Bank of Spain.

17. Granger, C.W.J., 1966, "The Typical Spectral Shape of an Economic Variable," Econometrica 34(1): $150-161$.

18. Granger, C.W.J., 1979, Seasonality: Causation, Interpretation, and Implications, in A. Zellner (ed.) Seasonal Analysis of Economic Time Series, National Bureau of Economic Research, US.

19. Granger, C.W.J. and M. Hatanaka, 1964, Spectral Analysis of Economic Time Series, Princeton University Press, New Jersey, US.

20. Granger, C.W.J. and O. Morgenstern, 1963, "Spectral Analysis of Stock Market Prices," Kyklos 16: $1-27$.

21. Hamilton, J., 1994, Time Series Analysis, Princeton University Press, New Jersey, US.

22. Hatanaka, M., 1963, A Spectral Analysis of Business Cycle Indicators: Lead-lag in Terms of All Time Points, Econometric Research Program, Princeton Research Memorandum 53, Princeton University, US.

23. Henderson, R., 1916, "Note on Graduation by Adjusted Average," Transactions of the American Society of Actuaries 17: 43-48.

24. Hood, C.C.H., 2007, Assessment of Diagnostics for the Presence of Seasonality, Proceedings of the International Conference on Establishment Surveys III, June 2007.

25. Hood, C.C.H. and D.F. Findley, 2001, Comparing Direct and Indirect Seasonal Adjustments of Aggregate Series, American Statistical Association Proceedings, October 2001.

26. Hood, C.C.H. and Kathleen M. McDonald-Johnson, 2009, Getting Started with X-12-ARIMA Diagnostics, Catherine Hood Consulting: http://www. catherinechhood.net/papers/gsx12diag.pdf.

27. Kendall, M. and J.K. Ord, 1990, Time Series, Third edition, Oxford University Press, UK.

28. Koyck, L.M., 1954, Distributed Lags and Investment Analysis, North-Holland Publishing Co., Amsterdam, The Netherlands.

29. Ladiray, D., 2008, Theoretical and Real Trading-Day Frequencies, American Statistical Association Proceedings, 2008.

30. Ladiray, D. and B. Quenneville, 2001, Seasonal Adjustment with the X-11 Method, Lecture Notes in Statistics 158, Springer, New York, US.

31. Ladiray, D. and G.L. Mazzi, 2003, Seasonal Adjustment of European Aggregates: Direct versus Indirect Approach, in M. Manna and R. Peronacci (eds.) Seasonal Adjustment, European Central Bank. 
32. Lothian, J., 1978, The Identification and Treatment of Moving Seasonality in the X-11-ARIMA Seasonal Adjustment Program, Research Paper, Seasonal Adjustment and Time Series Staff, Statistics Canada.

33. Lothian, J. and M. Morry, 1978, A Set of Quality Control Statistics for the X-11-ARIMA Seasonal Adjustment Method, Research Paper, Statistics Canada.

34. Maravall, A., 2002, "An Application of TRAMO-SEAT: Automatic Procedure and Sectoral Aggregation. The Japanese Foreign Trade Series," Documento de Trabajo 0207, Banco de España.

35. Maravall, A., 2005, "An Application of the TRAMO-SEATS Automatic Procedure; Direct Versus Indirect Adjustment," Documento de Trabajo 0524, Banco de España.

36. Medel, C.A., 2013, "How Informative are In-sample Information Criteria to Forecasting? The Case of Chilean GDP," Latin American Journal of Economics 50(1): 133-161.

37. Nerlove, M., 1964, "Spectral Analysis of Seasonal Adjustment Procedures," Econometrica 32(3): 241286.

38. Otto, M.C., 1985, Effects of Forecasts on the Revisions of Seasonally Adjusted Data Using the X-11 Seasonal Adjustment Procedure, Proceedings of the Business and Economic Statistics Section, American Statistical Association, pp. 463-466.

39. Otto, M.C., W.R. Bell and J.P. Burman, 1987, An Iterative GLS Approach to Maximum Likelihood Estimation of Regression Models with ARIMA Errors, Proceedings of the Business and Economic Statistics Section, American Statistical Association, pp. 632-637.

40. Otranto, E. and U. Triacca, 2000, A Distance-based Method for the Choice of Direct or Indirect Seasonal Adjustment, mimeo, Istituto Nazionale di Statistica, Italy.

41. Peronacci, R., 2003, The Seasonal Adjustment of Euro Area Monetary Aggregates: Direct versus Indirect Approach, in M. Manna and R. Peronacci (eds.) Seasonal Adjustment, European Central Bank.

42. Priestley, M.B., 1981, Spectral Analysis and Time Series, Volume 1: Univariate Series, Academic Press, Massachusetts, US.

43. Scheiblecker, M., 2014, "Direct versus Indirect Approach in Seasonal Adjustment," Working Paper 460, Austrian Institute of Economic Research.

44. Shiskin, J., A.H. Young and J.C. Musgrave, 1967, The X-11 Variant of the Census Method II Seasonal Adjustment Program, Technical Paper 15, Bureau of the Census, US Department of Commerce, New York, US.

45. Soukup, R.J. and D.F. Findley, 1999, On the Spectrum Diagnostics used by X-12-ARIMA to Indicate the Presence of Trading Day Effects after Modeling for Adjustment, American Statistical Association Proceedings, September 1999.

46. Stanger, M., 2007, "Empalme del PIB y de los Componentes del Gasto: Series Anuales y Trimestrales 1986-2002, Base 2003 ," Estudio Económico Estadístico 55, Banco Central de Chile.

47. Wallis, W.A. and G.H. Moore, 1941, A Significance Test for Time Series, National Bureau of Economic Research, Technical Paper No. 1, US.

48. US Census Bureau, 2011, X-12-ARIMA Reference Manual, Version 0.3, available at http://www.census.gov/srd/www/x12/. 


\section{A Quality measures in X-12-ARIMA}

\section{M1-M11 and $Q$ Statistics}

This annex, based on Lothian and Morry (1978), reviews the statistics used by X12 to assess the quality of an adjustment. These statistics constitute a set of eleven elements, which can be summarized into one-the $Q$ statistic-when weighted by a specific constant factor. They are presented within "Table F.3" in the X12 log-file. The main purpose is to analyze the contribution of the trend-cycle, seasonally adjusted and irregular component to changes in original series. Notice that all estimations should be done with stationary series; otherwise, variance-as well as other moments-is not defined. The statistics are the following (its weight to conform the $Q$-stat is shown in [ ]).

- M1 [13\%] Relative contribution of the irregular component to the variance of original series, over span k. This measure is important because if the irregular variation is too high compared with the variation of the seasonal component, the two components cannot be separated successfully. Consider the following estimation for irregular series:

$$
\bar{y}^{i r}(k)^{2}=\frac{1}{T-1} \sum_{t=2}^{T}\left(y_{t}^{i r}-y_{t-1}^{i r}\right)^{2},
$$

and similarly $\bar{y}^{\tau}(k)^{2}$ and $\bar{y}^{f}(k)^{2}$ for trend-cycle and seasonal factor series, respectively; all for lag $k$. Then, the variance of original series with lag $k$ is $\bar{\sigma}(k)^{2}=\bar{y}^{\tau}(k)^{2}+\bar{y}^{s a}(k)^{2}+\bar{y}^{i r}(k)^{2}$. Hence, the relative variance contribution of irregular component, $R_{i r(k)}$, is defined as: $R_{i r(k)}=\left(\bar{y}^{i r}(k)^{2} / \bar{\sigma}(k)^{2}\right) \times 100$. Lothian and Morry (1978) suggest the use of a order lag 3 with monthly series $(k=3)$, consequently, equal to 1 with quarterly series $(k=1)$. This differencing also converts series into a stationary one. These lags allow a maximum contribution of the irregular series equal to $10 \%$ to be acceptable. So, a relative contribution $R_{i r(1)}>10 \%$ fails the test. This leads to the standardized statistic $M 1$ :

$$
M 1=\frac{R_{i r(1)}}{10},
$$

which is not acceptable-the relative contribution of irregular is too high-if it exhibit values greater than 1.

- M2 [13\%] Relative contribution of the irregular component to the variance of original series, over span $\mathrm{k}$, with different transformation to achieve stationarity. This measure is similar to $M 1$, with the difference that the transformation to achieve stationarity is a linear trend remotion instead of differencing. Hence, if:

$$
\text { Contribution of } \widetilde{y}^{i r}=\frac{\text { variance of } \widetilde{y}^{i r}}{\text { variance of } \widetilde{y}},
$$

where $\widetilde{y}$ stands for "after trend remotion", then the $M 2$ statistic corresponds to:

$$
M 2=\frac{\text { Contribution of } \widetilde{y}^{i r}}{10} \times 100,
$$

keeping the decision rule anchored to 1 .

- M3 [10\%] The amount of quarter-on-quarter change due to irregular component compared with quarteron-quarter change due to trend-cycle. In the same spirit of $M 1$, this measure stands for analyzing whether it is possible to separate the series into the typical components of seasonal adjustment. If the movements of irregular series are dominant, it is difficult to identify each component, jeopardizing the overall adjustment process. The $M 3$ statistic is:

$$
M 3=\left(\frac{\bar{y}^{i r}}{\bar{y}^{\tau}}-\frac{1}{3}\right) \times \frac{2}{3},
$$

where $\bar{y}^{i r}$ and $\bar{y}^{\tau}$ are the mean of the quarter-on-quarter changes of series $y^{i r}$ and $y^{\tau}$, respectively. For monthly series, the values of $\frac{1}{3}$ and $\frac{2}{3}$ change to 1 and 2 . Decision rule holds anchored to 1 . 
- M4 [5\%] The autocorrelation of irregular component. As its name indicates, the irregular component should have a purely random behavior, with mean equal to 0 , a constant variance, and null covariance with other components. X12 makes use of the Average Duration of Run (ADR) to test randomness in the irregular component. This test, developed by Wallis and Moore (1941), is based on the number of turning points-sign changes in quarter-on-quarter series-to test against the alternative hypothesis that the process is an $\mathrm{AR}(1)$. A series of infinite length should exhibit an ADR statistic of 1.50. For a sample size of 120 observations, ADR's $99 \%$ interval of confidence is $(1.30,1.75)$, and values on the left (right) indicate negative (positive) autocorrelation. The approximation of ADR to normal distribution of Bradley (1968) helps in the construction of the M4 statistic:

$$
M 4=\frac{\left|\frac{T-1}{A D R}-\frac{2(T-1)}{3}\right|}{\sqrt{\frac{16 T-29}{90}}} \times \frac{1}{2.58},
$$

where $T$ is the sample size, and 2.58 is the $1 \%$ limit value of the standard normal distribution in two-sided tests. If $M 4$ is greater than 1, the irregular component exhibits significant autocorrelation, and the test fails.

- M5 [11\%] Quarters for cyclical dominance statistic. This statistic is built to cast for the number of quarters needed for the trend-cycle absolute changes to dominate those of the irregular component. It measures the relative size of changes in the irregular component respect to the trend-cycle, similarly to $M 3$. As the ratio $\bar{y}^{i r} / \bar{y}^{\tau}$ is estimated with a lag varying from 1 to 4 for quarterly series, the same estimation is used to find $k$-the Quarters for Cyclical Dominance (QCD):

$$
Q C D=k \text { if }\left\{\begin{array}{c}
\frac{\bar{y}^{i r}(k)}{\bar{y}^{\tau}(k)} \leq 1, \text { and } \\
\frac{\bar{y}^{i r}(k-1)}{\bar{y}^{\tau}(k-1)}>1 .
\end{array}\right.
$$

For instance, if a successive estimation of $\frac{\bar{y}^{i r}(1)}{\bar{y}^{\tau}(1)}, \ldots, \frac{\bar{y}^{i r}(4)}{\bar{y}^{\tau}(4)}$ results in $\{1.22,0.73,0.90,1.54\}$, the QCD is $k=3$, hence, implying that it takes 3 quarters for absolute changes in trend-cycle to become higher than changes in the irregular component. A QCD value lower than 2 in quarterly series has been considered acceptable. Hence, the M5 statistic corresponds to:

$$
M 5=\frac{Q C D-0.17}{1.67},
$$

which reflects that if $Q C D>2$, absolute changes in trend-cycle are not higher than those of the irregular.

- M6 [10\%] The amount of year-on-year change due to irregular component compared with year-on-year change due to seasonal component. This measure also tackles the issue of identification. One of the steps of the X-11 algorithm (step 7 in table 1) involves the application of $M_{3 \times 5}$ filter to (preliminary) seasonally adjusted and irregular components in order to separate both. According to Lothian and Morry (1978), when year-on-year changes in the irregular component are too small with respect to that of the seasonal component-a low $\bar{y}^{i r} / \bar{y}^{f}$ ratio-the $M_{3 \times 5}$ does not work well in accounting for seasonal movements. On the other hand, when the ratio $\bar{y}^{i r} / \bar{y}^{f}$ is too high, the filter does not fully permeate the seasonal component from irregular dynamics. Lothian (1978) pointed out-with actual seasonal series-that when the ratio $\bar{y}^{i r} / \bar{y}^{f}$ fell between 1.5 and 6.5 , the $M_{3 \times 5}$ filter works well. If instead, the value of the ratio $\bar{y}^{i r} / \bar{y}^{f}$ fell at the left or the right of the interval, identification is not successful. The statistic is built using these cut offs:

$$
M 6=\left|\frac{\bar{y}^{i r} / \bar{y}^{f}-4.0}{2.5}\right|
$$

As in previous cases, values above 1 fail the test, and no successful identification can be done. 
- M7 [16\%] The amount of stable seasonality relative to the amount of moving seasonality. As its label suggests, $M 7$ statistic is compounded by two measures: stable and moving seasonality. Both tests, included in X-11, consist on a F-test applied to final $\bar{y}^{i r} / \bar{y}^{f}$ ratio to check for both kinds of seasonality. The seasonality is called identifiable if the absolute error of seasonal factors is low. Hence, the deviation, or distortion, depends on both F-values: $\mathrm{F}_{S}$ and $\mathrm{F}_{M}$, for stable and moving. The $M 7$ statistic, considering $50 \%$ distortion in the seasonal factor, is constructed as:

$$
M 7=\left(\frac{7}{2 F_{S}}+\frac{3 F_{M}}{2 F_{S}}\right)^{\frac{1}{2}}
$$

and the decision rule remains constant.

- M8 [7\%] Changes in seasonal factor across all the sample. The M8 statistic compound one of the four statistics-together with M9 to M11-that cast for year-on-year movements in the seasonal component. Note that if seasonality is not present, year-on-year movements of a detrended series should be a constant in the middle stages of the sample span. But, if the seasonality is present and also varying across the sample, seasonal factors are hard to estimate without error. This simply points out that at least two kinds of seasonality emerges: that with changes in the same direction-linear-and that with quasi random fluctuations. The former can be measured and analyzed with ease along with the M9 and $M 11$ statistics, while the latter is tested with the $M 8$ and $M 10$ statistics. The difference between the pair $(M 8, M 9)$ with respect to $(M 10, M 11)$ is just the sample with which they are estimated. $M 10$ and M11 are estimated considering only the last three years of observations. This is because the use of seasonal adjustment is often concerned with most recent data. Moreover, linear estimates at the end of the sample are almost surely distorted. To have a sensitive measure of this distortion, X12 normalize seasonal factors in the following way:

$$
\widetilde{y}_{t}^{f}=\frac{y_{t}^{f}-\bar{y}_{t}^{f}}{\sigma\left(y_{t}^{f}\right)}
$$

where $\bar{y}_{t}^{f}$ stands for the mean of $y_{t}^{f}$, and $\sigma(\cdot)$ for its standard deviation. Thus, fluctuations of the seasonal factors of systematic-linear-changes are estimated with the average absolute change:

$$
\left|\Delta \overline{\widetilde{y}}^{f}\right|_{M 8}=\frac{1}{S(T-1)} \sum_{s=1}^{S} \sum_{t=2}^{T}\left|\widetilde{y}_{S t+s}^{f}-\widetilde{y}_{S(t-1)+s}^{f}\right|,
$$

where $F$ is the length of the sample measured in years ( $T=\{4 \times T, 12 \times T\}$,for quarterly and monthly series), and $S$ is the seasonal frequency $(S=\{4,12\})$. The maximum change acceptable by $\mathrm{X} 12$ is $10 \%$. Hence, the $M 8$ statistic is:

$$
M 8=\frac{100}{10} \times\left|\Delta \overline{\widetilde{y}}_{t}^{f}\right|_{M 8},
$$

indicating that values above 1 fail the test.

- M9 [7\%] Average linear changes of seasonal factor across all the sample. Notice that M8 statistic makes use of the absolute averaging measure because of systematic movements. Instead, when quasi random fluctuations of year-on-year variation is present, it is expected that its mean is close to zero. If the changes go in the same direction, the absolute average change will be very close to the average arithmetic change. By using the formula:

$$
\sum_{t=1}^{T-1} \Delta \widetilde{y}_{S t+S}^{f}=\widetilde{y}_{S(t-1)+s}^{f}-\widetilde{y}_{s}^{f},
$$

and considering an acceptance limit of $10 \%$, the $M 9$ statistic corresponds to:

$$
M 9=\frac{100}{10} \times \frac{\sum_{s=1}^{S}\left|\widetilde{y}_{S(T-1)+s}^{f}-\widetilde{y}_{s}^{f}\right|}{S(T-1)},
$$


implying that values above 1 fail the test.

- M10 [4\%] Changes in seasonal factor for last years of sample. As is explained above, this measure has the same shape as $M 8$, but estimated with the latest data. In particular, the years involved in calculations are: $T-2, T-3, T-4$, and $T-5$. Thus, the average absolute change becomes:

$$
\left|\Delta \overline{\widetilde{y}}^{f}\right|_{M 10}=\frac{1}{3 S} \sum_{s=1}^{S} \sum_{t=F-4}^{F-2}\left|\widetilde{y}_{S t+s}^{f}-\widetilde{y}_{S(t-1)+s}^{f}\right|,
$$

and the statistic is given by:

$$
M 10=\frac{100}{10} \times\left|\Delta \overline{\widetilde{y}}_{t}^{f}\right|_{M 10}
$$

indicating that values above 1 fail the test.

- M11 [4\%] Average linear changes of seasonal factor for last years of sample. As is explained above, this measure has the same shape as $M 9$, but estimated with the latest data. In particular, the years involved in calculations are: $T-2, T-3, T-4$, and $T-5$. Thus, $M 11$ statistic corresponds to:

$$
M 11=\frac{100}{10} \times \frac{\sum_{s=1}^{S}\left|\widetilde{y}_{S(F-2)+s}^{f}-\widetilde{y}_{S(F-5)+s}^{f}\right|}{3 \mp},
$$

indicating that values above 1 imply highly distorted seasonal factors in recent data due to the flattening effect of the end weights on linear movements.

- $\mathbf{Q}$ The $Q$ statistic is a weighted sum of all $M$ statistics that kept anchored to 1 the decision rule about adjustment quality. As each $M$-stat test for special potential problem, an overall quality assessment of the adjustment is required. One of the advantages of summarizing eleven $M$ 's output is that the interactions between them-what they are already measuring-are always considered. For instance, if the ratio $\bar{y}^{i r} / \bar{y}^{f}$ is low, it is more likely that $M 1$ and $M 2$ will fail, with a priori unknown spillovers effects onto remaining $M$-stats. Notice that a common strategy to improve the adjustment quality could be to keep some $M$-stats fixed and work in enhancing those that fail. Again, the $Q$-stat serves as a natural way to evaluate the effects of user interventions in the adjustment process. Nevertheless, the analysis should be done by considering always both $M$ and $Q$ statistics. This because, for instance, with certain trend-cycle shapes the proportion of the irregular to seasonal component can be large, failing the $M 3$ test, but not representing an overall poor adjustment. All these shortcomings have to be avoided depending on the use of the adjustment. 


\section{B A simulated series for benchmarking}

In this annex I make use of an extremely seasonal series to illustrate the seasonal adjustment process and the typical shape of their spectral plots. First, the illustrator series is built in "intrayear" cycles of 4 observations. Thus, it mimics a quarterly series. Second, it is composed of a (nonstochastic) trend divided by seasonal factors across "years" without outliers or trading day effect. These factors fluctuate by a little rate across years, leaving room for an irregular component. Hence, they correspond primarily to a multiplicative adjustment. Third, by construction, it contains a little variation of the irregular component relative to the variance of the series. Fourth, the series is an index with a base year (1989) equal to 100, spanning from 1986 to 2009 (96 observations).

\section{Figure B1: An example with a highly seasonal series}
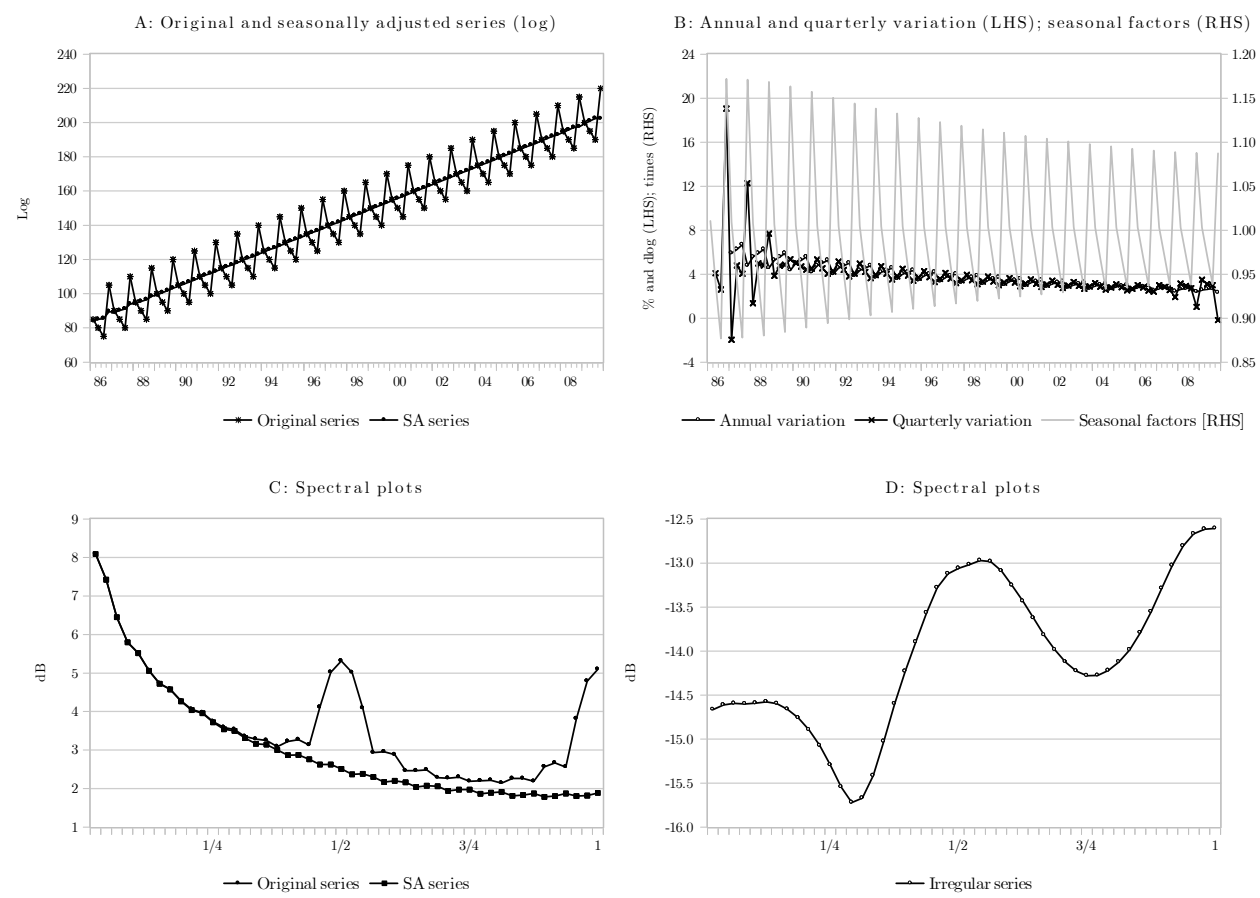

Source: Author's elaboration

The original and derivate series are presented in figure B1. Panel A shows the logarithmic level of the original and seasonally adjusted series. Notice that adjusted series should not exactly coincide with the original trend-the trend originally used to construct the series-because of the irregular component. Panel B shows the annual and quarterly variation of previous series, respectively. Obviously, the repeating pattern across the years of the quarterly variation of the seasonally adjusted series is given by the behavior of seasonal factors. Recall that the method is mean preserving. Hence, the yearly average of factors is always equal to 1. The seasonal factors are also depicted in panel B. Note that as they shrink as sample increases, the absolute value of quarterly variation decreases.

Panels C and D depict three different spectral plots. The first two, are those of original and seasonally adjusted series, while the third is of irregular component. Notice in panel $\mathrm{C}$ the effect on the spectrum caused by removing seasonality: a complete removal of peaks at seasonal frequencies. The resulting spectrum illustrates the typical spectral shape of an economic variable as Clive W.J. Granger shows on his influential Econometrica paper published in $1966 .{ }^{24}$ As should be the case, panel D shows an erratic cyclical behavior of irregular series, typically associated to a successful seasonal adjustment.

\footnotetext{
24 "The long-term fluctuations in economic variables, if decomposed into frequency components, are such that the amplitude of the components decreases smoothly with decreasing period." Granger (1966), p. 155.
} 


\section{Chilean GDP in levels by demand side}

\begin{tabular}{|c|c|c|c|c|c|c|c|}
\hline \multicolumn{8}{|c|}{$\begin{array}{c}g d p=i d+e d=c+i+g+(x-m)= \\
(c n+c d)+(m e q+c w+c i)+g+(x g+x s-m g-m s)\end{array}$} \\
\hline \multicolumn{2}{|r|}{ Aggregation 1} & \multicolumn{2}{|r|}{ Aggregation 2} & \multicolumn{2}{|r|}{ Aggregation 3} & \multicolumn{2}{|c|}{ Aggregation 6} \\
\hline$c n$ & $\begin{array}{l}\text { Household consumption } \\
\text { expenditure: nondurables }\end{array}$ & $c$ & $\begin{array}{l}\text { Household consumption } \\
\text { expenditure }\end{array}$ & $i d$ & $\begin{array}{l}\text { Internal demand } \\
(c+i+g)\end{array}$ & $g d p$ & $\begin{array}{l}\text { Gross } \\
\text { domestic }\end{array}$ \\
\hline$c d$ & $\begin{array}{l}\text { Household consumption } \\
\text { expenditure: durables }\end{array}$ & $i$ & $\begin{array}{l}(c n+c d) \\
\text { Investment }\end{array}$ & $e d$ & $\begin{array}{l}\text { External demand } \\
(x-m)\end{array}$ & & $\begin{array}{l}\text { product } \\
(i d+e d)\end{array}$ \\
\hline meq & Machinery and equipment & & $(m e q+c w)$ & & & & \\
\hline$c w$ & Construction and works & $c i$ & Changes in inventories $(*)$ & & & & \\
\hline$c i$ & Changes in inventories $(*)$ & $g$ & Government consumption & & & & \\
\hline$g$ & Government consumption & & expenditure $(g)$ & & & & \\
\hline & expenditure & $x$ & Exports & & & & \\
\hline$x g$ & Exports of goods & & $(x g+x s)$ & & & & \\
\hline xs & Exports of services & $m$ & $\operatorname{Imports}(* *)$ & & & & \\
\hline$m g$ & Imports of goods $(* *)$ & & $(m g+m s)$ & & & & \\
\hline ms & Imports of services $(* *)$ & & & & & & \\
\hline
\end{tabular}

$\left(^{*}\right)$ Not considered in analysis. $\left.{ }^{* *}\right)$ Imports are subtracted. Source: Central Bank of Chile.

\section{Chilean GDP in levels by supply side}

Table D1: Chilean GDP in levels by supply side $g d p=g d p n r+g d p n n r+o t h e r s=(e g w+c a f+\min )+$

\begin{tabular}{|c|c|c|c|c|c|}
\hline \multicolumn{2}{|c|}{ Aggregation 6} & \multicolumn{2}{|r|}{ Aggregation 4} & \multicolumn{2}{|r|}{ Aggregation 5} \\
\hline \multirow[t]{17}{*}{$g d p$} & Gross & $g d p n r$ & GDP Natural resources & egw & Electricity, gas and water \\
\hline & domestic & & $(e g w+c a f+\min )$ & caf & Capture fishery \\
\hline & product & $g d p n n r$ & GDP Non-natural resources & $\min$ & Mining \\
\hline & $(g d p n r+$ & & $(\operatorname{com}+\operatorname{man}+\operatorname{con}+$ & com & Wholesale and retail trade, \\
\hline & $g d p n n r+$ & & $a g r+t r a+f i n+$ & & hotels and restaurants \\
\hline & others) & & $p e r+o o d+p u b)$ & man & Manufacturing \\
\hline & & others & Other sectors & con & Construction \\
\hline & & & $(-d u t+v a t+c i f)$ & $a g r$ & Agriculture and forestry \\
\hline & & & & tra & Transportation and communications \\
\hline & & & & fin & Financial intermediation and \\
\hline & & & & & business services \\
\hline & & & & per & Personal and social services \\
\hline & & & & ood & Owner-occupied dwellings \\
\hline & & & & $p u b$ & Public administration \\
\hline & & & & $d u t$ & Duties + taxes on goods and services $(*)$ \\
\hline & & & & vat & Non-deductible VAT \\
\hline & & & & cif & Imports CIF \\
\hline
\end{tabular}

$\left(^{*}\right)$ DUT are subtracted. Source: Central Bank of Chile. 


\section{E Shares of sectorial components on real GDP}

Table E1: Shares of sectorial components on real GDP

\begin{tabular}{|c|c|c|c|c|c|c|c|c|c|}
\hline \multicolumn{2}{|r|}{ Aggregation 1} & \multicolumn{2}{|r|}{ Aggregation 2} & \multicolumn{2}{|c|}{ Aggregation 3} & \multicolumn{2}{|r|}{ Aggregation 4} & \multicolumn{2}{|r|}{ Aggregation 5} \\
\hline $58.2 \%$ & Household consumption & $62.8 \%$ & Household consumption & $95.9 \%$ & Internal demand & $12.5 \%$ & GDP Natural & $2.9 \%$ & Electricity, gas and water \\
\hline & expenditure: nondurables & & expenditure & & $(c+i+g)$ & & resources & $1.2 \%$ & Capture fishery \\
\hline $4.6 \%$ & Household consumption & & $(c n+c d)$ & $4.1 \%$ & External demand & & $(e g w+c a f+\min )$ & $8.4 \%$ & Mining \\
\hline & expenditure: durables & $20.1 \%$ & Investment & & $(x-m)$ & $82.5 \%$ & GDP Non-natural & $9.7 \%$ & Wholesale and retail trade, \\
\hline $6.9 \%$ & Machinery and equipment & & $(m e q+c w+c i)$ & & & & resources & & hotels and restaurants \\
\hline $13.3 \%$ & Construction and works & $12.0 \%$ & Government consumption & & & & $(\operatorname{com}+\operatorname{man}+\operatorname{con}+$ & $16.4 \%$ & Manufacturing \\
\hline $1.0 \%$ & Changes in inventories $(*)$ & & expenditure $(g)$ & & & & $a g r+t r a+f i n+$ & $6.9 \%$ & Construction \\
\hline \multirow[t]{2}{*}{$12.0 \%$} & Government consumption & $36.5 \%$ & Exports & & & & per+ood + pub) & $3.6 \%$ & Agriculture and forestry \\
\hline & expenditure & & $(x g+x s)$ & & & $5.0 \%$ & Other sectors & $9.2 \%$ & Transportation and communications \\
\hline $29.2 \%$ & Exports of goods & $32.4 \%$ & Imports $(* *)$ & & & & $(-d u t+v a t+c i f)$ & $15.0 \%$ & Financial intermediation and \\
\hline $7.3 \%$ & Exports of services & & $(m g+m s)$ & & & & & & business services \\
\hline $26.0 \%$ & Imports of goods $(* *)$ & $1.0 \%$ & Changes in inventories $(*)$ & & & & & $11.6 \%$ & Personal and social services \\
\hline \multirow[t]{5}{*}{$6.4 \%$} & Imports of services $(* *)$ & & & & & & & $5.8 \%$ & Owner-occupied dwellings \\
\hline & & & & & & & & $4.3 \%$ & Public administration \\
\hline & & & & & & & & $3.4 \%$ & $\begin{array}{l}\text { Duties }+ \text { taxes on goods } \\
\text { and services }(* *)\end{array}$ \\
\hline & & & & & & & & $7.4 \%$ & Non-deductible VAT \\
\hline & & & & & & & & $1.0 \%$ & Imports CIF \\
\hline
\end{tabular}

$(*)$ Not considered in analysis. (**) Subtracted. Source: Central Bank of Chile. 


\section{F Typical statistics of series}

Table F1: Typical statistics of demand side series, full sample

\begin{tabular}{|c|c|c|c|c|c|c|}
\hline & \multicolumn{3}{|c|}{$\begin{array}{c}\text { Mean } \\
\text { (Standard deviation) }\end{array}$} & \multicolumn{3}{|c|}{$\begin{array}{l}\text { Maximum } \\
\text { (Minimum) }\end{array}$} \\
\hline & Level $(*)$ & $\%(* *)$ & $d \log (s a)(* * *)$ & Level $(*)$ & $\%(* *)$ & $d \log (s a)(* * *)$ \\
\hline$c n$ & $\begin{array}{l}6068013 \\
(2241842)\end{array}$ & $\begin{array}{l}5.811 \\
(2.917)\end{array}$ & $\begin{array}{l}0.014 \\
(0.011)\end{array}$ & $\begin{array}{l}10545773 \\
(2604436)\end{array}$ & $\begin{array}{l}15.747 \\
(-1.763)\end{array}$ & $\begin{array}{c}0.045 \\
(-0.011)\end{array}$ \\
\hline$c d$ & $\begin{array}{l}586936 \\
(346364)\end{array}$ & $\begin{array}{l}13.067 \\
(20.681)\end{array}$ & $\begin{array}{l}0.030 \\
(0.094)\end{array}$ & $\begin{array}{l}1433854 \\
(66897)\end{array}$ & $\begin{array}{c}76.864 \\
(-36.143)\end{array}$ & $\begin{array}{c}0.488 \\
(-0.203)\end{array}$ \\
\hline meq & $\begin{array}{l}848577 \\
(597871)\end{array}$ & $\begin{array}{l}13.893 \\
(20.247)\end{array}$ & $\begin{array}{l}0.029 \\
(0.075)\end{array}$ & $\begin{array}{l}2621727 \\
(114903)\end{array}$ & $\begin{array}{c}57.374 \\
(-31.887)\end{array}$ & $\begin{array}{c}0.168 \\
(-0.212)\end{array}$ \\
\hline$c w$ & $\begin{array}{l}1451274 \\
(493573)\end{array}$ & $\begin{array}{c}6.345 \\
(-21.837)\end{array}$ & $\begin{array}{l}0.014 \\
(0.040)\end{array}$ & $\begin{array}{l}2435179 \\
(571050)\end{array}$ & $\begin{array}{c}32.680 \\
(-21.837)\end{array}$ & $\begin{array}{c}0.122 \\
(-0.089)\end{array}$ \\
\hline$g$ & $\begin{array}{c}1337538 \\
(3982019)\end{array}$ & $\begin{array}{c}4.143 \\
(2.237)\end{array}$ & $\begin{array}{c}0.009 \\
(0.009)\end{array}$ & $\begin{array}{c}2203213 \\
(713499)\end{array}$ & $\begin{array}{c}8.640 \\
(-3.946)\end{array}$ & $\begin{array}{c}0.059 \\
(-0.018)\end{array}$ \\
\hline$x g$ & $\begin{array}{l}2848950 \\
(1373321)\end{array}$ & $\begin{array}{l}7.567 \\
(6.998)\end{array}$ & $\begin{array}{l}0.018 \\
(0.050)\end{array}$ & $\begin{array}{l}5418178 \\
(858705)\end{array}$ & $\begin{array}{c}24.643 \\
(-6.480)\end{array}$ & $\begin{array}{c}0.178 \\
(-0.187)\end{array}$ \\
\hline$x s$ & $\begin{array}{c}685501 \\
(363399)\end{array}$ & $\begin{array}{l}13.086 \\
(29.508)\end{array}$ & $\begin{array}{l}0.019 \\
(0.192)\end{array}$ & $\begin{array}{c}1441582 \\
(45949)\end{array}$ & $\begin{array}{l}169.307 \\
(-46.181)\end{array}$ & $\begin{array}{c}1.034 \\
(-0.535)\end{array}$ \\
\hline$(m g)$ & $\begin{array}{c}2855276 \\
(1868065)\end{array}$ & $\begin{array}{c}12.112 \\
(13.192)\end{array}$ & $\begin{array}{c}0.028 \\
(0.055)\end{array}$ & $\begin{array}{l}7724684 \\
(400759)\end{array}$ & $\begin{array}{c}41.315 \\
(-22.396)\end{array}$ & $\begin{array}{c}0.161 \\
(-0.199)\end{array}$ \\
\hline$(m s)$ & $\begin{array}{c}580860 \\
(296040)\end{array}$ & $\begin{array}{c}7.741 \\
(10.237)\end{array}$ & $\begin{array}{c}0.017 \\
(0.058)\end{array}$ & $\begin{array}{c}1103390 \\
(174309)\end{array}$ & $\begin{array}{c}47.292 \\
(-27.912)\end{array}$ & $\begin{array}{c}0.261 \\
(-0.181)\end{array}$ \\
\hline$c$ & $\begin{array}{c}6652570 \\
(2569375)\end{array}$ & $\begin{array}{c}6.183 \\
(3.857)\end{array}$ & $\begin{array}{l}0.015 \\
(0.013)\end{array}$ & $\begin{array}{l}11965071 \\
(2671333)\end{array}$ & $\begin{array}{c}18.070 \\
(-5.102)\end{array}$ & $\begin{array}{c}0.049 \\
(-0.025)\end{array}$ \\
\hline$i$ & $\begin{array}{c}2256083 \\
(1116785)\end{array}$ & $\begin{array}{c}9.513 \\
(13.269)\end{array}$ & $\begin{array}{l}0.021 \\
(0.046)\end{array}$ & $\begin{array}{l}4940206 \\
(545627)\end{array}$ & $\begin{array}{c}36.790 \\
(-25.618)\end{array}$ & $\begin{array}{c}0.129 \\
(-0.147)\end{array}$ \\
\hline$x$ & $\begin{array}{c}3533607 \\
(1722640)\end{array}$ & $\begin{array}{c}7.901 \\
(6.816)\end{array}$ & $\begin{array}{l}0.018 \\
(0.041)\end{array}$ & $\begin{array}{l}6737383 \\
(992725)\end{array}$ & $\begin{array}{c}27.058 \\
(-7.217)\end{array}$ & $\begin{array}{c}0.141 \\
(-0.070)\end{array}$ \\
\hline$(m)$ & $\begin{array}{c}3438889 \\
(2151185)\end{array}$ & $\begin{array}{c}10.992 \\
(11.427)\end{array}$ & $\begin{array}{l}0.026 \\
(0.050)\end{array}$ & $\begin{array}{l}8774539 \\
(575068)\end{array}$ & $\begin{array}{c}34.234 \\
(-19.163)\end{array}$ & $\begin{array}{c}0.136 \\
(-0.173)\end{array}$ \\
\hline$i d$ & $\begin{array}{l}10254896 \\
(4120949)\end{array}$ & $\begin{array}{l}6.591 \\
(6.543)\end{array}$ & $\begin{array}{l}0.016 \\
(0.030)\end{array}$ & $\begin{array}{l}18747826 \\
(3591484)\end{array}$ & $\begin{array}{c}21.216 \\
(-10.031)\end{array}$ & $\begin{array}{c}0.109 \\
(-0.061)\end{array}$ \\
\hline$e d(\diamond)$ & $\begin{array}{c}94717 \\
(679884)\end{array}$ & $\begin{array}{c}39.716 \\
(414.744)\end{array}$ & $\begin{array}{l}\mathrm{NA} \\
\mathrm{NA}\end{array}$ & $\begin{array}{c}1050973 \\
(-2531999)\end{array}$ & $\begin{array}{c}2046.979 \\
(-1793.768)\end{array}$ & $\begin{array}{l}\text { NA } \\
\text { NA }\end{array}$ \\
\hline$g d p$ & $\begin{array}{r}10473599 \\
(3585032) \\
\end{array}$ & $\begin{array}{l}5.445 \\
(3.725)\end{array}$ & $\begin{array}{c}0.013 \\
(0.014) \\
\end{array}$ & $\begin{array}{l}16874801 \\
(4616475)\end{array}$ & $\begin{array}{c}16.263 \\
(-4.476) \\
\end{array}$ & $\begin{array}{c}0.052 \\
(-0.035) \\
\end{array}$ \\
\hline
\end{tabular}

$\left(^{*}\right)$ Includes all observations from 1986.I to 2009.IV (96 observations). (**) Estimated from 1987.I

to 2009.IV. (***) Estimated from 1986.II to 2009.IV. ( $\diamond)$ Log-differenced changes not calculated as with negative values. Source: Author's elaboration. 
Table F2: Typical statistics of supply side series, full sample

\begin{tabular}{|c|c|c|c|c|c|c|}
\hline & \multicolumn{3}{|c|}{$\begin{array}{c}\text { Mean } \\
\text { (Standard deviation) }\end{array}$} & \multicolumn{3}{|c|}{$\begin{array}{l}\text { Maximum } \\
\text { (Minimum) }\end{array}$} \\
\hline & Level $(*)$ & $\%(* *)$ & $d \log (s a)(* * *)$ & Level $(*)$ & $\%(* *)$ & $d \log (s a)(* * *)$ \\
\hline$e g w$ & $\begin{array}{l}283364 \\
(78522)\end{array}$ & $\begin{array}{l}-0.001 \\
(0.090)\end{array}$ & $\begin{array}{c}0.009 \\
(0.054)\end{array}$ & $\begin{array}{c}430088 \\
(142348)\end{array}$ & $\begin{array}{c}0.246 \\
(-0.215)\end{array}$ & $\begin{array}{c}0.129 \\
(-0.187)\end{array}$ \\
\hline min & $\begin{array}{l}804793 \\
(276430)\end{array}$ & $\begin{array}{l}0.000 \\
(0.117)\end{array}$ & $\begin{array}{c}0.010 \\
(0.028)\end{array}$ & $\begin{array}{l}1220424 \\
(392020)\end{array}$ & $\begin{array}{c}0.204 \\
(-0.298)\end{array}$ & $\begin{array}{c}0.097 \\
(-0.060)\end{array}$ \\
\hline$c a f$ & $\begin{array}{c}117646 \\
(58319)\end{array}$ & $\begin{array}{c}-0.008 \\
(0.434)\end{array}$ & $\begin{array}{c}0.018 \\
(0.128)\end{array}$ & $\begin{array}{l}254936 \\
(30590)\end{array}$ & $\begin{array}{c}0.967 \\
(-0.869)\end{array}$ & $\begin{array}{c}0.394 \\
(-0.515)\end{array}$ \\
\hline$a g r$ & $\begin{array}{c}388555 \\
(192637)\end{array}$ & $\begin{array}{l}-0.007 \\
(0.729)\end{array}$ & $\begin{array}{c}0.013 \\
(0.031)\end{array}$ & $\begin{array}{c}941539 \\
(123887)\end{array}$ & $\begin{array}{c}1.070 \\
(-1.076)\end{array}$ & $\begin{array}{c}0.139 \\
(-0.059)\end{array}$ \\
\hline $\operatorname{man}$ & $\begin{array}{l}1832821 \\
(476964)\end{array}$ & $\begin{array}{l}-0.001 \\
(0.066)\end{array}$ & $\begin{array}{c}0.010 \\
(0.026)\end{array}$ & $\begin{array}{l}2634049 \\
(889423)\end{array}$ & $\begin{array}{c}0.163 \\
(-0.197)\end{array}$ & $\begin{array}{c}0.071 \\
(-0.059)\end{array}$ \\
\hline $\mathrm{com}$ & $\begin{array}{l}1039792 \\
(397285)\end{array}$ & $\begin{array}{l}-0.001 \\
(0.136)\end{array}$ & $\begin{array}{c}0.015 \\
(0.021)\end{array}$ & $\begin{array}{l}1807611 \\
(377328)\end{array}$ & $\begin{array}{c}0.293 \\
(-0.232)\end{array}$ & $\begin{array}{c}0.066 \\
(-0.062)\end{array}$ \\
\hline con & $\begin{array}{c}765692 \\
(244934)\end{array}$ & $\begin{array}{l}0.000 \\
(0.113)\end{array}$ & $\begin{array}{c}0.013 \\
(0.036)\end{array}$ & $\begin{array}{l}1239985 \\
(330116)\end{array}$ & $\begin{array}{c}0.210 \\
(-0.245)\end{array}$ & $\begin{array}{c}0.111 \\
(-0.076)\end{array}$ \\
\hline $\operatorname{tra}$ & $\begin{array}{c}883142 \\
(428532)\end{array}$ & $\begin{array}{c}0.000 \\
(0.055)\end{array}$ & $\begin{array}{c}0.019 \\
(0.018)\end{array}$ & $\begin{array}{l}1743795 \\
(270632)\end{array}$ & $\begin{array}{c}0.165 \\
(-0.130)\end{array}$ & $\begin{array}{c}0.069 \\
(-0.022)\end{array}$ \\
\hline fin & $\begin{array}{l}1572100 \\
(618350)\end{array}$ & $\begin{array}{c}-0.001 \\
(0.073)\end{array}$ & $\begin{array}{c}0.015 \\
(0.017)\end{array}$ & $\begin{array}{l}2703326 \\
(585050)\end{array}$ & $\begin{array}{c}0.136 \\
(-0.197)\end{array}$ & $\begin{array}{c}0.062 \\
(-0.047)\end{array}$ \\
\hline per & $\begin{array}{l}1256098 \\
(353191)\end{array}$ & $\begin{array}{l}-0.003 \\
(0.370)\end{array}$ & $\begin{array}{c}0.001 \\
(0.673)\end{array}$ & $\begin{array}{l}1952350 \\
(598307)\end{array}$ & $\begin{array}{c}0.706 \\
(-0.396)\end{array}$ & $\begin{array}{c}1.102 \\
(-1.036)\end{array}$ \\
\hline ood & $\begin{array}{c}660505 \\
(125509)\end{array}$ & $\begin{array}{l}0.000 \\
(0.003)\end{array}$ & $\begin{array}{c}0.008 \\
(0.006)\end{array}$ & $\begin{array}{c}916461 \\
(492724)\end{array}$ & $\begin{array}{c}0.025 \\
(-0.021)\end{array}$ & $\begin{array}{c}0.036 \\
(-0.008)\end{array}$ \\
\hline$p u b$ & $\begin{array}{l}519036 \\
(67809)\end{array}$ & $\begin{array}{c}0.000 \\
(0.009)\end{array}$ & $\begin{array}{c}0.004 \\
(0.005)\end{array}$ & $\begin{array}{c}674628 \\
(438530)\end{array}$ & $\begin{array}{c}0.026 \\
(-0.041)\end{array}$ & $\begin{array}{c}0.015 \\
(-0.025)\end{array}$ \\
\hline$(d u t)$ & $\begin{array}{c}388081 \\
(160611)\end{array}$ & $\begin{array}{c}0.000 \\
(0.058)\end{array}$ & $\begin{array}{c}0.015 \\
(0.019)\end{array}$ & $\begin{array}{c}723465 \\
(165031)\end{array}$ & $\begin{array}{c}0.173 \\
(-0.116)\end{array}$ & $\begin{array}{c}0.068 \\
(-0.057)\end{array}$ \\
\hline vat & $\begin{array}{c}776675 \\
(324558)\end{array}$ & $\begin{array}{c}-0.001 \\
(0.058)\end{array}$ & $\begin{array}{c}0.016 \\
(0.016)\end{array}$ & $\begin{array}{l}1436665 \\
(279024)\end{array}$ & $\begin{array}{c}0.117 \\
(-0.110)\end{array}$ & $\begin{array}{c}0.060 \\
(-0.034)\end{array}$ \\
\hline cif & $\begin{array}{l}120050 \\
(88293)\end{array}$ & $\begin{array}{c}-0.004 \\
(0.128)\end{array}$ & $\begin{array}{c}0.030 \\
(0.062)\end{array}$ & $\begin{array}{l}375036 \\
(15246)\end{array}$ & $\begin{array}{c}0.318 \\
(-0.360)\end{array}$ & $\begin{array}{c}0.172 \\
(-0.130)\end{array}$ \\
\hline$g d p n r$ & $\begin{array}{l}1203425 \\
(393755)\end{array}$ & $\begin{array}{c}-0.001 \\
(0.086)\end{array}$ & $\begin{array}{c}0.010 \\
(0.027)\end{array}$ & $\begin{array}{l}1782751 \\
(586220)\end{array}$ & $\begin{array}{c}0.265 \\
(-0.169)\end{array}$ & $\begin{array}{c}0.134 \\
(-0.052)\end{array}$ \\
\hline$g d p n n r$ & $\begin{array}{c}8844037 \\
(2871629)\end{array}$ & $\begin{array}{c}-0.001 \\
(0.064)\end{array}$ & $\begin{array}{c}0.012 \\
(0.015)\end{array}$ & $\begin{array}{l}14248987 \\
(4015997)\end{array}$ & $\begin{array}{c}0.129 \\
(-0.116)\end{array}$ & $\begin{array}{c}0.061 \\
(-0.032)\end{array}$ \\
\hline others & $\begin{array}{c}518683 \\
(242264)\end{array}$ & $\begin{array}{l}-0.001 \\
(0.057)\end{array}$ & $\begin{array}{c}0.007 \\
(0.121)\end{array}$ & $\begin{array}{l}1035604 \\
(149443)\end{array}$ & $\begin{array}{c}0.112 \\
(-0.110)\end{array}$ & $\begin{array}{c}0.121 \\
(-1.132)\end{array}$ \\
\hline$g d p$ & $\begin{array}{c}10473599 \\
(3585032)\end{array}$ & $\begin{array}{c}-0.001 \\
(0.069)\end{array}$ & $\begin{array}{c}0.013 \\
(0.014)\end{array}$ & $\begin{array}{l}16874801 \\
(4616475) \\
\end{array}$ & $\begin{array}{c}0.164 \\
(-0.127)\end{array}$ & $\begin{array}{c}0.052 \\
(-0.035)\end{array}$ \\
\hline
\end{tabular}

(*) Includes all observations from 1986.I to 2009.IV (96 observations). (**) Estimated from 1987.I to 2009.IV. (***) Estimated from 1986.II to 2009.IV. Source: Author's elaboration. 


\section{G GDP Components: Original series in levels}

Figure G1: Chilean GDP - Original series in logarithmic levels
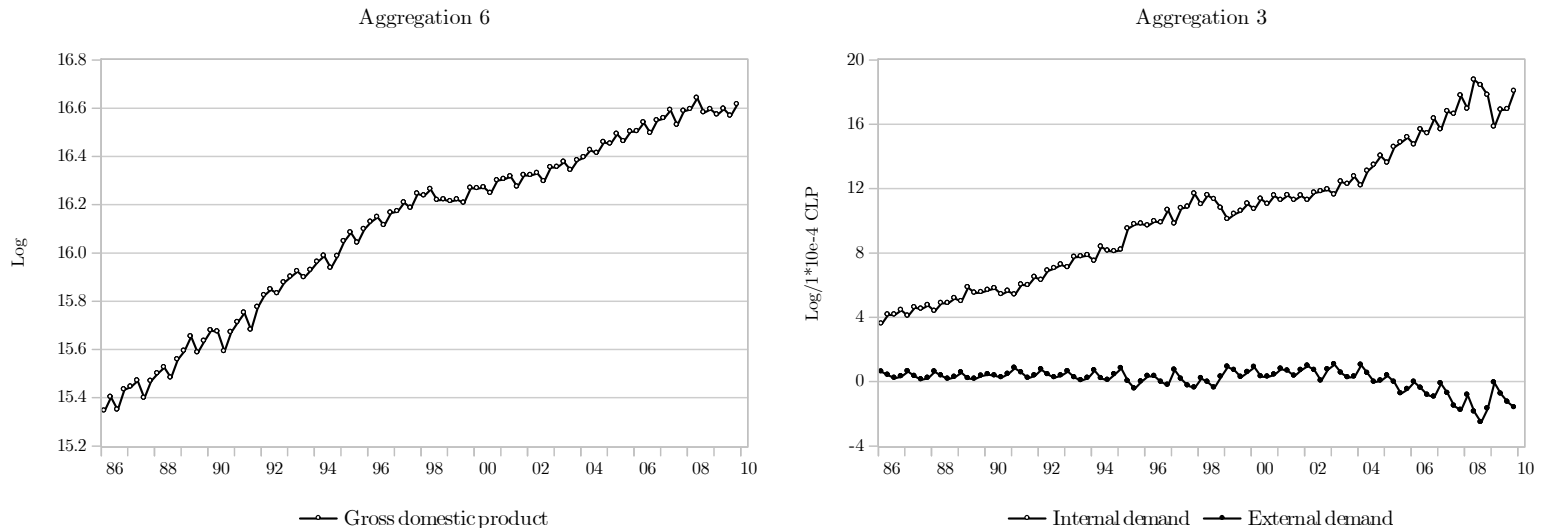

Aggregation 4
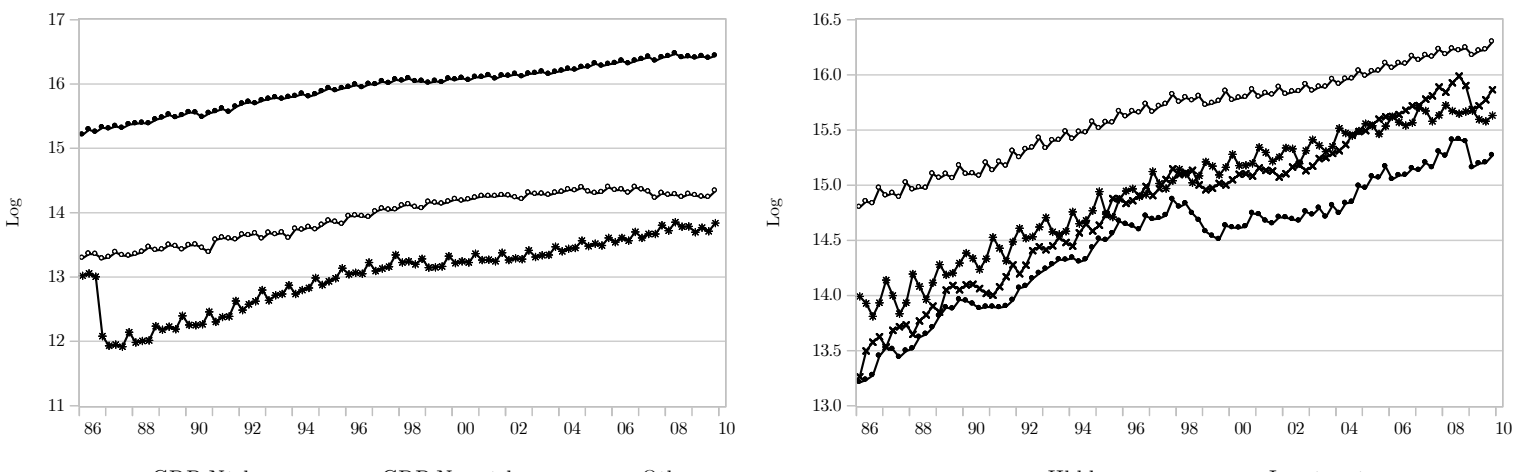

$\simeq$ GDP Ntrl. rsres. $\longleftarrow$ GDP Nonntrl. rsres. $\longleftarrow$ Others

$$
\begin{aligned}
& \simeq \text { Hhlds. cons. exp. } \longrightarrow \text { Investment } \\
& \longrightarrow \text { Exports }
\end{aligned}
$$

Aggregation 5

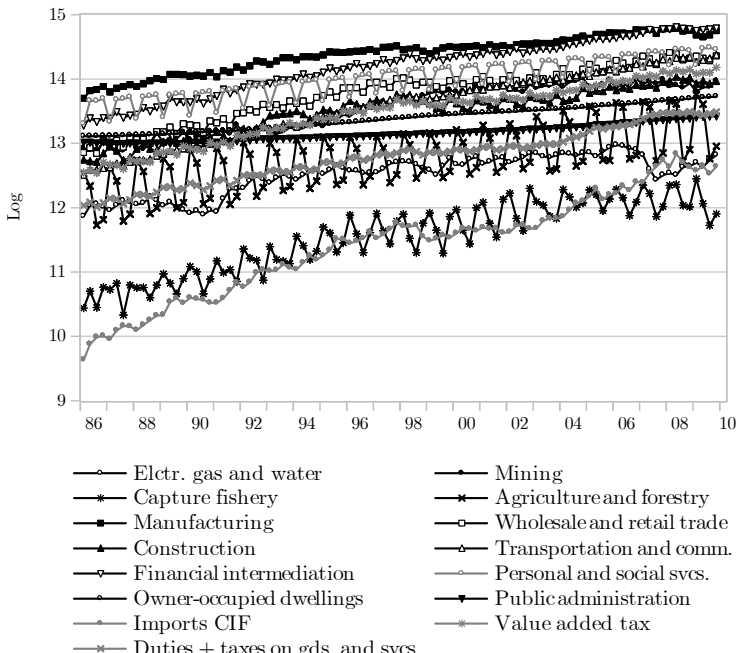

Aggregation 1

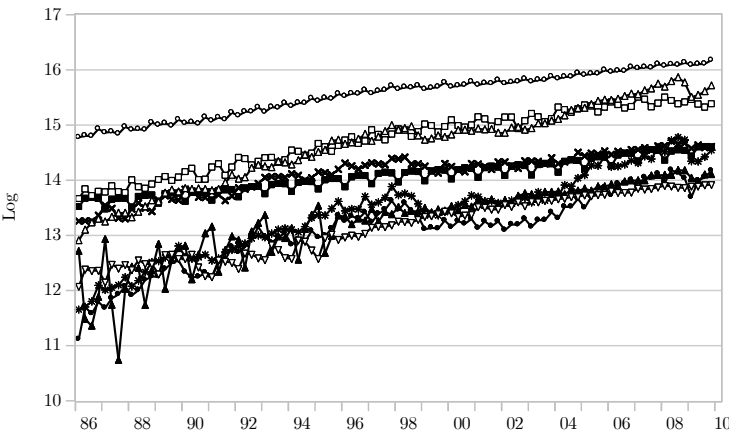

— Hholds. cons. exp.: Nondrbls. —— Hholds. cons. exp.: Drbls.

$\longrightarrow$ - Machinery and equipment $\longrightarrow$ Construction and works

$\longrightarrow$ Gvmnt. cons. exp. $\longrightarrow$ Exports of goods

$\longrightarrow$ Exports of services $\longrightarrow$ Imports of goods

Source: Central Bank of Chile. 


\section{H An user-written Eviews script for X-12-ARIMA}

'Program code for "How to Seasonally Adjust the Chilean GDP with X-12-ARIMA?".

'Written by Carlos A. Medel (cnmedel@gmail.com) on 19 August 2013 (v.1.0).

'X-12-ARIMA is a product of US Census Bureau and is free available at http://www.census.gov/.

$w f c r e a t e(w f=$ chile_gdp,page=howtoseas) Q 19862010

$\operatorname{read}(\mathrm{t}=\mathrm{xls}, \mathrm{c} 3, \mathrm{~s}=\mathrm{pib})$

$\mathrm{M}: \backslash$ Howto_seas $\backslash$ Data $\backslash$ gdp_series.xls 36

for $! \mathrm{d}=61$ to 96

smpl @first @first+ $\{! d\}$

\%kind="m" 'Seasonal adjustment method: $[($ default="m")] "m" (multiplicative adjustment; Series must take only nonnegative values), "a" (additive adjustment), "p" (pseudoadditive adjustment), "l" (log-additive seasonal adjustment; Series must take only positive values).

\%filter="msr" 'Seasonal filter: $[($ default= "msr" ) "msr" (automatic, moving seasonality ratio), "x11" (X11 default), "stable" (stable), "s3x1" (3x1 moving average), "s3x3" (3x3 moving average), "s $3 \times 5$ " ( $3 \times 5$ moving average), "s $3 \times 9$ " ( $3 \times 9$ moving average), "s3x15" (3x15 moving average seasonal filter; Series must have at least 20 years of data).

\%trans="0" 'Transformation for regARIMA: "logit" (Logit transformation), "auto" (automatically choose between no transformation and $\log$ transformation), number (Box-Cox power transformation using specified parameter; use " $\mathrm{t} f=0$ " for log transformation).

\%arspec="f, outsmpl" 'Automatically choose the ARIMA spec. f: Use forecasts from the chosen model in seasonal adjustment. Cannot be used together with the "arima=" option and must be used together with the "mfile=" option. b: Automatically choose the ARIMA spec. Use forecasts and backcasts from the chosen model in seasonal adjustment. Cannot be used together with the "arima=" option and must be used together with the "mfile=" option.

\%easter=" "'NO:",ea" 'ea: Nonparametric Easter holiday adjustment (x11easter). Cannot be used together with the "easter $[\mathrm{w}]$ " regressor in the "reg=" or "x11reg=" options.

'outsmpl: Use out-of-sample forecasts for automatic model selection. Default is in-sample forecasts. Must be used together with the "amdl=" option.

'sspan: Sliding spans stability analysis. Cannot be used along with the "h" option.

'history: Historical record of seasonal adjustment revisions. Cannot be used along with the "sspan" option. 'check: Check residuals of regARIMA.

'outlier: Outlier analysis of regARIMA.

\author{
'Adjusting process \\ series $\mathrm{de}=\mathrm{x}-\mathrm{m}$ \\ series ve_sa $=$ ve \\ series ve_ir $=$ ve \\ series ve_tc=ve
}

'Aggregation 1

for $\% \mathrm{k}$ cn meq $\mathrm{cw} \mathrm{g} x \mathrm{mg} \mathrm{ms}$

$\{\% \mathrm{k}\} \cdot \mathrm{x} 12($ mode $=\{\% \mathrm{kind}\}$, filter $=\{\%$ filter $\}$, save $=" \mathrm{~d} 10 \mathrm{~d} 11 \mathrm{~d} 12$

$\mathrm{d} 13^{\prime \prime}, \mathrm{tf}=\{\%$ trans $\}$, sspan,check,outlier,

amdl $=\{\%$ arspec $\}$,plotspectra $\{\%$ easter $\})$

next

cd. $x 12($ mode $=$ m, filter $=$ stable, save $=" \mathrm{~d} 10 \quad \mathrm{~d} 11 \quad \mathrm{~d} 12$

$\mathrm{d} 13^{\prime \prime}, \mathrm{tf}=$ auto, check, outlier, amdl $=\{\%$ arspec $\}$,

plotspectra $\{\%$ easter $\}$ )

if !d $>69$ then

$\mathrm{xs} . \mathrm{x} 12(\operatorname{mode}=\mathrm{m}$, filter $=\mathrm{msr}, \mathrm{save}=" \mathrm{~d} 10 \quad \mathrm{~d} 11 \quad \mathrm{~d} 12$

$\mathrm{d} 13^{\prime \prime}, \mathrm{tf}=$ auto,check,outlier,arima $="\left(\begin{array}{lll}0 & 0 & 1\end{array}\right)$ ",plotspectra $)$

else

xs. $x 12($ mode $=m$, filter $=\{\%$ filter $\}$, save $=" \mathrm{~d} 10 \quad \mathrm{~d} 11 \quad \mathrm{~d} 12$

$\mathrm{d} 13^{\prime \prime}, \mathrm{tf}=$ auto, check,outlier, amdl $=\{\%$ arspec $\}$,plotspectra $\{\%$ easter $\left.\}\right)$

endif

'Aggregation 2

for $\% \mathrm{k} \mathrm{c} \mathrm{i} \mathrm{g} \mathrm{x} \mathrm{m}$

$\{\% \mathrm{k}\} \cdot \mathrm{x} 12($ mode $=\{\%$ kind $\}$, filter $=\{\%$ filter $\}$, save $=" \mathrm{~d} 10 \mathrm{~d} 11 \mathrm{~d} 12$

$\mathrm{d} 13^{\prime \prime}, \mathrm{tf}=\{\%$ trans $\}$, sspan, check,outlier, amdl $=\{\%$ arspec $\}$,

plotspectra $\{\%$ easter $\}$ )

next

'Aggregation 3

for $\% \mathrm{k}$ id

$\{\% \mathrm{k}\} \cdot \mathrm{x} 12($ mode $=\mathrm{m}$, filter $=$ msr, save $=" \mathrm{~d} 10 \quad \mathrm{~d} 11 \quad \mathrm{~d} 12$

$\mathrm{d} 13^{\prime \prime}, \mathrm{tf}=$ auto, check,outlier,arima $="\left(\begin{array}{lll}0 & 0 & 1\end{array}\right) "$, plotspectra $)$

next

series ed_sa $=x_{-}$sa-m_sa

series ed_ir $=\mathrm{x}_{-}$ir $-\mathrm{m}_{-}$ir

series ed_tc $=x_{-}$tc-m_tc

'Aggregation 4

for $\% \mathrm{k}$ nr nnr others

$\{\% \mathrm{k}\} \cdot \mathrm{x} 12($ mode $=\{\% \mathrm{kind}\}$, filter $=\{\%$ filter $\}$, save $=" \mathrm{~d} 10 \mathrm{~d} 11 \mathrm{~d} 12$ $\mathrm{d} 13^{\prime \prime}, \mathrm{tf}=\{\%$ trans $\}$, sspan, check,outlier,amdl $=\{\%$ arspec $\}$,

plotspectra $\{\%$ easter $\}$ )

next

'Aggregation 5

for $\% \mathrm{k}$ egw min com ind con tra fin per ood pub dut vat cif 
$\{\% \mathrm{k}\} \cdot \mathrm{x} 12($ mode $=\{\%$ kind $\}$, filter $=\{\%$ filter $\}$, save $=" \mathrm{~d} 10 \mathrm{~d} 11 \mathrm{~d} 12$ $\mathrm{d} 13 ", \mathrm{tf}=\{\%$ trans $\}$, sspan, check,outlier, amdl $=\{\%$ arspec $\}$, plotspectra $\{\%$ easter $\})$

next

agr.$x 12($ mode $=m$, filter $=\{\%$ filter $\}$, save $=" \mathrm{~d} 10$

d11

$\mathrm{d} 13 ", \mathrm{tf}=$ auto,sspan, check,outlier, amdl $=\{\%$ ars caf. $x 12(\operatorname{mode}=\mathrm{m}$
$01)^{\prime}$, plotspectra $)$

\section{'Aggregation 6}

gdp.x12 $(\operatorname{mode}=\{\%$ kind $\}$, filter $=\{\%$ filter $\}$, save $=" \mathrm{~d} 10 \quad \mathrm{~d} 11 \mathrm{~d} 12$ $\mathrm{d} 13 ", \mathrm{tf}=\{\%$ trans $\}$, sspan, check,outlier, amdl $=\{\%$ arspec $\}$, plotspectra $\{\%$ easter $\}$ )

'Aggregations: Original series

genr $\operatorname{aggr} 1=\mathrm{cn}+\mathrm{cd}+\mathrm{meq}+\mathrm{cw}+\mathrm{g}+\mathrm{xg}+\mathrm{xs}-\mathrm{mg}-\mathrm{ms}+\mathrm{ci}$

genr $\operatorname{aggr} 2=\mathrm{c}+\mathrm{i}+\mathrm{g}+\mathrm{x}-\mathrm{m}+\mathrm{ci}$

genr $\operatorname{aggr} 3=\mathrm{id}+\mathrm{ed}$

genr $\operatorname{aggr} 4=\mathrm{nr}+\mathrm{nnr}+$ others

genr $\operatorname{aggr} 5=\operatorname{egw}+\mathrm{cap}+\mathrm{min}+\mathrm{com}+\mathrm{ind}+\mathrm{con}+\mathrm{agr}+\operatorname{tra}$

+ fin + per + ood + pub-dut + vat + cif

genr $\operatorname{aggr} 6=\operatorname{gdp}$

'Aggregations: Trend-cycle series

genr aggr1_tc $=\mathrm{cn}$ $_{-} \mathrm{tc}+\mathrm{cd} \mathrm{t}_{-} \mathrm{tc}+\mathrm{meq}_{-} \mathrm{tc}+\mathrm{cw}+\mathrm{tc}+\mathrm{g} \_\mathrm{tc}$

$+\mathrm{xg}_{-} \mathrm{tc}+\mathrm{xs} \mathrm{tc}_{-\mathrm{mg}} \mathrm{tc}-\mathrm{ms} \mathrm{tc}_{\mathrm{C}} \mathrm{ci} \mathrm{tc}_{\mathrm{C}}$

genr aggr2_tc $=c_{-}+{ }^{t c}+i_{-} t c+g_{-} t c+x_{-} t c-m_{-} t c+c i \_t c$

genr aggr3_tc $=\mathrm{id}{ }_{-} \mathrm{tc}+\mathrm{ed} \_\mathrm{tc}$

genr aggr $4_{-} \mathrm{tc}=\mathrm{nr} \_\mathrm{tc}+\mathrm{nnr} \_\mathrm{tc}+\mathrm{others} \_\mathrm{tc}$

genr aggr5_tc=egw $5_{-} \mathrm{tc}+\mathrm{caf} \_\mathrm{tc}+\mathrm{min} \_\mathrm{tc}+\mathrm{com} \_\mathrm{tc}$

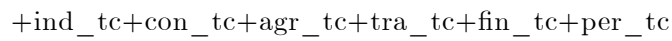

+ ood_tc+pub_tc-dut_tc+vat_tc+cif_tc

genr aggr6_tc=gdp_tc

'Aggregations: Seasonally adjusted series

genr aggr1_sa $=\mathrm{cn} \_\mathrm{sa}+\mathrm{cd} \mathrm{s}_{-} \mathrm{sa}+\mathrm{meq}{ }_{-} \mathrm{sa}+\mathrm{cw} \_\mathrm{sa}+$

g_sa+xg_sa+xs_sa-mg_sa-ms_sa+ci_sa

genr aggr $2 \_s a=c_{-}$sa $+\mathrm{i} \_s a+g_{-}$sa $+x_{-}$sa-m_sa + ci_sa

genr aggr3_sa $=\mathrm{id} \_$sa+ed_sa

genr aggr4_sa $=$ nr_sa+nnr_sa+others_sa

genr aggr5_sa $=$ egw_sa+caf_sa + min_sa + com_sa+ind_sa

+con_sa+agr_sa+tra_sa+fin_sa+per_sa+ood_sa+pub_sa -dut_sa+vat_sa+cif_sa

genr aggr6_sa=gdp_sa

'Aggregations: Irregular series

12 genr aggr1_ir $=\mathrm{cn} \_\mathrm{ir}+\mathrm{cd} \mathrm{C}_{-} \mathrm{ir}+\mathrm{meq}_{-} \mathrm{ir}+\mathrm{cw} \_\mathrm{ir}+\mathrm{g} \_\mathrm{ir}+\mathrm{xg} \mathrm{e}_{-} \mathrm{ir}$

\%exsiteriyt)mg_ir $+\mathrm{ms}_{-}$ir $+\mathrm{ci}$ ir

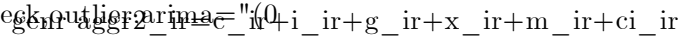

genr aggr3_ir $=\mathrm{id} \_\mathrm{ir}+\mathrm{ed} \_\mathrm{ir}$

genr aggr4_ir $=\mathrm{nr} \_\mathrm{ir}+\mathrm{nnr} \_$ir + others_ir

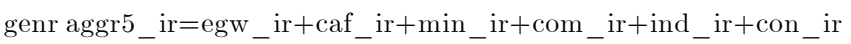

+agr_ir+tra_ir+fin_ir+per_ir+ood_ir+pub_ir-dut_ir+vat_ir+cif_ir genr aggr6_ir=gdp_ir

'Sorting results in terms of aggregations

'All three series

for $! \mathrm{x}=1$ to 6

table res_tagg $\{! \mathrm{x}\}$

table res_sagg $\{! \mathrm{x}\}$

table res_iagg $\{! \mathrm{x}\}$

for $! t=1$ to 36

$! j=\{! t\}+60$

for $! r=1$ to $\{! j\}$

res_tagg $\{! \mathrm{x}\}(\{! \mathrm{r}\},\{! \mathrm{t}\})=$ aatrend $\{! \mathrm{j}\}(\{! \mathrm{r}\}+1,\{! \mathrm{x}\}+1)$

res_sagg $\{! \mathrm{x}\}(\{! \mathrm{r}\},\{! \mathrm{t}\})=\operatorname{aaseas}\{! \mathrm{j}\}(\{! \mathrm{r}\}+1,\{! \mathrm{x}\}+1)$

res_iagg $\{! \mathrm{x}\}(\{! \mathrm{r}\},\{! \mathrm{t}\})=\operatorname{aairr}\{! \mathrm{j}\}(\{! \mathrm{r}\}+1,\{! \mathrm{x}\}+1)$

next

next

next

pagecreate $($ page $=\mathrm{d} 12) \mathrm{Q} 19862010$

pagecreate $($ page $=\mathrm{d} 11) \mathrm{Q} 19862010$

pagecreate $($ page $=$ d13) Q 19862010

pageselect howtoseas

for $! a=1$ to 6

copy howtoseas $\backslash$ res_tagg $\{$ !a $\}$ d $12 \backslash \operatorname{agg}\{! a\}$

copy howtoseas $\backslash$ res_sagg $\{$ !a $\}$ d11 $\backslash \operatorname{agg}\{! \mathrm{a}\}$

copy howtoseas $\backslash$ res_iagg $\{! \mathrm{a}\}$ d $13 \backslash \operatorname{agg}\{$ !a $\}$

next

pageselect howtoseas

delete aa*

@ uiprompt("Process completed") 


\section{Diagnostic Result 1}

\section{Spectral plots of final seasonally adjusted and irregular series}

Figure I1: Spectral plots of final seasonally adjusted series $(*)$

A: Aggregation 1. Spectral plot.

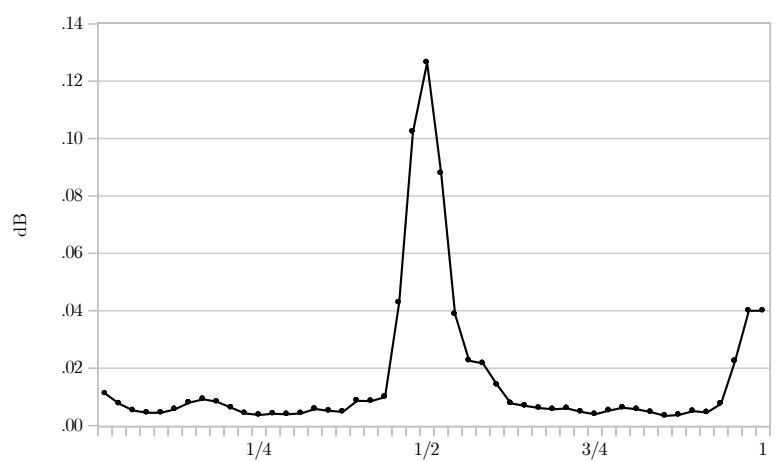

C: Aggregation 3. Spectral plot.

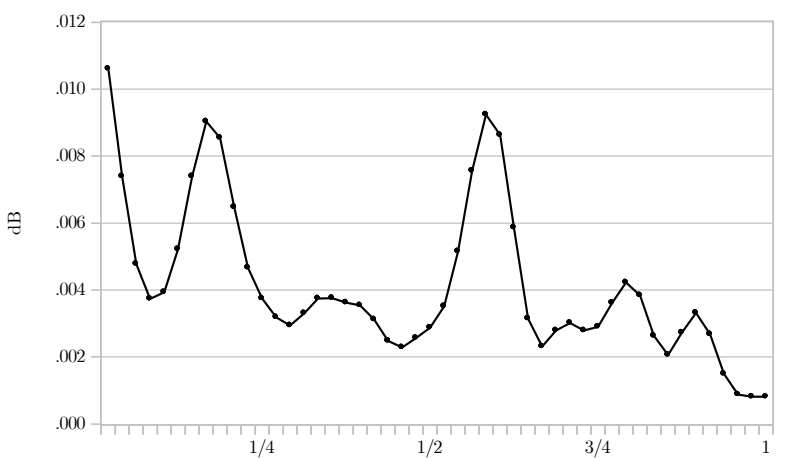

E: Aggregation 5. Spectral plot.

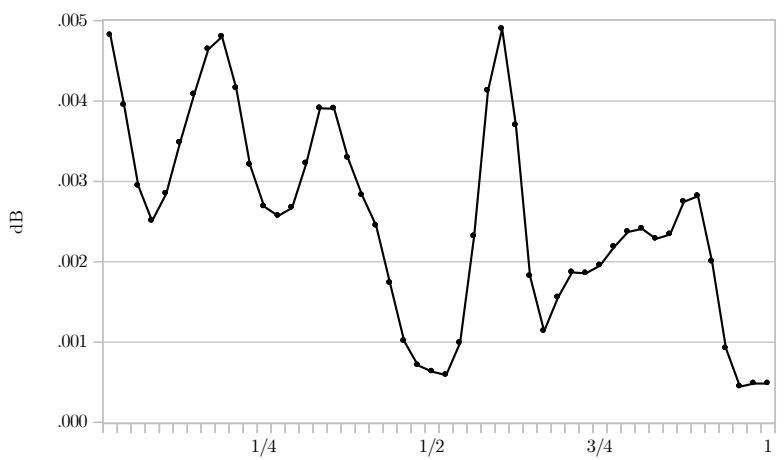

B: Aggregation 2. Spectral plot.

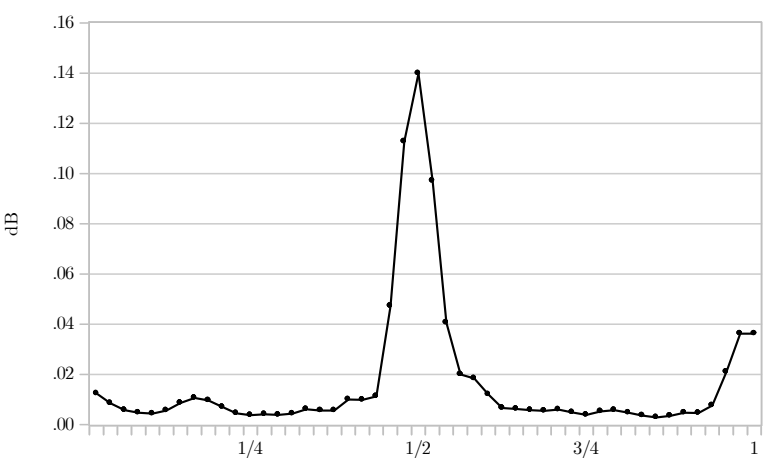

D: Aggregation 4. Spectral plot.

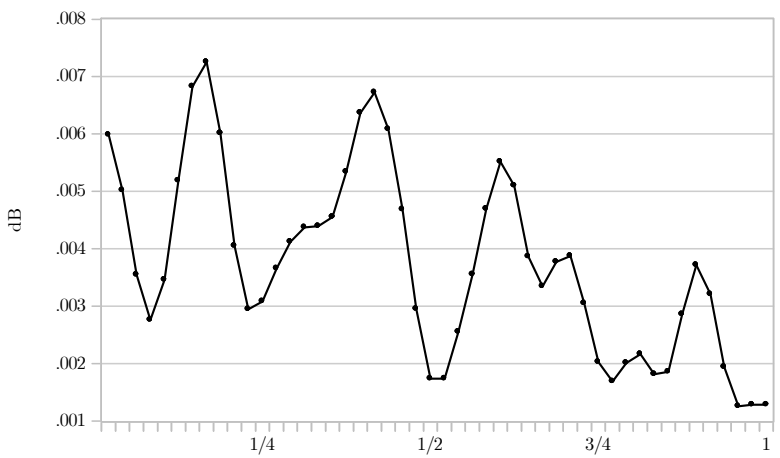

F: Aggregation 6. Spectral plot.

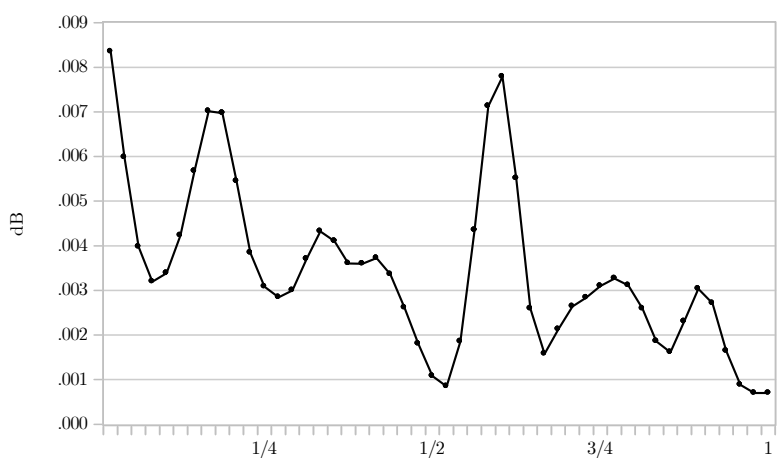

(*) $10 \times(\log$-diff.). Bartlett window length=30. Source: Author's elaboration. 
A: Aggregation 1. Spectral plot.

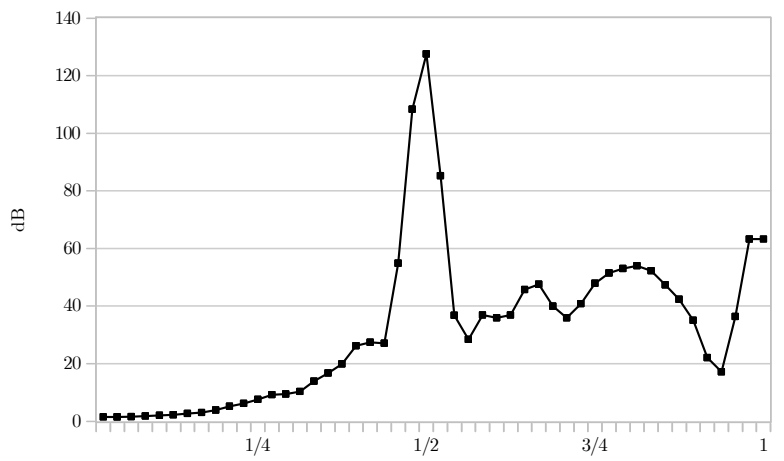

C: Aggregation 3. Spectral plot.

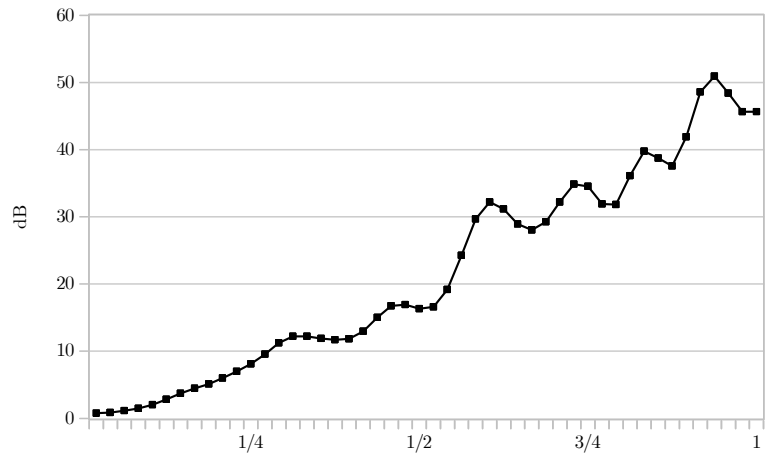

E: Aggregation 5. Spectral plot.

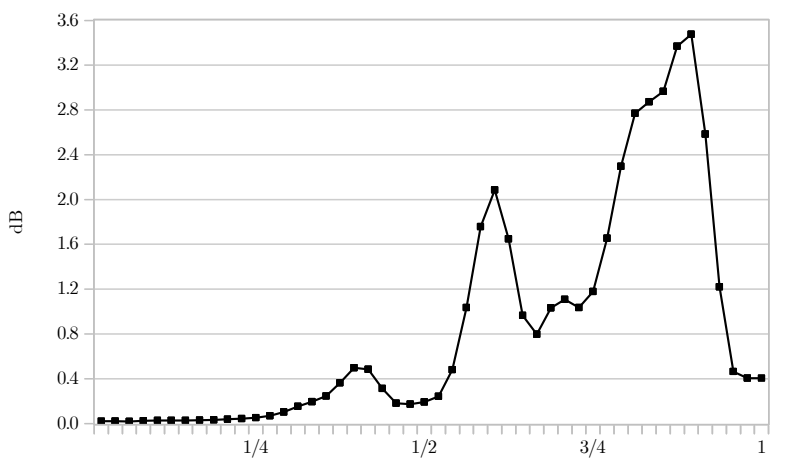

B: Aggregation 2. Spectral plot.

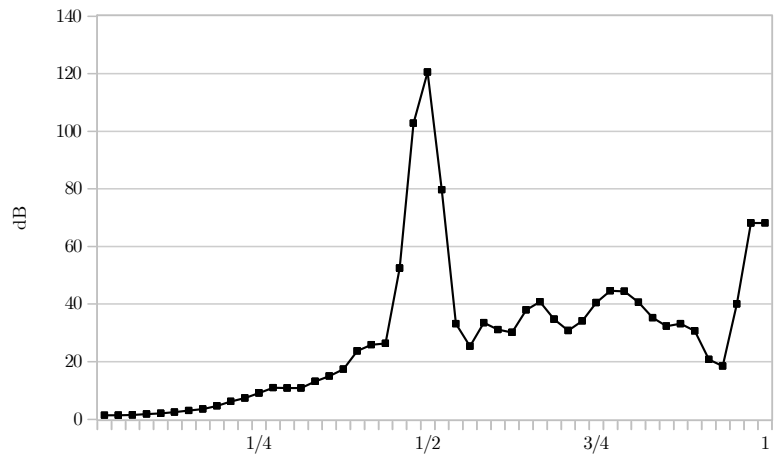

D: Aggregation 4. Spectral plot.

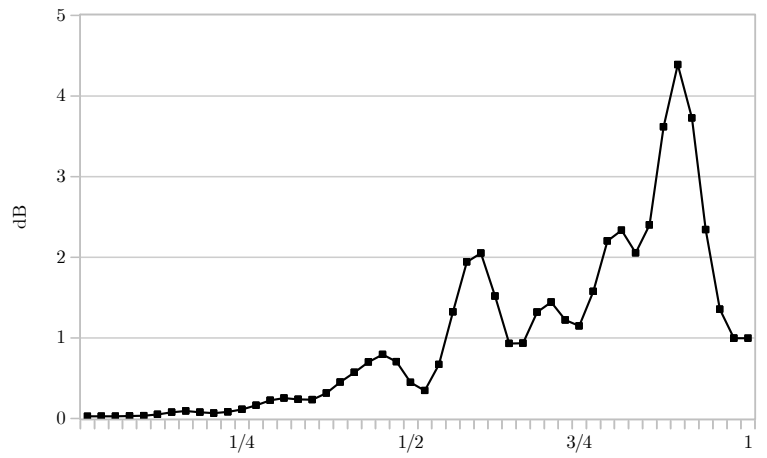

F: Aggregation 6. Spectral plot.

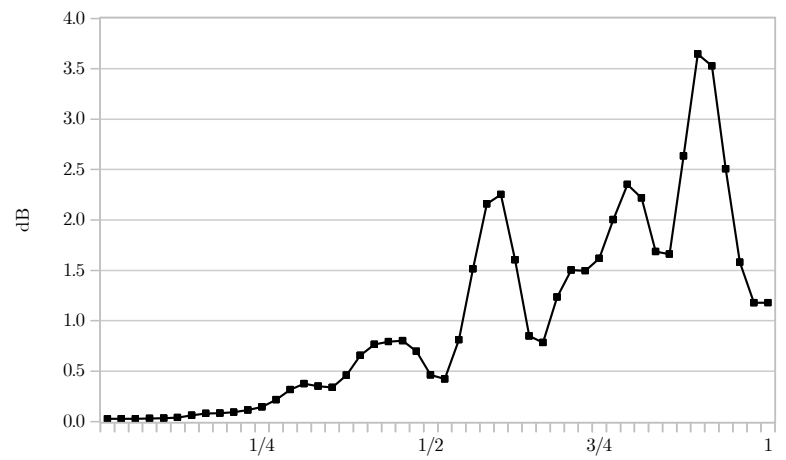

(*) Bartlett window length $=30$. Source: Author's elaboration. 


\section{J Diagnostic Result 2}

\section{Sliding spans of (log-differenced) seasonally adjusted series}

\begin{tabular}{|c|c|c|c|c|c|c|c|c|c|c|c|c|c|}
\hline No. Obs. & Date & $\mathrm{S}(1)$ & $\mathrm{S}(2)$ & $\mathrm{S}(3)$ & S (4) & $\mathrm{S}(5)$ & $\mathrm{S}(6)$ & $\mathrm{S}(7)$ & $\mathrm{S}(8)$ & $\mathrm{S}(9)$ & $\mathrm{S}(10)$ & $\mathrm{s} \max$ & Score \\
\hline 40 & $1995 \mathrm{Q} 4$ & -2.419 & -2.424 & -2.440 & -2.560 & -2.645 & -2.620 & -2.653 & -2.950 & -2.610 & -2.449 & 53.1 & * \\
\hline 41 & $1996 \mathrm{Q} 1$ & 3.445 & 3.528 & 3.557 & 3.631 & 3.723 & 3.782 & 3.806 & 4.695 & 3.789 & 3.788 & 125.0 & x \\
\hline 42 & $1996 \mathrm{Q} 2$ & 4.243 & 4.113 & 4.114 & 4.030 & 4.004 & 3.937 & 3.868 & 3.669 & 3.996 & 4.036 & 57.4 & $x$ \\
\hline 43 & $1996 \mathrm{Q} 3$ & 2.050 & 2.097 & 2.089 & 2.204 & 2.217 & 2.205 & 2.262 & 1.856 & 2.196 & 1.603 & 65.9 & $\boldsymbol{x}$ \\
\hline 44 & $1996 \mathrm{Q} 4$ & -3.193 & -3.174 & -3.205 & -3.414 & -3.494 & -3.475 & -3.470 & -3.669 & -3.518 & -2.647 & 102.2 & $\boldsymbol{x}$ \\
\hline 45 & $1997 \mathrm{Q} 1$ & 3.241 & 3.290 & 3.306 & 3.524 & 3.614 & 3.670 & 3.683 & 4.500 & 3.648 & 3.564 & 125.9 & $\boldsymbol{x}$ \\
\hline 46 & $1997 \mathrm{Q} 2$ & 3.665 & 3.543 & 3.602 & 3.527 & 3.530 & 3.467 & 3.393 & 3.067 & 3.453 & 3.157 & 59.8 & $\boldsymbol{x}$ \\
\hline 47 & $1997 \mathrm{Q} 3$ & 3.012 & 3.059 & 3.005 & 3.039 & 2.993 & 2.984 & 3.025 & 2.744 & 3.096 & 2.385 & 71.1 & $\boldsymbol{x}$ \\
\hline 48 & $1997 \mathrm{Q} 4$ & -2.313 & -2.255 & -2.269 & -2.466 & -2.503 & -2.484 & -2.458 & -2.477 & -2.622 & -1.223 & 139.9 & $\boldsymbol{x}$ \\
\hline 49 & 1998Q 1 & 1.077 & 1.083 & 1.034 & 1.262 & 1.344 & 1.390 & 1.409 & 1.933 & 1.557 & 1.058 & 89.9 & x \\
\hline 50 & $1998 \mathrm{Q} 2$ & 3.790 & 3.675 & 3.852 & 3.861 & 3.888 & 3.832 & 3.745 & 3.374 & 3.622 & 3.373 & 51.5 & $\boldsymbol{x}$ \\
\hline 51 & 1998Q 3 & 0.840 & 0.888 & 0.775 & 0.643 & 0.532 & 0.525 & 0.555 & 0.536 & 0.731 & 0.086 & 80.2 & $\boldsymbol{x}$ \\
\hline 52 & $1998 \mathrm{Q} 4$ & -7.044 & -6.994 & -7.018 & -7.102 & -7.087 & -7.073 & -7.033 & -7.024 & -7.064 & -6.071 & 103.1 & $\boldsymbol{x}$ \\
\hline 53 & $1999 \mathrm{Q} 1$ & 1.906 & 1.967 & 1.873 & 2.134 & 2.196 & 2.243 & 2.269 & 2.476 & 2.060 & 2.121 & 60.3 & $\boldsymbol{x}$ \\
\hline 54 & $1999 \mathrm{Q} 2$ & 1.296 & 1.098 & 1.377 & 1.296 & 1.387 & 1.332 & 1.230 & 1.002 & 1.290 & 0.900 & 48.7 & $\boldsymbol{x}$ \\
\hline 55 & $1999 \mathrm{Q} 3$ & 3.089 & 3.169 & 3.061 & 2.939 & 2.698 & 2.696 & 2.727 & 2.800 & 2.886 & 2.672 & 49.7 & $\boldsymbol{x}$ \\
\hline 56 & $1999 \mathrm{Q} 4$ & -1.541 & -1.482 & -1.603 & -1.647 & -1.540 & -1.537 & -1.498 & -1.433 & -1.452 & -1.116 & 53.1 & $\boldsymbol{x}$ \\
\hline 57 & $2000 \mathrm{Q} 1$ & 1.862 & 1.947 & 1.832 & 2.146 & 2.212 & 2.278 & 2.316 & 2.266 & 2.063 & 2.359 & 52.7 & $\boldsymbol{*}$ \\
\hline 58 & $2000 \mathrm{Q} 2$ & 1.290 & 1.083 & 1.482 & 1.263 & 1.330 & 1.250 & 1.141 & 1.052 & 1.218 & 0.738 & 74.4 & $x$ \\
\hline 59 & $2000 \mathrm{Q} 3$ & 2.193 & 2.226 & 2.110 & 2.031 & 1.725 & 1.743 & 1.769 & 1.871 & 1.869 & 1.673 & 55.3 & * \\
\hline 60 & $2000 \mathrm{Q} 4$ & -3.141 & -3.047 & -3.245 & -3.213 & -3.015 & -3.024 & -2.975 & -2.888 & -2.926 & -2.586 & 65.9 & $\boldsymbol{x}$ \\
\hline 61 & $2001 \mathrm{Q} 1$ & NA & 3.110 & 2.978 & 3.363 & 3.419 & 3.506 & 3.542 & 3.374 & 3.329 & 3.631 & 65.3 & $\boldsymbol{x}$ \\
\hline 62 & $2001 \mathrm{Q} 2$ & $\mathrm{NA}$ & 2.660 & 3.137 & 2.598 & 2.710 & 2.607 & 2.493 & 2.510 & 2.591 & 2.188 & 94.9 & $\boldsymbol{x}$ \\
\hline 63 & $2001 \mathrm{Q} 3$ & $\mathrm{NA}$ & -0.307 & -0.434 & -0.274 & -0.754 & -0.735 & -0.716 & -0.658 & -0.682 & -0.692 & 48.0 & * \\
\hline 64 & $2001 \mathrm{Q} 4$ & NA & -2.665 & -2.892 & -2.769 & -2.464 & -2.467 & -2.393 & -2.306 & -2.311 & -2.387 & 58.6 & * \\
\hline 65 & $2002 \mathrm{Q} 1$ & $\mathrm{NA}$ & NA & 2.633 & 2.931 & 3.084 & 3.193 & 3.218 & 3.060 & 3.002 & 3.320 & 68.7 & $\boldsymbol{x}$ \\
\hline 66 & $2002 \mathrm{Q} 2$ & $\mathrm{NA}$ & N A & 2.268 & 1.480 & 1.478 & 1.333 & 1.196 & 1.216 & 1.322 & 1.049 & 121.9 & $\boldsymbol{x}$ \\
\hline 67 & $2002 \mathrm{Q} 3$ & NA & NA & 0.255 & 0.640 & 0.109 & 0.154 & 0.182 & 0.255 & 0.181 & 0.586 & 53.1 & * \\
\hline 68 & $2002 \mathrm{Q} 4$ & $\mathrm{NA}$ & NA & -2.114 & -1.786 & -1.381 & -1.417 & -1.309 & -1.309 & -1.274 & -1.787 & 84.0 & $\boldsymbol{x}$ \\
\hline 69 & 2003Q 1 & $\mathrm{NA}$ & $\mathrm{NA}$ & $\mathrm{NA}$ & 3.116 & 3.330 & 3.523 & 3.520 & 3.471 & 3.415 & 3.921 & 80.5 & x \\
\hline 70 & $2003 \mathrm{Q} 2$ & NA & NA & NA & 2.083 & 1.960 & 1.712 & 1.594 & 1.562 & 1.682 & 1.149 & 93.4 & $\boldsymbol{x}$ \\
\hline 71 & $2003 \mathrm{Q} 3$ & $\mathrm{NA}$ & NA & NA & 1.291 & 0.625 & 0.692 & 0.614 & 0.730 & 0.591 & 0.949 & 70.0 & $\boldsymbol{x}$ \\
\hline 72 & $2003 \mathrm{Q} 4$ & $\mathrm{NA}$ & $\mathrm{NA}$ & $\mathrm{NA}$ & -4.013 & -3.401 & -3.398 & -3.064 & -3.125 & -3.109 & -3.281 & 94.9 & $\boldsymbol{x}$ \\
\hline 73 & $2004 \mathrm{Q} 1$ & $\mathrm{NA}$ & NA & NA & $\mathrm{NA}$ & 4.769 & 5.012 & 4.832 & 4.798 & 4.900 & 5.445 & 67.6 & $\boldsymbol{x}$ \\
\hline 74 & $2004 \mathrm{Q} 2$ & NA & N A & N A & NA & 2.457 & 2.063 & 1.972 & 1.927 & 1.981 & 1.154 & 130.3 & * \\
\hline 75 & $2004 \mathrm{Q} 3$ & NA & N A & $\mathrm{NA}$ & $\mathrm{NA}$ & 3.428 & 3.553 & 3.408 & 3.644 & 3.389 & 3.502 & 25.5 & $v$ \\
\hline 76 & $2004 \mathrm{Q} 4$ & $\mathrm{NA}$ & NA & NA & $\mathrm{NA}$ & -2.768 & -2.698 & -2.109 & -2.277 & -2.323 & -1.988 & 78.0 & $\boldsymbol{x}$ \\
\hline 77 & $2005 \mathrm{Q} 1$ & $\mathrm{NA}$ & $\mathrm{NA}$ & $\mathrm{NA}$ & $\mathrm{NA}$ & $\mathrm{NA}$ & 2.868 & 2.433 & 2.330 & 2.739 & 3.032 & 70.2 & $\boldsymbol{x}$ \\
\hline 78 & $2005 \mathrm{Q} 2$ & $\mathrm{NA}$ & $\mathrm{NA}$ & NA & $\mathrm{NA}$ & NA & 2.693 & 2.683 & 2.661 & 2.664 & 1.895 & 79.8 & $\boldsymbol{x}$ \\
\hline 79 & $2005 \mathrm{Q} 3$ & NA & NA & NA & NA & NA & 2.056 & 1.823 & 2.283 & 1.733 & 1.738 & 55.0 & $\boldsymbol{x}$ \\
\hline 80 & $2005 \mathrm{Q} 4$ & $\mathrm{NA}$ & NA & NA & NA & NA & -3.159 & -2.298 & -2.567 & -2.632 & -1.776 & 138.3 & * \\
\hline 81 & $2006 \mathrm{Q} 1$ & NA & N A & $\mathrm{NA}$ & $\mathrm{NA}$ & NA & $\mathrm{NA}$ & 2.942 & 2.595 & 3.474 & 3.390 & 87.9 & * \\
\hline 82 & $2006 \mathrm{Q} 2$ & $\mathrm{NA}$ & NA & $\mathrm{NA}$ & $\mathrm{NA}$ & NA & NA & 2.035 & 2.055 & 1.961 & 1.112 & 94.3 & $\boldsymbol{x}$ \\
\hline 83 & $2006 \mathrm{Q} 3$ & NA & NA & NA & $\mathrm{NA}$ & NA & NA & 0.828 & 1.621 & 0.674 & 0.488 & 113.3 & $\boldsymbol{x}$ \\
\hline 84 & $2006 \mathrm{Q} 4$ & $\mathrm{NA}$ & $\mathrm{NA}$ & NA & $\mathrm{NA}$ & NA & NA & -0.928 & -1.192 & -1.263 & 0.014 & 127.7 & $\boldsymbol{x}$ \\
\hline 85 & $2007 \mathrm{Q} 1$ & $\mathrm{NA}$ & $\mathrm{NA}$ & $\mathrm{NA}$ & $\mathrm{NA}$ & $\mathrm{NA}$ & NA & NA & 2.629 & 3.977 & 3.812 & 134.8 & * \\
\hline 86 & $2007 \mathrm{Q} 2$ & N A & $\mathrm{NA}$ & N A & NA & N A & N A & $\mathrm{NA}$ & 1.685 & 1.608 & 0.838 & 84.7 & * \\
\hline 87 & $2007 \mathrm{Q} 3$ & $\mathrm{NA}$ & $\mathrm{NA}$ & NA & $\mathrm{NA}$ & NA & NA & NA & 0.545 & -0.886 & -1.606 & 215.1 & $\boldsymbol{x}$ \\
\hline \multirow[t]{3}{*}{88} & $2007 \mathrm{Q} 4$ & $\mathrm{NA}$ & $\mathrm{NA}$ & $\mathrm{NA}$ & $\mathrm{NA}$ & $\mathrm{NA}$ & $\mathrm{NA}$ & $\mathrm{NA}$ & -0.679 & -0.775 & 1.253 & 202.8 & $\boldsymbol{x}$ \\
\hline & Median & - & - & - & - & - & - & - & - & - & - & 78.00 & - \\
\hline & Mean & - & - & - & - & - & - & - & - & - & - & 86.20 & $98 \%$ \\
\hline
\end{tabular}


Table J2: Sliding spans of seasonally adjusted series (log-diff), Aggregation 2

\begin{tabular}{|c|c|c|c|c|c|c|c|c|c|c|c|c|c|}
\hline No. Obs. & Date & $\mathrm{S}(1)$ & $\mathrm{S}(2)$ & $\mathrm{S}(3)$ & S (4) & $\mathrm{S}(5)$ & $\mathrm{S}(6)$ & $\mathrm{S}(7)$ & $\mathrm{S}(8)$ & $\mathrm{S}(9)$ & $\mathrm{S}(10)$ & $\mathrm{s} \max$ & Score \\
\hline 40 & $1995 \mathrm{Q} 4$ & -2.763 & -2.749 & -2.757 & -2.753 & -2.796 & -2.797 & -2.819 & -2.796 & -2.817 & -2.137 & 68.2 & $\boldsymbol{x}$ \\
\hline 41 & $1996 \mathrm{Q} 1$ & 3.017 & 2.991 & 3.009 & 3.011 & 3.067 & 3.067 & 3.043 & 3.067 & 3.042 & 2.587 & 48.0 & $\boldsymbol{x}$ \\
\hline 42 & $1996 \mathrm{Q} 2$ & 4.707 & 4.712 & 4.708 & 4.702 & 4.686 & 4.689 & 4.717 & 4.685 & 4.717 & 4.359 & 35.8 & $x$ \\
\hline 43 & $1996 \mathrm{Q} 3$ & 1.548 & 1.553 & 1.550 & 1.545 & 1.545 & 1.543 & 1.546 & 1.545 & 1.546 & 1.407 & 14.6 & $v$ \\
\hline 44 & $1996 \mathrm{Q} 4$ & -3.932 & -3.903 & -3.919 & -3.909 & -3.948 & -3.952 & -3.953 & -3.948 & -3.952 & -2.802 & 115.1 & $\boldsymbol{x}$ \\
\hline 45 & $1997 \mathrm{Q} 1$ & 4.072 & 4.022 & 4.028 & 4.035 & 4.094 & 4.095 & 4.078 & 4.094 & 4.078 & 3.752 & 34.3 & $\boldsymbol{x}$ \\
\hline 46 & $1997 \mathrm{Q} 2$ & 3.943 & 3.947 & 3.998 & 3.989 & 3.982 & 3.991 & 3.998 & 3.982 & 3.999 & 3.354 & 64.5 & $\boldsymbol{x}$ \\
\hline 47 & $1997 \mathrm{Q} 3$ & 2.918 & 2.942 & 2.884 & 2.857 & 2.810 & 2.810 & 2.808 & 2.811 & 2.808 & 2.364 & 57.8 & $\boldsymbol{x}$ \\
\hline 48 & $1997 \mathrm{Q} 4$ & -3.453 & -3.416 & -3.414 & -3.375 & -3.361 & -3.384 & -3.361 & -3.361 & -3.361 & -1.626 & 182.7 & * \\
\hline 49 & 1998Q 1 & 2.079 & 1.984 & 1.959 & 1.969 & 2.012 & 2.033 & 2.006 & 2.013 & 2.007 & 1.168 & 91.1 & $\boldsymbol{x}$ \\
\hline 50 & $1998 \mathrm{Q} 2$ & 3.772 & 3.814 & 3.942 & 3.913 & 3.916 & 3.921 & 3.918 & 3.912 & 3.919 & 3.474 & 46.8 & $\boldsymbol{x}$ \\
\hline 51 & $1998 \mathrm{Q} 3$ & 0.975 & 1.000 & 0.881 & 0.842 & 0.741 & 0.741 & 0.743 & 0.743 & 0.742 & 0.325 & 67.5 & $\boldsymbol{x}$ \\
\hline 52 & $1998 \mathrm{Q} 4$ & -7.767 & -7.757 & -7.745 & -7.670 & -7.587 & -7.631 & -7.587 & -7.586 & -7.589 & -6.292 & 147.5 & $\boldsymbol{x}$ \\
\hline 53 & $1999 \mathrm{Q} 1$ & 2.604 & 2.569 & 2.502 & 2.515 & 2.522 & 2.574 & 2.528 & 2.529 & 2.528 & 2.042 & 56.2 & $\boldsymbol{x}$ \\
\hline 54 & $1999 \mathrm{Q} 2$ & 1.355 & 1.309 & 1.523 & 1.451 & 1.510 & 1.495 & 1.491 & 1.491 & 1.496 & 1.237 & 28.6 & $v$ \\
\hline 55 & $1999 \mathrm{Q} 3$ & 3.173 & 3.236 & 3.136 & 3.100 & 2.872 & 2.886 & 2.884 & 2.882 & 2.880 & 2.746 & 49.0 & * \\
\hline 56 & $1999 \mathrm{Q} 4$ & -2.205 & -2.171 & -2.296 & -2.170 & -1.975 & -2.043 & -1.973 & -1.973 & -1.976 & -1.222 & 107.4 & $x$ \\
\hline 57 & $2000 \mathrm{Q} 1$ & 2.449 & 2.403 & 2.400 & 2.420 & 2.412 & 2.498 & 2.432 & 2.434 & 2.430 & 2.085 & 41.3 & $\boldsymbol{x}$ \\
\hline 58 & $2000 \mathrm{Q} 2$ & 1.239 & 1.173 & 1.423 & 1.243 & 1.288 & 1.257 & 1.243 & 1.242 & 1.258 & 0.929 & 49.4 & * \\
\hline 59 & $2000 \mathrm{Q} 3$ & 2.348 & 2.423 & 2.356 & 2.366 & 2.063 & 2.058 & 2.071 & 2.070 & 2.058 & 1.957 & 46.6 & $\boldsymbol{x}$ \\
\hline 60 & $2000 \mathrm{Q} 4$ & -3.451 & -3.395 & -3.644 & -3.409 & -3.126 & -3.161 & -3.092 & -3.093 & -3.095 & -2.367 & 127.7 & $\boldsymbol{x}$ \\
\hline 61 & $2001 \mathrm{Q} 1$ & $\mathrm{NA}$ & 3.349 & 3.408 & 3.389 & 3.413 & 3.493 & 3.438 & 3.44 & 3.434 & 3.196 & 29.7 & $v$ \\
\hline 62 & $2001 \mathrm{Q} 2$ & NA & 2.668 & 2.944 & 2.582 & 2.608 & 2.566 & 2.526 & 2.525 & 2.554 & 2.161 & 78.3 & $\boldsymbol{x}$ \\
\hline 63 & $2001 \mathrm{Q} 3$ & $\mathrm{NA}$ & -0.135 & -0.179 & -0.040 & -0.485 & -0.511 & -0.486 & -0.484 & -0.508 & -0.386 & 47.1 & $\boldsymbol{x}$ \\
\hline 64 & $2001 \mathrm{Q} 4$ & $\mathrm{NA}$ & -3.035 & -3.392 & -2.997 & -2.595 & -2.586 & -2.517 & -2.520 & -2.522 & -2.263 & 112.9 & x \\
\hline 65 & $2002 \mathrm{Q} 1$ & $\mathrm{NA}$ & $\mathrm{NA}$ & 3.011 & 2.860 & 3.010 & 3.074 & 3.041 & 3.038 & 3.035 & 2.847 & 22.7 & $v$ \\
\hline 66 & $2002 \mathrm{Q} 2$ & NA & $\mathrm{NA}$ & 2.135 & 1.562 & 1.374 & 1.322 & 1.236 & 1.241 & 1.276 & 1.064 & 107.1 & $\boldsymbol{x}$ \\
\hline 67 & $2002 \mathrm{Q} 3$ & $\mathrm{NA}$ & NA & 0.614 & 0.968 & 0.529 & 0.489 & 0.540 & 0.548 & 0.512 & 0.985 & 49.6 & $\boldsymbol{x}$ \\
\hline 68 & $2002 \mathrm{Q} 4$ & $\mathrm{NA}$ & NA & -2.465 & -1.914 & -1.395 & -1.381 & -1.308 & -1.315 & -1.317 & -1.538 & 115.7 & $\boldsymbol{x}$ \\
\hline 69 & $2003 \mathrm{Q} 1$ & $\mathrm{NA}$ & $\mathrm{NA}$ & $\mathrm{NA}$ & 2.960 & 3.194 & 3.333 & 3.311 & 3.292 & 3.302 & 3.374 & 41.4 & $\boldsymbol{x}$ \\
\hline 70 & $2003 \mathrm{Q} 2$ & $\mathrm{NA}$ & NA & $\mathrm{NA}$ & 2.158 & 1.737 & 1.593 & 1.497 & 1.503 & 1.544 & 1.204 & 95.4 & $\boldsymbol{x}$ \\
\hline 71 & $2003 \mathrm{Q} 3$ & $\mathrm{NA}$ & $\mathrm{NA}$ & $\mathrm{NA}$ & 1.222 & 0.758 & 0.724 & 0.676 & 0.740 & 0.670 & 1.075 & 55.2 & $x$ \\
\hline 72 & $2003 \mathrm{Q} 4$ & $\mathrm{NA}$ & $\mathrm{NA}$ & $\mathrm{NA}$ & -4.188 & -3.417 & -3.371 & -3.080 & -3.151 & -3.147 & -3.225 & 110.8 & $\boldsymbol{x}$ \\
\hline 73 & $2004 \mathrm{Q} 1$ & NA & NA & $\mathrm{NA}$ & $\mathrm{NA}$ & 4.995 & 5.196 & 5.031 & 5.031 & 5.081 & 5.232 & 23.7 & $v$ \\
\hline 74 & $2004 \mathrm{Q} 2$ & $\mathrm{NA}$ & NA & $\mathrm{NA}$ & $\mathrm{NA}$ & 2.079 & 1.828 & 1.723 & 1.684 & 1.733 & 1.281 & 79.8 & $\boldsymbol{x}$ \\
\hline 75 & $2004 \mathrm{Q} 3$ & $\mathrm{NA}$ & $\mathrm{NA}$ & $\mathrm{NA}$ & $\mathrm{NA}$ & 3.596 & 3.537 & 3.399 & 3.609 & 3.439 & 3.489 & 21.0 & $v$ \\
\hline 76 & $2004 \mathrm{Q} 4$ & $\mathrm{NA}$ & NA & $\mathrm{NA}$ & $\mathrm{NA}$ & -2.951 & -2.821 & -2.210 & -2.429 & -2.376 & -1.988 & 96.3 & $\boldsymbol{x}$ \\
\hline 77 & $2005 \mathrm{Q} 1$ & $\mathrm{NA}$ & $\mathrm{NA}$ & $\mathrm{NA}$ & $\mathrm{NA}$ & $\mathrm{NA}$ & 3.318 & 2.888 & 2.947 & 3.052 & 2.986 & 43.0 & $\boldsymbol{x}$ \\
\hline 78 & $2005 \mathrm{Q} 2$ & NA & $\mathrm{NA}$ & $\mathrm{NA}$ & $\mathrm{NA}$ & $\mathrm{NA}$ & 2.458 & 2.398 & 2.263 & 2.381 & 2.021 & 43.7 & $\boldsymbol{x}$ \\
\hline 79 & $2005 \mathrm{Q} 3$ & NA & NA & $\mathrm{NA}$ & NA & $\mathrm{NA}$ & 2.026 & 1.757 & 2.186 & 1.772 & 1.644 & 54.2 & $\boldsymbol{x}$ \\
\hline 80 & $2005 \mathrm{Q} 4$ & $\mathrm{NA}$ & $\mathrm{NA}$ & $\mathrm{NA}$ & $\mathrm{NA}$ & $\mathrm{NA}$ & -3.526 & -2.509 & -2.905 & -2.828 & -1.931 & 159.5 & $\boldsymbol{x}$ \\
\hline 81 & $2006 \mathrm{Q} 1$ & $\mathrm{NA}$ & NA & $\mathrm{NA}$ & $\mathrm{NA}$ & $\mathrm{NA}$ & $\mathrm{NA}$ & 3.573 & 3.683 & 4.050 & 3.640 & 47.7 & $\boldsymbol{x}$ \\
\hline 82 & $2006 \mathrm{Q} 2$ & $\mathrm{NA}$ & $\mathrm{NA}$ & $\mathrm{NA}$ & $\mathrm{NA}$ & $\mathrm{NA}$ & $\mathrm{NA}$ & 1.727 & 1.506 & 1.614 & 1.203 & 52.4 & $\boldsymbol{x}$ \\
\hline 83 & $2006 \mathrm{Q} 3$ & $\mathrm{NA}$ & NA & $\mathrm{NA}$ & $\mathrm{NA}$ & $\mathrm{NA}$ & $\mathrm{NA}$ & 0.634 & 1.240 & 0.454 & 0.203 & 103.7 & $\boldsymbol{x}$ \\
\hline 84 & $2006 \mathrm{Q} 4$ & $\mathrm{NA}$ & $\mathrm{NA}$ & $\mathrm{NA}$ & $\mathrm{NA}$ & $\mathrm{NA}$ & $\mathrm{NA}$ & -1.105 & -1.591 & -1.418 & -0.152 & 143.9 & $\boldsymbol{x}$ \\
\hline 85 & $2007 \mathrm{Q} 1$ & $\mathrm{NA}$ & NA & $\mathrm{NA}$ & NA & $\mathrm{NA}$ & $\mathrm{NA}$ & $\mathrm{NA}$ & 4.239 & 4.965 & 4.325 & 72.6 & $\boldsymbol{x}$ \\
\hline 86 & $2007 \mathrm{Q} 2$ & NA & NA & $\mathrm{NA}$ & NA & $\mathrm{NA}$ & $\mathrm{NA}$ & $\mathrm{NA}$ & 1.065 & 1.154 & 0.760 & 39.4 & $x$ \\
\hline 87 & $2007 \mathrm{Q} 3$ & $\mathrm{NA}$ & $\mathrm{NA}$ & $\mathrm{NA}$ & $\mathrm{NA}$ & $\mathrm{NA}$ & $\mathrm{NA}$ & $\mathrm{NA}$ & -0.173 & -1.441 & -1.883 & 171.0 & $x$ \\
\hline \multirow[t]{3}{*}{88} & $2007 \mathrm{Q} 4$ & $\mathrm{NA}$ & $\mathrm{NA}$ & $\mathrm{NA}$ & $\mathrm{NA}$ & $\mathrm{NA}$ & $\mathrm{NA}$ & $\mathrm{NA}$ & -1.199 & -0.936 & 1.009 & 220.8 & $\boldsymbol{x}$ \\
\hline & Median & - & - & - & - & - & - & - & - & - & - & 56.20 & - \\
\hline & Mean & - & - & - & - & - & - & - & - & - & - & 75.89 & $86 \%$ \\
\hline
\end{tabular}

Source: Author's elaboration 
Table J3: Sliding spans of seasonally adjusted series (log-diff), Aggregation 3

\begin{tabular}{|c|c|c|c|c|c|c|c|c|c|c|c|c|c|}
\hline No. Obs. & Date & $\mathrm{S}(1)$ & $\mathrm{S}(2)$ & $\mathrm{S}(3)$ & S (4) & $\mathrm{S}(5)$ & $\mathrm{S}(6)$ & $\mathrm{S}(7)$ & $\mathrm{S}(8)$ & $\mathrm{S}(9)$ & $\mathrm{S}(10)$ & $\mathrm{s} \max$ & Score \\
\hline 40 & $1995 \mathrm{Q} 4$ & 2.668 & 4.046 & 0.836 & 0.452 & 0.401 & 0.412 & 0.400 & 1.006 & 0.459 & 2.187 & 364.6 & $\boldsymbol{x}$ \\
\hline 41 & $1996 \mathrm{Q} 1$ & 0.862 & 0.712 & 0.571 & 0.609 & 1.025 & 1.029 & 0.683 & 1.255 & 1.236 & 1.619 & 104.8 & $\boldsymbol{x}$ \\
\hline 42 & $1996 \mathrm{Q} 2$ & 3.404 & 1.325 & 4.161 & 5.869 & 4.719 & 4.702 & 5.848 & 3.541 & 4.349 & 1.176 & 469.3 & $\boldsymbol{x}$ \\
\hline 43 & $1996 \mathrm{Q} 3$ & -1.045 & -0.190 & 0.342 & -1.099 & -0.253 & -0.253 & -1.095 & 0.165 & -0.144 & 1.025 & 212.4 & * \\
\hline 44 & $1996 \mathrm{Q} 4$ & 2.649 & 4.072 & 0.779 & 0.420 & 0.274 & 0.290 & 0.354 & 1.036 & 0.348 & 1.842 & 379.8 & $\boldsymbol{x}$ \\
\hline 45 & $1997 \mathrm{Q} 1$ & 0.061 & -0.449 & -0.489 & 0.046 & 0.079 & 0.091 & 0.104 & -0.200 & 0.251 & 0.899 & 138.8 & $\boldsymbol{x}$ \\
\hline 46 & $1997 \mathrm{Q} 2$ & 3.890 & 2.450 & 5.265 & 6.067 & 5.830 & 5.780 & 6.132 & 4.983 & 5.442 & 2.383 & 374.9 & $\boldsymbol{x}$ \\
\hline 47 & $1997 \mathrm{Q} 3$ & 0.716 & 1.262 & 1.560 & 0.656 & 0.869 & 0.902 & 0.567 & 1.395 & 1.063 & 2.156 & 158.9 & x \\
\hline 48 & $1997 \mathrm{Q} 4$ & 3.056 & 4.344 & 1.405 & 1.090 & 1.021 & 1.032 & 1.041 & 1.610 & 1.051 & 2.082 & 332.3 & $\boldsymbol{x}$ \\
\hline 49 & 1998Q 1 & -1.001 & -1.644 & -1.575 & -0.999 & -1.058 & -1.045 & -0.946 & -1.637 & -0.934 & -0.353 & 129.1 & * \\
\hline 50 & $1998 \mathrm{Q} 2$ & 2.533 & 1.596 & 4.136 & 4.485 & 4.680 & 4.604 & 4.637 & 4.335 & 4.307 & 1.901 & 308.4 & * \\
\hline 51 & $1998 \mathrm{Q} 3$ & -1.111 & -0.589 & -0.795 & -1.365 & -1.573 & -1.507 & -1.546 & -1.031 & -1.275 & -0.233 & 134.0 & $\boldsymbol{x}$ \\
\hline 52 & $1998 \mathrm{Q} 4$ & -2.698 & -1.937 & -4.086 & -4.360 & -4.305 & -4.294 & -4.390 & -4.036 & -4.315 & -3.734 & 245.3 & $\boldsymbol{x}$ \\
\hline 53 & $1999 \mathrm{Q} 1$ & -0.626 & -1.059 & -0.835 & -0.156 & -0.272 & -0.263 & -0.218 & -1.183 & -0.380 & 0.079 & 126.2 & $x$ \\
\hline 54 & $1999 \mathrm{Q} 2$ & 0.808 & 0.096 & 2.005 & 1.815 & 2.341 & 2.203 & 2.319 & 2.920 & 2.281 & 0.334 & 282.4 & $\boldsymbol{x}$ \\
\hline 55 & $1999 \mathrm{Q} 3$ & 2.016 & 2.613 & 2.189 & 2.064 & 1.429 & 1.545 & 1.569 & 1.631 & 1.635 & 2.834 & 140.5 & $\boldsymbol{*}$ \\
\hline 56 & $1999 \mathrm{Q} 4$ & 2.658 & 2.872 & 1.422 & 1.255 & 1.438 & 1.520 & 1.266 & 1.112 & 1.383 & 1.501 & 176.0 & $x$ \\
\hline 57 & $2000 \mathrm{Q} 1$ & -0.521 & -0.641 & -0.118 & 0.354 & 0.274 & 0.204 & 0.196 & -0.084 & 0.116 & 0.744 & 138.5 & $\boldsymbol{x}$ \\
\hline 58 & $2000 \mathrm{Q} 2$ & 0.916 & 0.329 & 1.345 & 0.906 & 1.609 & 1.432 & 1.846 & 2.285 & 1.646 & -0.260 & 254.5 & x \\
\hline 59 & $2000 \mathrm{Q} 3$ & 1.320 & 2.058 & 1.545 & 1.799 & 0.874 & 0.982 & 0.890 & 0.900 & 1.111 & 2.089 & 121.5 & $\boldsymbol{x}$ \\
\hline 60 & $2000 \mathrm{Q} 4$ & 1.398 & 1.064 & 0.269 & 0.087 & 0.312 & 0.554 & 0.147 & -0.253 & 0.206 & 0.604 & 165.1 & * \\
\hline 61 & $2001 \mathrm{Q} 1$ & $\mathrm{NA}$ & -0.149 & 0.498 & 0.890 & 0.921 & 0.859 & 0.594 & 0.847 & 0.561 & 1.368 & 151.7 & * \\
\hline 62 & $2001 \mathrm{Q} 2$ & NA & 2.382 & 2.804 & 2.120 & 2.935 & 2.509 & 3.710 & 3.681 & 3.359 & 0.978 & 273.2 & $\boldsymbol{x}$ \\
\hline 63 & $2001 \mathrm{Q} 3$ & $\mathrm{NA}$ & -0.662 & -1.035 & -0.512 & -1.627 & -1.606 & -1.981 & -1.862 & -1.597 & -0.549 & 146.9 & $\boldsymbol{x}$ \\
\hline 64 & $2001 \mathrm{Q} 4$ & $\mathrm{NA}$ & 0.883 & 0.182 & 0.131 & 0.171 & 0.927 & 0.049 & -0.277 & 0.076 & 0.722 & 120.4 & x \\
\hline 65 & $2002 \mathrm{Q} 1$ & NA & $\mathrm{NA}$ & -0.557 & -0.374 & 0.022 & -0.116 & -0.479 & 0.151 & -0.526 & 0.490 & 104.7 & $x$ \\
\hline 66 & $2002 \mathrm{Q} 2$ & NA & $\mathrm{NA}$ & 3.165 & 2.358 & 3.155 & 2.190 & 4.421 & 3.452 & 3.953 & 0.661 & 376.0 & $\boldsymbol{x}$ \\
\hline 67 & $2002 \mathrm{Q} 3$ & $\mathrm{NA}$ & $\mathrm{NA}$ & -0.854 & -0.145 & -1.451 & -1.280 & -2.123 & -1.315 & -1.555 & 0.099 & 222.2 & * \\
\hline 68 & $2002 \mathrm{Q} 4$ & $\mathrm{NA}$ & NA & 1.614 & 1.690 & 1.658 & 2.796 & 1.415 & 1.129 & 1.390 & 2.223 & 166.7 & $\boldsymbol{x}$ \\
\hline 69 & $2003 \mathrm{Q} 1$ & $\mathrm{NA}$ & $\mathrm{NA}$ & $\mathrm{NA}$ & -0.906 & -0.195 & -0.182 & -0.617 & -0.052 & -0.695 & 0.665 & 157.1 & $\boldsymbol{x}$ \\
\hline 70 & $2003 \mathrm{Q} 2$ & $\mathrm{NA}$ & NA & $\mathrm{NA}$ & 3.886 & 4.502 & 2.813 & 6.090 & 4.521 & 5.467 & 1.086 & 500.4 & $\boldsymbol{x}$ \\
\hline 71 & $2003 \mathrm{Q} 3$ & $\mathrm{NA}$ & $\mathrm{NA}$ & $\mathrm{NA}$ & 0.759 & -0.597 & -0.293 & -1.629 & -0.039 & -0.700 & 1.285 & 291.4 & * \\
\hline 72 & $2003 \mathrm{Q} 4$ & $\mathrm{NA}$ & $\mathrm{NA}$ & $\mathrm{NA}$ & -0.973 & -1.003 & 0.701 & -1.296 & -1.738 & -1.511 & -0.288 & 243.9 & * \\
\hline 73 & $2004 \mathrm{Q} 1$ & NA & NA & $\mathrm{NA}$ & $\mathrm{NA}$ & 0.764 & 0.683 & 0.741 & 1.009 & 0.496 & 2.235 & 173.9 & $\boldsymbol{*}$ \\
\hline 74 & $2004 \mathrm{Q} 2$ & $\mathrm{NA}$ & $\mathrm{NA}$ & $\mathrm{NA}$ & $\mathrm{NA}$ & 5.801 & 3.590 & 7.085 & 5.492 & 6.532 & 1.251 & 583.4 & $\boldsymbol{x}$ \\
\hline 75 & $2004 \mathrm{Q} 3$ & $\mathrm{NA}$ & $\mathrm{NA}$ & $\mathrm{NA}$ & $\mathrm{NA}$ & 1.441 & 1.893 & 0.342 & 2.376 & 1.673 & 3.684 & 334.2 & * \\
\hline 76 & $2004 \mathrm{Q} 4$ & NA & NA & $\mathrm{NA}$ & NA & -0.094 & 1.878 & -0.221 & -0.924 & -0.911 & 0.560 & 280.2 & $\boldsymbol{x}$ \\
\hline 77 & $2005 \mathrm{Q} 1$ & $\mathrm{NA}$ & $\mathrm{NA}$ & $\mathrm{NA}$ & $\mathrm{NA}$ & $\mathrm{NA}$ & -1.784 & -1.601 & -1.615 & -1.798 & 0.233 & 203.1 & $\boldsymbol{x}$ \\
\hline 78 & $2005 \mathrm{Q} 2$ & $\mathrm{NA}$ & $\mathrm{NA}$ & $\mathrm{NA}$ & $\mathrm{NA}$ & $\mathrm{NA}$ & 4.725 & 8.199 & 7.049 & 7.738 & 2.111 & 608.8 & $x$ \\
\hline 79 & $2005 \mathrm{Q} 3$ & NA & NA & $\mathrm{NA}$ & NA & $\mathrm{NA}$ & -0.233 & -1.766 & 0.163 & -0.237 & 2.030 & 379.6 & * \\
\hline 80 & $2005 \mathrm{Q} 4$ & $\mathrm{NA}$ & $\mathrm{NA}$ & $\mathrm{NA}$ & $\mathrm{NA}$ & $\mathrm{NA}$ & 2.043 & -0.156 & -0.905 & -1.044 & 0.118 & 308.7 & $*$ \\
\hline 81 & $2006 \mathrm{Q} 1$ & $\mathrm{NA}$ & NA & $\mathrm{NA}$ & NA & $\mathrm{NA}$ & $\mathrm{NA}$ & -1.064 & -1.352 & -1.433 & 0.943 & 237.6 & x \\
\hline 82 & $2006 \mathrm{Q} 2$ & $\mathrm{NA}$ & $\mathrm{NA}$ & $\mathrm{NA}$ & $\mathrm{NA}$ & $\mathrm{NA}$ & $\mathrm{NA}$ & 7.542 & 6.862 & 7.363 & 1.519 & 602.3 & * \\
\hline 83 & $2006 \mathrm{Q} 3$ & $\mathrm{NA}$ & $\mathrm{NA}$ & $\mathrm{NA}$ & $\mathrm{NA}$ & $\mathrm{NA}$ & $\mathrm{NA}$ & -2.963 & -1.141 & -1.547 & 0.923 & 388.6 & * \\
\hline 84 & $2006 \mathrm{Q} 4$ & NA & $\mathrm{NA}$ & $\mathrm{NA}$ & NA & $\mathrm{NA}$ & $\mathrm{NA}$ & 1.367 & 0.355 & 0.570 & 1.275 & 101.2 & * \\
\hline 85 & $2007 \mathrm{Q} 1$ & $\mathrm{NA}$ & NA & $\mathrm{NA}$ & NA & $\mathrm{NA}$ & $\mathrm{NA}$ & $\mathrm{NA}$ & -0.884 & -1.116 & 1.644 & 276.0 & x \\
\hline 86 & $2007 \mathrm{Q} 2$ & NA & NA & $\mathrm{NA}$ & NA & $\mathrm{NA}$ & $\mathrm{NA}$ & $\mathrm{NA}$ & 6.859 & 7.099 & 1.333 & 576.6 & x \\
\hline 87 & $2007 \mathrm{Q} 3$ & $\mathrm{NA}$ & NA & $\mathrm{NA}$ & NA & $\mathrm{NA}$ & $\mathrm{NA}$ & $\mathrm{NA}$ & -2.861 & -3.229 & -0.799 & 243.0 & $*$ \\
\hline \multirow[t]{3}{*}{88} & $2007 \mathrm{Q} 4$ & $\mathrm{NA}$ & $\mathrm{NA}$ & $\mathrm{NA}$ & $\mathrm{NA}$ & $\mathrm{NA}$ & $\mathrm{NA}$ & $\mathrm{NA}$ & 0.962 & 1.614 & 1.840 & 87.8 & $x$ \\
\hline & Median & - & - & - & - & - & - & - & - & - & - & 243.00 & - \\
\hline & Mean & - & - & - & - & - & - & - & - & - & - & 263.20 & $100 \%$ \\
\hline
\end{tabular}

Source: Author's elaboration. 
Table J4: Sliding spans of seasonally adjusted series (log-diff), Aggregation 4

\begin{tabular}{|c|c|c|c|c|c|c|c|c|c|c|c|c|c|}
\hline No. Obs. & Date & $\mathrm{S}(1)$ & $\mathrm{S}(2)$ & $\mathrm{S}(3)$ & S (4) & $\mathrm{S}(5)$ & $\mathrm{S}(6)$ & $\mathrm{S}(7)$ & $\mathrm{S}(8)$ & $\mathrm{S}(9)$ & $\mathrm{S}(10)$ & $\mathrm{s} \max$ & Score \\
\hline 40 & $1995 \mathrm{Q} 4$ & 0.824 & 0.812 & 0.816 & 0.816 & 0.815 & 0.834 & 0.834 & 0.834 & 0.834 & 0.828 & 2.2 & $v$ \\
\hline 41 & $1996 \mathrm{Q} 1$ & 2.621 & 2.639 & 2.638 & 2.638 & 2.643 & 2.660 & 2.659 & 2.660 & 2.660 & 2.718 & 9.7 & $v$ \\
\hline 42 & $1996 \mathrm{Q} 2$ & 1.257 & 1.244 & 1.243 & 1.242 & 1.243 & 1.185 & 1.185 & 1.184 & 1.184 & 1.195 & 7.3 & $v$ \\
\hline 43 & $1996 \mathrm{Q} 3$ & 0.809 & 0.824 & 0.820 & 0.820 & 0.815 & 0.852 & 0.852 & 0.852 & 0.852 & 0.791 & 6.1 & $v$ \\
\hline 44 & $1996 \mathrm{Q} 4$ & 2.213 & 2.189 & 2.196 & 2.198 & 2.194 & 2.189 & 2.190 & 2.190 & 2.190 & 2.168 & 4.5 & $v$ \\
\hline 45 & $1997 \mathrm{Q} 1$ & 0.339 & 0.359 & 0.361 & 0.362 & 0.371 & 0.414 & 0.412 & 0.412 & 0.412 & 0.480 & 14.1 & $v$ \\
\hline 46 & $1997 \mathrm{Q} 2$ & 2.743 & 2.722 & 2.715 & 2.711 & 2.714 & 2.613 & 2.613 & 2.613 & 2.613 & 2.678 & 13.0 & $v$ \\
\hline 47 & $1997 \mathrm{Q} 3$ & 1.828 & 1.866 & 1.861 & 1.864 & 1.852 & 1.932 & 1.933 & 1.933 & 1.934 & 1.752 & 18.2 & $v$ \\
\hline 48 & $1997 \mathrm{Q} 4$ & 2.447 & 2.414 & 2.425 & 2.427 & 2.423 & 2.411 & 2.413 & 2.412 & 2.412 & 2.508 & 9.7 & $v$ \\
\hline 49 & 1998Q 1 & -0.573 & -0.555 & -0.554 & -0.553 & -0.537 & -0.536 & -0.539 & -0.539 & -0.539 & -0.543 & 3.7 & $v$ \\
\hline 50 & $1998 \mathrm{Q} 2$ & 1.793 & 1.728 & 1.725 & 1.716 & 1.723 & 1.683 & 1.680 & 1.681 & 1.681 & 1.779 & 11.3 & $v$ \\
\hline 51 & $1998 \mathrm{Q} 3$ & -0.650 & -0.522 & -0.547 & -0.538 & -0.570 & -0.519 & -0.515 & -0.513 & -0.514 & -0.687 & 17.4 & $v$ \\
\hline 52 & $1998 \mathrm{Q} 4$ & -3.048 & -3.120 & -3.083 & -3.078 & -3.068 & -3.089 & -3.085 & -3.088 & -3.089 & -3.066 & 7.2 & $v$ \\
\hline 53 & $1999 \mathrm{Q} 1$ & -0.328 & -0.327 & -0.339 & -0.344 & -0.324 & -0.326 & -0.333 & -0.333 & -0.332 & -0.245 & 9.9 & $v$ \\
\hline 54 & $1999 \mathrm{Q} 2$ & 0.265 & 0.148 & 0.145 & 0.128 & 0.137 & 0.139 & 0.135 & 0.136 & 0.136 & 0.080 & 18.5 & $v$ \\
\hline 55 & $1999 \mathrm{Q} 3$ & 2.142 & 2.398 & 2.375 & 2.395 & 2.336 & 2.350 & 2.360 & 2.364 & 2.361 & 2.404 & 26.2 & $v$ \\
\hline 56 & $1999 \mathrm{Q} 4$ & 2.487 & 2.355 & 2.412 & 2.424 & 2.453 & 2.430 & 2.435 & 2.430 & 2.431 & 2.397 & 13.2 & $v$ \\
\hline 57 & $2000 \mathrm{Q} 1$ & 0.368 & 0.351 & 0.295 & 0.278 & 0.320 & 0.306 & 0.294 & 0.292 & 0.295 & 0.309 & 9.0 & $v$ \\
\hline 58 & $2000 \mathrm{Q} 2$ & -0.049 & -0.236 & -0.218 & -0.242 & -0.249 & -0.179 & -0.189 & -0.186 & -0.186 & -0.205 & 20.0 & $v$ \\
\hline 59 & $2000 \mathrm{Q} 3$ & 1.140 & 1.558 & 1.558 & 1.578 & 1.468 & 1.413 & 1.436 & 1.438 & 1.431 & 1.449 & 43.8 & $\boldsymbol{x}$ \\
\hline 60 & $2000 \mathrm{Q} 4$ & 1.443 & 1.231 & 1.291 & 1.352 & 1.432 & 1.424 & 1.430 & 1.435 & 1.433 & 1.452 & 22.1 & $v$ \\
\hline 61 & $2001 \mathrm{Q} 1$ & $\mathrm{NA}$ & 1.085 & 0.977 & 0.903 & 0.974 & 0.976 & 0.958 & 0.946 & 0.964 & 0.941 & 18.2 & $v$ \\
\hline 62 & $2001 \mathrm{Q} 2$ & NA & 0.932 & 0.955 & 0.922 & 0.908 & 0.962 & 0.929 & 0.929 & 0.920 & 0.903 & 5.9 & $v$ \\
\hline 63 & $2001 \mathrm{Q} 3$ & $\mathrm{NA}$ & -0.628 & -0.561 & -0.513 & -0.738 & -0.790 & -0.728 & -0.718 & -0.730 & -0.692 & 27.7 & $v$ \\
\hline 64 & $2001 \mathrm{Q} 4$ & $\mathrm{NA}$ & 0.835 & 0.873 & 0.988 & 1.150 & 1.166 & 1.167 & 1.174 & 1.174 & 1.186 & 35.1 & $\boldsymbol{x}$ \\
\hline 65 & $2002 \mathrm{Q} 1$ & $\mathrm{NA}$ & NA & 0.406 & 0.250 & 0.410 & 0.390 & 0.355 & 0.341 & 0.371 & 0.345 & 16.0 & $v$ \\
\hline 66 & $2002 \mathrm{Q} 2$ & NA & NA & 0.612 & 0.570 & 0.492 & 0.508 & 0.452 & 0.431 & 0.420 & 0.343 & 26.9 & $v$ \\
\hline 67 & $2002 \mathrm{Q} 3$ & $\mathrm{NA}$ & $\mathrm{NA}$ & 0.495 & 0.583 & 0.222 & 0.224 & 0.339 & 0.371 & 0.345 & 0.468 & 36.1 & * \\
\hline 68 & $2002 \mathrm{Q} 4$ & $\mathrm{NA}$ & NA & 1.721 & 1.902 & 2.176 & 2.210 & 2.205 & 2.220 & 2.224 & 2.213 & 50.3 & $\boldsymbol{x}$ \\
\hline 69 & $2003 \mathrm{Q} 1$ & $\mathrm{NA}$ & $\mathrm{NA}$ & $\mathrm{NA}$ & 0.902 & 1.166 & 1.113 & 1.046 & 1.027 & 1.069 & 1.041 & 26.4 & $v$ \\
\hline 70 & $2003 \mathrm{Q} 2$ & $\mathrm{NA}$ & NA & $\mathrm{NA}$ & 0.641 & 0.482 & 0.453 & 0.367 & 0.295 & 0.281 & 0.167 & 47.4 & $\boldsymbol{x}$ \\
\hline 71 & $2003 \mathrm{Q} 3$ & $\mathrm{NA}$ & $\mathrm{NA}$ & $\mathrm{NA}$ & 0.945 & 0.450 & 0.507 & 0.712 & 0.816 & 0.772 & 0.925 & 49.5 & * \\
\hline 72 & $2003 \mathrm{Q} 4$ & NA & $\mathrm{NA}$ & $\mathrm{NA}$ & 0.181 & 0.564 & 0.613 & 0.597 & 0.606 & 0.623 & 0.606 & 44.2 & $\boldsymbol{x}$ \\
\hline 73 & $2004 \mathrm{Q} 1$ & NA & NA & $\mathrm{NA}$ & $\mathrm{NA}$ & 2.634 & 2.572 & 2.422 & 2.390 & 2.430 & 2.415 & 24.4 & $v$ \\
\hline 74 & $2004 \mathrm{Q} 2$ & $\mathrm{NA}$ & NA & $\mathrm{NA}$ & NA & 1.090 & 1.012 & 0.929 & 0.752 & 0.765 & 0.614 & 47.6 & $\boldsymbol{x}$ \\
\hline 75 & $2004 \mathrm{Q} 3$ & $\mathrm{NA}$ & $\mathrm{NA}$ & $\mathrm{NA}$ & $\mathrm{NA}$ & 2.597 & 2.691 & 3.013 & 3.289 & 3.189 & 3.313 & 71.6 & $\boldsymbol{x}$ \\
\hline 76 & $2004 \mathrm{Q} 4$ & $\mathrm{NA}$ & NA & NA & $\mathrm{NA}$ & 1.332 & 1.370 & 1.317 & 1.281 & 1.330 & 1.396 & 11.5 & $v$ \\
\hline 77 & $2005 \mathrm{Q} 1$ & $\mathrm{NA}$ & $\mathrm{NA}$ & $\mathrm{NA}$ & $\mathrm{NA}$ & $\mathrm{NA}$ & 0.605 & 0.357 & 0.284 & 0.345 & 0.310 & 32.1 & $v$ \\
\hline 78 & $2005 \mathrm{Q} 2$ & $\mathrm{NA}$ & $\mathrm{NA}$ & $\mathrm{NA}$ & NA & $\mathrm{NA}$ & 2.023 & 1.942 & 1.654 & 1.657 & 1.583 & 44.0 & * \\
\hline 79 & $2005 \mathrm{Q} 3$ & $\mathrm{NA}$ & $\mathrm{NA}$ & $\mathrm{NA}$ & $\mathrm{NA}$ & $\mathrm{NA}$ & 0.866 & 1.340 & 1.870 & 1.707 & 1.736 & 100.4 & * \\
\hline 80 & $2005 \mathrm{Q} 4$ & $\mathrm{NA}$ & NA & $\mathrm{NA}$ & NA & $\mathrm{NA}$ & 0.904 & 0.790 & 0.648 & 0.746 & 0.775 & 25.6 & $\checkmark$ \\
\hline 81 & $2006 \mathrm{Q} 1$ & $\mathrm{NA}$ & NA & NA & $\mathrm{NA}$ & $\mathrm{NA}$ & $\mathrm{NA}$ & 1.143 & 1.018 & 1.113 & 1.140 & 12.5 & $v$ \\
\hline 82 & $2006 \mathrm{Q} 2$ & $\mathrm{NA}$ & $\mathrm{NA}$ & $\mathrm{NA}$ & $\mathrm{NA}$ & $\mathrm{NA}$ & $\mathrm{NA}$ & 1.404 & 0.994 & 1.003 & 0.968 & 43.6 & $\boldsymbol{x}$ \\
\hline 83 & $2006 \mathrm{Q} 3$ & $\mathrm{NA}$ & NA & $\mathrm{NA}$ & $\mathrm{NA}$ & $\mathrm{NA}$ & $\mathrm{NA}$ & 0.127 & 0.953 & 0.669 & 0.629 & 82.6 & $\boldsymbol{x}$ \\
\hline 84 & $2006 \mathrm{Q} 4$ & $\mathrm{NA}$ & NA & $\mathrm{NA}$ & NA & $\mathrm{NA}$ & $\mathrm{NA}$ & 1.932 & 1.671 & 1.852 & 1.847 & 26.1 & $v$ \\
\hline 85 & $2007 \mathrm{Q} 1$ & NA & NA & $\mathrm{NA}$ & NA & $\mathrm{NA}$ & $\mathrm{NA}$ & $\mathrm{NA}$ & 1.754 & 1.887 & 1.978 & 22.4 & $v$ \\
\hline 86 & $2007 \mathrm{Q} 2$ & NA & NA & $\mathrm{NA}$ & NA & $\mathrm{NA}$ & $\mathrm{NA}$ & $\mathrm{NA}$ & 0.617 & 0.621 & 0.735 & 11.8 & $v$ \\
\hline 87 & $2007 \mathrm{Q} 3$ & $\mathrm{NA}$ & NA & $\mathrm{NA}$ & $\mathrm{NA}$ & $\mathrm{NA}$ & $\mathrm{NA}$ & $\mathrm{NA}$ & -0.453 & -0.848 & -1.099 & 64.6 & $x$ \\
\hline \multirow[t]{3}{*}{88} & $2007 \mathrm{Q} 4$ & $\mathrm{NA}$ & $\mathrm{NA}$ & $\mathrm{NA}$ & $\mathrm{NA}$ & $\mathrm{NA}$ & $\mathrm{NA}$ & $\mathrm{NA}$ & 2.074 & 2.331 & 2.283 & 25.7 & $v$ \\
\hline & Median & - & - & - & - & - & - & - & - & - & - & 22.10 & - \\
\hline & Mean & - & - & - & - & - & - & - & - & - & - & 26.88 & $30 \%$ \\
\hline
\end{tabular}

Source: Author's elaboration. 
Table J5: Sliding spans of seasonally adjusted series (log-diff), Aggregation 5

\begin{tabular}{|c|c|c|c|c|c|c|c|c|c|c|c|c|c|}
\hline No. Obs. & Date & $\mathrm{S}(1)$ & $\mathrm{S}(2)$ & $\mathrm{S}(3)$ & S (4) & $\mathrm{S}(5)$ & $\mathrm{S}(6)$ & $\mathrm{S}(7)$ & $\mathrm{S}(8)$ & $\mathrm{S}(9)$ & $\mathrm{S}(10)$ & $\mathrm{s} \max$ & Score \\
\hline 40 & $1995 \mathrm{Q} 4$ & 1.634 & 1.630 & 1.539 & 1.635 & 1.522 & 1.621 & 1.625 & 1.624 & 1.612 & 1.474 & 16.1 & $v$ \\
\hline 41 & $1996 \mathrm{Q} 1$ & 2.650 & 2.649 & 2.659 & 2.604 & 2.660 & 2.649 & 2.644 & 2.644 & 2.650 & 2.562 & 9.8 & $v$ \\
\hline 42 & $1996 \mathrm{Q} 2$ & 0.393 & 0.362 & 0.421 & 0.417 & 0.432 & 0.394 & 0.396 & 0.396 & 0.402 & 0.502 & 14.0 & $v$ \\
\hline 43 & $1996 \mathrm{Q} 3$ & 0.972 & 1.011 & 1.017 & 0.994 & 1.018 & 0.991 & 0.991 & 0.991 & 0.991 & 1.112 & 14.0 & $v$ \\
\hline 44 & $1996 \mathrm{Q} 4$ & 1.969 & 1.966 & 1.904 & 1.981 & 1.895 & 1.951 & 1.953 & 1.952 & 1.940 & 1.771 & 21.0 & $v$ \\
\hline 45 & $1997 \mathrm{Q} 1$ & 1.205 & 1.198 & 1.186 & 1.137 & 1.183 & 1.198 & 1.195 & 1.195 & 1.201 & 1.109 & 9.6 & $v$ \\
\hline 46 & $1997 \mathrm{Q} 2$ & 2.170 & 2.133 & 2.201 & 2.196 & 2.214 & 2.168 & 2.169 & 2.169 & 2.177 & 2.430 & 29.7 & $v$ \\
\hline 47 & $1997 \mathrm{Q} 3$ & 1.830 & 1.874 & 1.891 & 1.867 & 1.885 & 1.873 & 1.874 & 1.874 & 1.873 & 1.812 & 7.9 & $v$ \\
\hline 48 & $1997 \mathrm{Q} 4$ & 2.253 & 2.274 & 2.198 & 2.278 & 2.197 & 2.224 & 2.225 & 2.225 & 2.212 & 2.132 & 14.6 & $v$ \\
\hline 49 & 1998Q 1 & -0.070 & -0.106 & -0.125 & -0.172 & -0.134 & -0.101 & -0.103 & -0.103 & -0.098 & -0.159 & 10.2 & $v$ \\
\hline 50 & $1998 \mathrm{Q} 2$ & 1.470 & 1.407 & 1.482 & 1.473 & 1.497 & 1.459 & 1.459 & 1.458 & 1.466 & 1.677 & 27.0 & $v$ \\
\hline 51 & $1998 \mathrm{Q} 3$ & -0.544 & -0.443 & -0.403 & -0.437 & -0.406 & -0.426 & -0.424 & -0.423 & -0.420 & -0.549 & 14.6 & $v$ \\
\hline 52 & $1998 \mathrm{Q} 4$ & -3.115 & -3.095 & -3.190 & -3.091 & -3.190 & -3.177 & -3.177 & -3.176 & -3.192 & -3.340 & 24.9 & $v$ \\
\hline 53 & $1999 \mathrm{Q} 1$ & 0.113 & 0.050 & -0.005 & -0.058 & -0.016 & 0.002 & 0.000 & -0.001 & 0.004 & 0.150 & 20.8 & $v$ \\
\hline 54 & $1999 \mathrm{Q} 2$ & 0.064 & -0.040 & 0.062 & 0.054 & 0.071 & 0.107 & 0.105 & 0.103 & 0.110 & 0.203 & 24.3 & $v$ \\
\hline 55 & $1999 \mathrm{Q} 3$ & 2.114 & 2.291 & 2.388 & 2.337 & 2.387 & 2.328 & 2.333 & 2.335 & 2.341 & 2.337 & 27.4 & $v$ \\
\hline 56 & $1999 \mathrm{Q} 4$ & 2.305 & 2.336 & 2.193 & 2.328 & 2.221 & 2.185 & 2.185 & 2.188 & 2.170 & 2.022 & 31.4 & $v$ \\
\hline 57 & $2000 \mathrm{Q} 1$ & 0.760 & 0.653 & 0.525 & 0.429 & 0.466 & 0.505 & 0.502 & 0.498 & 0.504 & 0.523 & 33.1 & $v$ \\
\hline 58 & $2000 \mathrm{Q} 2$ & -0.267 & -0.439 & -0.250 & -0.248 & -0.235 & -0.114 & -0.121 & -0.127 & -0.123 & -0.045 & 39.4 & * \\
\hline 59 & $2000 \mathrm{Q} 3$ & 1.099 & 1.386 & 1.513 & 1.499 & 1.553 & 1.421 & 1.432 & 1.439 & 1.448 & 1.482 & 45.4 & $\boldsymbol{x}$ \\
\hline 60 & $2000 \mathrm{Q} 4$ & 1.458 & 1.475 & 1.312 & 1.443 & 1.350 & 1.281 & 1.288 & 1.293 & 1.276 & 1.192 & 28.3 & $v$ \\
\hline 61 & $2001 \mathrm{Q} 1$ & $\mathrm{NA}$ & 1.128 & 0.892 & 0.720 & 0.769 & 0.833 & 0.815 & 0.813 & 0.819 & 0.802 & 40.8 & $\boldsymbol{x}$ \\
\hline 62 & $2001 \mathrm{Q} 2$ & NA & 0.735 & 1.000 & 1.056 & 1.022 & 1.238 & 1.230 & 1.209 & 1.211 & 1.235 & 50.3 & $\boldsymbol{x}$ \\
\hline 63 & $2001 \mathrm{Q} 3$ & $\mathrm{NA}$ & -0.699 & -0.517 & -0.501 & -0.424 & -0.682 & -0.660 & -0.637 & -0.631 & -0.547 & 27.5 & $v$ \\
\hline 64 & $2001 \mathrm{Q} 4$ & $\mathrm{NA}$ & 1.086 & 0.916 & 1.051 & 0.981 & 0.940 & 0.960 & 0.963 & 0.951 & 0.877 & 20.9 & $v$ \\
\hline 65 & $2002 \mathrm{Q} 1$ & NA & NA & 0.319 & 0.071 & 0.129 & 0.203 & 0.161 & 0.162 & 0.165 & 0.141 & 24.8 & $v$ \\
\hline 66 & $2002 \mathrm{Q} 2$ & NA & NA & 0.620 & 0.676 & 0.596 & 0.911 & 0.894 & 0.845 & 0.851 & 0.868 & 31.5 & $v$ \\
\hline 67 & $2002 \mathrm{Q} 3$ & $\mathrm{NA}$ & $\mathrm{NA}$ & 0.542 & 0.657 & 0.759 & 0.304 & 0.355 & 0.410 & 0.407 & 0.516 & 45.5 & * \\
\hline 68 & $2002 \mathrm{Q} 4$ & $\mathrm{NA}$ & NA & 1.907 & 2.040 & 1.973 & 2.075 & 2.112 & 2.114 & 2.108 & 1.980 & 20.7 & $v$ \\
\hline 69 & $2003 \mathrm{Q} 1$ & $\mathrm{NA}$ & $\mathrm{NA}$ & $\mathrm{NA}$ & 1.165 & 1.261 & 1.301 & 1.211 & 1.202 & 1.206 & 1.199 & 13.6 & $v$ \\
\hline 70 & $2003 \mathrm{Q} 2$ & $\mathrm{NA}$ & NA & $\mathrm{NA}$ & 0.066 & -0.081 & 0.270 & 0.236 & 0.153 & 0.159 & 0.170 & 35.1 & $\boldsymbol{x}$ \\
\hline 71 & $2003 \mathrm{Q} 3$ & $\mathrm{NA}$ & $\mathrm{NA}$ & $\mathrm{NA}$ & 0.682 & 0.789 & 0.171 & 0.296 & 0.423 & 0.412 & 0.559 & 61.8 & * \\
\hline 72 & $2003 \mathrm{Q} 4$ & NA & $\mathrm{NA}$ & $\mathrm{NA}$ & 0.251 & 0.193 & 0.482 & 0.518 & 0.496 & 0.501 & 0.292 & 32.5 & $v$ \\
\hline 73 & $2004 \mathrm{Q} 1$ & NA & NA & $\mathrm{NA}$ & $\mathrm{NA}$ & 3.085 & 3.094 & 2.928 & 2.887 & 2.893 & 2.960 & 20.7 & $v$ \\
\hline 74 & $2004 \mathrm{Q} 2$ & $\mathrm{NA}$ & NA & $\mathrm{NA}$ & NA & 0.625 & 0.937 & 0.882 & 0.755 & 0.751 & 0.765 & 31.2 & $v$ \\
\hline 75 & $2004 \mathrm{Q} 3$ & $\mathrm{NA}$ & $\mathrm{NA}$ & $\mathrm{NA}$ & $\mathrm{NA}$ & 3.068 & 2.376 & 2.648 & 2.919 & 2.898 & 2.991 & 69.2 & x \\
\hline 76 & $2004 \mathrm{Q} 4$ & $\mathrm{NA}$ & NA & $\mathrm{NA}$ & $\mathrm{NA}$ & 0.979 & 1.405 & 1.397 & 1.331 & 1.360 & 1.278 & 42.6 & $\boldsymbol{x}$ \\
\hline 77 & $2005 \mathrm{Q} 1$ & $\mathrm{NA}$ & $\mathrm{NA}$ & $\mathrm{NA}$ & $\mathrm{NA}$ & $\mathrm{NA}$ & 0.928 & 0.656 & 0.524 & 0.539 & 0.482 & 44.6 & $\boldsymbol{x}$ \\
\hline 78 & $2005 \mathrm{Q} 2$ & $\mathrm{NA}$ & NA & $\mathrm{NA}$ & $\mathrm{NA}$ & $\mathrm{NA}$ & 1.883 & 1.830 & 1.653 & 1.612 & 1.662 & 27.1 & $v$ \\
\hline 79 & $2005 \mathrm{Q} 3$ & NA & NA & $\mathrm{NA}$ & $\mathrm{NA}$ & $\mathrm{NA}$ & 0.813 & 1.224 & 1.765 & 1.722 & 1.801 & 98.8 & * \\
\hline 80 & $2005 \mathrm{Q} 4$ & $\mathrm{NA}$ & NA & $\mathrm{NA}$ & NA & $\mathrm{NA}$ & 0.787 & 0.750 & 0.536 & 0.644 & 0.538 & 25.1 & $\checkmark$ \\
\hline 81 & $2006 \mathrm{Q} 1$ & $\mathrm{NA}$ & NA & $\mathrm{NA}$ & $\mathrm{NA}$ & $\mathrm{NA}$ & $\mathrm{NA}$ & 1.378 & 1.163 & 1.166 & 1.142 & 23.6 & $v$ \\
\hline 82 & $2006 \mathrm{Q} 2$ & $\mathrm{NA}$ & $\mathrm{NA}$ & $\mathrm{NA}$ & $\mathrm{NA}$ & $\mathrm{NA}$ & $\mathrm{NA}$ & 1.244 & 1.011 & 0.922 & 0.977 & 32.2 & $v$ \\
\hline 83 & $2006 \mathrm{Q} 3$ & $\mathrm{NA}$ & $\mathrm{NA}$ & $\mathrm{NA}$ & $\mathrm{NA}$ & $\mathrm{NA}$ & $\mathrm{NA}$ & 0.123 & 0.962 & 0.878 & 0.985 & 86.2 & $\boldsymbol{x}$ \\
\hline 84 & $2006 \mathrm{Q} 4$ & $\mathrm{NA}$ & NA & $\mathrm{NA}$ & NA & $\mathrm{NA}$ & $\mathrm{NA}$ & 1.928 & 1.557 & 1.777 & 1.583 & 37.1 & $\boldsymbol{x}$ \\
\hline 85 & $2007 \mathrm{Q} 1$ & NA & NA & $\mathrm{NA}$ & NA & $\mathrm{NA}$ & $\mathrm{NA}$ & $\mathrm{NA}$ & 1.951 & 1.961 & 1.906 & 5.5 & $v$ \\
\hline 86 & $2007 \mathrm{Q} 2$ & NA & NA & $\mathrm{NA}$ & NA & $\mathrm{NA}$ & $\mathrm{NA}$ & $\mathrm{NA}$ & 0.544 & 0.354 & 0.644 & 29.0 & $v$ \\
\hline 87 & $2007 \mathrm{Q} 3$ & $\mathrm{NA}$ & NA & $\mathrm{NA}$ & $\mathrm{NA}$ & $\mathrm{NA}$ & $\mathrm{NA}$ & $\mathrm{NA}$ & -0.549 & -0.647 & -0.635 & 9.8 & $v$ \\
\hline \multirow[t]{3}{*}{88} & $2007 \mathrm{Q} 4$ & $\mathrm{NA}$ & $\mathrm{NA}$ & $\mathrm{NA}$ & $\mathrm{NA}$ & $\mathrm{NA}$ & $\mathrm{NA}$ & $\mathrm{NA}$ & 2.000 & 2.324 & 1.970 & 35.4 & $\boldsymbol{x}$ \\
\hline & Median & - & - & - & - & - & - & - & - & - & - & 27.40 & - \\
\hline & Mean & - & - & - & - & - & - & - & - & - & - & 30.34 & $30 \%$ \\
\hline
\end{tabular}

Source: Author's elaboration 
Table J6: Sliding spans of seasonally adjusted series (log-diff), Aggregation 6

\begin{tabular}{|c|c|c|c|c|c|c|c|c|c|c|c|c|c|}
\hline No. Obs. & Date & $\mathrm{S}(1)$ & $\mathrm{S}(2)$ & $\mathrm{S}(3)$ & S (4) & $\mathrm{S}(5)$ & $\mathrm{S}(6)$ & $\mathrm{S}(7)$ & $\mathrm{S}(8)$ & $\mathrm{S}(9)$ & $\mathrm{S}(10)$ & $\mathrm{s} \max$ & Score \\
\hline 40 & $1995 \mathrm{Q} 4$ & 2.351 & 2.349 & 2.350 & 2.351 & 2.352 & 2.355 & 2.352 & 2.352 & 2.352 & 2.288 & 6.7 & $v$ \\
\hline 41 & $1996 \mathrm{Q} 1$ & 1.969 & 1.975 & 1.974 & 1.970 & 1.969 & 1.968 & 1.970 & 1.970 & 1.970 & 2.212 & 24.4 & $v$ \\
\hline 42 & $1996 \mathrm{Q} 2$ & 1.202 & 1.193 & 1.194 & 1.198 & 1.199 & 1.202 & 1.199 & 1.199 & 1.199 & 1.138 & 6.4 & $v$ \\
\hline 43 & $1996 \mathrm{Q} 3$ & 1.690 & 1.697 & 1.696 & 1.693 & 1.692 & 1.685 & 1.692 & 1.692 & 1.691 & 1.516 & 18.1 & $v$ \\
\hline 44 & $1996 \mathrm{Q} 4$ & 1.584 & 1.584 & 1.585 & 1.587 & 1.588 & 1.594 & 1.588 & 1.588 & 1.589 & 1.611 & 2.7 & $v$ \\
\hline 45 & $1997 \mathrm{Q} 1$ & 0.149 & 0.146 & 0.145 & 0.141 & 0.141 & 0.142 & 0.142 & 0.142 & 0.142 & 0.324 & 18.3 & $v$ \\
\hline 46 & $1997 \mathrm{Q} 2$ & 2.850 & 2.838 & 2.841 & 2.845 & 2.846 & 2.846 & 2.845 & 2.845 & 2.845 & 2.836 & 1.4 & $v$ \\
\hline 47 & $1997 \mathrm{Q} 3$ & 2.450 & 2.470 & 2.469 & 2.465 & 2.462 & 2.449 & 2.461 & 2.462 & 2.461 & 2.196 & 27.4 & $v$ \\
\hline 48 & $1997 \mathrm{Q} 4$ & 2.097 & 2.106 & 2.107 & 2.111 & 2.113 & 2.124 & 2.114 & 2.114 & 2.114 & 2.273 & 17.6 & $v$ \\
\hline 49 & 1998Q 1 & -0.684 & -0.708 & -0.710 & -0.713 & -0.711 & -0.704 & -0.709 & -0.711 & -0.710 & -0.613 & 10.0 & $v$ \\
\hline 50 & $1998 \mathrm{Q} 2$ & 1.937 & 1.889 & 1.895 & 1.897 & 1.899 & 1.901 & 1.898 & 1.898 & 1.898 & 1.899 & 4.8 & $v$ \\
\hline 51 & $1998 \mathrm{Q} 3$ & -0.298 & -0.193 & -0.198 & -0.205 & -0.220 & -0.257 & -0.223 & -0.219 & -0.222 & -0.436 & 24.3 & $v$ \\
\hline 52 & $1998 \mathrm{Q} 4$ & -3.573 & -3.591 & -3.589 & -3.578 & -3.564 & -3.532 & -3.560 & -3.563 & -3.560 & -3.455 & 13.6 & $v$ \\
\hline 53 & $1999 \mathrm{Q} 1$ & -0.411 & -0.460 & -0.464 & -0.466 & -0.462 & -0.452 & -0.461 & -0.463 & -0.462 & -0.427 & 5.5 & $v$ \\
\hline 54 & $1999 \mathrm{Q} 2$ & 0.405 & 0.301 & 0.304 & 0.297 & 0.297 & 0.304 & 0.296 & 0.293 & 0.293 & 0.257 & 14.8 & $v$ \\
\hline 55 & $1999 \mathrm{Q} 3$ & 2.333 & 2.572 & 2.583 & 2.574 & 2.543 & 2.462 & 2.538 & 2.546 & 2.541 & 2.581 & 25.0 & $v$ \\
\hline 56 & $1999 \mathrm{Q} 4$ & 2.249 & 2.183 & 2.148 & 2.178 & 2.207 & 2.283 & 2.214 & 2.213 & 2.217 & 2.211 & 13.5 & $v$ \\
\hline 57 & $2000 \mathrm{Q} 1$ & 0.408 & 0.329 & 0.372 & 0.372 & 0.387 & 0.392 & 0.388 & 0.384 & 0.385 & 0.389 & 7.9 & $v$ \\
\hline 58 & $2000 \mathrm{Q} 2$ & 0.121 & -0.062 & -0.102 & -0.136 & -0.144 & -0.135 & -0.148 & -0.157 & -0.157 & -0.190 & 31.1 & $v$ \\
\hline 59 & $2000 \mathrm{Q} 3$ & 1.233 & 1.649 & 1.701 & 1.679 & 1.611 & 1.488 & 1.602 & 1.612 & 1.605 & 1.618 & 46.8 & $\boldsymbol{x}$ \\
\hline 60 & $2000 \mathrm{Q} 4$ & 1.266 & 1.120 & 1.043 & 1.132 & 1.205 & 1.333 & 1.225 & 1.233 & 1.240 & 1.272 & 29.0 & $v$ \\
\hline 61 & $2001 \mathrm{Q} 1$ & $\mathrm{NA}$ & 1.055 & 1.149 & 1.150 & 1.158 & 1.150 & 1.149 & 1.158 & 1.159 & 1.151 & 10.4 & $v$ \\
\hline 62 & $2001 \mathrm{Q} 2$ & NA & 0.874 & 0.766 & 0.654 & 0.680 & 0.682 & 0.671 & 0.616 & 0.615 & 0.578 & 29.6 & $v$ \\
\hline 63 & $2001 \mathrm{Q} 3$ & $\mathrm{NA}$ & -0.459 & -0.335 & -0.355 & -0.532 & -0.678 & -0.536 & -0.489 & -0.500 & -0.470 & 34.3 & $\boldsymbol{x}$ \\
\hline 64 & $2001 \mathrm{Q} 4$ & $\mathrm{NA}$ & 0.676 & 0.543 & 0.731 & 0.879 & 1.047 & 0.913 & 0.910 & 0.919 & 0.931 & 50.4 & $\boldsymbol{x}$ \\
\hline 65 & $2002 \mathrm{Q} 1$ & $\mathrm{NA}$ & NA & 0.638 & 0.618 & 0.662 & 0.651 & 0.648 & 0.695 & 0.702 & 0.704 & 8.6 & $v$ \\
\hline 66 & $2002 \mathrm{Q} 2$ & NA & NA & 0.470 & 0.261 & 0.284 & 0.254 & 0.242 & 0.104 & 0.099 & 0.006 & 46.4 & $\boldsymbol{x}$ \\
\hline 67 & $2002 \mathrm{Q} 3$ & $\mathrm{NA}$ & $\mathrm{NA}$ & 0.753 & 0.753 & 0.432 & 0.288 & 0.452 & 0.554 & 0.541 & 0.655 & 46.5 & $\boldsymbol{x}$ \\
\hline 68 & $2002 \mathrm{Q} 4$ & $\mathrm{NA}$ & NA & 1.385 & 1.679 & 1.944 & 2.151 & 2.013 & 2.006 & 2.019 & 1.999 & 76.6 & $\boldsymbol{x}$ \\
\hline 69 & $2003 \mathrm{Q} 1$ & $\mathrm{NA}$ & $\mathrm{NA}$ & $\mathrm{NA}$ & 0.759 & 0.856 & 0.850 & 0.822 & 0.903 & 0.916 & 0.927 & 16.8 & $v$ \\
\hline 70 & $2003 \mathrm{Q} 2$ & $\mathrm{NA}$ & NA & $\mathrm{NA}$ & 1.325 & 1.314 & 1.212 & 1.186 & 0.945 & 0.928 & 0.816 & 50.9 & $\boldsymbol{x}$ \\
\hline 71 & $2003 \mathrm{Q} 3$ & $\mathrm{NA}$ & $\mathrm{NA}$ & $\mathrm{NA}$ & 0.943 & 0.480 & 0.369 & 0.601 & 0.788 & 0.773 & 0.885 & 57.4 & * \\
\hline 72 & $2003 \mathrm{Q} 4$ & $\mathrm{NA}$ & $\mathrm{NA}$ & $\mathrm{NA}$ & -0.134 & 0.245 & 0.486 & 0.325 & 0.318 & 0.342 & 0.314 & 62.0 & $\boldsymbol{x}$ \\
\hline 73 & $2004 \mathrm{Q} 1$ & NA & NA & $\mathrm{NA}$ & $\mathrm{NA}$ & 2.173 & 2.192 & 2.118 & 2.203 & 2.226 & 2.253 & 13.5 & $v$ \\
\hline 74 & $2004 \mathrm{Q} 2$ & $\mathrm{NA}$ & NA & $\mathrm{NA}$ & $\mathrm{NA}$ & 1.788 & 1.575 & 1.538 & 1.189 & 1.154 & 1.056 & 73.2 & $\boldsymbol{x}$ \\
\hline 75 & $2004 \mathrm{Q} 3$ & $\mathrm{NA}$ & $\mathrm{NA}$ & $\mathrm{NA}$ & $\mathrm{NA}$ & 2.635 & 2.580 & 2.902 & 3.218 & 3.183 & 3.219 & 63.9 & $\boldsymbol{x}$ \\
\hline 76 & $2004 \mathrm{Q} 4$ & NA & NA & NA & NA & 1.074 & 1.350 & 1.169 & 1.147 & 1.209 & 1.251 & 27.6 & $v$ \\
\hline 77 & $2005 \mathrm{Q} 1$ & $\mathrm{NA}$ & $\mathrm{NA}$ & $\mathrm{NA}$ & $\mathrm{NA}$ & $\mathrm{NA}$ & 0.239 & 0.102 & 0.170 & 0.210 & 0.209 & 13.7 & $v$ \\
\hline 78 & $2005 \mathrm{Q} 2$ & $\mathrm{NA}$ & $\mathrm{NA}$ & $\mathrm{NA}$ & $\mathrm{NA}$ & $\mathrm{NA}$ & 2.487 & 2.426 & 1.947 & 1.868 & 1.891 & 61.9 & * \\
\hline 79 & $2005 \mathrm{Q} 3$ & NA & NA & $\mathrm{NA}$ & $\mathrm{NA}$ & $\mathrm{NA}$ & 0.764 & 1.205 & 1.733 & 1.651 & 1.561 & 96.9 & $\boldsymbol{x}$ \\
\hline 80 & $2005 \mathrm{Q} 4$ & $\mathrm{NA}$ & NA & $\mathrm{NA}$ & NA & $\mathrm{NA}$ & 0.927 & 0.709 & 0.624 & 0.779 & 0.801 & 30.3 & $\checkmark$ \\
\hline 81 & $2006 \mathrm{Q} 1$ & $\mathrm{NA}$ & NA & NA & $\mathrm{NA}$ & $\mathrm{NA}$ & $\mathrm{NA}$ & 0.954 & 0.978 & 1.032 & 1.045 & 9.1 & $v$ \\
\hline 82 & $2006 \mathrm{Q} 2$ & $\mathrm{NA}$ & $\mathrm{NA}$ & $\mathrm{NA}$ & $\mathrm{NA}$ & $\mathrm{NA}$ & $\mathrm{NA}$ & 1.740 & 1.158 & 1.018 & 1.208 & 72.2 & $\boldsymbol{x}$ \\
\hline 83 & $2006 \mathrm{Q} 3$ & $\mathrm{NA}$ & $\mathrm{NA}$ & $\mathrm{NA}$ & $\mathrm{NA}$ & $\mathrm{NA}$ & $\mathrm{NA}$ & 0.016 & 0.766 & 0.618 & 0.359 & 75.0 & $\boldsymbol{x}$ \\
\hline 84 & $2006 \mathrm{Q} 4$ & $\mathrm{NA}$ & $\mathrm{NA}$ & $\mathrm{NA}$ & NA & $\mathrm{NA}$ & $\mathrm{NA}$ & 1.916 & 1.761 & 2.037 & 2.021 & 27.6 & $v$ \\
\hline 85 & $2007 \mathrm{Q} 1$ & $\mathrm{NA}$ & NA & $\mathrm{NA}$ & NA & $\mathrm{NA}$ & $\mathrm{NA}$ & $\mathrm{NA}$ & 1.749 & 1.814 & 1.884 & 13.5 & $v$ \\
\hline 86 & $2007 \mathrm{Q} 2$ & NA & NA & $\mathrm{NA}$ & NA & $\mathrm{NA}$ & $\mathrm{NA}$ & $\mathrm{NA}$ & 0.705 & 0.490 & 0.888 & 39.8 & $x$ \\
\hline 87 & $2007 \mathrm{Q} 3$ & $\mathrm{NA}$ & NA & $\mathrm{NA}$ & $\mathrm{NA}$ & $\mathrm{NA}$ & $\mathrm{NA}$ & $\mathrm{NA}$ & -0.627 & -0.826 & -1.356 & 72.9 & $x$ \\
\hline \multirow[t]{3}{*}{88} & $2007 \mathrm{Q} 4$ & $\mathrm{NA}$ & $\mathrm{NA}$ & $\mathrm{NA}$ & $\mathrm{NA}$ & $\mathrm{NA}$ & $\mathrm{NA}$ & $\mathrm{NA}$ & 2.136 & 2.526 & 2.505 & 39.0 & $\boldsymbol{x}$ \\
\hline & Median & - & - & - & - & - & - & - & - & - & - & 27.40 & - \\
\hline & Mean & - & - & - & - & - & - & - & - & - & - & 32.03 & $34 \%$ \\
\hline
\end{tabular}

Source: Author's elaboration 


\section{K Diagnostic Result 3}

\section{Revision history of trend-cycle and final seasonally adjusted series}

Figure K1: Revision history of trend-cycle series (log-differenced) $\left(^{*}\right)$

A: Aggregation 1 .

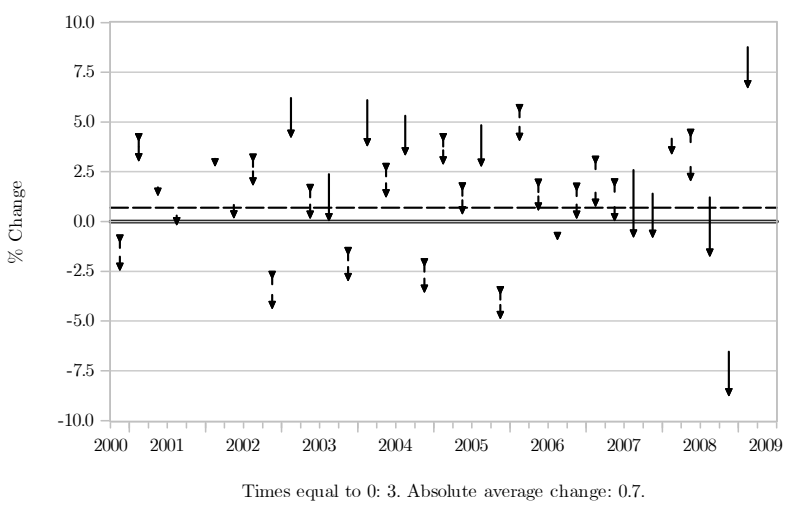

C: Aggregation 3 .

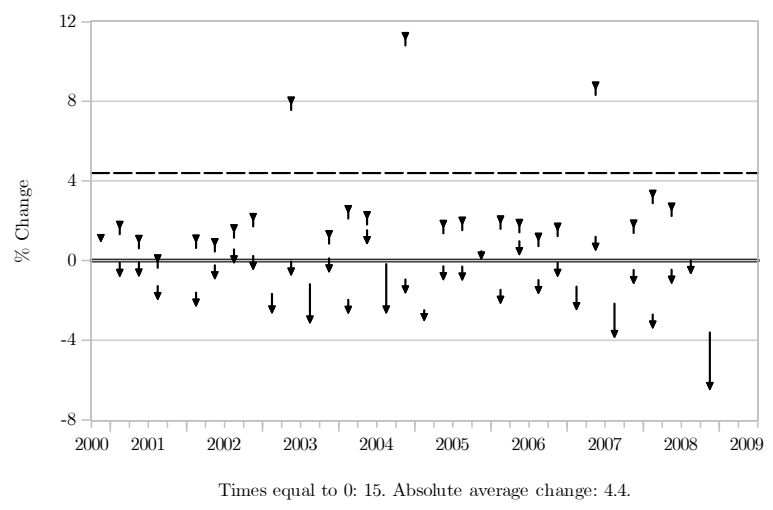

E: Aggregation 5 .

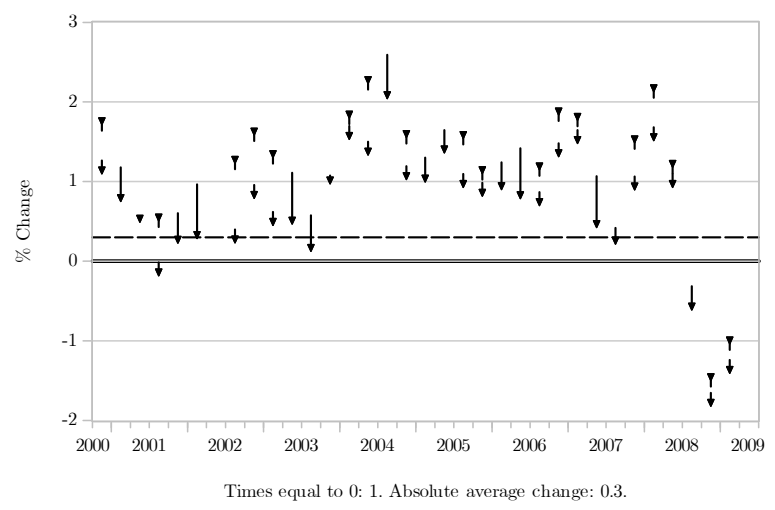

B: Aggregation 2 .

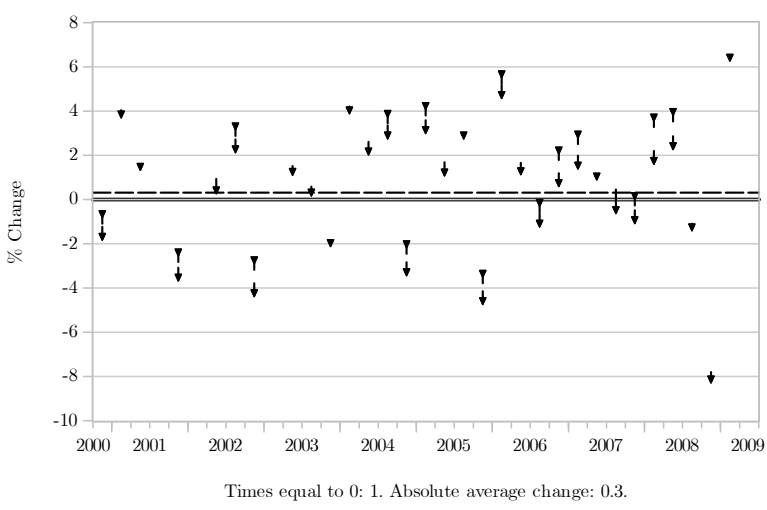

D: Aggregation 4

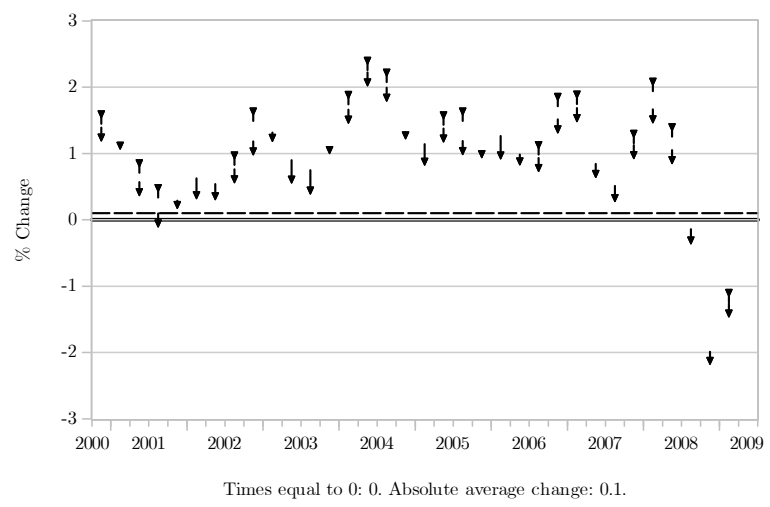

F: Aggregation 6 .

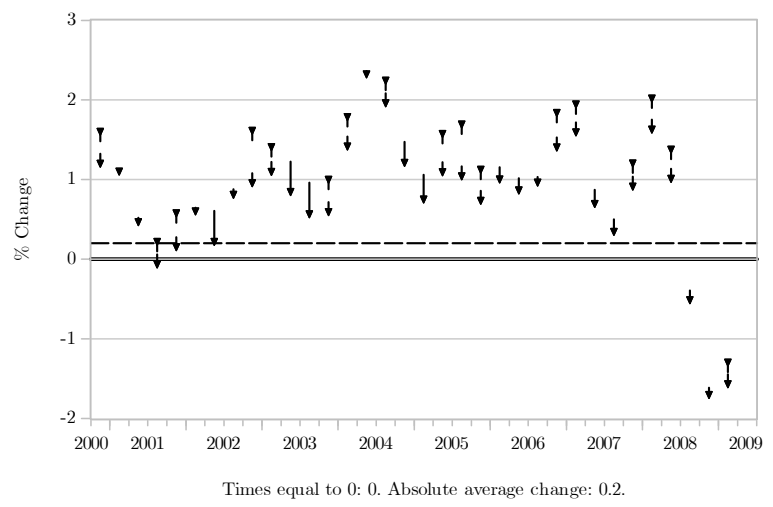

(*) $\mathbf{v}=$ Most recent. Source: Author's elaboration. 
Figure K2: Revision history of seasonally adjusted series (log-differenced) (*)

A: Aggregation 1.

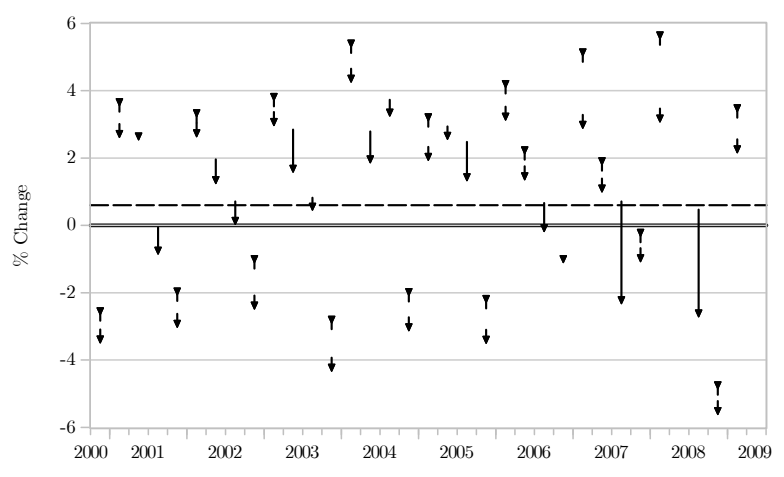

Times equal to $0: 3$. Absolute average change: 0.6 .

C: Aggregation 3 .

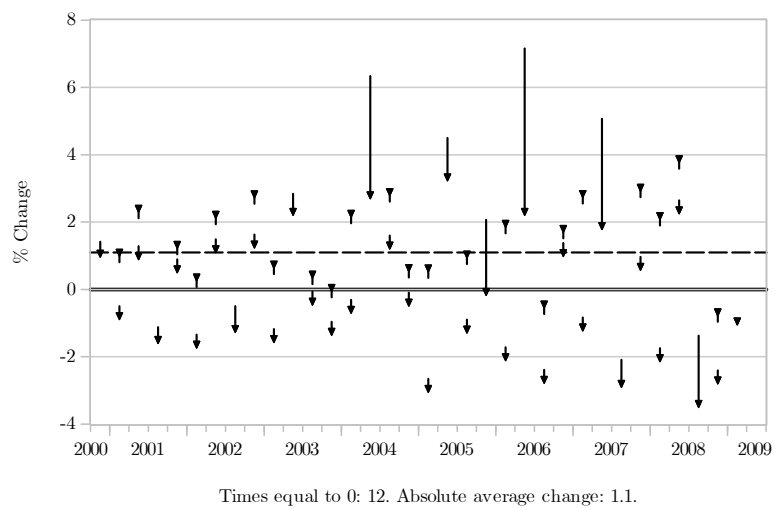

E: Aggregation 5

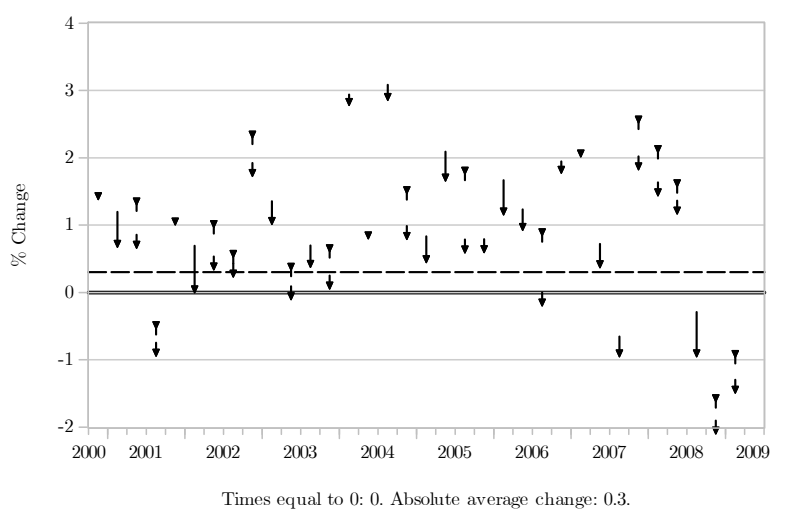

B: Aggregation 2 .

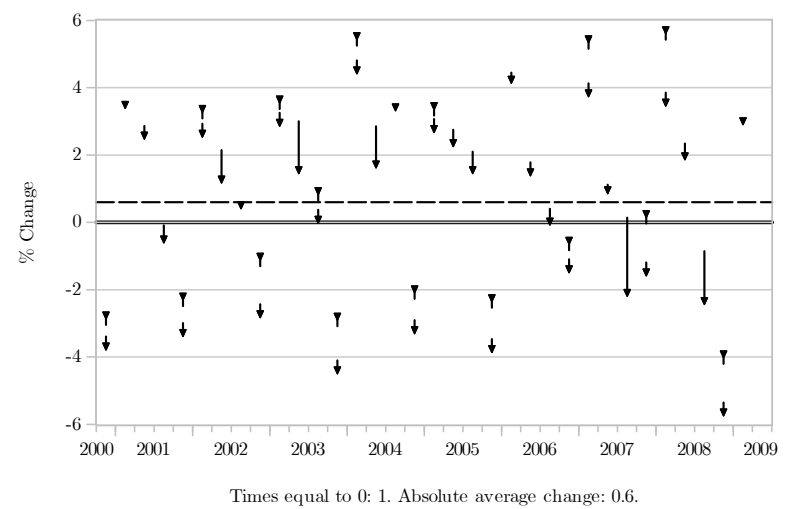

D: Aggregation 4

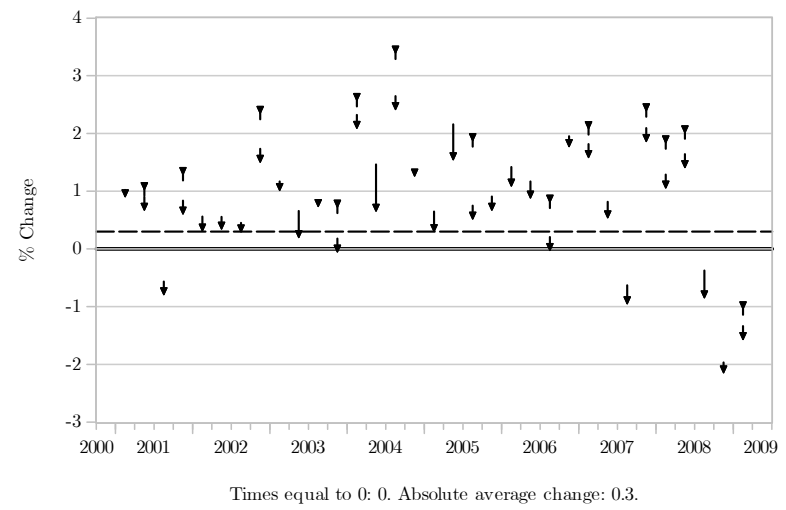

F: Aggregation 6 .

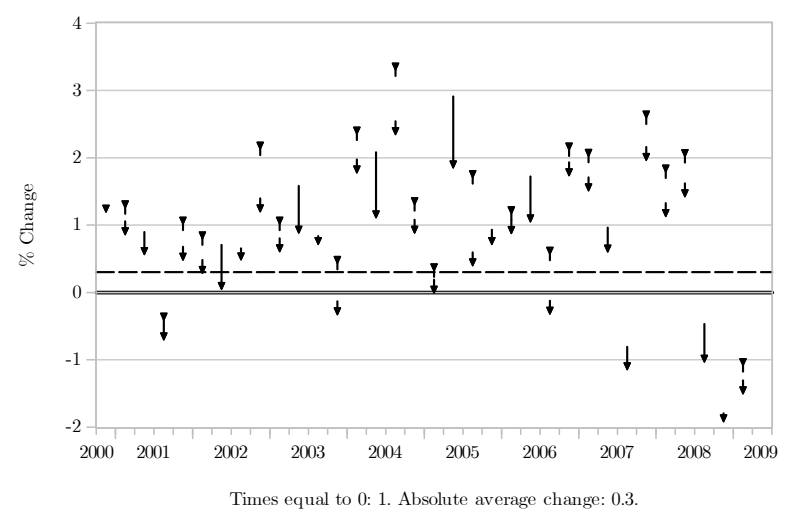

(*) Aggregation 3 contains an outlier at 2008.III: from -106.9 (concurrent) to -0.4 (most recent). $\mathbf{v}=$ Most recent. Source: Author's elaboration. 
Companion Tables to

A Comparison Between Direct and Indirect Seasonal Adjustment of the Chilean GDP 1986-2009 with X-12-ARIMA

Carlos A. Medel*

May 1, 2014

${ }^{*}$ E-mail: carlos_medel@yahoo.com. 


\section{Sliding spans diagnostic results}

\section{$1 \quad$ Sliding spans of (log-differenced) trend-cycle series}

Table 1: Sliding spans of trend-cycle series (log-diff), Aggregation 1

\begin{tabular}{|c|c|c|c|c|c|c|c|c|c|c|c|c|c|}
\hline No. Obs. & Date & $\mathrm{S}(1)$ & $\mathrm{S}(2)$ & $\mathrm{S}(3)$ & $\mathrm{S}(4)$ & $\mathrm{S}(5)$ & $\mathrm{S}(6)$ & $\mathrm{S}(7)$ & $\mathrm{S}(8)$ & $\mathrm{S}(9)$ & $\mathrm{S}(10)$ & $\mathrm{s}^{\max }$ & Score \\
\hline 40 & 1995Q4 & -5.059 & -5.019 & -5.026 & -4.561 & -4.630 & -4.562 & -4.664 & -4.637 & -4.628 & -4.710 & 49.8 & $\boldsymbol{x}$ \\
\hline 41 & 1996Q1 & 7.081 & 7.077 & 7.089 & 6.695 & 6.724 & 6.737 & 6.803 & 7.146 & 6.791 & 6.804 & 45.1 & $\boldsymbol{x}$ \\
\hline 42 & 1996Q2 & 1.989 & 1.943 & 1.954 & 1.636 & 1.661 & 1.634 & 1.722 & 1.723 & 1.678 & 1.712 & 35.5 & $\boldsymbol{x}$ \\
\hline 43 & 1996Q3 & 2.482 & 2.443 & 2.434 & 2.486 & 2.461 & 2.433 & 2.424 & 2.063 & 2.431 & 2.448 & 42.3 & $\boldsymbol{x}$ \\
\hline 44 & 1996Q4 & -1.517 & -1.466 & -1.459 & -1.474 & -1.471 & -1.438 & -1.405 & -2.762 & -1.374 & -1.361 & 140.1 & $\boldsymbol{x}$ \\
\hline 45 & 1997Q1 & 0.694 & 0.712 & 0.743 & 0.760 & 0.786 & 0.806 & 0.785 & 3.591 & 0.573 & 0.503 & 308.8 & $\boldsymbol{*}$ \\
\hline 46 & 1997Q2 & 5.091 & 5.064 & 5.061 & 5.120 & 5.123 & 5.098 & 5.071 & 3.738 & 3.720 & 3.681 & 144.2 & $\boldsymbol{x}$ \\
\hline 47 & 1997Q3 & 2.076 & 2.072 & 2.053 & 1.972 & 1.953 & 1.921 & 1.914 & 1.674 & 4.727 & 4.834 & 316.0 & $\boldsymbol{x}$ \\
\hline 48 & 1997Q4 & -1.680 & -1.612 & -1.658 & -1.699 & -1.836 & -1.773 & -1.672 & -1.546 & -3.055 & -3.017 & 150.9 & $\boldsymbol{x}$ \\
\hline 49 & 1998Q1 & 2.713 & 2.675 & 2.693 & 2.804 & 2.666 & 2.672 & 2.793 & 3.020 & 2.586 & 2.504 & 51.6 & $\boldsymbol{x}$ \\
\hline 50 & 1998Q2 & 0.739 & 0.671 & 0.712 & 0.792 & 0.827 & 0.810 & 0.743 & 0.714 & 0.944 & 0.884 & 27.3 & $\checkmark$ \\
\hline 51 & 1998Q3 & 2.449 & 2.464 & 2.466 & 2.320 & 2.895 & 2.884 & 2.309 & 2.154 & 2.528 & 2.587 & 74.1 & $\boldsymbol{x}$ \\
\hline 52 & 1998Q4 & -7.554 & -7.493 & -7.600 & -7.661 & -8.283 & -8.247 & -7.571 & -7.497 & -7.578 & -7.505 & 79.0 & $\boldsymbol{*}$ \\
\hline 53 & 1999Q1 & 2.405 & 2.400 & 2.427 & 2.558 & 2.963 & 2.926 & 2.650 & 2.684 & 2.469 & 2.420 & 56.3 & $\boldsymbol{x}$ \\
\hline 54 & 1999Q2 & 1.089 & 1.072 & 1.173 & 1.194 & 1.096 & 1.084 & 1.113 & 1.041 & 1.070 & 1.029 & 16.5 & $\checkmark$ \\
\hline 55 & 1999Q3 & 3.309 & 3.296 & 3.317 & 3.162 & 3.083 & 3.065 & 3.059 & 3.051 & 3.222 & 3.232 & 26.6 & $\checkmark$ \\
\hline 56 & 1999Q4 & -3.346 & -3.312 & -3.418 & -3.385 & -3.355 & -3.320 & -3.263 & -3.197 & -3.273 & -3.237 & 22.1 & $\checkmark$ \\
\hline 57 & 2000Q1 & 3.274 & 3.417 & 3.122 & 3.214 & 3.163 & 3.175 & 3.172 & 3.123 & 3.043 & 3.051 & 37.4 & $\boldsymbol{x}$ \\
\hline 58 & 2000Q2 & 2.884 & 2.870 & 2.965 & 3.040 & 3.052 & 3.031 & 2.991 & 2.906 & 2.945 & 2.915 & 18.2 & $\checkmark$ \\
\hline 59 & 2000Q3 & -0.936 & -1.107 & -0.829 & -0.751 & -0.742 & -0.809 & -0.833 & -0.714 & -0.662 & -0.678 & 44.5 & $\boldsymbol{x}$ \\
\hline 60 & 2000Q4 & -1.783 & -1.604 & -1.428 & -1.877 & -1.977 & -2.037 & -2.063 & -1.285 & -1.339 & -1.325 & 77.8 & $\boldsymbol{x}$ \\
\hline 61 & 2001Q1 & NA & 3.938 & 3.882 & 4.709 & 4.887 & 5.087 & 5.277 & 3.745 & 3.688 & 3.697 & 158.9 & $\boldsymbol{x}$ \\
\hline 62 & 2001Q2 & NA & 1.582 & 1.639 & 0.853 & 0.908 & 0.845 & 0.696 & 1.465 & 1.507 & 1.502 & 94.3 & $\boldsymbol{x}$ \\
\hline 63 & 2001Q3 & NA & 0.181 & 0.057 & 0.041 & -0.081 & -0.144 & -0.201 & -0.047 & 0.025 & 0.027 & 38.2 & $\boldsymbol{x}$ \\
\hline 64 & 2001Q4 & NA & -2.939 & -3.199 & -2.966 & -2.924 & -2.922 & -2.827 & -2.924 & -2.949 & -2.951 & 37.2 & $\boldsymbol{x}$ \\
\hline 65 & 2002Q1 & NA & NA & 2.990 & 3.117 & 3.061 & 3.067 & 3.115 & 2.987 & 2.935 & 2.952 & 18.2 & $\checkmark$ \\
\hline 66 & 2002Q2 & NA & NA & 0.848 & 0.732 & 0.530 & 0.466 & 0.396 & 0.360 & 0.375 & 0.371 & 48.8 & $\boldsymbol{x}$ \\
\hline 67 & 2002Q3 & NA & $\mathrm{NA}$ & 2.578 & 2.778 & 2.744 & 2.717 & 2.669 & 2.715 & 2.709 & 2.709 & 20.0 & $\checkmark$ \\
\hline 68 & 2002Q4 & NA & NA & -3.753 & -3.615 & -3.414 & -3.333 & -3.308 & -3.218 & -3.201 & -3.199 & 55.4 & $\boldsymbol{x}$ \\
\hline 69 & 2003Q1 & NA & NA & NA & 3.919 & 4.158 & 4.250 & 4.273 & 4.250 & 4.336 & 4.340 & 42.1 & $\boldsymbol{x}$ \\
\hline 70 & 2003Q2 & NA & NA & NA & 1.436 & 1.259 & 1.265 & 1.267 & 1.225 & 1.202 & 1.202 & 23.4 & $\checkmark$ \\
\hline 71 & 2003Q3 & NA & NA & NA & 0.663 & 0.343 & 0.318 & 0.366 & 0.371 & 0.265 & 0.244 & 41.9 & $\boldsymbol{*}$ \\
\hline 72 & 2003Q4 & NA & NA & NA & -2.308 & -1.952 & -2.032 & -1.987 & -1.985 & -1.963 & -1.968 & 35.6 & $\boldsymbol{x}$ \\
\hline 73 & 2004Q1 & NA & NA & NA & NA & 4.058 & 3.963 & 3.905 & 3.821 & 3.885 & 3.923 & 23.7 & $\checkmark$ \\
\hline 74 & 2004Q2 & NA & NA & NA & NA & 2.403 & 2.430 & 2.251 & 2.321 & 2.254 & 2.241 & 18.9 & $\checkmark$ \\
\hline 75 & 2004Q3 & NA & NA & NA & NA & 3.430 & 3.487 & 3.615 & 3.693 & 3.560 & 3.491 & 26.3 & $\checkmark$ \\
\hline 76 & 2004Q4 & NA & NA & NA & NA & -2.910 & -2.759 & -2.586 & -2.630 & -2.593 & -2.551 & 35.9 & $\boldsymbol{x}$ \\
\hline 77 & 2005Q1 & NA & NA & NA & NA & NA & 3.568 & 3.502 & 3.340 & 3.584 & 3.700 & 36.0 & $\boldsymbol{x}$ \\
\hline 78 & 2005Q2 & NA & NA & NA & NA & NA & 1.522 & 1.259 & 1.372 & 1.364 & 1.284 & 26.3 & $\checkmark$ \\
\hline 79 & 2005Q3 & NA & $\mathrm{NA}$ & NA & NA & NA & 3.035 & 3.231 & 3.497 & 3.113 & 2.932 & 56.5 & $\boldsymbol{x}$ \\
\hline 80 & 2005Q4 & NA & NA & NA & NA & NA & -4.277 & -4.064 & -4.193 & -4.112 & -4.011 & 26.6 & $\checkmark$ \\
\hline 81 & 2006Q1 & NA & NA & NA & NA & NA & NA & 4.685 & 4.260 & 4.796 & 5.094 & 83.4 & $\boldsymbol{*}$ \\
\hline 82 & 2006Q2 & NA & NA & NA & NA & NA & NA & 1.587 & 1.545 & 1.559 & 1.464 & 12.3 & $\checkmark$ \\
\hline 83 & 2006Q3 & NA & NA & NA & NA & NA & NA & -0.275 & 0.183 & -0.414 & -0.708 & 89.1 & $\boldsymbol{x}$ \\
\hline 84 & 2006Q4 & NA & NA & NA & NA & NA & NA & 0.840 & 1.066 & 1.103 & 1.272 & 43.2 & $\boldsymbol{x}$ \\
\hline 85 & 2007Q1 & NA & NA & NA & NA & NA & NA & NA & 1.454 & 2.087 & 2.606 & 115.2 & $\boldsymbol{x}$ \\
\hline 86 & 2007Q2 & NA & NA & NA & NA & NA & NA & NA & 1.360 & 1.743 & 1.494 & 38.3 & $x$ \\
\hline 87 & 2007Q3 & NA & NA & NA & NA & NA & NA & NA & 1.520 & 0.361 & -0.583 & 210.3 & $\boldsymbol{x}$ \\
\hline \multirow[t]{3}{*}{88} & 2007Q4 & NA & $\mathrm{NA}$ & NA & NA & NA & NA & $\mathrm{NA}$ & 1.399 & -0.459 & -0.605 & 200.4 & $\boldsymbol{x}$ \\
\hline & Median & - & - & - & - & - & - & - & - & - & - & 42.30 & - \\
\hline & Mean & - & - & - & - & - & - & - & - & - & - & 69.81 & $71 \%$ \\
\hline
\end{tabular}


Table 2: Sliding spans of trend-cycle series (log-diff), Aggregation 2

\begin{tabular}{|c|c|c|c|c|c|c|c|c|c|c|c|c|c|}
\hline No. Obs. & Date & $\mathrm{S}(1)$ & $\mathrm{S}(2)$ & $\mathrm{S}(3)$ & $\mathrm{S}(4)$ & $\mathrm{S}(5)$ & $\mathrm{S}(6)$ & $\mathrm{S}(7)$ & $\mathrm{S}(8)$ & $\mathrm{S}(9)$ & $\mathrm{S}(10)$ & $\mathrm{s}^{\max }$ & Score \\
\hline 40 & 1995Q4 & -5.259 & -5.253 & -5.261 & -5.261 & -5.208 & -5.208 & -5.224 & -5.208 & -5.224 & -5.208 & 5.3 & $v$ \\
\hline 41 & 1996Q1 & 7.286 & 7.281 & 7.280 & 7.279 & 7.311 & 7.313 & 7.299 & 7.311 & 7.299 & 7.311 & 3.4 & 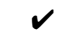 \\
\hline 42 & 1996Q2 & 2.104 & 2.096 & 2.106 & 2.104 & 2.047 & 2.048 & 2.049 & 2.047 & 2.048 & 2.047 & 5.9 & $\checkmark$ \\
\hline 43 & 1996Q3 & 2.148 & 2.176 & 2.178 & 2.179 & 2.172 & 2.170 & 2.165 & 2.173 & 2.165 & 2.173 & 3.1 & $\checkmark$ \\
\hline 44 & 1996Q4 & -1.379 & -1.367 & -1.380 & -1.374 & -1.325 & -1.329 & -1.332 & -1.325 & -1.332 & -1.325 & 5.5 & $\nu$ \\
\hline 45 & 1997Q1 & 0.952 & 0.918 & 0.935 & 0.940 & 0.915 & 0.917 & 0.910 & 0.915 & 0.910 & 0.915 & 4.2 & $\checkmark$ \\
\hline 46 & 1997Q2 & 4.984 & 4.958 & 4.969 & 4.954 & 4.896 & 4.903 & 4.901 & 4.896 & 4.901 & 4.896 & 8.8 & $\nu$ \\
\hline 47 & 1997Q3 & 2.072 & 2.127 & 2.115 & 2.108 & 2.093 & 2.088 & 2.099 & 2.094 & 2.098 & 2.094 & 5.5 & $\checkmark$ \\
\hline 48 & 1997Q4 & -1.796 & -1.773 & -1.813 & -1.791 & -1.786 & -1.794 & -1.790 & -1.785 & -1.790 & -1.786 & 4.0 & $\checkmark$ \\
\hline 49 & 1998Q1 & 2.679 & 2.653 & 2.687 & 2.701 & 2.740 & 2.747 & 2.737 & 2.739 & 2.738 & 2.739 & 9.4 & $\checkmark$ \\
\hline 50 & 1998Q2 & 0.839 & 0.845 & 0.876 & 0.843 & 0.820 & 0.833 & 0.820 & 0.818 & 0.821 & 0.819 & 5.8 & $\checkmark$ \\
\hline 51 & 1998Q3 & 2.469 & 2.353 & 2.336 & 2.316 & 2.286 & 2.271 & 2.288 & 2.286 & 2.287 & 2.286 & 19.8 & $\checkmark$ \\
\hline 52 & 1998Q4 & -7.803 & -7.917 & -8.003 & -7.983 & -7.971 & -7.977 & -7.966 & -7.964 & -7.967 & -7.966 & 20.0 & $\checkmark$ \\
\hline 53 & 1999Q1 & 2.480 & 2.552 & 2.610 & 2.639 & 2.715 & 2.718 & 2.713 & 2.714 & 2.715 & 2.714 & 23.8 & $\checkmark$ \\
\hline 54 & 1999Q2 & 1.225 & 1.337 & 1.439 & 1.408 & 1.367 & 1.368 & 1.362 & 1.361 & 1.364 & 1.363 & 21.4 & $\checkmark$ \\
\hline 55 & 1999Q3 & 3.452 & 3.474 & 3.402 & 3.378 & 3.262 & 3.302 & 3.260 & 3.258 & 3.258 & 3.258 & 21.6 & $\nu$ \\
\hline 56 & 1999Q4 & -3.302 & -3.270 & -3.379 & -3.320 & -3.343 & -3.294 & -3.328 & -3.328 & -3.333 & -3.332 & 10.9 & $\checkmark$ \\
\hline 57 & 2000Q1 & 3.032 & 3.045 & 2.774 & 2.756 & 2.858 & 2.831 & 2.858 & 2.859 & 2.861 & 2.861 & 28.9 & $\checkmark$ \\
\hline 58 & 2000Q2 & 2.632 & 2.636 & 2.646 & 2.682 & 2.901 & 2.840 & 2.868 & 2.870 & 2.876 & 2.875 & 26.9 & $\checkmark$ \\
\hline 59 & 2000Q3 & -1.007 & -1.027 & -0.799 & -0.670 & -0.565 & -0.595 & -0.576 & -0.576 & -0.576 & -0.576 & 46.2 & $\boldsymbol{x}$ \\
\hline 60 & 2000Q4 & -1.250 & -1.162 & -1.029 & -1.012 & -1.133 & -1.124 & -1.091 & -1.093 & -1.105 & -1.104 & 23.8 & $\checkmark$ \\
\hline 61 & 2001Q1 & NA & 4.168 & 4.110 & 3.891 & 3.764 & 3.796 & 3.772 & 3.771 & 3.776 & 3.775 & 40.4 & $\boldsymbol{x}$ \\
\hline 62 & 2001Q2 & NA & 1.552 & 1.748 & 1.615 & 1.501 & 1.498 & 1.456 & 1.458 & 1.466 & 1.465 & 29.2 & $\checkmark$ \\
\hline 63 & 2001Q3 & NA & -0.080 & -0.155 & -0.017 & -0.125 & -0.138 & -0.121 & -0.120 & -0.125 & -0.125 & 13.8 & $\checkmark$ \\
\hline 64 & 2001Q4 & NA & -3.131 & -3.317 & -3.095 & -2.913 & -2.955 & -2.872 & -2.881 & -2.882 & -2.877 & 44.5 & $\boldsymbol{x}$ \\
\hline 65 & 2002Q1 & NA & NA & 3.136 & 3.048 & 2.936 & 2.905 & 2.963 & 2.954 & 2.957 & 2.962 & 23.1 & $\checkmark$ \\
\hline 66 & 2002Q2 & NA & NA & 1.020 & 0.816 & 0.503 & 0.457 & 0.438 & 0.438 & 0.429 & 0.421 & 59.9 & $\boldsymbol{x}$ \\
\hline 67 & 2002Q3 & NA & NA & 2.535 & 2.760 & 2.903 & 2.895 & 2.839 & 2.848 & 2.841 & 2.831 & 36.8 & $\boldsymbol{*}$ \\
\hline 68 & 2002Q4 & NA & NA & -3.864 & -3.744 & -3.310 & -3.226 & -3.252 & -3.254 & -3.242 & -3.238 & 63.8 & $\boldsymbol{x}$ \\
\hline 69 & 2003Q1 & NA & NA & NA & 3.890 & 4.048 & 4.159 & 4.206 & 4.196 & 4.175 & 4.194 & 31.6 & $\checkmark$ \\
\hline 70 & 2003Q2 & NA & NA & NA & 1.307 & 1.067 & 1.189 & 1.241 & 1.264 & 1.232 & 1.242 & 24.0 & $\checkmark$ \\
\hline 71 & 2003Q3 & NA & NA & NA & 0.735 & 0.274 & 0.277 & 0.312 & 0.333 & 0.329 & 0.317 & 46.1 & $\boldsymbol{x}$ \\
\hline 72 & 2003Q4 & NA & NA & NA & -1.857 & -1.932 & -1.962 & -1.995 & -2.017 & -1.980 & -1.984 & 16.0 & $\checkmark$ \\
\hline 73 & 2004Q1 & NA & NA & NA & NA & 4.109 & 4.030 & 3.938 & 3.881 & 3.941 & 3.958 & 22.8 & $\checkmark$ \\
\hline 74 & 2004Q2 & NA & NA & NA & NA & 2.426 & 2.333 & 2.141 & 2.207 & 2.191 & 2.161 & 28.5 & $\checkmark$ \\
\hline 75 & 2004Q3 & NA & NA & NA & NA & 3.436 & 3.325 & 3.449 & 3.488 & 3.413 & 3.379 & 16.3 & $\checkmark$ \\
\hline 76 & 2004Q4 & NA & NA & NA & NA & -2.879 & -2.690 & -2.505 & -2.537 & -2.539 & -2.491 & 38.8 & $\boldsymbol{x}$ \\
\hline 77 & 2005Q1 & NA & NA & NA & NA & NA & 3.674 & 3.623 & 3.512 & 3.666 & 3.726 & 21.4 & $\checkmark$ \\
\hline 78 & 2005Q2 & NA & NA & NA & NA & NA & 1.604 & 1.247 & 1.369 & 1.330 & 1.224 & 38.0 & $\boldsymbol{x}$ \\
\hline 79 & 2005Q3 & NA & NA & NA & NA & NA & 2.861 & 3.075 & 3.141 & 2.935 & 2.866 & 28.0 & $\checkmark$ \\
\hline 80 & 2005Q4 & NA & NA & NA & NA & NA & -4.234 & -3.961 & -4.004 & -3.994 & -3.861 & 37.3 & $\boldsymbol{x}$ \\
\hline 81 & 2006Q1 & NA & $\mathrm{NA}$ & NA & NA & NA & NA & 4.814 & 4.667 & 4.986 & 5.099 & 43.2 & $\boldsymbol{x}$ \\
\hline 82 & 2006Q2 & NA & NA & NA & NA & NA & NA & 1.467 & 1.327 & 1.393 & 1.272 & 19.5 & $\nu$ \\
\hline 83 & 2006Q3 & NA & NA & NA & NA & NA & NA & -0.649 & -0.430 & -0.659 & -0.596 & 22.9 & $\checkmark$ \\
\hline 84 & 2006Q4 & NA & NA & NA & NA & NA & NA & 1.173 & 1.523 & 1.540 & 1.760 & 58.7 & $\boldsymbol{x}$ \\
\hline 85 & 2007Q1 & NA & NA & NA & NA & NA & NA & NA & 2.118 & 2.463 & 2.479 & 36.1 & $\boldsymbol{x}$ \\
\hline 86 & 2007Q2 & NA & NA & NA & NA & NA & NA & NA & 1.253 & 1.354 & 1.036 & 31.8 & $\checkmark$ \\
\hline 87 & 2007Q3 & NA & NA & NA & NA & NA & NA & NA & 0.322 & -0.173 & -0.482 & 80.4 & $\boldsymbol{x}$ \\
\hline \multirow[t]{3}{*}{88} & 2007Q4 & NA & NA & NA & NA & NA & NA & NA & -0.491 & -0.184 & -0.270 & 30.7 & $\checkmark$ \\
\hline & Median & - & - & - & - & - & - & - & - & - & - & 23.80 & - \\
\hline & Mean & - & - & - & - & - & - & - & - & - & - & 26.28 & $27 \%$ \\
\hline
\end{tabular}

Source: Author's elaboration. 
Table 3: Sliding spans of trend-cycle series (log-diff), Aggregation 3

\begin{tabular}{|c|c|c|c|c|c|c|c|c|c|c|c|c|c|}
\hline No. Obs. & Date & $\mathrm{S}(1)$ & $\mathrm{S}(2)$ & $\mathrm{S}(3)$ & $\mathrm{S}(4)$ & $\mathrm{S}(5)$ & $\mathrm{S}(6)$ & $\mathrm{S}(7)$ & $\mathrm{S}(8)$ & $\mathrm{S}(9)$ & $\mathrm{S}(10)$ & $\mathrm{S}^{\max }$ & Score \\
\hline 40 & 1995Q4 & 2.105 & 2.678 & 0.665 & 0.951 & -0.091 & -0.079 & 0.993 & 0.395 & 0.009 & 1.790 & 276.9 & $x$ \\
\hline 41 & 1996Q1 & 3.323 & 2.942 & 2.604 & 3.280 & 3.386 & 3.386 & 3.322 & 3.301 & 3.400 & 3.352 & 79.6 & $\boldsymbol{x}$ \\
\hline 42 & 1996Q2 & 2.343 & 1.205 & 2.521 & 3.107 & 2.782 & 2.772 & 3.056 & 2.225 & 2.667 & 2.032 & 190.2 & $\boldsymbol{x}$ \\
\hline 43 & 1996Q3 & -2.298 & -4.438 & 1.593 & 1.130 & 1.216 & 1.215 & 1.114 & 1.311 & 1.130 & -2.949 & 603.1 & $\boldsymbol{x}$ \\
\hline 44 & 1996Q4 & 6.402 & 10.893 & 1.408 & 0.593 & 1.033 & 1.049 & 0.619 & 1.532 & 1.089 & 7.899 & 1030.0 & $\boldsymbol{x}$ \\
\hline 45 & 1997Q1 & -1.821 & -3.679 & -3.051 & -2.051 & -2.742 & -2.746 & -2.056 & -2.626 & -2.350 & -2.626 & 185.8 & $\boldsymbol{x}$ \\
\hline 46 & 1997Q2 & 1.807 & 1.513 & 11.251 & 7.758 & 8.363 & 8.346 & 7.729 & 7.395 & 7.716 & 1.683 & 973.8 & $\boldsymbol{x}$ \\
\hline 47 & 1997Q3 & 3.092 & 2.826 & -3.172 & -0.082 & -0.584 & -0.584 & -0.116 & 0.049 & -0.217 & 3.238 & 641.0 & $\boldsymbol{x}$ \\
\hline 48 & 1997Q4 & 1.628 & 1.879 & -0.168 & 1.002 & 1.069 & 1.055 & 0.940 & 1.370 & 1.127 & 1.950 & 211.8 & $\boldsymbol{x}$ \\
\hline 49 & 1998Q1 & 0.744 & 0.903 & 1.097 & 0.723 & 0.825 & 0.791 & 0.799 & 0.450 & 0.715 & 0.698 & 64.7 & $\boldsymbol{x}$ \\
\hline 50 & 1998Q2 & 0.306 & 0.252 & 1.948 & 1.454 & 1.572 & 1.588 & 1.512 & 1.309 & 1.488 & -0.077 & 202.5 & $\boldsymbol{x}$ \\
\hline 51 & 1998Q3 & -0.453 & -0.267 & -0.279 & -0.524 & -0.601 & -0.556 & -0.582 & -0.183 & -0.511 & -0.55 & 41.8 & $\boldsymbol{x}$ \\
\hline 52 & 1998Q4 & -2.267 & -1.690 & -3.212 & -3.353 & -3.468 & -3.429 & -3.493 & -3.437 & -3.388 & -1.997 & 180.3 & $\boldsymbol{x}$ \\
\hline 53 & 1999Q1 & -0.983 & -1.291 & -1.205 & -0.907 & -0.735 & -0.781 & -0.749 & -1.053 & -0.855 & -0.844 & 55.6 & $\boldsymbol{x}$ \\
\hline 54 & 1999Q2 & 0.868 & 0.444 & 1.731 & 1.818 & 1.870 & 1.824 & 1.936 & 1.996 & 1.873 & 0.659 & 155.2 & $\boldsymbol{x}$ \\
\hline 55 & 1999Q3 & 2.243 & 2.478 & 2.297 & 2.038 & 1.903 & 1.957 & 1.926 & 2.176 & 2.004 & 1.991 & 57.5 & $\boldsymbol{x}$ \\
\hline 56 & 1999Q4 & 1.735 & 2.068 & 1.252 & 1.208 & 1.165 & 1.216 & 0.982 & 0.720 & 1.044 & 2.040 & 134.8 & $\boldsymbol{x}$ \\
\hline 57 & 2000Q1 & 0.886 & 0.682 & 0.065 & 0.620 & 0.146 & 0.214 & 0.550 & 0.656 & 0.542 & 0.641 & 82.1 & $\boldsymbol{x}$ \\
\hline 58 & 2000Q2 & 0.117 & 0.029 & 0.255 & 0.693 & 0.488 & 0.469 & 0.926 & 1.265 & 0.906 & 0.706 & 123.6 & $\boldsymbol{x}$ \\
\hline 59 & 2000Q3 & 0.935 & 0.910 & 1.267 & 0.874 & 1.367 & 1.341 & 1.100 & 0.984 & 1.133 & 1.257 & 49.3 & $\boldsymbol{x}$ \\
\hline 60 & 2000Q4 & 1.207 & 1.426 & 1.695 & 1.263 & 1.552 & 1.602 & 0.869 & 0.513 & 0.912 & 1.150 & 118.2 & $\boldsymbol{x}$ \\
\hline 61 & 2001Q1 & NA & 1.720 & 1.805 & 1.685 & 1.750 & 1.685 & 1.872 & 1.913 & 1.732 & 1.318 & 59.5 & $\boldsymbol{x}$ \\
\hline 62 & 2001Q2 & NA & 0.541 & 0.967 & 0.924 & 1.098 & 0.780 & 1.353 & 1.497 & 1.256 & 0.604 & 95.6 & $\boldsymbol{x}$ \\
\hline 63 & 2001Q3 & NA & 0.279 & -0.139 & 0.058 & -0.447 & -0.316 & -0.368 & -0.491 & -0.254 & -0.360 & 77.0 & $\boldsymbol{x}$ \\
\hline 64 & 2001Q4 & $\mathrm{NA}$ & 0.011 & -0.677 & -0.488 & -0.670 & -0.178 & -0.650 & -0.409 & -0.402 & 0.018 & 69.5 & $\boldsymbol{x}$ \\
\hline 65 & 2002Q1 & NA & NA & 0.581 & -1.786 & 0.751 & 0.599 & -1.602 & -1.700 & -1.816 & 0.631 & 256.7 & $\boldsymbol{x}$ \\
\hline 66 & 2002Q2 & NA & NA & 1.233 & 5.579 & 1.218 & 0.491 & 5.305 & 5.197 & 5.109 & 0.449 & 513.0 & $\boldsymbol{x}$ \\
\hline 67 & 2002Q3 & NA & NA & 1.367 & -0.846 & 1.314 & 1.330 & -1.217 & -1.363 & -1.072 & 1.141 & 273.0 & $\boldsymbol{x}$ \\
\hline 68 & 2002Q4 & NA & NA & 0.234 & 0.024 & 0.085 & 1.453 & 0.127 & 0.413 & 0.204 & 1.707 & 168.3 & $\boldsymbol{x}$ \\
\hline 69 & 2003Q1 & NA & NA & $\mathrm{NA}$ & 1.060 & -3.010 & -2.397 & 0.953 & 1.590 & 1.539 & -2.475 & 460.0 & $\boldsymbol{x}$ \\
\hline 70 & 2003Q2 & NA & NA & NA & 1.822 & 8.774 & 6.776 & 2.174 & 2.715 & 2.733 & 7.285 & 695.2 & $\boldsymbol{x}$ \\
\hline 71 & 2003Q3 & NA & NA & NA & 1.358 & -2.717 & -2.453 & 1.079 & 0.577 & 0.705 & -3.001 & 435.9 & $\boldsymbol{x}$ \\
\hline 72 & 2003Q4 & NA & NA & NA & 0.112 & 0.238 & 1.077 & -0.256 & -0.557 & -0.982 & 0.843 & 205.9 & $\boldsymbol{x}$ \\
\hline 73 & 2004Q1 & NA & NA & NA & NA & 2.588 & 2.132 & -1.221 & -2.373 & -1.600 & 2.086 & 496.1 & $\boldsymbol{x}$ \\
\hline 74 & 2004Q2 & NA & NA & NA & NA & 3.398 & 1.978 & 9.224 & 11.578 & 9.348 & 1.793 & 978.5 & $\boldsymbol{x}$ \\
\hline 75 & 2004Q3 & NA & NA & NA & NA & 2.001 & -2.170 & -0.904 & -2.229 & -0.510 & -2.470 & 447.1 & $\boldsymbol{x}$ \\
\hline 76 & 2004Q4 & NA & NA & NA & NA & -0.953 & 6.942 & 0.079 & -0.840 & 0.117 & 10.267 & 1122.0 & $\boldsymbol{x}$ \\
\hline 77 & 2005Q1 & NA & NA & NA & NA & NA & -1.481 & -2.037 & 0.902 & -2.762 & -2.862 & 376.4 & $\boldsymbol{x}$ \\
\hline 78 & 2005Q2 & NA & NA & NA & NA & NA & 2.408 & 8.958 & 3.661 & 9.344 & 1.360 & 798.4 & $\boldsymbol{x}$ \\
\hline 79 & 2005Q3 & NA & NA & NA & NA & NA & 2.097 & -1.952 & 2.045 & -1.534 & 1.508 & 404.9 & $\boldsymbol{x}$ \\
\hline 80 & 2005Q4 & NA & NA & NA & NA & NA & 0.477 & -0.957 & -0.766 & -1.323 & 0.261 & 180.0 & $\boldsymbol{*}$ \\
\hline 81 & 2006Q1 & NA & NA & NA & NA & NA & NA & 0.610 & -3.318 & 1.251 & 1.584 & 490.2 & $\boldsymbol{x}$ \\
\hline 82 & 2006Q2 & NA & NA & NA & NA & $\mathrm{NA}$ & NA & 2.629 & 9.603 & 3.270 & 1.408 & 819.5 & $\boldsymbol{x}$ \\
\hline 83 & 2006Q3 & NA & NA & NA & NA & $\mathrm{NA}$ & NA & 2.382 & -2.632 & 1.626 & 0.716 & 501.4 & $\boldsymbol{x}$ \\
\hline 84 & 2006Q4 & NA & NA & NA & NA & NA & NA & -0.104 & -0.104 & -0.405 & 1.220 & 162.5 & $\boldsymbol{x}$ \\
\hline 85 & 2007Q1 & NA & NA & NA & NA & NA & NA & NA & 1.788 & -2.383 & -2.302 & 417.1 & $\boldsymbol{x}$ \\
\hline 86 & 2007Q2 & NA & NA & NA & NA & NA & NA & $\mathrm{NA}$ & 1.907 & 8.833 & 7.986 & 692.6 & $\boldsymbol{x}$ \\
\hline 87 & 2007Q3 & NA & NA & NA & NA & NA & NA & $\mathrm{NA}$ & 1.360 & -3.001 & -3.740 & 510.0 & $\boldsymbol{x}$ \\
\hline \multirow[t]{3}{*}{88} & 2007Q4 & NA & NA & NA & NA & NA & NA & NA & -0.477 & 1.614 & 1.373 & 209.1 & $\boldsymbol{x}$ \\
\hline & Median & - & - & - & - & - & - & - & - & - & - & 211.80 & - \\
\hline & Mean & - & - & - & - & - & - & - & - & - & - & 354.56 & $100 \%$ \\
\hline
\end{tabular}

Source: Author's elaboration. 
Table 4: Sliding spans of trend-cycle series (log-diff), Aggregation 4

\begin{tabular}{|c|c|c|c|c|c|c|c|c|c|c|c|c|c|}
\hline No. Obs. & Date & $\mathrm{S}(1)$ & $\mathrm{S}(2)$ & $\mathrm{S}(3)$ & $\mathrm{S}(4)$ & $\mathrm{S}(5)$ & $\mathrm{S}(6)$ & $\mathrm{S}(7)$ & $\mathrm{S}(8)$ & $\mathrm{S}(9)$ & $\mathrm{S}(10)$ & $\mathrm{s}^{\max }$ & Score \\
\hline 40 & 1995Q4 & 1.448 & 1.453 & 1.452 & 1.453 & 1.453 & 1.476 & 1.476 & 1.476 & 1.476 & 1.476 & 2.8 & $v$ \\
\hline 41 & 1996Q1 & 1.893 & 1.892 & 1.893 & 1.893 & 1.896 & 1.889 & 1.889 & 1.889 & 1.889 & 1.889 & 0.7 & $\checkmark$ \\
\hline 42 & 1996Q2 & 1.496 & 1.504 & 1.501 & 1.499 & 1.501 & 1.484 & 1.483 & 1.483 & 1.483 & 1.483 & 2.1 & $\checkmark$ \\
\hline 43 & 1996Q3 & 1.259 & 1.260 & 1.261 & 1.259 & 1.255 & 1.253 & 1.253 & 1.252 & 1.252 & 1.252 & 0.9 & $\checkmark$ \\
\hline 44 & 1996Q4 & 1.269 & 1.254 & 1.257 & 1.259 & 1.257 & 1.290 & 1.290 & 1.290 & 1.290 & 1.290 & 3.6 & $\nu$ \\
\hline 45 & 1997Q1 & 1.455 & 1.436 & 1.436 & 1.438 & 1.443 & 1.426 & 1.427 & 1.427 & 1.427 & 1.427 & 2.9 & $\checkmark$ \\
\hline 46 & 1997Q2 & 1.847 & 1.866 & 1.860 & 1.859 & 1.861 & 1.842 & 1.842 & 1.842 & 1.842 & 1.842 & 2.4 & $\nu$ \\
\hline 47 & 1997Q3 & 2.437 & 2.451 & 2.452 & 2.453 & 2.442 & 2.450 & 2.451 & 2.452 & 2.452 & 2.452 & 1.6 & $\checkmark$ \\
\hline 48 & 1997Q4 & 1.760 & 1.759 & 1.764 & 1.767 & 1.763 & 1.786 & 1.786 & 1.786 & 1.786 & 1.786 & 2.7 & $\checkmark$ \\
\hline 49 & 1998Q1 & 1.151 & 1.129 & 1.131 & 1.127 & 1.139 & 1.113 & 1.111 & 1.110 & 1.110 & 1.111 & 4.1 & $\checkmark$ \\
\hline 50 & 1998Q2 & 0.348 & 0.314 & 0.312 & 0.314 & 0.321 & 0.324 & 0.325 & 0.325 & 0.325 & 0.325 & 3.6 & $\checkmark$ \\
\hline 51 & 1998Q3 & -1.099 & -1.053 & -1.064 & -1.054 & -1.038 & -1.021 & -1.018 & -1.018 & -1.018 & -1.018 & 8.1 & $\checkmark$ \\
\hline 52 & 1998Q4 & -2.049 & -2.019 & -2.034 & -2.032 & -2.020 & -2.021 & -2.019 & -2.020 & -2.019 & -2.019 & 3.0 & $\checkmark$ \\
\hline 53 & 1999Q1 & -1.060 & -1.156 & -1.147 & -1.162 & -1.167 & -1.187 & -1.189 & -1.190 & -1.189 & -1.189 & 13.0 & $\checkmark$ \\
\hline 54 & 1999Q2 & 0.743 & 0.753 & 0.759 & 0.754 & 0.721 & 0.731 & 0.730 & 0.732 & 0.731 & 0.731 & 3.8 & $\checkmark$ \\
\hline 55 & 1999Q3 & 2.065 & 2.183 & 2.193 & 2.206 & 2.185 & 2.191 & 2.194 & 2.196 & 2.194 & 2.194 & 14.1 & $\nu$ \\
\hline 56 & 1999Q4 & 2.093 & 2.100 & 2.103 & 2.106 & 2.125 & 2.106 & 2.106 & 2.105 & 2.106 & 2.106 & 3.2 & $\checkmark$ \\
\hline 57 & 2000Q1 & 0.677 & 0.526 & 0.519 & 0.528 & 0.549 & 0.559 & 0.558 & 0.552 & 0.553 & 0.553 & 15.8 & $\checkmark$ \\
\hline 58 & 2000Q2 & 0.132 & 0.169 & 0.153 & 0.154 & 0.106 & 0.129 & 0.132 & 0.130 & 0.128 & 0.128 & 6.3 & $\checkmark$ \\
\hline 59 & 2000Q3 & 0.930 & 1.065 & 1.100 & 1.108 & 1.076 & 1.063 & 1.069 & 1.077 & 1.072 & 1.072 & 17.8 & $\checkmark$ \\
\hline 60 & 2000Q4 & 1.380 & 1.394 & 1.392 & 1.401 & 1.455 & 1.424 & 1.428 & 1.432 & 1.436 & 1.437 & 7.5 & $\checkmark$ \\
\hline 61 & 2001Q1 & NA & 1.150 & 1.075 & 1.050 & 1.110 & 1.131 & 1.113 & 1.108 & 1.116 & 1.116 & 10.0 & $\checkmark$ \\
\hline 62 & 2001Q2 & NA & 0.584 & 0.742 & 0.698 & 0.711 & 0.737 & 0.725 & 0.710 & 0.706 & 0.705 & 15.8 & $\checkmark$ \\
\hline 63 & 2001Q3 & NA & 0.112 & 0.306 & 0.364 & 0.327 & 0.329 & 0.351 & 0.351 & 0.337 & 0.337 & 25.2 & $\checkmark$ \\
\hline 64 & 2001Q4 & NA & 0.288 & 0.156 & 0.194 & 0.213 & 0.188 & 0.205 & 0.220 & 0.226 & 0.229 & 13.2 & $\checkmark$ \\
\hline 65 & 2002Q1 & NA & NA & 0.419 & 0.339 & 0.413 & 0.404 & 0.362 & 0.358 & 0.374 & 0.371 & 8.0 & $\checkmark$ \\
\hline 66 & 2002Q2 & NA & NA & 0.576 & 0.508 & 0.397 & 0.393 & 0.363 & 0.366 & 0.362 & 0.361 & 21.5 & $\checkmark$ \\
\hline 67 & $2002 \mathrm{Q} 3$ & NA & $\mathrm{NA}$ & 0.763 & 0.884 & 0.749 & 0.784 & 0.814 & 0.842 & 0.822 & 0.825 & 13.5 & $\checkmark$ \\
\hline 68 & 2002Q4 & NA & NA & 1.174 & 1.251 & 1.407 & 1.424 & 1.458 & 1.467 & 1.474 & 1.480 & 30.6 & $\checkmark$ \\
\hline 69 & 2003Q1 & NA & NA & NA & 1.161 & 1.366 & 1.326 & 1.266 & 1.215 & 1.238 & 1.230 & 20.5 & $\checkmark$ \\
\hline 70 & 2003Q2 & NA & NA & NA & 0.847 & 0.674 & 0.639 & 0.635 & 0.621 & 0.611 & 0.607 & 24.0 & $\checkmark$ \\
\hline 71 & 2003Q3 & NA & NA & NA & 0.751 & 0.290 & 0.334 & 0.424 & 0.453 & 0.439 & 0.445 & 46.1 & $\boldsymbol{x}$ \\
\hline 72 & 2003Q4 & NA & NA & NA & 1.084 & 0.922 & 0.982 & 1.009 & 1.111 & 1.046 & 1.051 & 18.9 & $\checkmark$ \\
\hline 73 & 2004Q1 & NA & $\mathrm{NA}$ & NA & $\mathrm{NA}$ & 1.714 & 1.680 & 1.742 & 1.767 & 1.710 & 1.725 & 8.7 & $\checkmark$ \\
\hline 74 & 2004Q2 & NA & NA & NA & NA & 2.184 & 2.121 & 2.234 & 2.183 & 2.235 & 2.230 & 11.4 & $\checkmark$ \\
\hline 75 & 2004Q3 & NA & NA & NA & NA & 1.969 & 2.019 & 2.010 & 1.997 & 2.075 & 2.055 & 10.6 & $\checkmark$ \\
\hline 76 & 2004Q4 & NA & NA & NA & NA & 1.310 & 1.468 & 1.323 & 1.243 & 1.264 & 1.267 & 22.5 & $\checkmark$ \\
\hline 77 & 2005Q1 & NA & NA & NA & NA & NA & 1.124 & 0.981 & 0.860 & 0.888 & 0.876 & 26.4 & $\checkmark$ \\
\hline 78 & 2005Q2 & NA & NA & NA & NA & NA & 1.316 & 1.358 & 1.486 & 1.441 & 1.424 & 17.0 & $\checkmark$ \\
\hline 79 & 2005Q3 & NA & NA & NA & NA & NA & 1.147 & 1.336 & 1.534 & 1.460 & 1.477 & 38.7 & $\boldsymbol{x}$ \\
\hline 80 & 2005Q4 & NA & NA & NA & NA & NA & 1.000 & 0.957 & 0.912 & 0.960 & 0.989 & 8.8 & $\checkmark$ \\
\hline 81 & 2006Q1 & NA & NA & NA & NA & NA & NA & 1.107 & 0.870 & 0.957 & 0.971 & 23.7 & $\checkmark$ \\
\hline 82 & 2006Q2 & NA & NA & NA & NA & NA & NA & 1.010 & 0.962 & 0.885 & 0.880 & 13.0 & $\nu$ \\
\hline 83 & 2006Q3 & NA & NA & NA & NA & NA & NA & 0.930 & 1.113 & 1.019 & 0.978 & 18.3 & $\checkmark$ \\
\hline 84 & 2006Q4 & NA & NA & NA & NA & NA & NA & 1.501 & 1.616 & 1.711 & 1.695 & 21.0 & $\checkmark$ \\
\hline 85 & 2007Q1 & NA & NA & NA & NA & NA & NA & NA & 1.561 & 1.596 & 1.731 & 17.0 & $\checkmark$ \\
\hline 86 & 2007Q2 & NA & NA & NA & NA & NA & NA & $\mathrm{NA}$ & 0.709 & 0.605 & 0.692 & 10.4 & $\checkmark$ \\
\hline 87 & 2007Q3 & NA & NA & NA & NA & NA & NA & NA & 0.485 & 0.467 & 0.332 & 15.3 & $\checkmark$ \\
\hline \multirow[t]{3}{*}{88} & 2007Q4 & NA & NA & NA & NA & NA & NA & NA & 1.117 & 1.225 & 1.148 & 10.8 & 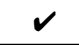 \\
\hline & Median & - & - & - & - & - & - & - & - & - & - & 11.40 & - \\
\hline & Mean & - & - & - & - & - & - & - & - & - & - & 13.08 & $5 \%$ \\
\hline
\end{tabular}

Source: Author's elaboration. 
Table 5: Sliding spans of trend-cycle series (log-diff), Aggregation 5

\begin{tabular}{|c|c|c|c|c|c|c|c|c|c|c|c|c|c|}
\hline No. Obs. & Date & $\mathrm{S}(1)$ & $\mathrm{S}(2)$ & $\mathrm{S}(3)$ & $\mathrm{S}(4)$ & $\mathrm{S}(5)$ & $\mathrm{S}(6)$ & $\mathrm{S}(7)$ & $\mathrm{S}(8)$ & $\mathrm{S}(9)$ & $\mathrm{S}(10)$ & $\mathrm{s}^{\max }$ & Score \\
\hline 40 & 1995Q4 & 1.782 & 1.790 & 1.732 & 1.789 & 1.735 & 1.627 & 1.627 & 1.626 & 1.624 & 1.785 & 16.6 & $\checkmark$ \\
\hline 41 & 1996Q1 & 1.813 & 1.792 & 1.801 & 1.821 & 1.805 & 2.165 & 2.164 & 2.163 & 2.163 & 1.781 & 38.4 & $\boldsymbol{x}$ \\
\hline 42 & 1996Q2 & 1.100 & 1.077 & 1.155 & 1.097 & 1.157 & 0.917 & 0.918 & 0.919 & 0.923 & 1.112 & 24.0 & $\checkmark$ \\
\hline 43 & 1996Q3 & 1.030 & 1.041 & 1.042 & 1.031 & 1.036 & 1.006 & 1.008 & 1.008 & 1.006 & 1.063 & 5.7 & $\checkmark$ \\
\hline 44 & 1996Q4 & 1.484 & 1.493 & 1.449 & 1.475 & 1.442 & 1.489 & 1.489 & 1.489 & 1.482 & 1.470 & 5.1 & $\nu$ \\
\hline 45 & 1997Q1 & 1.683 & 1.680 & 1.662 & 1.657 & 1.661 & 1.674 & 1.673 & 1.673 & 1.675 & 1.646 & 3.7 & $\checkmark$ \\
\hline 46 & 1997Q2 & 1.838 & 1.842 & 1.883 & 1.848 & 1.889 & 1.857 & 1.857 & 1.857 & 1.865 & 1.866 & 5.1 & $\nu$ \\
\hline 47 & 1997Q3 & 2.211 & 2.220 & 2.234 & 2.249 & 2.236 & 2.221 & 2.222 & 2.222 & 2.220 & 2.238 & 3.8 & $\checkmark$ \\
\hline 48 & 1997Q4 & 1.686 & 1.693 & 1.661 & 1.689 & 1.640 & 1.664 & 1.666 & 1.666 & 1.654 & 1.656 & 5.3 & $\checkmark$ \\
\hline 49 & 1998Q1 & 1.011 & 0.973 & 0.943 & 0.965 & 0.942 & 0.978 & 0.978 & 0.977 & 0.970 & 0.967 & 6.9 & $\checkmark$ \\
\hline 50 & 1998Q2 & 0.253 & 0.206 & 0.264 & 0.207 & 0.276 & 0.251 & 0.250 & 0.250 & 0.272 & 0.255 & 7.0 & $\checkmark$ \\
\hline 51 & 1998Q3 & -0.998 & -0.989 & -0.758 & -1.001 & -0.750 & -1.002 & -1.002 & -0.999 & -0.926 & -0.923 & 25.2 & $v$ \\
\hline 52 & 1998Q4 & -1.508 & -1.492 & -2.016 & -1.472 & -2.003 & -1.529 & -1.528 & -1.530 & -1.673 & -1.652 & 54.4 & $\boldsymbol{x}$ \\
\hline 53 & 1999Q1 & -0.861 & -0.894 & -0.649 & -0.881 & -0.646 & -0.867 & -0.869 & -0.869 & -0.812 & -0.801 & 24.8 & $\checkmark$ \\
\hline 54 & 1999Q2 & 0.684 & 0.748 & 0.809 & 0.734 & 0.795 & 0.770 & 0.768 & 0.767 & 0.781 & 0.739 & 12.5 & $\checkmark$ \\
\hline 55 & 1999Q3 & 1.758 & 1.857 & 1.860 & 1.883 & 1.878 & 1.857 & 1.860 & 1.861 & 1.857 & 1.859 & 12.5 & $\nu$ \\
\hline 56 & 1999Q4 & 1.991 & 2.009 & 1.934 & 1.969 & 1.937 & 1.924 & 1.926 & 1.927 & 1.920 & 1.952 & 8.9 & $\checkmark$ \\
\hline 57 & 2000Q1 & 0.855 & 0.729 & 0.711 & 0.645 & 0.661 & 0.693 & 0.690 & 0.687 & 0.687 & 0.702 & 21.0 & $\checkmark$ \\
\hline 58 & 2000Q2 & 0.260 & 0.214 & 0.330 & 0.298 & 0.344 & 0.347 & 0.346 & 0.344 & 0.354 & 0.329 & 14.0 & $\checkmark$ \\
\hline 59 & 2000Q3 & 0.801 & 0.935 & 1.005 & 0.978 & 1.075 & 1.046 & 1.053 & 1.057 & 1.055 & 0.889 & 27.4 & $\checkmark$ \\
\hline 60 & 2000Q4 & 1.257 & 1.461 & 1.340 & 1.544 & 1.332 & 1.321 & 1.322 & 1.327 & 1.320 & 1.626 & 36.9 & $\boldsymbol{*}$ \\
\hline 61 & 2001Q1 & NA & 1.153 & 1.064 & 0.918 & 0.983 & 0.975 & 0.968 & 0.963 & 0.965 & 0.793 & 36.0 & $\boldsymbol{x}$ \\
\hline 62 & 2001Q2 & NA & 0.554 & 0.654 & 0.658 & 0.584 & 0.560 & 0.559 & 0.555 & 0.543 & 0.533 & 12.5 & $\checkmark$ \\
\hline 63 & 2001Q3 & NA & -0.008 & 0.324 & 0.409 & 0.261 & 0.376 & 0.393 & 0.398 & 0.385 & 0.429 & 43.7 & $\boldsymbol{x}$ \\
\hline 64 & 2001Q4 & NA & 0.601 & 0.230 & 0.173 & 0.451 & 0.232 & 0.233 & 0.246 & 0.251 & 0.273 & 42.8 & $\boldsymbol{x}$ \\
\hline 65 & 2002Q1 & NA & NA & 0.461 & 0.340 & 0.239 & 0.381 & 0.353 & 0.344 & 0.362 & 0.328 & 22.2 & $\checkmark$ \\
\hline 66 & 2002Q2 & NA & NA & 0.522 & 0.543 & 0.595 & 0.616 & 0.605 & 0.590 & 0.597 & 0.555 & 9.4 & $\checkmark$ \\
\hline 67 & 2002Q3 & NA & NA & 0.685 & 0.924 & 1.019 & 1.019 & 1.054 & 1.065 & 1.063 & 1.146 & 46.1 & $\boldsymbol{*}$ \\
\hline 68 & 2002Q4 & NA & NA & 0.954 & 1.295 & 1.365 & 1.726 & 1.756 & 1.791 & 1.791 & 1.499 & 83.7 & $\boldsymbol{x}$ \\
\hline 69 & 2003Q1 & NA & NA & $\mathrm{NA}$ & 1.268 & 1.394 & 1.094 & 1.058 & 1.024 & 1.017 & 1.219 & 37.7 & $\boldsymbol{x}$ \\
\hline 70 & 2003Q2 & NA & NA & NA & 0.717 & 0.702 & 0.471 & 0.440 & 0.424 & 0.426 & 0.509 & 29.3 & $\checkmark$ \\
\hline 71 & 2003Q3 & NA & NA & NA & 0.527 & 0.212 & 0.203 & 0.209 & 0.213 & 0.212 & 0.167 & 36.0 & $\boldsymbol{x}$ \\
\hline 72 & 2003Q4 & NA & NA & NA & 1.068 & 1.043 & 1.131 & 1.111 & 1.076 & 1.077 & 1.011 & 12.0 & $\checkmark$ \\
\hline 73 & 2004Q1 & NA & $\mathrm{NA}$ & NA & $\mathrm{NA}$ & 1.631 & 1.751 & 1.721 & 1.711 & 1.707 & 1.705 & 12.0 & $\checkmark$ \\
\hline 74 & 2004Q2 & NA & NA & NA & NA & 1.573 & 1.927 & 2.003 & 2.087 & 2.075 & 2.131 & 55.8 & $\boldsymbol{x}$ \\
\hline 75 & 2004Q3 & $\mathrm{NA}$ & NA & NA & NA & 2.582 & 1.862 & 1.961 & 2.030 & 2.034 & 2.066 & 72.0 & $\boldsymbol{x}$ \\
\hline 76 & 2004Q4 & NA & NA & NA & NA & 1.186 & 1.610 & 1.558 & 1.465 & 1.486 & 1.465 & 42.4 & $\boldsymbol{x}$ \\
\hline 77 & 2005Q1 & NA & NA & NA & NA & NA & 1.382 & 1.232 & 1.075 & 1.045 & 1.033 & 34.9 & $\boldsymbol{x}$ \\
\hline 78 & 2005Q2 & NA & NA & NA & NA & NA & 1.282 & 1.380 & 1.419 & 1.376 & 1.396 & 13.7 & $\checkmark$ \\
\hline 79 & 2005Q3 & NA & NA & NA & NA & NA & 1.059 & 1.218 & 1.415 & 1.440 & 1.453 & 39.4 & $\boldsymbol{x}$ \\
\hline 80 & 2005Q4 & NA & NA & NA & NA & NA & 0.981 & 0.950 & 0.957 & 1.032 & 1.018 & 8.2 & $\checkmark$ \\
\hline 81 & 2006Q1 & NA & $\mathrm{NA}$ & NA & NA & NA & NA & 1.164 & 0.895 & 0.902 & 0.942 & 26.9 & $\checkmark$ \\
\hline 82 & 2006Q2 & NA & NA & NA & NA & NA & NA & 0.921 & 0.942 & 0.838 & 0.829 & 11.3 & $\nu$ \\
\hline 83 & 2006Q3 & NA & NA & NA & NA & NA & NA & 0.909 & 1.120 & 1.131 & 1.065 & 22.2 & $\checkmark$ \\
\hline 84 & 2006Q4 & NA & NA & NA & NA & NA & NA & 1.470 & 1.583 & 1.749 & 1.746 & 27.9 & $\checkmark$ \\
\hline 85 & 2007Q1 & NA & NA & NA & NA & NA & NA & NA & 1.575 & 1.601 & 1.678 & 10.3 & $\checkmark$ \\
\hline 86 & 2007Q2 & NA & NA & NA & NA & NA & NA & $\mathrm{NA}$ & 0.625 & 0.458 & 0.466 & 16.7 & $\checkmark$ \\
\hline 87 & 2007Q3 & NA & NA & NA & NA & NA & NA & NA & 0.407 & 0.326 & 0.259 & 14.8 & $\checkmark$ \\
\hline \multirow[t]{3}{*}{88} & 2007Q4 & NA & NA & NA & NA & NA & NA & NA & 1.060 & 1.403 & 1.400 & 34.3 & $x$ \\
\hline & Median & - & - & - & - & - & - & - & - & - & - & 22.20 & - \\
\hline & Mean & - & - & - & - & - & - & - & - & - & - & 24.76 & $34 \%$ \\
\hline
\end{tabular}

Source: Author's elaboration. 
Table 6: Sliding spans of trend-cycle series (log-diff), Aggregation 6

\begin{tabular}{|c|c|c|c|c|c|c|c|c|c|c|c|c|c|}
\hline No. Obs. & Date & $\mathrm{S}(1)$ & $\mathrm{S}(2)$ & $\mathrm{S}(3)$ & $\mathrm{S}(4)$ & $\mathrm{S}(5)$ & $\mathrm{S}(6)$ & $\mathrm{S}(7)$ & $\mathrm{S}(8)$ & $\mathrm{S}(9)$ & $\mathrm{S}(10)$ & $\mathrm{s}^{\max }$ & Score \\
\hline 40 & 1995Q4 & 1.895 & 1.897 & 1.897 & 1.896 & 1.896 & 1.896 & 1.896 & 1.896 & 1.896 & 1.896 & 0.2 & $\checkmark$ \\
\hline 41 & 1996Q1 & 1.939 & 1.939 & 1.938 & 1.938 & 1.938 & 1.940 & 1.939 & 1.939 & 1.939 & 1.939 & 0.2 & $\checkmark$ \\
\hline 42 & 1996Q2 & 1.459 & 1.458 & 1.458 & 1.458 & 1.458 & 1.456 & 1.457 & 1.457 & 1.457 & 1.457 & 0.3 & $\checkmark$ \\
\hline 43 & 1996Q3 & 1.606 & 1.608 & 1.608 & 1.608 & 1.608 & 1.605 & 1.607 & 1.608 & 1.607 & 1.607 & 0.3 & $\checkmark$ \\
\hline 44 & 1996Q4 & 1.157 & 1.152 & 1.154 & 1.158 & 1.160 & 1.167 & 1.160 & 1.160 & 1.160 & 1.160 & 1.5 & $\nu$ \\
\hline 45 & 1997Q1 & 1.110 & 1.098 & 1.100 & 1.104 & 1.107 & 1.114 & 1.107 & 1.106 & 1.107 & 1.107 & 1.6 & $\checkmark$ \\
\hline 46 & 1997Q2 & 2.071 & 2.075 & 2.074 & 2.070 & 2.067 & 2.059 & 2.067 & 2.067 & 2.067 & 2.067 & 1.6 & $\nu$ \\
\hline 47 & 1997Q3 & 2.721 & 2.743 & 2.741 & 2.736 & 2.733 & 2.724 & 2.733 & 2.734 & 2.733 & 2.733 & 2.2 & $\checkmark$ \\
\hline 48 & 1997Q4 & 1.846 & 1.840 & 1.839 & 1.842 & 1.845 & 1.850 & 1.844 & 1.844 & 1.844 & 1.844 & 1.1 & $\checkmark$ \\
\hline 49 & 1998Q1 & 1.074 & 1.032 & 1.032 & 1.034 & 1.038 & 1.047 & 1.039 & 1.037 & 1.038 & 1.038 & 4.2 & $\checkmark$ \\
\hline 50 & 1998Q2 & 0.201 & 0.204 & 0.207 & 0.209 & 0.206 & 0.211 & 0.206 & 0.207 & 0.207 & 0.207 & 1.0 & $\checkmark$ \\
\hline 51 & 1998Q3 & -1.301 & -1.247 & -1.245 & -1.243 & -1.247 & -1.248 & -1.247 & -1.245 & -1.245 & -1.245 & 5.8 & $v$ \\
\hline 52 & 1998Q4 & -2.038 & -2.020 & -2.023 & -2.024 & -2.021 & -2.023 & -2.020 & -2.020 & -2.020 & -2.020 & 1.8 & $\checkmark$ \\
\hline 53 & 1999Q1 & -0.983 & -1.068 & -1.071 & -1.077 & -1.069 & -1.058 & -1.067 & -1.071 & -1.070 & -1.070 & 9.4 & $\checkmark$ \\
\hline 54 & 1999Q2 & 0.827 & 0.831 & 0.838 & 0.829 & 0.818 & 0.796 & 0.815 & 0.816 & 0.815 & 0.814 & 4.2 & $\checkmark$ \\
\hline 55 & 1999Q3 & 2.095 & 2.188 & 2.182 & 2.184 & 2.174 & 2.152 & 2.173 & 2.176 & 2.175 & 2.175 & 9.3 & $\nu$ \\
\hline 56 & 1999Q4 & 2.014 & 2.043 & 2.042 & 2.059 & 2.072 & 2.091 & 2.074 & 2.076 & 2.078 & 2.078 & 7.7 & $\checkmark$ \\
\hline 57 & 2000Q1 & 0.660 & 0.495 & 0.493 & 0.494 & 0.516 & 0.558 & 0.518 & 0.512 & 0.514 & 0.515 & 16.7 & $\checkmark$ \\
\hline 58 & 2000Q2 & 0.294 & 0.307 & 0.322 & 0.287 & 0.259 & 0.214 & 0.253 & 0.249 & 0.246 & 0.246 & 10.8 & $\checkmark$ \\
\hline 59 & 2000Q3 & 0.985 & 1.134 & 1.119 & 1.122 & 1.102 & 1.074 & 1.103 & 1.107 & 1.105 & 1.105 & 14.9 & $\checkmark$ \\
\hline 60 & 2000Q4 & 1.315 & 1.358 & 1.369 & 1.422 & 1.445 & 1.478 & 1.452 & 1.467 & 1.469 & 1.469 & 16.3 & $\checkmark$ \\
\hline 61 & 2001Q1 & NA & 1.090 & 1.075 & 1.069 & 1.106 & 1.134 & 1.102 & 1.093 & 1.095 & 1.096 & 6.5 & $\checkmark$ \\
\hline 62 & 2001Q2 & NA & 0.531 & 0.549 & 0.478 & 0.495 & 0.553 & 0.498 & 0.461 & 0.467 & 0.468 & 9.2 & $\checkmark$ \\
\hline 63 & 2001Q3 & NA & 0.086 & 0.066 & 0.091 & 0.089 & 0.148 & 0.107 & 0.096 & 0.099 & 0.099 & 8.2 & $\checkmark$ \\
\hline 64 & 2001Q4 & NA & 0.273 & 0.303 & 0.408 & 0.399 & 0.360 & 0.405 & 0.461 & 0.458 & 0.457 & 18.8 & $\checkmark$ \\
\hline 65 & 2002Q1 & NA & NA & 0.623 & 0.590 & 0.632 & 0.538 & 0.607 & 0.603 & 0.599 & 0.600 & 9.4 & $\checkmark$ \\
\hline 66 & 2002Q2 & NA & NA & 0.529 & 0.374 & 0.293 & 0.363 & 0.262 & 0.225 & 0.220 & 0.220 & 30.9 & $\checkmark$ \\
\hline 67 & 2002Q3 & NA & NA & 0.862 & 0.894 & 0.792 & 0.863 & 0.812 & 0.818 & 0.811 & 0.808 & 10.2 & $\checkmark$ \\
\hline 68 & 2002Q4 & NA & NA & 1.075 & 1.265 & 1.345 & 1.329 & 1.396 & 1.474 & 1.483 & 1.483 & 40.8 & $\boldsymbol{x}$ \\
\hline 69 & 2003Q1 & NA & NA & NA & 1.180 & 1.361 & 1.274 & 1.318 & 1.269 & 1.277 & 1.280 & 18.1 & $\checkmark$ \\
\hline 70 & 2003Q2 & NA & NA & NA & 1.084 & 0.962 & 0.871 & 0.912 & 0.857 & 0.844 & 0.843 & 24.1 & $\checkmark$ \\
\hline 71 & 2003Q3 & NA & NA & NA & 0.903 & 0.535 & 0.478 & 0.561 & 0.581 & 0.571 & 0.566 & 42.5 & $\boldsymbol{x}$ \\
\hline 72 & 2003Q4 & NA & NA & NA & 0.715 & 0.717 & 0.824 & 0.784 & 0.852 & 0.871 & 0.873 & 15.8 & $\checkmark$ \\
\hline 73 & 2004Q1 & NA & $\mathrm{NA}$ & NA & $\mathrm{NA}$ & 1.562 & 1.615 & 1.476 & 1.640 & 1.651 & 1.652 & 17.6 & $\checkmark$ \\
\hline 74 & 2004Q2 & NA & NA & NA & NA & 2.270 & 2.148 & 2.218 & 2.310 & 2.302 & 2.299 & 16.2 & $\checkmark$ \\
\hline 75 & 2004Q3 & NA & NA & NA & NA & 2.064 & 2.066 & 2.195 & 2.103 & 2.106 & 2.102 & 13.1 & $\checkmark$ \\
\hline 76 & 2004Q4 & NA & NA & NA & NA & 1.463 & 1.583 & 1.512 & 1.215 & 1.213 & 1.207 & 37.6 & $\boldsymbol{x}$ \\
\hline 77 & 2005Q1 & NA & NA & NA & NA & NA & 1.200 & 1.023 & 0.754 & 0.739 & 0.751 & 46.1 & $\boldsymbol{x}$ \\
\hline 78 & 2005Q2 & NA & NA & NA & NA & NA & 1.277 & 1.408 & 1.482 & 1.435 & 1.445 & 20.5 & $\checkmark$ \\
\hline 79 & 2005Q3 & NA & NA & NA & NA & NA & 1.055 & 1.244 & 1.582 & 1.581 & 1.560 & 52.7 & $\boldsymbol{x}$ \\
\hline 80 & 2005Q4 & NA & NA & NA & NA & NA & 0.855 & 0.806 & 0.927 & 1.016 & 0.998 & 21.0 & $\checkmark$ \\
\hline 81 & 2006Q1 & NA & NA & NA & NA & NA & NA & 1.034 & 0.890 & 0.941 & 0.998 & 14.4 & $\checkmark$ \\
\hline 82 & 2006Q2 & NA & NA & NA & NA & NA & NA & 0.966 & 0.982 & 0.844 & 0.863 & 13.8 & $\nu$ \\
\hline 83 & 2006Q3 & NA & NA & NA & NA & NA & NA & 0.977 & 1.086 & 1.036 & 0.961 & 12.5 & $\checkmark$ \\
\hline 84 & 2006Q4 & NA & NA & NA & NA & NA & NA & 1.515 & 1.592 & 1.751 & 1.704 & 23.6 & $\checkmark$ \\
\hline 85 & 2007Q1 & NA & NA & NA & NA & NA & NA & NA & 1.630 & 1.684 & 1.806 & 17.6 & $\checkmark$ \\
\hline 86 & 2007Q2 & NA & NA & NA & NA & NA & NA & NA & 0.724 & 0.611 & 0.695 & 11.3 & $\checkmark$ \\
\hline 87 & 2007Q3 & NA & NA & NA & NA & NA & NA & NA & 0.461 & 0.466 & 0.344 & 12.2 & $\checkmark$ \\
\hline \multirow[t]{3}{*}{88} & 2007Q4 & NA & NA & NA & NA & NA & NA & NA & 1.031 & 1.188 & 1.079 & 15.7 & $\checkmark$ \\
\hline & Median & - & - & - & - & - & - & - & - & - & - & 12.20 & - \\
\hline & Mean & - & - & - & - & - & - & - & - & - & - & 14.11 & $11 \%$ \\
\hline
\end{tabular}

Source: Author's elaboration. 


\section{$2 \quad$ Sliding spans of seasonally adjusted series (log)}

Table 7: Sliding spans of seasonally-adjusted series (log), Aggregation 1

\begin{tabular}{|c|c|c|c|c|c|c|c|c|c|c|c|c|c|}
\hline No. Obs. & Date & $\mathrm{S}(1)$ & $\mathrm{S}(2)$ & $\mathrm{S}(3)$ & $\mathrm{S}(4)$ & $\mathrm{S}(5)$ & $\mathrm{S}(6)$ & $\mathrm{S}(7)$ & $\mathrm{S}(8)$ & $\mathrm{S}(9)$ & $\mathrm{S}(10)$ & $\mathrm{S}^{\max }$ & Score \\
\hline 40 & 1995Q4 & 9464611 & 9463831 & 9462119 & 9459166 & 9453467 & 9452869 & 9452742 & 9407386 & 9450576 & 9455226 & 0.60 & $v$ \\
\hline 41 & 1996Q1 & 9796389 & 9803656 & 9804715 & 9808929 & 9812097 & 9817197 & 9819453 & 9859593 & 9815492 & 9820290 & 0.64 & $\checkmark$ \\
\hline 42 & 1996Q2 & 10221015 & 10215336 & 10216528 & 10212288 & 10212911 & 10211446 & 10206705 & 10228078 & 10215641 & 10224749 & 0.20 & $\checkmark$ \\
\hline 43 & 1996Q3 & 10432711 & 10431819 & 10432208 & 10439907 & 10441859 & 10439095 & 10440192 & 10419642 & 10442445 & 10389966 & 0.50 & $\checkmark$ \\
\hline 44 & 1996Q4 & 10104866 & 10105924 & 10103201 & 10089543 & 10083305 & 10082591 & 10084129 & 10044311 & 10081494 & 10118585 & 0.73 & $\checkmark$ \\
\hline 45 & 1997Q1 & 10437712 & 10443927 & 10442760 & 10451466 & 10454414 & 10459447 & 10462400 & 10506647 & 10456093 & 10485714 & 0.66 & $\checkmark$ \\
\hline 46 & 1997Q2 & 10827366 & 10820596 & 10825722 & 10826698 & 10830078 & 10828487 & 10823453 & 10833837 & 10823445 & 10821987 & 0.12 & $\checkmark$ \\
\hline 47 & 1997Q3 & 11158442 & 11156742 & 11155964 & 11160793 & 11159124 & 11156498 & 11155878 & 11135269 & 11163762 & 11083196 & 0.72 & $\checkmark$ \\
\hline 48 & 1997Q4 & 10903355 & 10907972 & 10905661 & 10888930 & 10883281 & 10882759 & 10885014 & 10862788 & 10874816 & 10948453 & 0.78 & $\checkmark$ \\
\hline 49 & 1998Q1 & 11021469 & 11026746 & 11019043 & 11027244 & 11030499 & 11035096 & 11039446 & 11074863 & 11045492 & 11064854 & 0.50 & $\checkmark$ \\
\hline 50 & 1998Q2 & 11447187 & 11439482 & 11451792 & 11461314 & 11467764 & 11466195 & 11460757 & 11454857 & 11452918 & 11444494 & 0.24 & $\checkmark$ \\
\hline 51 & 1998Q3 & 11543757 & 11541488 & 11540877 & 11535241 & 11528917 & 11526555 & 11524570 & 11516439 & 11536969 & 11454292 & 0.78 & $\checkmark$ \\
\hline 52 & 1998Q4 & 10758546 & 10761844 & 10758721 & 10744428 & 10740112 & 10739410 & 10741913 & 10735330 & 10750092 & 10779633 & 0.41 & $\checkmark$ \\
\hline 53 & 1999Q1 & 10965604 & 10975658 & 10962078 & 10976217 & 10978519 & 10983003 & 10988467 & 11004470 & 10973786 & 11010736 & 0.44 & $\checkmark$ \\
\hline 54 & 1999Q2 & 11108689 & 11096793 & 11114021 & 11119432 & 11131829 & 11130265 & 11124514 & 11115236 & 11116243 & 11110249 & 0.31 & $\checkmark$ \\
\hline 55 & 1999Q3 & 11457188 & 11454126 & 11459477 & 11451100 & 11436256 & 11434396 & 11432061 & 11430857 & 11441739 & 11411074 & 0.42 & $\checkmark$ \\
\hline 56 & 1999Q4 & 11281972 & 11285622 & 11277230 & 11264097 & 11261534 & 11259940 & 11262042 & 11268255 & 11276798 & 11284452 & 0.22 & $\checkmark$ \\
\hline 57 & 2000Q1 & 11494059 & 11507451 & 11485750 & 11508383 & 11513379 & 11519414 & 11525910 & 11526563 & 11511805 & 11553853 & 0.59 & $\checkmark$ \\
\hline 58 & 2000Q2 & 11643278 & 11632740 & 11657247 & 11654598 & 11667473 & 11664318 & 11658211 & 11648493 & 11652895 & 11639423 & 0.29 & $\checkmark$ \\
\hline 59 & 2000Q3 & 11901457 & 11894544 & 11905863 & 11893691 & 11870504 & 11869387 & 11866308 & 11868459 & 11872708 & 11835771 & 0.59 & $\checkmark$ \\
\hline 60 & 2000Q4 & 11533435 & 11537581 & 11525719 & 11517630 & 11517971 & 11515790 & 11518497 & 11530544 & 11530395 & 11533646 & 0.18 & $\checkmark$ \\
\hline 61 & 2001Q1 & NA & 11902050 & 11874061 & 11911608 & 11918636 & 11926718 & 11933832 & 11926179 & 11920746 & 11960113 & 0.72 & $\checkmark$ \\
\hline 62 & 2001Q2 & NA & 12222935 & 12252473 & 12225128 & 12246077 & 12241751 & 12235102 & 12229255 & 12233633 & 12224721 & 0.24 & $\checkmark$ \\
\hline 63 & 2001Q3 & $\mathrm{NA}$ & 12185491 & 12199467 & 12191623 & 12154104 & 12152146 & 12147764 & 12149105 & 12150526 & 12140405 & 0.48 & $\checkmark$ \\
\hline 64 & 2001Q4 & $\mathrm{NA}$ & 11865083 & 11851768 & 11858612 & 11858259 & 11856003 & 11860577 & 11872196 & 11872935 & 11854066 & 0.17 & $\checkmark$ \\
\hline 65 & 2002Q1 & $\mathrm{NA}$ & NA & 12167992 & 12211279 & 12229678 & 12240718 & 12248468 & 12241111 & 12234750 & 12254241 & 0.70 & $\checkmark$ \\
\hline 66 & 2002Q2 & $\mathrm{NA}$ & $\mathrm{NA}$ & 12447167 & 12393325 & 12411792 & 12404926 & 12395854 & 12390849 & 12397590 & 12383434 & 0.51 & $\checkmark$ \\
\hline 67 & 2002Q3 & NA & $\mathrm{NA}$ & 12478997 & 12472944 & 12425289 & 12424040 & 12418489 & 12422518 & 12420045 & 12456229 & 0.48 & $\checkmark$ \\
\hline 68 & 2002Q4 & $\mathrm{NA}$ & $\mathrm{NA}$ & 12218015 & 12252172 & 12254870 & 12249174 & 12257048 & 12260942 & 12262814 & 12235615 & 0.36 & $\checkmark$ \\
\hline 69 & 2003Q1 & NA & $\mathrm{NA}$ & NA & 12640021 & 12669781 & 12688466 & 12696165 & 12693947 & 12688775 & 12724907 & 0.67 & $\checkmark$ \\
\hline 70 & 2003Q2 & $\mathrm{NA}$ & $\mathrm{NA}$ & $\mathrm{NA}$ & 12906018 & 12920542 & 12907614 & 12900143 & 12893739 & 12903944 & 12871996 & 0.37 & $\checkmark$ \\
\hline 71 & 2003Q3 & $\mathrm{NA}$ & $\mathrm{NA}$ & $\mathrm{NA}$ & 13073718 & 13001555 & 12997295 & 12979613 & 12988204 & 12980485 & 12994759 & 0.72 & $\checkmark$ \\
\hline 72 & 2003Q4 & $\mathrm{NA}$ & $\mathrm{NA}$ & $\mathrm{NA}$ & 12559458 & 12566852 & 12563127 & 12587959 & 12588537 & 12583187 & 12575262 & 0.23 & $\checkmark$ \\
\hline 73 & 2004Q1 & $\mathrm{NA}$ & $\mathrm{NA}$ & $\mathrm{NA}$ & NA & 13180697 & 13208899 & 13211170 & 13207209 & 13215132 & 13279014 & 0.74 & $\checkmark$ \\
\hline 74 & 2004Q2 & $\mathrm{NA}$ & $\mathrm{NA}$ & $\mathrm{NA}$ & $\mathrm{NA}$ & 13508616 & 13484225 & 13474343 & 13464175 & 13479592 & 13433168 & 0.56 & $\checkmark$ \\
\hline 75 & 2004Q3 & NA & $\mathrm{NA}$ & $\mathrm{NA}$ & $\mathrm{NA}$ & 13979696 & 13971866 & 13941394 & 13963890 & 13944186 & 13911983 & 0.48 & $\checkmark$ \\
\hline 76 & 2004Q4 & $\mathrm{NA}$ & $\mathrm{NA}$ & $\mathrm{NA}$ & $\mathrm{NA}$ & 13598085 & 13599920 & 13650485 & 13649589 & 13624060 & 13638095 & 0.38 & $\checkmark$ \\
\hline 77 & 2005Q1 & $\mathrm{NA}$ & $\mathrm{NA}$ & $\mathrm{NA}$ & $\mathrm{NA}$ & NA & 13995552 & 13986659 & 13971352 & 14002438 & 14057899 & 0.61 & $\checkmark$ \\
\hline 78 & 2005Q2 & $\mathrm{NA}$ & $\mathrm{NA}$ & $\mathrm{NA}$ & $\mathrm{NA}$ & $\mathrm{NA}$ & 14377525 & 14367012 & 14348084 & 14380473 & 14326899 & 0.37 & $\checkmark$ \\
\hline 79 & 2005Q3 & $\mathrm{NA}$ & $\mathrm{NA}$ & $\mathrm{NA}$ & $\mathrm{NA}$ & $\mathrm{NA}$ & 14676173 & 14631265 & 14679402 & 14631812 & 14578139 & 0.69 & $\checkmark$ \\
\hline 80 & 2005Q4 & $\mathrm{NA}$ & $\mathrm{NA}$ & $\mathrm{NA}$ & $\mathrm{NA}$ & $\mathrm{NA}$ & 14219850 & 14298920 & 14307438 & 14251762 & 14321527 & 0.71 & $\checkmark$ \\
\hline 81 & 2006Q1 & $\mathrm{NA}$ & $\mathrm{NA}$ & $\mathrm{NA}$ & NA & $\mathrm{NA}$ & NA & 14725780 & 14683613 & 14755523 & 14815346 & 0.89 & $\checkmark$ \\
\hline 82 & 2006Q2 & $\mathrm{NA}$ & $\mathrm{NA}$ & $\mathrm{NA}$ & $\mathrm{NA}$ & $\mathrm{NA}$ & $\mathrm{NA}$ & 15028461 & 14988515 & 15047779 & 14980962 & 0.44 & $\checkmark$ \\
\hline 83 & 2006Q3 & $\mathrm{NA}$ & $\mathrm{NA}$ & $\mathrm{NA}$ & NA & $\mathrm{NA}$ & $\mathrm{NA}$ & 15153350 & 15233455 & 15149521 & 15054287 & 1.19 & $\checkmark$ \\
\hline 84 & 2006Q4 & $\mathrm{NA}$ & $\mathrm{NA}$ & $\mathrm{NA}$ & $\mathrm{NA}$ & $\mathrm{NA}$ & $\mathrm{NA}$ & 15013410 & 15053024 & 14959445 & 15056328 & 0.64 & $\checkmark$ \\
\hline 85 & 2007Q1 & $\mathrm{NA}$ & $\mathrm{NA}$ & $\mathrm{NA}$ & $\mathrm{NA}$ & $\mathrm{NA}$ & $\mathrm{NA}$ & NA & 15453969 & 15566350 & 15641428 & 1.21 & $\checkmark$ \\
\hline 86 & 2007Q2 & $\mathrm{NA}$ & $\mathrm{NA}$ & $\mathrm{NA}$ & $\mathrm{NA}$ & $\mathrm{NA}$ & $\mathrm{NA}$ & $\mathrm{NA}$ & 15716614 & 15818723 & 15773010 & 0.64 & $\checkmark$ \\
\hline 87 & 2007Q3 & $\mathrm{NA}$ & $\mathrm{NA}$ & $\mathrm{NA}$ & $\mathrm{NA}$ & $\mathrm{NA}$ & $\mathrm{NA}$ & $\mathrm{NA}$ & 15802547 & 15679224 & 15521658 & 1.80 & $\checkmark$ \\
\hline \multirow[t]{3}{*}{88} & 2007Q4 & $\mathrm{NA}$ & $\mathrm{NA}$ & $\mathrm{NA}$ & $\mathrm{NA}$ & $\mathrm{NA}$ & $\mathrm{NA}$ & $\mathrm{NA}$ & 15695663 & 15558195 & 15717386 & 1.02 & $\checkmark$ \\
\hline & Median & - & - & - & - & - & - & - & - & - & - & 0.56 & - \\
\hline & Mean & - & - & - & - & - & - & - & - & - & - & 0.58 & $0 \%$ \\
\hline
\end{tabular}

Source: Author's elaboration. 
Table 8: Sliding spans of seasonally-adjusted series (log), Aggregation 2

\begin{tabular}{|c|c|c|c|c|c|c|c|c|c|c|c|c|c|}
\hline No. Obs. & Date & $\mathrm{S}(1)$ & $\mathrm{S}(2)$ & $\mathrm{S}(3)$ & $\mathrm{S}(4)$ & $\mathrm{S}(5)$ & $\mathrm{S}(6)$ & $\mathrm{S}(7)$ & $\mathrm{S}(8)$ & $\mathrm{S}(9)$ & $\mathrm{S}(10)$ & $\mathrm{S}^{\max }$ & Score \\
\hline 40 & 1995Q4 & 9475554 & 9476889 & 9475999 & 9476158 & 9472754 & 9472656 & 9472723 & 9472753 & 9472759 & 9517182 & 0.47 & $\checkmark$ \\
\hline 41 & 1996Q1 & 9765788 & 9764614 & 9765421 & 9765786 & 9767795 & 9767697 & 9765366 & 9767799 & 9765395 & 9766632 & 0.03 & $\checkmark$ \\
\hline 42 & 1996Q2 & 10236427 & 10235715 & 10236147 & 10235975 & 10236369 & 10236651 & 10237075 & 10236357 & 10237079 & 10201808 & 0.34 & $\checkmark$ \\
\hline 43 & 1996Q3 & 10396111 & 10395913 & 10396085 & 10395318 & 10395735 & 10395780 & 10396563 & 10395744 & 10396525 & 10346313 & 0.48 & $\checkmark$ \\
\hline 44 & 1996Q4 & 9995223 & 9998005 & 9996503 & 9996783 & 9993309 & 9992982 & 9993641 & 9993337 & 9993643 & 10060450 & 0.67 & $\checkmark$ \\
\hline 45 & 1997Q1 & 10410582 & 10408336 & 10407353 & 10408399 & 10410925 & 10410697 & 10409623 & 10410922 & 10409632 & 10445133 & 0.36 & $\checkmark$ \\
\hline 46 & 1997Q2 & 10829260 & 10827353 & 10831871 & 10831955 & 10833888 & 10834542 & 10834280 & 10833799 & 10834320 & 10801358 & 0.30 & $\checkmark$ \\
\hline 47 & 1997Q3 & 11149930 & 11150680 & 11148814 & 11145931 & 11142616 & 11143263 & 11142862 & 11142670 & 11142831 & 11059753 & 0.82 & $\checkmark$ \\
\hline 48 & 1997Q4 & 10771510 & 10776219 & 10774637 & 10776049 & 10774321 & 10772501 & 10774573 & 10774376 & 10774519 & 10881407 & 1.02 & $\checkmark$ \\
\hline 49 & 1998Q1 & 10997838 & 10992104 & 10987848 & 10990343 & 10993244 & 10993771 & 10992908 & 10993424 & 10992907 & 11009201 & 0.19 & $\checkmark$ \\
\hline 50 & 1998Q2 & 11420586 & 11419396 & 11429691 & 11428908 & 11432324 & 11433446 & 11432144 & 11432019 & 11432270 & 11398330 & 0.30 & $\checkmark$ \\
\hline 51 & 1998Q3 & 11532500 & 11534203 & 11530875 & 11525545 & 11517339 & 11518454 & 11517428 & 11517264 & 11517434 & 11435480 & 0.86 & $\checkmark$ \\
\hline 52 & 1998Q4 & 10670680 & 10673304 & 10671501 & 10674632 & 10675808 & 10672234 & 10675908 & 10675916 & 10675759 & 10738102 & 0.63 & $\checkmark$ \\
\hline 53 & 1999Q1 & 10952200 & 10951020 & 10941846 & 10946460 & 10948512 & 10950542 & 10949281 & 10949359 & 10949127 & 10959591 & 0.16 & $\checkmark$ \\
\hline 54 & 1999Q2 & 11101649 & 11095336 & 11109809 & 11106479 & 11115042 & 11115530 & 11113746 & 11113848 & 11114200 & 11095992 & 0.18 & $\checkmark$ \\
\hline 55 & 1999Q3 & 11459593 & 11460240 & 11463787 & 11456223 & 11438890 & 11441001 & 11438971 & 11438838 & 11438952 & 11404930 & 0.51 & $\checkmark$ \\
\hline 56 & 1999Q4 & 11209625 & 11214131 & 11203564 & 11210263 & 11215200 & 11209637 & 11215475 & 11215408 & 11215177 & 11266366 & 0.56 & $\checkmark$ \\
\hline 57 & 2000Q1 & 11487581 & 11486896 & 11475697 & 11484879 & 11489008 & 11493157 & 11491606 & 11491753 & 11491043 & 11503778 & 0.24 & $\checkmark$ \\
\hline 58 & 2000Q2 & 11630822 & 11622436 & 11640141 & 11628471 & 11637960 & 11638486 & 11635325 & 11635335 & 11636545 & 11611173 & 0.24 & $\checkmark$ \\
\hline 59 & 2000Q3 & 11907153 & 11907443 & 11917590 & 11906908 & 11880567 & 11880544 & 11878748 & 11878728 & 11878545 & 11840647 & 0.64 & $\checkmark$ \\
\hline 60 & 2000Q4 & 11503266 & 11509924 & 11491140 & 11507845 & 11514930 & 11510860 & 11517050 & 11516908 & 11516489 & 11563667 & 0.63 & $\checkmark$ \\
\hline 61 & 2001Q1 & NA & 11901914 & 11889485 & 11904519 & 11914660 & 11919998 & 11919922 & 11920019 & 11918806 & 11939152 & 0.41 & $\checkmark$ \\
\hline 62 & 2001Q2 & $\mathrm{NA}$ & 12223758 & 12244737 & 12215955 & 12229475 & 12229865 & 12224832 & 12224867 & 12227135 & 12200022 & 0.36 & $\checkmark$ \\
\hline 63 & 2001Q3 & $\mathrm{NA}$ & 12207239 & 12222878 & 12211040 & 12170324 & 12167507 & 12165567 & 12165845 & 12165224 & 12153044 & 0.57 & $\checkmark$ \\
\hline 64 & 2001Q4 & $\mathrm{NA}$ & 11842350 & 11815273 & 11850532 & 11858583 & 11856903 & 11863212 & 11863057 & 11862309 & 11881053 & 0.55 & $\checkmark$ \\
\hline 65 & 2002Q1 & $\mathrm{NA}$ & $\mathrm{NA}$ & 12176483 & 12194316 & 12220976 & 12227042 & 12229532 & 12229037 & 12227864 & 12224165 & 0.43 & $\checkmark$ \\
\hline 66 & 2002Q2 & NA & NA & 12439247 & 12386268 & 12390075 & 12389800 & 12381661 & 12381761 & 12384887 & 12354910 & 0.68 & $\checkmark$ \\
\hline 67 & 2002Q3 & $\mathrm{NA}$ & $\mathrm{NA}$ & 12515852 & 12506705 & 12455771 & 12450509 & 12448648 & 12449818 & 12448511 & 12477216 & 0.54 & $\checkmark$ \\
\hline 68 & 2002Q4 & $\mathrm{NA}$ & NA & 12211120 & 12269549 & 12283211 & 12279698 & 12286935 & 12287114 & 12285627 & 12286761 & 0.62 & $\checkmark$ \\
\hline 69 & 2003Q1 & $\mathrm{NA}$ & $\mathrm{NA}$ & $\mathrm{NA}$ & 12638135 & 12681871 & 12695929 & 12700510 & 12698325 & 12698050 & 12708404 & 0.55 & $\checkmark$ \\
\hline 70 & 2003Q2 & NA & $\mathrm{NA}$ & $\mathrm{NA}$ & 12913780 & 12904126 & 12899807 & 12892098 & 12890641 & 12895601 & 12862344 & 0.39 & $\checkmark$ \\
\hline 71 & 2003Q3 & $\mathrm{NA}$ & $\mathrm{NA}$ & $\mathrm{NA}$ & 13072584 & 13002271 & 12993584 & 12979514 & 12986373 & 12982315 & 13001300 & 0.71 & $\checkmark$ \\
\hline 72 & 2003Q4 & $\mathrm{NA}$ & $\mathrm{NA}$ & $\mathrm{NA}$ & 12536427 & 12565431 & 12562843 & 12585863 & 12583516 & 12580088 & 12588640 & 0.41 & $\checkmark$ \\
\hline 73 & 2004Q1 & $\mathrm{NA}$ & $\mathrm{NA}$ & $\mathrm{NA}$ & $\mathrm{NA}$ & 13209068 & 13232857 & 13235291 & 13232766 & 13235783 & 13264790 & 0.42 & $\checkmark$ \\
\hline 74 & 2004Q2 & $\mathrm{NA}$ & $\mathrm{NA}$ & $\mathrm{NA}$ & $\mathrm{NA}$ & 13486500 & 13477030 & 13465336 & 13457480 & 13467153 & 13435819 & 0.37 & $\checkmark$ \\
\hline 75 & 2004Q3 & $\mathrm{NA}$ & $\mathrm{NA}$ & $\mathrm{NA}$ & $\mathrm{NA}$ & 13980237 & 13962295 & 13930883 & 13952074 & 13938404 & 13912813 & 0.48 & $\checkmark$ \\
\hline 76 & 2004Q4 & $\mathrm{NA}$ & $\mathrm{NA}$ & $\mathrm{NA}$ & $\mathrm{NA}$ & 13573702 & 13573907 & 13626389 & 13617263 & 13611090 & 13638926 & 0.48 & $\checkmark$ \\
\hline 77 & 2005Q1 & NA & NA & NA & NA & NA & 14031823 & 14025598 & 14024504 & 14032889 & 14052386 & 0.19 & $\checkmark$ \\
\hline 78 & 2005Q2 & NA & $\mathrm{NA}$ & $\mathrm{NA}$ & $\mathrm{NA}$ & $\mathrm{NA}$ & 14380963 & 14366011 & 14345434 & 14371031 & 14339282 & 0.29 & $\checkmark$ \\
\hline 79 & 2005Q3 & NA & $\mathrm{NA}$ & NA & NA & NA & 14675365 & 14620622 & 14662514 & 14627952 & 14576963 & 0.67 & $\checkmark$ \\
\hline 80 & 2005Q4 & $\mathrm{NA}$ & $\mathrm{NA}$ & $\mathrm{NA}$ & $\mathrm{NA}$ & $\mathrm{NA}$ & 14166866 & 14258325 & 14242761 & 14220117 & 14298118 & 0.92 & $\checkmark$ \\
\hline 81 & 2006Q1 & $\mathrm{NA}$ & $\mathrm{NA}$ & $\mathrm{NA}$ & $\mathrm{NA}$ & $\mathrm{NA}$ & $\mathrm{NA}$ & 14776980 & 14777059 & 14807831 & 14828222 & 0.34 & $\checkmark$ \\
\hline 82 & 2006Q2 & $\mathrm{NA}$ & NA & $\mathrm{NA}$ & NA & $\mathrm{NA}$ & $\mathrm{NA}$ & 15034462 & 15001334 & 15048827 & 15007670 & 0.31 & $\checkmark$ \\
\hline 83 & 2006Q3 & NA & $\mathrm{NA}$ & $\mathrm{NA}$ & $\mathrm{NA}$ & $\mathrm{NA}$ & $\mathrm{NA}$ & 15130083 & 15188490 & 15117338 & 15038128 & 0.99 & $\checkmark$ \\
\hline 84 & 2006Q4 & $\mathrm{NA}$ & NA & $\mathrm{NA}$ & $\mathrm{NA}$ & $\mathrm{NA}$ & $\mathrm{NA}$ & 14963876 & 14948684 & 14904522 & 15015321 & 0.74 & $\checkmark$ \\
\hline 85 & 2007Q1 & NA & NA & NA & NA & NA & $\mathrm{NA}$ & NA & 15596018 & 15663246 & 15678915 & 0.53 & $\checkmark$ \\
\hline 86 & 2007Q2 & NA & NA & NA & NA & NA & $\mathrm{NA}$ & NA & 15763067 & 15845078 & 15798600 & 0.52 & $\checkmark$ \\
\hline 87 & 2007Q3 & $\mathrm{NA}$ & $\mathrm{NA}$ & $\mathrm{NA}$ & $\mathrm{NA}$ & $\mathrm{NA}$ & $\mathrm{NA}$ & $\mathrm{NA}$ & 15735813 & 15618342 & 15503884 & 1.49 & $\checkmark$ \\
\hline \multirow[t]{3}{*}{88} & 2007Q4 & $\mathrm{NA}$ & $\mathrm{NA}$ & $\mathrm{NA}$ & $\mathrm{NA}$ & $\mathrm{NA}$ & $\mathrm{NA}$ & $\mathrm{NA}$ & 15548266 & 15472891 & 15661162 & 1.21 & $\checkmark$ \\
\hline & Median & - & - & - & - & - & - & - & - & - & - & 0.49 & - \\
\hline & Mean & - & - & - & - & - & - & - & - & - & - & 0.53 & $0 \%$ \\
\hline
\end{tabular}

Source: Author's elaboration. 
Table 9: Sliding spans of seasonally-adjusted series (log), Aggregation 3

\begin{tabular}{|c|c|c|c|c|c|c|c|c|c|c|c|c|c|}
\hline No. Obs. & Date & $\mathrm{S}(1)$ & $\mathrm{S}(2)$ & $\mathrm{S}(3)$ & $\mathrm{S}(4)$ & $\mathrm{S}(5)$ & $\mathrm{S}(6)$ & $\mathrm{S}(7)$ & $\mathrm{S}(8)$ & $\mathrm{S}(9)$ & $\mathrm{S}(10)$ & $\mathrm{S}^{\max }$ & Score \\
\hline 40 & 1995Q4 & 9784890 & 9877900 & 9737399 & 9684133 & 9692566 & 9692990 & 9679761 & 9721569 & 9692488 & 9788268 & 2.04 & $\checkmark$ \\
\hline 41 & 1996Q1 & 9869648 & 9948451 & 9793201 & 9743273 & 9792409 & 9793267 & 9746080 & 9844388 & 9813035 & 9948036 & 2.10 & $\checkmark$ \\
\hline 42 & 1996Q2 & 10211415 & 10081169 & 10209265 & 10332207 & 10265593 & 10264744 & 10333043 & 10199216 & 10249217 & 10065737 & 2.65 & $\checkmark$ \\
\hline 43 & 1996Q3 & 10105288 & 10062047 & 10244235 & 10219277 & 10239635 & 10238773 & 10220468 & 10216085 & 10234505 & 10169449 & 1.81 & $\checkmark$ \\
\hline 44 & 1996Q4 & 10376509 & 10480239 & 10324303 & 10262291 & 10267703 & 10268556 & 10256713 & 10322484 & 10270154 & 10358481 & 2.17 & $\checkmark$ \\
\hline 45 & 1997Q1 & 10382834 & 10433268 & 10273890 & 10267005 & 10275859 & 10277925 & 10267395 & 10301878 & 10295921 & 10452047 & 1.80 & $\checkmark$ \\
\hline 46 & 1997Q2 & 10794641 & 10692053 & 10829290 & 10909161 & 10892790 & 10889526 & 10916684 & 10828267 & 10871736 & 10704092 & 2.10 & $\checkmark$ \\
\hline 47 & 1997Q3 & 10872165 & 10827857 & 10999595 & 10980942 & 10987906 & 10988148 & 10978752 & 10980380 & 10987937 & 10937375 & 1.57 & $\checkmark$ \\
\hline 48 & 1997Q4 & 11209599 & 11308600 & 11155243 & 11101305 & 11100688 & 11102078 & 11093613 & 11158650 & 11104078 & 11167530 & 1.97 & $\checkmark$ \\
\hline 49 & 1998Q1 & 11097971 & 11124261 & 10980956 & 10990970 & 10983896 & 10986629 & 10989137 & 10977499 & 11000832 & 11128135 & 1.37 & $\checkmark$ \\
\hline 50 & 1998Q2 & 11382657 & 11303187 & 11444653 & 11495161 & 11510211 & 11504272 & 11510691 & 11463815 & 11484971 & 11341759 & 1.83 & $\checkmark$ \\
\hline 51 & 1998Q3 & 11256911 & 11236851 & 11354070 & 11339368 & 11330578 & 11332193 & 11334051 & 11346204 & 11339495 & 11315403 & 1.04 & $\checkmark$ \\
\hline 52 & 1998Q4 & 10957209 & 11021328 & 10899486 & 10855617 & 10853120 & 10855913 & 10847197 & 10897437 & 10860592 & 10900707 & 1.60 & $\checkmark$ \\
\hline 53 & 1999Q1 & 10888882 & 10905184 & 10808824 & 10838643 & 10823603 & 10827410 & 10823555 & 10769271 & 10819444 & 10909304 & 1.30 & $\checkmark$ \\
\hline 54 & 1999Q2 & 10977213 & 10915699 & 11027687 & 11037145 & 11079934 & 11068597 & 11077529 & 11088409 & 11069038 & 10945766 & 1.58 & $\checkmark$ \\
\hline 55 & 1999Q3 & 11200723 & 11204638 & 11271776 & 11267340 & 11239370 & 11240925 & 11252721 & 11270711 & 11251520 & 11260384 & 0.63 & $\checkmark$ \\
\hline 56 & 1999Q4 & 11502459 & 11531061 & 11433248 & 11409647 & 11402204 & 11413039 & 11396078 & 11396710 & 11408162 & 11430707 & 1.18 & $\checkmark$ \\
\hline 57 & 2000Q1 & 11442744 & 11457424 & 11419737 & 11450122 & 11433480 & 11436362 & 11418398 & 11387104 & 11421447 & 11516074 & 1.13 & $\checkmark$ \\
\hline 58 & 2000Q2 & 11548012 & 11495183 & 11574416 & 11554374 & 11618965 & 11601352 & 11631186 & 11650244 & 11610949 & 11486217 & 1.42 & $\checkmark$ \\
\hline 59 & 2000Q3 & 11701448 & 11734193 & 11754573 & 11764166 & 11720929 & 11715850 & 11735169 & 11755594 & 11740683 & 11728734 & 0.53 & $\checkmark$ \\
\hline 60 & 2000Q4 & 11866240 & 11859668 & 11786227 & 11774379 & 11757588 & 11780921 & 11752428 & 11725909 & 11764865 & 11799758 & 1.19 & $\checkmark$ \\
\hline 61 & 2001Q1 & NA & 11842029 & 11845026 & 11879681 & 11866418 & 11882519 & 11822453 & 11825672 & 11830996 & 11962299 & 1.18 & $\checkmark$ \\
\hline 62 & 2001Q2 & $\mathrm{NA}$ & 12127492 & 12181896 & 12134269 & 12219841 & 12184455 & 12269289 & 12269032 & 12235181 & 12079869 & 1.56 & $\checkmark$ \\
\hline 63 & 2001Q3 & $\mathrm{NA}$ & 12047453 & 12056457 & 12072293 & 12022594 & 11990339 & 12028625 & 12042750 & 12041338 & 12013699 & 0.68 & $\checkmark$ \\
\hline 64 & 2001Q4 & $\mathrm{NA}$ & 12154280 & 12078449 & 12088098 & 12043156 & 12101990 & 12034517 & 12009493 & 12050462 & 12100752 & 1.20 & $\checkmark$ \\
\hline 65 & 2002Q1 & $\mathrm{NA}$ & $\mathrm{NA}$ & 12011396 & 12042959 & 12045760 & 12087933 & 11976962 & 12027590 & 11987188 & 12160176 & 1.52 & $\checkmark$ \\
\hline 66 & 2002Q2 & NA & NA & 12397637 & 12330307 & 12431854 & 12355521 & 12518333 & 12450031 & 12470513 & 12240801 & 2.26 & $\checkmark$ \\
\hline 67 & 2002Q3 & $\mathrm{NA}$ & $\mathrm{NA}$ & 12292195 & 12312439 & 12252823 & 12198415 & 12255389 & 12287392 & 12278142 & 12252966 & 0.93 & $\checkmark$ \\
\hline 68 & 2002Q4 & NA & NA & 12492221 & 12522253 & 12457610 & 12544247 & 12429999 & 12426948 & 12449938 & 12528409 & 0.94 & $\checkmark$ \\
\hline 69 & 2003Q1 & $\mathrm{NA}$ & $\mathrm{NA}$ & $\mathrm{NA}$ & 12409318 & 12433306 & 12521432 & 12353525 & 12420459 & 12363688 & 12611945 & 2.09 & $\checkmark$ \\
\hline 70 & 2003Q2 & NA & NA & $\mathrm{NA}$ & 12900974 & 13005804 & 12878656 & 13129189 & 12994814 & 13058434 & 12749671 & 2.97 & $\checkmark$ \\
\hline 71 & 2003Q3 & $\mathrm{NA}$ & $\mathrm{NA}$ & $\mathrm{NA}$ & 12999204 & 12928388 & 12841019 & 12917103 & 12989689 & 12967353 & 12914615 & 1.23 & $\checkmark$ \\
\hline 72 & 2003Q4 & $\mathrm{NA}$ & $\mathrm{NA}$ & $\mathrm{NA}$ & 12873337 & 12799356 & 12931404 & 12750767 & 12765923 & 12772882 & 12877488 & 1.41 & $\checkmark$ \\
\hline 73 & 2004Q1 & $\mathrm{NA}$ & $\mathrm{NA}$ & $\mathrm{NA}$ & NA & 12897513 & 13020054 & 12845560 & 12895423 & 12836338 & 13168487 & 2.58 & $\checkmark$ \\
\hline 74 & 2004Q2 & NA & $\mathrm{NA}$ & $\mathrm{NA}$ & $\mathrm{NA}$ & 13667802 & 13495961 & 13788650 & 13623431 & 13702861 & 13334244 & 3.40 & $\boldsymbol{x}$ \\
\hline 75 & 2004Q3 & NA & $\mathrm{NA}$ & $\mathrm{NA}$ & $\mathrm{NA}$ & 13866179 & 13753868 & 13835907 & 13951049 & 13934051 & 13834652 & 1.43 & $\checkmark$ \\
\hline 76 & 2004Q4 & $\mathrm{NA}$ & $\mathrm{NA}$ & $\mathrm{NA}$ & $\mathrm{NA}$ & 13853133 & 14014638 & 13805301 & 13822667 & 13807675 & 13912385 & 1.51 & $\checkmark$ \\
\hline 77 & 2005Q1 & NA & NA & NA & NA & NA & 13766787 & 13586020 & 13601165 & 13561578 & 13944902 & 2.82 & $\checkmark$ \\
\hline 78 & 2005Q2 & NA & $\mathrm{NA}$ & NA & $\mathrm{NA}$ & NA & 14432813 & 14746849 & 14594491 & 14652703 & 14242425 & 3.54 & $x$ \\
\hline 79 & 2005Q3 & NA & NA & NA & NA & NA & 14399222 & 14488679 & 14618237 & 14618008 & 14534572 & 1.52 & $\checkmark$ \\
\hline 80 & 2005Q4 & $\mathrm{NA}$ & $\mathrm{NA}$ & $\mathrm{NA}$ & $\mathrm{NA}$ & $\mathrm{NA}$ & 14696392 & 14466124 & 14486611 & 14466242 & 14551789 & 1.59 & $\checkmark$ \\
\hline 81 & 2006Q1 & $\mathrm{NA}$ & $\mathrm{NA}$ & $\mathrm{NA}$ & $\mathrm{NA}$ & $\mathrm{NA}$ & $\mathrm{NA}$ & 14312980 & 14292111 & 14260415 & 14689733 & 3.01 & $\boldsymbol{*}$ \\
\hline 82 & 2006Q2 & $\mathrm{NA}$ & NA & NA & NA & $\mathrm{NA}$ & $\mathrm{NA}$ & 15434187 & 15307233 & 15350107 & 14914635 & 3.48 & $\boldsymbol{x}$ \\
\hline 83 & 2006Q3 & $\mathrm{NA}$ & $\mathrm{NA}$ & $\mathrm{NA}$ & $\mathrm{NA}$ & $\mathrm{NA}$ & $\mathrm{NA}$ & 14983619 & 15133510 & 15114511 & 15052860 & 1.00 & $\checkmark$ \\
\hline 84 & 2006Q4 & $\mathrm{NA}$ & $\mathrm{NA}$ & $\mathrm{NA}$ & $\mathrm{NA}$ & $\mathrm{NA}$ & $\mathrm{NA}$ & 15189791 & 15187331 & 15200839 & 15246085 & 0.38 & $\checkmark$ \\
\hline 85 & 2007Q1 & NA & NA & NA & NA & NA & $\mathrm{NA}$ & $\mathrm{NA}$ & 15053720 & 15032173 & 15498770 & 3.10 & $\boldsymbol{*}$ \\
\hline 86 & 2007Q2 & $\mathrm{NA}$ & $\mathrm{NA}$ & $\mathrm{NA}$ & $\mathrm{NA}$ & $\mathrm{NA}$ & $\mathrm{NA}$ & $\mathrm{NA}$ & 16122422 & 16138103 & 15706764 & 2.74 & $\checkmark$ \\
\hline 87 & 2007Q3 & $\mathrm{NA}$ & $\mathrm{NA}$ & $\mathrm{NA}$ & $\mathrm{NA}$ & $\mathrm{NA}$ & $\mathrm{NA}$ & $\mathrm{NA}$ & 15667626 & 15625284 & 15581732 & 0.55 & $\checkmark$ \\
\hline \multirow[t]{3}{*}{88} & 2007Q4 & $\mathrm{NA}$ & $\mathrm{NA}$ & $\mathrm{NA}$ & NA & $\mathrm{NA}$ & $\mathrm{NA}$ & $\mathrm{NA}$ & 15819122 & 15879595 & 15871125 & 0.38 & $\checkmark$ \\
\hline & Median & - & - & - & - & - & - & - & - & - & - & 1.57 & - \\
\hline & Mean & - & - & - & - & - & - & - & - & - & - & 1.72 & $10 \%$ \\
\hline
\end{tabular}

Source: Author's elaboration. 
Table 10: Sliding spans of seasonally-adjusted series (log), Aggregation 4

\begin{tabular}{|c|c|c|c|c|c|c|c|c|c|c|c|c|c|}
\hline No. Obs. & Date & $\mathrm{S}(1)$ & $\mathrm{S}(2)$ & $\mathrm{S}(3)$ & $\mathrm{S}(4)$ & $\mathrm{S}(5)$ & $\mathrm{S}(6)$ & $\mathrm{S}(7)$ & $\mathrm{S}(8)$ & $\mathrm{S}(9)$ & $\mathrm{S}(10)$ & $\mathrm{S}^{\max }$ & Score \\
\hline 40 & 1995Q4 & 9777058 & 9776110 & 9776307 & 9776346 & 9776062 & 9776869 & 9776912 & 9776888 & 9776887 & 9774155 & 0.02 & $\checkmark$ \\
\hline 41 & 1996Q1 & 10036706 & 10037501 & 10037618 & 10037644 & 10037857 & 10040403 & 10040375 & 10040424 & 10040412 & 10043484 & 0.06 & $\checkmark$ \\
\hline 42 & 1996Q2 & 10163658 & 10163197 & 10163137 & 10163085 & 10163396 & 10160089 & 10160044 & 10160019 & 10160021 & 10164242 & 0.04 & $\checkmark$ \\
\hline 43 & 1996Q3 & 10246190 & 10247284 & 10246824 & 10246734 & 10246529 & 10246975 & 10246957 & 10246971 & 10246990 & 10244929 & 0.02 & $\checkmark$ \\
\hline 44 & 1996Q4 & 10475446 & 10474030 & 10474347 & 10474450 & 10473848 & 10473737 & 10473883 & 10473855 & 10473844 & 10469493 & 0.05 & $\checkmark$ \\
\hline 45 & 1997Q1 & 10510997 & 10511741 & 10512233 & 10512397 & 10512780 & 10517220 & 10517138 & 10517145 & 10517133 & 10519841 & 0.08 & $\checkmark$ \\
\hline 46 & 1997Q2 & 10803348 & 10801840 & 10801599 & 10801272 & 10801997 & 10795625 & 10795538 & 10795534 & 10795538 & 10805365 & 0.09 & $\checkmark$ \\
\hline 47 & 1997Q3 & 11002639 & 11005326 & 11004495 & 11004488 & 11003963 & 11006255 & 11006234 & 11006295 & 11006322 & 10996382 & 0.09 & $\checkmark$ \\
\hline 48 & 1997Q4 & 11275247 & 11274182 & 11274667 & 11274869 & 11273812 & 11274805 & 11275074 & 11275038 & 11275012 & 11275626 & 0.01 & $\checkmark$ \\
\hline 49 & 1998Q1 & 11210874 & 11211773 & 11212423 & 11212724 & 11213449 & 11214568 & 11214479 & 11214399 & 11214388 & 11214571 & 0.03 & $\checkmark$ \\
\hline 50 & 1998Q2 & 11413668 & 11407171 & 11407571 & 11406754 & 11408378 & 11404853 & 11404508 & 11404507 & 11404546 & 11415914 & 0.10 & $\checkmark$ \\
\hline 51 & 1998Q3 & 11339740 & 11347831 & 11345374 & 11345511 & 11343511 & 11345775 & 11345902 & 11346125 & 11346106 & 11337789 & 0.08 & $\checkmark$ \\
\hline 52 & 1998Q4 & 10999366 & 10999279 & 11000940 & 11001620 & 11000814 & 11000680 & 11001181 & 11001083 & 11001024 & 10995453 & 0.05 & $\checkmark$ \\
\hline 53 & 1999Q1 & 10963304 & 10963322 & 10963673 & 10963870 & 10965269 & 10964923 & 10964661 & 10964496 & 10964563 & 10968563 & 0.04 & $\checkmark$ \\
\hline 54 & 1999Q2 & 10992442 & 10979609 & 10979600 & 10977965 & 10980305 & 10980130 & 10979453 & 10979418 & 10979524 & 10977364 & 0.13 & $\checkmark$ \\
\hline 55 & 1999Q3 & 11230481 & 11246133 & 11243529 & 11244028 & 11239839 & 11241267 & 11241663 & 11242053 & 11241863 & 11244513 & 0.13 & $\checkmark$ \\
\hline 56 & 1999Q4 & 11513310 & 11514127 & 11518066 & 11519866 & 11518960 & 11517750 & 11518708 & 11518633 & 11518501 & 11517344 & 0.05 & $\checkmark$ \\
\hline 57 & 2000Q1 & 11555726 & 11554634 & 11552111 & 11551932 & 11555932 & 11553061 & 11552584 & 11552273 & 11552558 & 11552953 & 0.03 & $\checkmark$ \\
\hline 58 & 2000Q2 & 11550057 & 11527424 & 11526907 & 11523975 & 11527204 & 11532415 & 11530819 & 11530749 & 11531055 & 11529308 & 0.22 & $\checkmark$ \\
\hline 59 & 2000Q3 & 11682520 & 11708446 & 11707854 & 11707265 & 11697680 & 11696542 & 11697574 & 11697726 & 11697239 & 11697531 & 0.22 & $\checkmark$ \\
\hline 60 & 2000Q4 & 11852297 & 11853488 & 11860035 & 11866563 & 11866373 & 11864291 & 11866108 & 11866857 & 11866066 & 11868570 & 0.13 & $\checkmark$ \\
\hline 61 & 2001Q1 & $\mathrm{NA}$ & 11982821 & 11976426 & 11974161 & 11982560 & 11980678 & 11980275 & 11979594 & 11981014 & 11980773 & 0.07 & $\checkmark$ \\
\hline 62 & 2001Q2 & NA & 12095004 & 12091394 & 12085030 & 12091828 & 12096495 & 12092110 & 12091366 & 12091721 & 12089501 & 0.09 & $\checkmark$ \\
\hline 63 & 2001Q3 & NA & 12019232 & 12023701 & 12023211 & 12002907 & 12001359 & 12004448 & 12004898 & 12003718 & 12006125 & 0.18 & $\checkmark$ \\
\hline 64 & 2001Q4 & NA & 12120022 & 12129136 & 12142580 & 12141689 & 12142132 & 12145346 & 12146714 & 12145420 & 12149308 & 0.24 & $\checkmark$ \\
\hline 65 & 2002Q1 & $\mathrm{NA}$ & NA & 12178522 & 12172914 & 12191579 & 12189525 & 12188481 & 12188259 & 12190591 & 12191332 & 0.15 & $\checkmark$ \\
\hline 66 & 2002Q2 & $\mathrm{NA}$ & $\mathrm{NA}$ & 12253287 & 12242466 & 12251761 & 12251643 & 12243749 & 12240947 & 12241921 & 12233205 & 0.16 & $\checkmark$ \\
\hline 67 & 2002Q3 & $\mathrm{NA}$ & $\mathrm{NA}$ & 12314100 & 12314013 & 12278948 & 12279161 & 12285296 & 12286480 & 12284195 & 12290588 & 0.28 & $\checkmark$ \\
\hline 68 & 2002Q4 & NA & $\mathrm{NA}$ & 12527802 & 12550418 & 12549059 & 12553579 & 12559183 & 12562296 & 12560421 & 12565550 & 0.30 & $\checkmark$ \\
\hline 69 & 2003Q1 & $\mathrm{NA}$ & $\mathrm{NA}$ & $\mathrm{NA}$ & 12664117 & 12696287 & 12694105 & 12691289 & 12691956 & 12695423 & 12697096 & 0.26 & $\checkmark$ \\
\hline 70 & 2003Q2 & NA & $\mathrm{NA}$ & NA & 12745533 & 12757606 & 12751795 & 12737982 & 12729398 & 12731124 & 12718332 & 0.30 & $\checkmark$ \\
\hline 71 & 2003Q3 & $\mathrm{NA}$ & $\mathrm{NA}$ & $\mathrm{NA}$ & 12866501 & 12815173 & 12816647 & 12828950 & 12833655 & 12829742 & 12836518 & 0.40 & $\checkmark$ \\
\hline 72 & 2003Q4 & $\mathrm{NA}$ & NA & $\mathrm{NA}$ & 12889762 & 12887644 & 12895486 & 12905794 & 12911698 & 12909868 & 12914517 & 0.20 & $\checkmark$ \\
\hline 73 & 2004Q1 & $\mathrm{NA}$ & $\mathrm{NA}$ & $\mathrm{NA}$ & $\mathrm{NA}$ & 13231618 & 13231481 & 13222204 & 13224046 & 13227423 & 13230240 & 0.07 & $\checkmark$ \\
\hline 74 & 2004Q2 & $\mathrm{NA}$ & $\mathrm{NA}$ & $\mathrm{NA}$ & $\mathrm{NA}$ & 13376573 & 13366098 & 13345618 & 13323920 & 13328958 & 13311750 & 0.48 & $\checkmark$ \\
\hline 75 & 2004Q3 & NA & $\mathrm{NA}$ & NA & $\mathrm{NA}$ & 13728513 & 13730722 & 13753879 & 13769491 & 13760852 & 13760123 & 0.29 & $\checkmark$ \\
\hline 76 & 2004Q4 & $\mathrm{NA}$ & $\mathrm{NA}$ & $\mathrm{NA}$ & $\mathrm{NA}$ & 13912587 & 13920092 & 13936227 & 13946991 & 13945087 & 13953524 & 0.29 & $\checkmark$ \\
\hline 77 & 2005Q1 & NA & $\mathrm{NA}$ & $\mathrm{NA}$ & NA & NA & 14004528 & 13986080 & 13986613 & 13993327 & 13996904 & 0.13 & $\checkmark$ \\
\hline 78 & 2005Q2 & $\mathrm{NA}$ & $\mathrm{NA}$ & $\mathrm{NA}$ & NA & $\mathrm{NA}$ & 14290673 & 14260388 & 14219903 & 14227152 & 14220303 & 0.49 & $\checkmark$ \\
\hline 79 & 2005Q3 & NA & $\mathrm{NA}$ & $\mathrm{NA}$ & NA & NA & 14415009 & 14452726 & 14488249 & 14472074 & 14469320 & 0.50 & $\checkmark$ \\
\hline 80 & 2005Q4 & NA & $\mathrm{NA}$ & $\mathrm{NA}$ & NA & NA & 14545915 & 14567411 & 14582379 & 14580403 & 14581960 & 0.25 & $\checkmark$ \\
\hline 81 & 2006Q1 & $\mathrm{NA}$ & $\mathrm{NA}$ & $\mathrm{NA}$ & $\mathrm{NA}$ & $\mathrm{NA}$ & $\mathrm{NA}$ & 14734891 & 14731644 & 14743521 & 14749139 & 0.11 & $\checkmark$ \\
\hline 82 & 2006Q2 & $\mathrm{NA}$ & $\mathrm{NA}$ & $\mathrm{NA}$ & NA & $\mathrm{NA}$ & $\mathrm{NA}$ & 14943265 & 14878754 & 14892145 & 14892645 & 0.43 & $\checkmark$ \\
\hline 83 & 2006Q3 & $\mathrm{NA}$ & $\mathrm{NA}$ & NA & NA & NA & NA & 14962244 & 15021234 & 14992164 & 14986549 & 0.39 & $\checkmark$ \\
\hline 84 & 2006Q4 & NA & $\mathrm{NA}$ & $\mathrm{NA}$ & $\mathrm{NA}$ & $\mathrm{NA}$ & $\mathrm{NA}$ & 15254172 & 15274316 & 15272431 & 15265971 & 0.13 & $\checkmark$ \\
\hline 85 & 2007Q1 & $\mathrm{NA}$ & $\mathrm{NA}$ & $\mathrm{NA}$ & $\mathrm{NA}$ & $\mathrm{NA}$ & $\mathrm{NA}$ & $\mathrm{NA}$ & 15544610 & 15563413 & 15570972 & 0.16 & $\checkmark$ \\
\hline 86 & 2007Q2 & NA & $\mathrm{NA}$ & $\mathrm{NA}$ & $\mathrm{NA}$ & $\mathrm{NA}$ & $\mathrm{NA}$ & NA & 15640815 & 15660432 & 15685862 & 0.28 & $\checkmark$ \\
\hline 87 & 2007Q3 & $\mathrm{NA}$ & $\mathrm{NA}$ & $\mathrm{NA}$ & $\mathrm{NA}$ & NA & NA & NA & 15570141 & 15528127 & 15514445 & 0.35 & $\checkmark$ \\
\hline \multirow[t]{3}{*}{88} & 2007Q4 & $\mathrm{NA}$ & $\mathrm{NA}$ & $\mathrm{NA}$ & $\mathrm{NA}$ & NA & NA & $\mathrm{NA}$ & 15896483 & 15894344 & 15872748 & 0.14 & $\checkmark$ \\
\hline & Median & - & - & - & - & - & - & - & - & - & - & 0.14 & - \\
\hline & Mean & - & - & - & - & - & - & - & - & - & - & 0.18 & $0 \%$ \\
\hline
\end{tabular}

Source: Author's elaboration. 
Table 11: Sliding spans of seasonally-adjusted series (log), Aggregation 5

\begin{tabular}{|c|c|c|c|c|c|c|c|c|c|c|c|c|c|}
\hline No. Obs. & Date & $\mathrm{S}(1)$ & $\mathrm{S}(2)$ & $\mathrm{S}(3)$ & $\mathrm{S}(4)$ & $\mathrm{S}(5)$ & $\mathrm{S}(6)$ & $\mathrm{S}(7)$ & $\mathrm{S}(8)$ & $\mathrm{S}(9)$ & $\mathrm{S}(10)$ & $\mathrm{S}^{\max }$ & Score \\
\hline 40 & 1995Q4 & 9814324 & 9814865 & 9810916 & 9815831 & 9810214 & 9813908 & 9814163 & 9814172 & 9813451 & 9812328 & 0.18 & $v$ \\
\hline 41 & 1996Q1 & 10077835 & 10078375 & 10075299 & 10074822 & 10074676 & 10077317 & 10077134 & 10077141 & 10077021 & 10066981 & 0.24 & $\checkmark$ \\
\hline 42 & 1996Q2 & 10117524 & 10114961 & 10117812 & 10116905 & 10118298 & 10117146 & 10117114 & 10117081 & 10117577 & 10117660 & 0.03 & $\checkmark$ \\
\hline 43 & 1996Q3 & 10216379 & 10217772 & 10221233 & 10218002 & 10221790 & 10217901 & 10217864 & 10217890 & 10218342 & 10230828 & 0.03 & $\checkmark$ \\
\hline 44 & 1996Q4 & 10419564 & 10420681 & 10417732 & 10422389 & 10417337 & 10419166 & 10419331 & 10419336 & 10418547 & 10413606 & 0.02 & $\checkmark$ \\
\hline 45 & 1997Q1 & 10545865 & 10546226 & 10542005 & 10541534 & 10541291 & 10544748 & 10544589 & 10544605 & 10544380 & 10529728 & 0.03 & $\checkmark$ \\
\hline 46 & 1997Q2 & 10777193 & 10773646 & 10776592 & 10775552 & 10777330 & 10775865 & 10775844 & 10775811 & 10776426 & 10788733 & 0.02 & $\checkmark$ \\
\hline 47 & 1997Q3 & 10976250 & 10977494 & 10982317 & 10978595 & 10982427 & 10979621 & 10979640 & 10979663 & 10980220 & 10986026 & 0.04 & $v$ \\
\hline 48 & 1997Q4 & 11226322 & 11229955 & 11226398 & 11231584 & 11226373 & 11226591 & 11226688 & 11226711 & 11225830 & 11222795 & 0.03 & $\nu$ \\
\hline 49 & 1998Q1 & 11218441 & 11218073 & 11212394 & 11212311 & 11211358 & 11215223 & 11215105 & 11215127 & 11214815 & 11205017 & 0.07 & $\checkmark$ \\
\hline 50 & 1998Q2 & 11384524 & 11377026 & 11379807 & 11378682 & 11380504 & 11380038 & 11379958 & 11379875 & 11380405 & 11394535 & 0.05 & $\checkmark$ \\
\hline 51 & 1998Q3 & 11322708 & 11326694 & 11334090 & 11329056 & 11334341 & 11331679 & 11331774 & 11331814 & 11332660 & 11332186 & 0.26 & $\checkmark$ \\
\hline 52 & 1998Q4 & 10975439 & 10981492 & 10978219 & 10984188 & 10978489 & 10977364 & 10977456 & 10977562 & 10976688 & 10959965 & 0.31 & $\checkmark$ \\
\hline 53 & 1999Q1 & 10987867 & 10986981 & 10977705 & 10977768 & 10976714 & 10977585 & 10977492 & 10977486 & 10977120 & 10976404 & 0.10 & $\checkmark$ \\
\hline 54 & 1999Q2 & 10994901 & 10982571 & 10984511 & 10983700 & 10984564 & 10989296 & 10989033 & 10988819 & 10989166 & 10998738 & 0.03 & $\checkmark$ \\
\hline 55 & 1999Q3 & 11229821 & 11237054 & 11250014 & 11243423 & 11249893 & 11248145 & 11248377 & 11248412 & 11249472 & 11258824 & 0.15 & $\checkmark$ \\
\hline 56 & 1999Q4 & 11491622 & 11502623 & 11499463 & 11508208 & 11502590 & 11496572 & 11496860 & 11497246 & 11496272 & 11488844 & 0.11 & $\checkmark$ \\
\hline 57 & 2000Q1 & 11579298 & 11577947 & 11559974 & 11557655 & 11556368 & 11554797 & 11554671 & 11554676 & 11554406 & 11549052 & 0.11 & $\checkmark$ \\
\hline 58 & 2000Q2 & 11548404 & 11527261 & 11531162 & 11529031 & 11529251 & 11541615 & 11540754 & 11540061 & 11540174 & 11543845 & 0.06 & $\checkmark$ \\
\hline 59 & 2000Q3 & 11676001 & 11688134 & 11707000 & 11703208 & 11709696 & 11706747 & 11707208 & 11707358 & 11708524 & 11716195 & 0.26 & $\checkmark$ \\
\hline 60 & 2000Q4 & 11847457 & 11861756 & 11861600 & 11873280 & 11868852 & 11857724 & 11859016 & 11859758 & 11858825 & 11856670 & 0.44 & $\checkmark$ \\
\hline 61 & 2001Q1 & NA & 11996274 & 11967904 & 11959120 & 11960531 & 11956949 & 11956110 & 11956522 & 11956376 & 11952128 & 0.19 & $\checkmark$ \\
\hline 62 & 2001Q2 & $\mathrm{NA}$ & 12084772 & 12088243 & 12086058 & 12083395 & 12105912 & 12104074 & 12101985 & 12102071 & 12100601 & 0.23 & $\checkmark$ \\
\hline 63 & 2001Q3 & $\mathrm{NA}$ & 12000603 & 12025943 & 12025619 & 12032217 & 12023658 & 12024426 & 12025097 & 12025951 & 12034597 & 0.40 & $\checkmark$ \\
\hline 64 & 2001Q4 & $\mathrm{NA}$ & 12131601 & 12136603 & 12152706 & 12150800 & 12137183 & 12140416 & 12141490 & 12140848 & 12140629 & 0.18 & $\checkmark$ \\
\hline 65 & 2002Q1 & NA & NA & 12175393 & 12161382 & 12166518 & 12161886 & 12159940 & 12161233 & 12160945 & 12157705 & 0.21 & $\checkmark$ \\
\hline 66 & 2002Q2 & $\mathrm{NA}$ & $\mathrm{NA}$ & 12251056 & 12243817 & 12239266 & 12273197 & 12269103 & 12264373 & 12264919 & 12263736 & 0.18 & $\checkmark$ \\
\hline 67 & 2002Q3 & $\mathrm{NA}$ & $\mathrm{NA}$ & 12317629 & 12324468 & 12332454 & 12310621 & 12312740 & 12314706 & 12314945 & 12327183 & 0.27 & $\checkmark$ \\
\hline 68 & 2002Q4 & $\mathrm{NA}$ & $\mathrm{NA}$ & 12554778 & 12578430 & 12578127 & 12568752 & 12575548 & 12577840 & 12577282 & 12573706 & 1.08 & $\checkmark$ \\
\hline 69 & 2003Q1 & $\mathrm{NA}$ & $\mathrm{NA}$ & NA & 12725795 & 12737786 & 12733354 & 12728768 & 12729916 & 12729895 & 12725358 & 0.34 & $\checkmark$ \\
\hline 70 & 2003Q2 & $\mathrm{NA}$ & $\mathrm{NA}$ & $\mathrm{NA}$ & 12734254 & 12727449 & 12767820 & 12758833 & 12749457 & 12750181 & 12747059 & 0.28 & $\checkmark$ \\
\hline 71 & 2003Q3 & $\mathrm{NA}$ & $\mathrm{NA}$ & $\mathrm{NA}$ & 12821432 & 12828276 & 12789664 & 12796636 & 12803499 & 12802843 & 12818507 & 0.27 & $\checkmark$ \\
\hline 72 & 2003Q4 & $\mathrm{NA}$ & $\mathrm{NA}$ & $\mathrm{NA}$ & 12853617 & 12853051 & 12851461 & 12863143 & 12867203 & 12867096 & 12855971 & 0.33 & $\checkmark$ \\
\hline 73 & 2004Q1 & $\mathrm{NA}$ & NA & $\mathrm{NA}$ & NA & 13255797 & 13255312 & 13245320 & 13244064 & 13244769 & 13242238 & 0.21 & $\checkmark$ \\
\hline 74 & 2004Q2 & NA & NA & $\mathrm{NA}$ & $\mathrm{NA}$ & 13338937 & 13380105 & 13362618 & 13344409 & 13344585 & 13343889 & 0.39 & $\checkmark$ \\
\hline 75 & 2004Q3 & $\mathrm{NA}$ & $\mathrm{NA}$ & $\mathrm{NA}$ & $\mathrm{NA}$ & 13754483 & 13701842 & 13721200 & 13739617 & 13736976 & 13749083 & 0.35 & $\checkmark$ \\
\hline 76 & 2004Q4 & $\mathrm{NA}$ & $\mathrm{NA}$ & $\mathrm{NA}$ & $\mathrm{NA}$ & 13889853 & 13895691 & 13914261 & 13923719 & 13925120 & 13925911 & 0.13 & $\checkmark$ \\
\hline 77 & 2005Q1 & $\mathrm{NA}$ & $\mathrm{NA}$ & $\mathrm{NA}$ & $\mathrm{NA}$ & NA & 14025257 & 14005787 & 13996826 & 14000316 & 13993198 & 0.30 & $\checkmark$ \\
\hline 78 & 2005Q2 & $\mathrm{NA}$ & $\mathrm{NA}$ & $\mathrm{NA}$ & $\mathrm{NA}$ & $\mathrm{NA}$ & 14291918 & 14264493 & 14230050 & 14227822 & 14227656 & 0.19 & $\checkmark$ \\
\hline 79 & 2005Q3 & $\mathrm{NA}$ & $\mathrm{NA}$ & $\mathrm{NA}$ & $\mathrm{NA}$ & $\mathrm{NA}$ & 14408544 & 14440207 & 14483451 & 14474916 & 14486179 & 0.24 & $\checkmark$ \\
\hline 80 & 2005Q4 & $\mathrm{NA}$ & $\mathrm{NA}$ & $\mathrm{NA}$ & NA & $\mathrm{NA}$ & 14522385 & 14548898 & 14561311 & 14568453 & 14564301 & 0.25 & $\checkmark$ \\
\hline 81 & 2006Q1 & $\mathrm{NA}$ & $\mathrm{NA}$ & NA & NA & NA & NA & 14750777 & 14731683 & 14739331 & 14731581 & 0.17 & $\checkmark$ \\
\hline 82 & 2006Q2 & NA & $\mathrm{NA}$ & $\mathrm{NA}$ & $\mathrm{NA}$ & $\mathrm{NA}$ & $\mathrm{NA}$ & 14935391 & 14881415 & 14875862 & 14876227 & 0.22 & $\checkmark$ \\
\hline 83 & 2006Q3 & NA & NA & $\mathrm{NA}$ & $\mathrm{NA}$ & $\mathrm{NA}$ & NA & 14953722 & 15025314 & 15007003 & 15023508 & 0.09 & $\checkmark$ \\
\hline 84 & 2006Q4 & $\mathrm{NA}$ & $\mathrm{NA}$ & $\mathrm{NA}$ & $\mathrm{NA}$ & $\mathrm{NA}$ & $\mathrm{NA}$ & 15244767 & 15261148 & 15276114 & 15263293 & 0.28 & $\checkmark$ \\
\hline 85 & 2007Q1 & $\mathrm{NA}$ & $\mathrm{NA}$ & $\mathrm{NA}$ & $\mathrm{NA}$ & $\mathrm{NA}$ & $\mathrm{NA}$ & NA & 15561812 & 15578619 & 15557005 & 0.17 & $\checkmark$ \\
\hline 86 & 2007Q2 & $\mathrm{NA}$ & $\mathrm{NA}$ & $\mathrm{NA}$ & $\mathrm{NA}$ & $\mathrm{NA}$ & $\mathrm{NA}$ & $\mathrm{NA}$ & 15646733 & 15633892 & 15657516 & 0.03 & $\checkmark$ \\
\hline 87 & 2007Q3 & NA & NA & NA & $\mathrm{NA}$ & NA & NA & $\mathrm{NA}$ & 15561013 & 15533051 & 15558381 & 0.13 & $\checkmark$ \\
\hline \multirow{3}{*}{88} & 2007Q4 & $\mathrm{NA}$ & $\mathrm{NA}$ & $\mathrm{NA}$ & NA & $\mathrm{NA}$ & $\mathrm{NA}$ & $\mathrm{NA}$ & 15875357 & 15898222 & 15867861 & 0.23 & $\checkmark$ \\
\hline & Median & - & - & - & - & - & - & - & - & - & - & 0.18 & - \\
\hline & Mean & - & - & - & - & - & - & - & - & - & - & 0.21 & $0 \%$ \\
\hline
\end{tabular}

Source: Author's elaboration. 
Table 12: Sliding spans of seasonally-adjusted series (log), Aggregation 6

\begin{tabular}{|c|c|c|c|c|c|c|c|c|c|c|c|c|c|}
\hline No. Obs. & Date & $\mathrm{S}(1)$ & $\mathrm{S}(2)$ & $\mathrm{S}(3)$ & $\mathrm{S}(4)$ & $\mathrm{S}(5)$ & $\mathrm{S}(6)$ & $\mathrm{S}(7)$ & $\mathrm{S}(8)$ & $\mathrm{S}(9)$ & $\mathrm{S}(10)$ & $\mathrm{S}^{\max }$ & Score \\
\hline 40 & 1995Q4 & 9790734 & 9790568 & 9790610 & 9790727 & 9790775 & 9790882 & 9790758 & 9790757 & 9790766 & 9779914 & 0.11 & $\checkmark$ \\
\hline 41 & 1996Q1 & 9985411 & 9985831 & 9985759 & 9985563 & 9985475 & 9985450 & 9985528 & 9985530 & 9985525 & 9998679 & 0.13 & $\checkmark$ \\
\hline 42 & 1996Q2 & 10106112 & 10105669 & 10105725 & 10105877 & 10105945 & 10106182 & 10105939 & 10105934 & 10105951 & 10113108 & 0.07 & $\checkmark$ \\
\hline 43 & 1996Q3 & 10278389 & 10278609 & 10278589 & 10278470 & 10278406 & 10277911 & 10278360 & 10278373 & 10278341 & 10267564 & 0.10 & $\checkmark$ \\
\hline 44 & 1996Q4 & 10442456 & 10442716 & 10442752 & 10442914 & 10442953 & 10443083 & 10442930 & 10442938 & 10442949 & 10434278 & 0.08 & $\checkmark$ \\
\hline 45 & 1997Q1 & 10458040 & 10458000 & 10457874 & 10457676 & 10457684 & 10457958 & 10457779 & 10457742 & 10457755 & 10468134 & 0.10 & $\checkmark$ \\
\hline 46 & 1997Q2 & 10760346 & 10759094 & 10759238 & 10759445 & 10759537 & 10759877 & 10759527 & 10759523 & 10759547 & 10769302 & 0.09 & $\checkmark$ \\
\hline 47 & 1997Q3 & 11027278 & 11028204 & 11028179 & 11027932 & 11027694 & 11026600 & 11027606 & 11027663 & 11027594 & 11008441 & 0.17 & $\checkmark$ \\
\hline 48 & 1997Q4 & 11260979 & 11262967 & 11262988 & 11263217 & 11263209 & 11263260 & 11263178 & 11263215 & 11263222 & 11261551 & 0.02 & $\checkmark$ \\
\hline 49 & 1998Q1 & 11184203 & 11183560 & 11183307 & 11183196 & 11183420 & 11184300 & 11183557 & 11183470 & 11183512 & 11192770 & 0.08 & $\checkmark$ \\
\hline 50 & 1998Q2 & 11402917 & 11396828 & 11397201 & 11397375 & 11397834 & 11398924 & 11397898 & 11397732 & 11397818 & 11407378 & 0.09 & $\checkmark$ \\
\hline 51 & 1998Q3 & 11368946 & 11374818 & 11374641 & 11374007 & 11372746 & 11369645 & 11372455 & 11372772 & 11372560 & 11357748 & 0.15 & $\checkmark$ \\
\hline 52 & 1998Q4 & 10969956 & 10973618 & 10973690 & 10974288 & 10974612 & 10975126 & 10974691 & 10974735 & 10974788 & 10971999 & 0.04 & $\checkmark$ \\
\hline 53 & 1999Q1 & 10924986 & 10923219 & 10922929 & 10923269 & 10924011 & 10925597 & 10924190 & 10924082 & 10924166 & 10925238 & 0.02 & $\checkmark$ \\
\hline 54 & 1999Q2 & 10969287 & 10956132 & 10956237 & 10955788 & 10956512 & 10958908 & 10956565 & 10956120 & 10956256 & 10953372 & 0.14 & $\checkmark$ \\
\hline 55 & 1999Q3 & 11228249 & 11241632 & 11242922 & 11241396 & 11238656 & 11232068 & 11238177 & 11238596 & 11238216 & 11239723 & 0.13 & $\checkmark$ \\
\hline 56 & 1999Q4 & 11483595 & 11489693 & 11487078 & 11488928 & 11489434 & 11491425 & 11489708 & 11490098 & 11490201 & 11491030 & 0.06 & $\checkmark$ \\
\hline 57 & 2000Q1 & 11530508 & 11527563 & 11529915 & 11531696 & 11534017 & 11536556 & 11534332 & 11534328 & 11534511 & 11535845 & 0.07 & $\checkmark$ \\
\hline 58 & 2000Q2 & 11544508 & 11520422 & 11518218 & 11516052 & 11517401 & 11520971 & 11517290 & 11516254 & 11516446 & 11513992 & 0.26 & $\checkmark$ \\
\hline 59 & 2000Q3 & 11687709 & 11711959 & 11715817 & 11710989 & 11704396 & 11693652 & 11703340 & 11703365 & 11702739 & 11701800 & 0.24 & $\checkmark$ \\
\hline 60 & 2000Q4 & 11836657 & 11843901 & 11838701 & 11844261 & 11846323 & 11850601 & 11847612 & 11848611 & 11848757 & 11851572 & 0.12 & $\checkmark$ \\
\hline 61 & 2001Q1 & $\mathrm{NA}$ & 11969503 & 11975521 & 11981305 & 11984294 & 11987722 & 11984497 & 11986581 & 11986932 & 11988830 & 0.16 & $\checkmark$ \\
\hline 62 & 2001Q2 & NA & 12074532 & 12067546 & 12059967 & 12066074 & 12069775 & 12065191 & 12060604 & 12060915 & 12058268 & 0.13 & $\checkmark$ \\
\hline 63 & 2001Q3 & NA & 12019234 & 12027192 & 12017283 & 12002089 & 11988266 & 12000687 & 12001717 & 12000715 & 12001768 & 0.32 & $\checkmark$ \\
\hline 64 & 2001Q4 & NA & 12100815 & 12092677 & 12105446 & 12108047 & 12114500 & 12110775 & 12111478 & 12111529 & 12114044 & 0.18 & $\checkmark$ \\
\hline 65 & 2002Q1 & $\mathrm{NA}$ & NA & 12170034 & 12180462 & 12188472 & 12193629 & 12189510 & 12195998 & 12196897 & 12199643 & 0.24 & $\checkmark$ \\
\hline 66 & 2002Q2 & $\mathrm{NA}$ & $\mathrm{NA}$ & 12227379 & 12212246 & 12223126 & 12224608 & 12219043 & 12208748 & 12208933 & 12200348 & 0.22 & $\checkmark$ \\
\hline 67 & 2002Q3 & $\mathrm{NA}$ & $\mathrm{NA}$ & 12319780 & 12304565 & 12276012 & 12259926 & 12274392 & 12276611 & 12275129 & 12280462 & 0.48 & $\checkmark$ \\
\hline 68 & 2002Q4 & NA & NA & 12491573 & 12512893 & 12517005 & 12526515 & 12523977 & 12525394 & 12525524 & 12528362 & 0.29 & $\checkmark$ \\
\hline 69 & 2003Q1 & $\mathrm{NA}$ & $\mathrm{NA}$ & $\mathrm{NA}$ & 12608177 & 12624622 & 12633461 & 12627373 & 12639027 & 12640826 & 12645064 & 0.29 & $\checkmark$ \\
\hline 70 & 2003Q2 & NA & $\mathrm{NA}$ & NA & 12776309 & 12791603 & 12787565 & 12778046 & 12759075 & 12758695 & 12748638 & 0.33 & $\checkmark$ \\
\hline 71 & 2003Q3 & $\mathrm{NA}$ & $\mathrm{NA}$ & $\mathrm{NA}$ & 12897399 & 12853107 & 12834804 & 12855136 & 12860076 & 12857650 & 12861924 & 0.48 & $\checkmark$ \\
\hline 72 & 2003Q4 & $\mathrm{NA}$ & $\mathrm{NA}$ & $\mathrm{NA}$ & 12880074 & 12884632 & 12897340 & 12896979 & 12901065 & 12901651 & 12902339 & 0.17 & $\checkmark$ \\
\hline 73 & 2004Q1 & $\mathrm{NA}$ & $\mathrm{NA}$ & $\mathrm{NA}$ & $\mathrm{NA}$ & 13167654 & 13183165 & 13172986 & 13188453 & 13192015 & 13196371 & 0.21 & $\checkmark$ \\
\hline 74 & 2004Q2 & $\mathrm{NA}$ & $\mathrm{NA}$ & $\mathrm{NA}$ & $\mathrm{NA}$ & 13405248 & 13392377 & 13377167 & 13346182 & 13345111 & 13336448 & 0.51 & $\checkmark$ \\
\hline 75 & 2004Q3 & NA & $\mathrm{NA}$ & NA & NA & 13763231 & 13742365 & 13771061 & 13782679 & 13776674 & 13772780 & 0.29 & $\checkmark$ \\
\hline 76 & 2004Q4 & $\mathrm{NA}$ & $\mathrm{NA}$ & $\mathrm{NA}$ & $\mathrm{NA}$ & 13911820 & 13929184 & 13933014 & 13941614 & 13944233 & 13946173 & 0.24 & $\checkmark$ \\
\hline 77 & 2005Q1 & NA & $\mathrm{NA}$ & NA & NA & NA & 13962511 & 13947192 & 13965393 & 13973583 & 13975284 & 0.20 & $\checkmark$ \\
\hline 78 & 2005Q2 & $\mathrm{NA}$ & $\mathrm{NA}$ & $\mathrm{NA}$ & $\mathrm{NA}$ & $\mathrm{NA}$ & 14314096 & 14289692 & 14239972 & 14237003 & 14242110 & 0.54 & $\checkmark$ \\
\hline 79 & 2005Q3 & NA & $\mathrm{NA}$ & $\mathrm{NA}$ & NA & NA & 14423901 & 14462975 & 14488836 & 14473999 & 14466139 & 0.45 & $\checkmark$ \\
\hline 80 & 2005Q4 & NA & $\mathrm{NA}$ & $\mathrm{NA}$ & NA & NA & 14558284 & 14565936 & 14579552 & 14587131 & 14582511 & 0.19 & $\checkmark$ \\
\hline 81 & 2006Q1 & $\mathrm{NA}$ & $\mathrm{NA}$ & $\mathrm{NA}$ & $\mathrm{NA}$ & $\mathrm{NA}$ & $\mathrm{NA}$ & 14705598 & 14722891 & 14738453 & 14735671 & 0.22 & $\checkmark$ \\
\hline 82 & 2006Q2 & $\mathrm{NA}$ & $\mathrm{NA}$ & $\mathrm{NA}$ & NA & $\mathrm{NA}$ & $\mathrm{NA}$ & 14963718 & 14894332 & 14889317 & 14914793 & 0.49 & $\checkmark$ \\
\hline 83 & 2006Q3 & $\mathrm{NA}$ & NA & NA & NA & NA & NA & 14966075 & 15008848 & 14981564 & 14968422 & 0.28 & $\checkmark$ \\
\hline 84 & 2006Q4 & NA & $\mathrm{NA}$ & $\mathrm{NA}$ & $\mathrm{NA}$ & $\mathrm{NA}$ & $\mathrm{NA}$ & 15255611 & 15275483 & 15289909 & 15273984 & 0.22 & $\checkmark$ \\
\hline 85 & 2007Q1 & $\mathrm{NA}$ & $\mathrm{NA}$ & $\mathrm{NA}$ & $\mathrm{NA}$ & $\mathrm{NA}$ & $\mathrm{NA}$ & $\mathrm{NA}$ & 15544979 & 15569765 & 15564517 & 0.15 & $\checkmark$ \\
\hline 86 & 2007Q2 & NA & $\mathrm{NA}$ & $\mathrm{NA}$ & NA & $\mathrm{NA}$ & NA & NA & 15654921 & 15646264 & 15703282 & 0.36 & $\checkmark$ \\
\hline 87 & 2007Q3 & $\mathrm{NA}$ & $\mathrm{NA}$ & $\mathrm{NA}$ & $\mathrm{NA}$ & NA & NA & NA & 15557102 & 15517540 & 15491721 & 0.42 & $\checkmark$ \\
\hline \multirow[t]{3}{*}{88} & 2007Q4 & $\mathrm{NA}$ & $\mathrm{NA}$ & $\mathrm{NA}$ & $\mathrm{NA}$ & NA & NA & $\mathrm{NA}$ & 15892978 & 15914556 & 15884665 & 0.18 & $\checkmark$ \\
\hline & Median & - & - & - & - & - & - & - & - & - & - & 0.19 & - \\
\hline & Mean & - & - & - & - & - & - & - & - & - & - & 0.22 & $0 \%$ \\
\hline
\end{tabular}

Source: Author's elaboration. 


\section{$3 \quad$ Sliding spans of trend-cycle series (log)}

Table 13: Sliding spans of trend-cycle series (log), Aggregation 1

\begin{tabular}{|c|c|c|c|c|c|c|c|c|c|c|c|c|c|}
\hline No. Obs. & Date & $\mathrm{S}(1)$ & $\mathrm{S}(2)$ & $\mathrm{S}(3)$ & $\mathrm{S}(4)$ & $\mathrm{S}(5)$ & $\mathrm{S}(6)$ & $\mathrm{S}(7)$ & $\mathrm{S}(8)$ & $\mathrm{S}(9)$ & $\mathrm{S}(10)$ & $\mathrm{s}^{\max }$ & Score \\
\hline 40 & 1995Q4 & 9288531 & 9290559 & 9289505 & 9350400 & 9347611 & 9348911 & 9334794 & 9327336 & 9342823 & 9339026 & 0.66 & $V$ \\
\hline 41 & 1996Q1 & 9970126 & 9971909 & 9971905 & 9997870 & 9997793 & 10000473 & 9991926 & 10018237 & 9999351 & 9996571 & 0.48 & $\checkmark$ \\
\hline 42 & 1996Q2 & 10170395 & 10167577 & 10168640 & 10162805 & 10165280 & 10165260 & 10165514 & 10192332 & 10168527 & 10169146 & 0.29 & $\checkmark$ \\
\hline 43 & 1996Q3 & 10425950 & 10418987 & 10419148 & 10418647 & 10418572 & 10415620 & 10414911 & 10404818 & 10418776 & 10421169 & 0.20 & $\checkmark$ \\
\hline 44 & 1996Q4 & 10268932 & 10267375 & 10268214 & 10266224 & 10266418 & 10266872 & 10269619 & 10121325 & 10276570 & 10280295 & 1.57 & $\checkmark$ \\
\hline 45 & 1997Q1 & 10340455 & 10340774 & 10344752 & 10344533 & 10347405 & 10349933 & 10350513 & 10491336 & 10335633 & 10332115 & 1.54 & $\checkmark$ \\
\hline 46 & 1997Q2 & 10880507 & 10877914 & 10881788 & 10888009 & 10891358 & 10891308 & 10888918 & 10890888 & 10727365 & 10719479 & 1.60 & $\checkmark$ \\
\hline 47 & 1997Q3 & 11108747 & 11105692 & 11107453 & 11104838 & 11106120 & 11102597 & 11099368 & 11074714 & 11246616 & 11250365 & 1.58 & $\checkmark$ \\
\hline 48 & 1997Q4 & 10923672 & 10928091 & 10924862 & 10917767 & 10904048 & 10907495 & 10915337 & 10904827 & 10908208 & 10915988 & 0.22 & $\checkmark$ \\
\hline 49 & 1998Q1 & 11224088 & 11224352 & 11223018 & 11228179 & 11198671 & 11202911 & 11224476 & 11239213 & 11194019 & 11192800 & 0.41 & $\checkmark$ \\
\hline 50 & 1998Q2 & 11307330 & 11299886 & 11303213 & 11317511 & 11291637 & 11293997 & 11308135 & 11319743 & 11300236 & 11292136 & 0.24 & $\checkmark$ \\
\hline 51 & 1998Q3 & 11587650 & 11581735 & 11585385 & 11583102 & 11623303 & 11624512 & 11572257 & 11566190 & 11589563 & 11588104 & 0.50 & $\checkmark$ \\
\hline 52 & 1998Q4 & 10744519 & 10745667 & 10737493 & 10728893 & 10699349 & 10704301 & 10728416 & 10730804 & 10743735 & 10750265 & 0.47 & $\checkmark$ \\
\hline 53 & 1999Q1 & 11006047 & 11006737 & 11001257 & 11006926 & 11021154 & 11022181 & 11016511 & 11022719 & 11012278 & 11013570 & 0.19 & $\checkmark$ \\
\hline 54 & 1999Q2 & 11126593 & 11125344 & 11131097 & 11139137 & 11142559 & 11142306 & 11139788 & 11138026 & 11130692 & 11127464 & 0.15 & $\checkmark$ \\
\hline 55 & 1999Q3 & 11500918 & 11498155 & 11506503 & 11496984 & 11491397 & 11489070 & 11485788 & 11483053 & 11495215 & 11492980 & 0.20 & $\checkmark$ \\
\hline 56 & 1999Q4 & 11122490 & 11123618 & 11119832 & 11114315 & 11112250 & 11113893 & 11117101 & 11121720 & 11125078 & 11126897 & 0.13 & $\checkmark$ \\
\hline 57 & 2000Q1 & 11492677 & 11510314 & 11472437 & 11477324 & 11469388 & 11472404 & 11475382 & 11474572 & 11468782 & 11471621 & 0.36 & $\checkmark$ \\
\hline 58 & 2000Q2 & 11828979 & 11845401 & 11817736 & 11831593 & 11824882 & 11825462 & 11823760 & 11812875 & 11811548 & 11810954 & 0.29 & $\checkmark$ \\
\hline 59 & 2000Q3 & 11718797 & 11714949 & 11720148 & 11743115 & 11737439 & 11730208 & 11725727 & 11728877 & 11733637 & 11731132 & 0.24 & $\checkmark$ \\
\hline 60 & 2000Q4 & 11511738 & 11528510 & 11553947 & 11524695 & 11507686 & 11493662 & 11486302 & 11579183 & 11577627 & 11576735 & 0.80 & $\checkmark$ \\
\hline 61 & 2001Q1 & NA & 11991596 & 12011279 & 12080364 & 12084027 & 12093492 & 12108716 & 12021071 & 12012606 & 12012796 & 0.97 & $\checkmark$ \\
\hline 62 & 2001Q2 & NA & 12182826 & 12209762 & 12183819 & 12194216 & 12196063 & 12193323 & 12198471 & 12194956 & 12194600 & 0.22 & $\checkmark$ \\
\hline 63 & 2001Q3 & NA & 12204925 & 12216720 & 12188849 & 12184331 & 12178509 & 12168860 & 12192773 & 12197982 & 12197942 & 0.39 & $\checkmark$ \\
\hline 64 & 2001Q4 & $\mathrm{NA}$ & 11851468 & 11832072 & 11832622 & 11833277 & 11827761 & 11829719 & 11841410 & 11843470 & 11843191 & 0.20 & $\checkmark$ \\
\hline 65 & 2002Q1 & NA & NA & 12191157 & 12207208 & 12201094 & 12196162 & 12203968 & 12200416 & 12196250 & 12198060 & 0.13 & $\checkmark$ \\
\hline 66 & 2002Q2 & $\mathrm{NA}$ & NA & 12294971 & 12296850 & 12265923 & 12253151 & 12252433 & 12244356 & 12242119 & 12243424 & 0.44 & $\checkmark$ \\
\hline 67 & 2002Q3 & $\mathrm{NA}$ & $\mathrm{NA}$ & 12616048 & 12643244 & 12607164 & 12590679 & 12583805 & 12581283 & 12578260 & 12579600 & 0.51 & $\checkmark$ \\
\hline 68 & 2002Q4 & $\mathrm{NA}$ & $\mathrm{NA}$ & 12151344 & 12194377 & 12184048 & 12177935 & 12174308 & 12182889 & 12181966 & 12183491 & 0.35 & $\checkmark$ \\
\hline 69 & 2003Q1 & $\mathrm{NA}$ & $\mathrm{NA}$ & NA & 12681809 & 12701399 & 12706705 & 12705750 & 12711815 & 12721782 & 12723957 & 0.33 & $\checkmark$ \\
\hline 70 & 2003Q2 & NA & $\mathrm{NA}$ & $\mathrm{NA}$ & 12865235 & 12862374 & 12868528 & 12867775 & 12868481 & 12875576 & 12877767 & 0.11 & $\checkmark$ \\
\hline 71 & 2003Q3 & $\mathrm{NA}$ & $\mathrm{NA}$ & $\mathrm{NA}$ & 12950839 & 12906618 & 12909468 & 12915018 & 12916350 & 12909763 & 12909221 & 0.34 & $\checkmark$ \\
\hline 72 & 2003Q4 & NA & $\mathrm{NA}$ & $\mathrm{NA}$ & 12655320 & 12657110 & 12649855 & 12660924 & 12662496 & 12658810 & 12657589 & 0.09 & $\checkmark$ \\
\hline 73 & 2004Q1 & $\mathrm{NA}$ & $\mathrm{NA}$ & $\mathrm{NA}$ & NA & 13181325 & 13161219 & 13165059 & 13155639 & 13160267 & 13164027 & 0.19 & $\checkmark$ \\
\hline 74 & 2004Q2 & NA & $\mathrm{NA}$ & $\mathrm{NA}$ & NA & 13501964 & 13484970 & 13464702 & 13464500 & 13460296 & 13462298 & 0.30 & $\checkmark$ \\
\hline 75 & 2004Q3 & $\mathrm{NA}$ & $\mathrm{NA}$ & $\mathrm{NA}$ & $\mathrm{NA}$ & 13973046 & 13963518 & 13960377 & 13971053 & 13948096 & 13940588 & 0.23 & $\checkmark$ \\
\hline 76 & 2004Q4 & $\mathrm{NA}$ & $\mathrm{NA}$ & $\mathrm{NA}$ & $\mathrm{NA}$ & 13572269 & 13583517 & 13604043 & 13608389 & 13591061 & 13589526 & 0.26 & $\checkmark$ \\
\hline 77 & 2005Q1 & $\mathrm{NA}$ & $\mathrm{NA}$ & $\mathrm{NA}$ & $\mathrm{NA}$ & NA & 14076865 & 14088961 & 14070531 & 14086982 & 14101732 & 0.22 & $\checkmark$ \\
\hline 78 & 2005Q2 & $\mathrm{NA}$ & $\mathrm{NA}$ & $\mathrm{NA}$ & $\mathrm{NA}$ & $\mathrm{NA}$ & 14292796 & 14267498 & 14264894 & 14280399 & 14283984 & 0.19 & $\checkmark$ \\
\hline 79 & 2005Q3 & $\mathrm{NA}$ & $\mathrm{NA}$ & $\mathrm{NA}$ & $\mathrm{NA}$ & $\mathrm{NA}$ & 14733266 & 14736035 & 14772601 & 14731986 & 14708959 & 0.43 & $\checkmark$ \\
\hline 80 & 2005Q4 & $\mathrm{NA}$ & $\mathrm{NA}$ & NA & NA & NA & 14116378 & 14149126 & 14165925 & 14138561 & 14130710 & 0.35 & $\checkmark$ \\
\hline 81 & 2006Q1 & $\mathrm{NA}$ & $\mathrm{NA}$ & $\mathrm{NA}$ & NA & NA & NA & 14827718 & 14782399 & 14833136 & 14869196 & 0.58 & $\checkmark$ \\
\hline 82 & 2006Q2 & $\mathrm{NA}$ & $\mathrm{NA}$ & $\mathrm{NA}$ & $\mathrm{NA}$ & $\mathrm{NA}$ & $\mathrm{NA}$ & 15064936 & 15012569 & 15066145 & 15088445 & 0.50 & $\checkmark$ \\
\hline 83 & 2006Q3 & $\mathrm{NA}$ & NA & $\mathrm{NA}$ & NA & NA & NA & 15023498 & 15040084 & 15003939 & 14982035 & 0.38 & $\checkmark$ \\
\hline 84 & 2006Q4 & $\mathrm{NA}$ & $\mathrm{NA}$ & $\mathrm{NA}$ & $\mathrm{NA}$ & $\mathrm{NA}$ & $\mathrm{NA}$ & 15150231 & 15201312 & 15170374 & 15173852 & 0.33 & $\checkmark$ \\
\hline 85 & 2007Q1 & $\mathrm{NA}$ & $\mathrm{NA}$ & $\mathrm{NA}$ & $\mathrm{NA}$ & $\mathrm{NA}$ & $\mathrm{NA}$ & $\mathrm{NA}$ & 15423995 & 15490249 & 15574409 & 0.97 & $\checkmark$ \\
\hline 86 & 2007Q2 & $\mathrm{NA}$ & $\mathrm{NA}$ & $\mathrm{NA}$ & $\mathrm{NA}$ & $\mathrm{NA}$ & $\mathrm{NA}$ & $\mathrm{NA}$ & 15635196 & 15762642 & 15808790 & 1.11 & $\checkmark$ \\
\hline 87 & 2007Q3 & $\mathrm{NA}$ & $\mathrm{NA}$ & $\mathrm{NA}$ & $\mathrm{NA}$ & $\mathrm{NA}$ & $\mathrm{NA}$ & $\mathrm{NA}$ & 15874616 & 15819665 & 15716959 & 1.00 & $\checkmark$ \\
\hline \multirow[t]{3}{*}{88} & 2007Q4 & $\mathrm{NA}$ & $\mathrm{NA}$ & $\mathrm{NA}$ & NA & NA & $\mathrm{NA}$ & $\mathrm{NA}$ & 16098259 & 15747199 & 15622227 & 3.04 & * \\
\hline & Median & - & - & - & - & - & - & - & - & - & - & 0.35 & - \\
\hline & Mean & - & - & - & - & - & - & - & - & - & - & 0.54 & $2 \%$ \\
\hline
\end{tabular}

Source: Author's elaboration. 
Table 14: Sliding spans of trend-cycle series (log), Aggregation 2

\begin{tabular}{|c|c|c|c|c|c|c|c|c|c|c|c|c|c|}
\hline No. Obs. & Date & $\mathrm{S}(1)$ & $\mathrm{S}(2)$ & $\mathrm{S}(3)$ & $\mathrm{S}(4)$ & $\mathrm{S}(5)$ & $\mathrm{S}(6)$ & $\mathrm{S}(7)$ & $\mathrm{S}(8)$ & $\mathrm{S}(9)$ & $\mathrm{S}(10)$ & $\mathrm{S}^{\max }$ & Score \\
\hline 40 & 1995Q4 & 9266144 & 9266763 & 9265844 & 9265782 & 9271575 & 9271545 & 9273788 & 9271569 & 9273838 & 9271572 & 0.08 & $V$ \\
\hline 41 & 1996Q1 & 9966433 & 9966643 & 9965592 & 9965421 & 9974833 & 9974958 & 9975997 & 9974810 & 9976034 & 9974812 & 0.10 & $\checkmark$ \\
\hline 42 & 1996Q2 & 10178310 & 10177761 & 10177662 & 10177297 & 10181114 & 10181354 & 10182492 & 10181105 & 10182492 & 10181104 & 0.05 & $\checkmark$ \\
\hline 43 & 1996Q3 & 10399289 & 10401684 & 10401806 & 10401539 & 10404693 & 10404714 & 10405384 & 10404722 & 10405352 & 10404717 & 0.05 & $\checkmark$ \\
\hline 44 & 1996Q4 & 10256915 & 10260481 & 10259288 & 10259594 & 10267701 & 10267390 & 10267662 & 10267727 & 10267653 & 10267717 & 0.10 & $\checkmark$ \\
\hline 45 & 1997Q1 & 10355064 & 10355140 & 10355688 & 10356514 & 10362105 & 10362010 & 10361504 & 10362082 & 10361541 & 10362081 & 0.06 & $\checkmark$ \\
\hline 46 & 1997Q2 & 10884198 & 10881447 & 10883235 & 10882483 & 10882059 & 10882697 & 10881940 & 10882035 & 10881973 & 10882059 & 0.02 & $\checkmark$ \\
\hline 47 & 1997Q3 & 11112062 & 11115402 & 11115844 & 11114345 & 11112262 & 11112284 & 11112731 & 11112292 & 11112703 & 11112297 & 0.03 & $\checkmark$ \\
\hline 48 & 1997Q4 & 10914273 & 10920060 & 10916105 & 10917047 & 10915522 & 10914746 & 10915618 & 10915644 & 10915555 & 10915609 & 0.05 & $\checkmark$ \\
\hline 49 & 1998Q1 & 11210608 & 11213638 & 11213434 & 11215896 & 11218745 & 11218713 & 11218547 & 11218758 & 11218563 & 11218748 & 0.07 & $\checkmark$ \\
\hline 50 & 1998Q2 & 11305042 & 11308775 & 11312121 & 11310891 & 11311119 & 11312602 & 11310915 & 11310952 & 11310997 & 11311017 & 0.06 & $\checkmark$ \\
\hline 51 & 1998Q3 & 11587597 & 11578026 & 11579535 & 11575881 & 11572705 & 11572481 & 11572678 & 11572527 & 11572700 & 11572571 & 0.13 & $\checkmark$ \\
\hline 52 & 1998Q4 & 10717777 & 10696729 & 10688952 & 10687689 & 10686104 & 10685172 & 10686591 & 10686610 & 10686491 & 10686509 & 0.30 & $\checkmark$ \\
\hline 53 & 1999Q1 & 10986860 & 10973228 & 10971599 & 10973491 & 10980171 & 10979591 & 10980512 & 10980596 & 10980604 & 10980560 & 0.13 & $\checkmark$ \\
\hline 54 & 1999Q2 & 11122300 & 11120894 & 11130646 & 11129050 & 11131316 & 11130870 & 11131093 & 11131090 & 11131370 & 11131251 & 0.09 & $\checkmark$ \\
\hline 55 & 1999Q3 & 11512978 & 11514069 & 11515794 & 11511462 & 11500365 & 11504588 & 11499915 & 11499763 & 11500006 & 11499919 & 0.13 & $\checkmark$ \\
\hline 56 & 1999Q4 & 11139029 & 11143597 & 11133198 & 11135561 & 11122309 & 11131799 & 11123477 & 11123360 & 11123017 & 11123023 & 0.19 & $\checkmark$ \\
\hline 57 & 2000Q1 & 11481949 & 11488099 & 11446381 & 11446765 & 11444801 & 11451410 & 11445973 & 11445975 & 11445876 & 11445880 & 0.37 & $\checkmark$ \\
\hline 58 & 2000Q2 & 11788209 & 11794896 & 11753311 & 11757871 & 11781682 & 11781239 & 11779048 & 11779244 & 11779852 & 11779744 & 0.35 & $\checkmark$ \\
\hline 59 & 2000Q3 & 11670122 & 11674381 & 11659812 & 11679308 & 11715303 & 11711356 & 11711368 & 11711555 & 11712137 & 11712031 & 0.47 & $\checkmark$ \\
\hline 60 & 2000Q4 & 11525130 & 11539543 & 11540468 & 11561705 & 11583263 & 11580449 & 11584247 & 11584262 & 11583476 & 11583443 & 0.51 & $\checkmark$ \\
\hline 61 & 2001Q1 & NA & 12030673 & 12024619 & 12020385 & 12027534 & 12028512 & 12029517 & 12029392 & 12029191 & 12029103 & 0.08 & $\checkmark$ \\
\hline 62 & 2001Q2 & $\mathrm{NA}$ & 12218802 & 12236672 & 12216057 & 12209443 & 12210089 & 12205970 & 12206071 & 12206841 & 12206652 & 0.25 & $\checkmark$ \\
\hline 63 & 2001Q3 & $\mathrm{NA}$ & 12209036 & 12217720 & 12213925 & 12194237 & 12193288 & 12191161 & 12191492 & 12191567 & 12191358 & 0.21 & $\checkmark$ \\
\hline 64 & 2001Q4 & $\mathrm{NA}$ & 11832647 & 11819064 & 11841673 & 11844186 & 11838220 & 11846059 & 11845318 & 11845214 & 11845587 & 0.22 & $\checkmark$ \\
\hline 65 & 2002Q1 & NA & NA & 12195535 & 12208186 & 12197034 & 12187132 & 12202361 & 12200496 & 12200673 & 12201667 & 0.17 & $\checkmark$ \\
\hline 66 & 2002Q2 & $\mathrm{NA}$ & $\mathrm{NA}$ & 12320591 & 12308190 & 12258537 & 12242965 & 12255903 & 12254099 & 12253165 & 12253139 & 0.63 & $\checkmark$ \\
\hline 67 & 2002Q3 & $\mathrm{NA}$ & $\mathrm{NA}$ & 12636861 & 12652596 & 12619668 & 12602553 & 12608836 & 12608051 & 12606229 & 12605039 & 0.39 & $\checkmark$ \\
\hline 68 & 2002Q4 & $\mathrm{NA}$ & $\mathrm{NA}$ & 12157940 & 12187673 & 12208771 & 12202531 & 12205363 & 12204387 & 12204053 & 12203477 & 0.41 & $\checkmark$ \\
\hline 69 & 2003Q1 & $\mathrm{NA}$ & $\mathrm{NA}$ & $\mathrm{NA}$ & 12671075 & 12713069 & 12720763 & 12729622 & 12727322 & 12724300 & 12726139 & 0.46 & $\checkmark$ \\
\hline 70 & 2003Q2 & $\mathrm{NA}$ & $\mathrm{NA}$ & $\mathrm{NA}$ & 12837759 & 12849390 & 12872953 & 12888552 & 12889263 & 12882058 & 12885189 & 0.40 & $\checkmark$ \\
\hline 71 & 2003Q3 & $\mathrm{NA}$ & $\mathrm{NA}$ & $\mathrm{NA}$ & 12932522 & 12884607 & 12908615 & 12928888 & 12932224 & 12924546 & 12926084 & 0.37 & $\checkmark$ \\
\hline 72 & 2003Q4 & NA & $\mathrm{NA}$ & NA & 12694620 & 12638056 & 12657795 & 12673463 & 12674044 & 12671185 & 12672195 & 0.44 & $\checkmark$ \\
\hline 73 & 2004Q1 & $\mathrm{NA}$ & NA & $\mathrm{NA}$ & NA & 13168173 & 13178357 & 13182556 & 13175562 & 13180519 & 13183768 & 0.11 & $\checkmark$ \\
\hline 74 & 2004Q2 & $\mathrm{NA}$ & $\mathrm{NA}$ & $\mathrm{NA}$ & NA & 13491571 & 13489402 & 13467838 & 13469514 & 13472486 & 13471736 & 0.17 & $\checkmark$ \\
\hline 75 & 2004Q3 & $\mathrm{NA}$ & $\mathrm{NA}$ & $\mathrm{NA}$ & $\mathrm{NA}$ & 13963232 & 13945534 & 13940461 & 13947658 & 13940205 & 13934720 & 0.20 & $\checkmark$ \\
\hline 76 & 2004Q4 & $\mathrm{NA}$ & $\mathrm{NA}$ & $\mathrm{NA}$ & $\mathrm{NA}$ & 13567029 & 13575388 & 13595651 & 13598290 & 13590720 & 13591905 & 0.23 & $\checkmark$ \\
\hline 77 & 2005Q1 & $\mathrm{NA}$ & $\mathrm{NA}$ & $\mathrm{NA}$ & $\mathrm{NA}$ & $\mathrm{NA}$ & 14083448 & 14097315 & 14084329 & 14098163 & 14107922 & 0.17 & $\checkmark$ \\
\hline 78 & 2005Q2 & $\mathrm{NA}$ & $\mathrm{NA}$ & $\mathrm{NA}$ & $\mathrm{NA}$ & $\mathrm{NA}$ & 14311110 & 14274270 & 14278426 & 14286976 & 14281623 & 0.25 & $\checkmark$ \\
\hline 79 & 2005Q3 & $\mathrm{NA}$ & $\mathrm{NA}$ & $\mathrm{NA}$ & $\mathrm{NA}$ & $\mathrm{NA}$ & 14726397 & 14720092 & 14733971 & 14712524 & 14696840 & 0.25 & $\checkmark$ \\
\hline 80 & 2005Q4 & NA & $\mathrm{NA}$ & NA & NA & NA & 14115966 & 14148409 & 14155659 & 14136537 & 14140178 & 0.28 & $\checkmark$ \\
\hline 81 & 2006Q1 & NA & NA & NA & NA & NA & NA & 14846235 & 14831999 & 14859180 & 14879855 & 0.32 & $\checkmark$ \\
\hline 82 & 2006Q2 & $\mathrm{NA}$ & $\mathrm{NA}$ & $\mathrm{NA}$ & $\mathrm{NA}$ & $\mathrm{NA}$ & $\mathrm{NA}$ & 15065562 & 15030171 & 15067600 & 15070337 & 0.26 & $\checkmark$ \\
\hline 83 & 2006Q3 & NA & $\mathrm{NA}$ & $\mathrm{NA}$ & NA & NA & $\mathrm{NA}$ & 14968065 & 14965708 & 14968558 & 14980739 & 0.10 & $\checkmark$ \\
\hline 84 & 2006Q4 & $\mathrm{NA}$ & $\mathrm{NA}$ & $\mathrm{NA}$ & $\mathrm{NA}$ & $\mathrm{NA}$ & $\mathrm{NA}$ & 15144620 & 15195366 & 15200801 & 15246665 & 0.67 & $\checkmark$ \\
\hline 85 & 2007Q1 & $\mathrm{NA}$ & $\mathrm{NA}$ & $\mathrm{NA}$ & $\mathrm{NA}$ & $\mathrm{NA}$ & $\mathrm{NA}$ & $\mathrm{NA}$ & 15520567 & 15579895 & 15629414 & 0.70 & $\checkmark$ \\
\hline 86 & 2007Q2 & $\mathrm{NA}$ & $\mathrm{NA}$ & $\mathrm{NA}$ & $\mathrm{NA}$ & $\mathrm{NA}$ & $\mathrm{NA}$ & $\mathrm{NA}$ & 15716287 & 15792290 & 15792231 & 0.48 & $\checkmark$ \\
\hline 87 & 2007Q3 & $\mathrm{NA}$ & $\mathrm{NA}$ & $\mathrm{NA}$ & $\mathrm{NA}$ & $\mathrm{NA}$ & $\mathrm{NA}$ & $\mathrm{NA}$ & 15766940 & 15764934 & 15716290 & 0.32 & $\checkmark$ \\
\hline \multirow[t]{3}{*}{88} & 2007Q4 & $\mathrm{NA}$ & $\mathrm{NA}$ & $\mathrm{NA}$ & $\mathrm{NA}$ & $\mathrm{NA}$ & $\mathrm{NA}$ & $\mathrm{NA}$ & 15689749 & 15735883 & 15673893 & 0.39 & $\checkmark$ \\
\hline & Median & - & - & - & - & - & - & - & - & - & - & 0.23 & - \\
\hline & Mean & - & - & - & - & - & - & - & - & - & - & 0.26 & $0 \%$ \\
\hline
\end{tabular}

Source: Author's elaboration. 
Table 15: Sliding spans of trend-cycle series (log), Aggregation 3

\begin{tabular}{|c|c|c|c|c|c|c|c|c|c|c|c|c|c|}
\hline No. Obs. & Date & $\mathrm{S}(1)$ & $\mathrm{S}(2)$ & $\mathrm{S}(3)$ & $\mathrm{S}(4)$ & $\mathrm{S}(5)$ & $\mathrm{S}(6)$ & $\mathrm{S}(7)$ & $\mathrm{S}(8)$ & $\mathrm{S}(9)$ & $\mathrm{S}(10)$ & $\mathrm{S}^{\max }$ & Score \\
\hline 40 & 1995Q4 & 9671298 & 9756410 & 9665693 & 9596191 & 9602736 & 9603241 & 9601605 & 9632222 & 9608678 & 9691974 & 1.66 & $\checkmark$ \\
\hline 41 & 1996Q1 & 9998056 & 10047676 & 9920689 & 9916163 & 9933467 & 9933930 & 9925932 & 9955464 & 9940963 & 10022401 & 1.32 & $\checkmark$ \\
\hline 42 & 1996Q2 & 10235053 & 10169433 & 10173931 & 10229141 & 10213728 & 10213159 & 10233974 & 10179458 & 10209705 & 10228188 & 0.64 & $\checkmark$ \\
\hline 43 & 1996Q3 & 10002544 & 9727962 & 10337312 & 10345391 & 10338716 & 10338025 & 10348605 & 10313751 & 10325733 & 9930932 & 6.37 & $\boldsymbol{x}$ \\
\hline 44 & 1996Q4 & 10663900 & 10847486 & 10483862 & 10406874 & 10446017 & 10447088 & 10412901 & 10473022 & 10438822 & 10747159 & 4.23 & $\boldsymbol{x}$ \\
\hline 45 & 1997Q1 & 10471499 & 10455612 & 10168833 & 10195582 & 10163514 & 10164164 & 10201044 & 10201538 & 10196342 & 10468624 & 3.03 & $\boldsymbol{x}$ \\
\hline 46 & 1997Q2 & 10662432 & 10615029 & 11379799 & 11017997 & 11050068 & 11048870 & 11020806 & 10984540 & 11014289 & 10646328 & 7.20 & $\boldsymbol{x}$ \\
\hline 47 & 1997Q3 & 10997212 & 10919297 & 11024474 & 11008945 & 10985758 & 10984570 & 11008080 & 10989889 & 10990461 & 10996663 & 0.96 & $\checkmark$ \\
\hline 48 & 1997Q4 & 11177670 & 11126395 & 11005951 & 11119843 & 11103834 & 11101035 & 11112011 & 11141439 & 11115001 & 11213202 & 1.88 & $\checkmark$ \\
\hline 49 & 1998Q1 & 11261134 & 11227371 & 11127335 & 11200564 & 11195788 & 11189219 & 11201180 & 11191667 & 11194721 & 11291797 & 1.47 & $\checkmark$ \\
\hline 50 & 1998Q2 & 11295593 & 11255721 & 11346196 & 11364640 & 11373207 & 11368302 & 11371785 & 11339079 & 11362541 & 11283089 & 1.04 & $\checkmark$ \\
\hline 51 & 1998Q3 & 11244512 & 11225654 & 11314593 & 11305236 & 11305073 & 11305286 & 11305749 & 11318376 & 11304618 & 11221221 & 0.86 & $\checkmark$ \\
\hline 52 & 1998Q4 & 10992457 & 11037577 & 10956929 & 10932424 & 10919781 & 10924205 & 10917615 & 10935990 & 10928012 & 10999379 & 1.09 & $\checkmark$ \\
\hline 53 & 1999Q1 & 10884973 & 10896044 & 10825705 & 10833685 & 10839804 & 10839192 & 10836096 & 10821465 & 10834925 & 10906911 & 0.78 & $\checkmark$ \\
\hline 54 & 1999Q2 & 10979818 & 10944534 & 11014730 & 11032431 & 11044466 & 11038698 & 11047913 & 11039604 & 11039732 & 10979010 & 0.94 & $\checkmark$ \\
\hline 55 & 1999Q3 & 11228825 & 11219074 & 11270639 & 11259583 & 11256643 & 11256875 & 11262718 & 11282447 & 11263179 & 11199785 & 0.73 & $\checkmark$ \\
\hline 56 & 1999Q4 & 11425315 & 11453555 & 11412645 & 11396463 & 11388512 & 11394600 & 11373903 & 11363957 & 11381386 & 11430659 & 0.78 & $\checkmark$ \\
\hline 57 & 2000Q1 & 11527024 & 11531976 & 11420092 & 11467386 & 11405160 & 11418965 & 11436602 & 11438804 & 11443244 & 11504186 & 1.11 & $\checkmark$ \\
\hline 58 & 2000Q2 & 11540510 & 11535318 & 11449276 & 11547162 & 11460952 & 11472615 & 11542980 & 11584438 & 11547361 & 11585674 & 1.19 & $\checkmark$ \\
\hline 59 & 2000Q3 & 11648964 & 11640784 & 11595246 & 11648558 & 11618715 & 11627541 & 11670711 & 11699042 & 11678939 & 11732182 & 1.18 & $\checkmark$ \\
\hline 60 & 2000Q4 & 11790464 & 11807993 & 11793425 & 11796620 & 11800428 & 11815314 & 11772583 & 11759193 & 11785919 & 11867909 & 0.92 & $\checkmark$ \\
\hline 61 & 2001Q1 & NA & 12012900 & 12008190 & 11997020 & 12008803 & 12016107 & 11995024 & 11986295 & 11991847 & 12025407 & 0.32 & $\checkmark$ \\
\hline 62 & 2001Q2 & NA & 12078116 & 12124860 & 12108374 & 12141397 & 12110184 & 12158403 & 12167087 & 12143386 & 12098316 & 0.73 & $\checkmark$ \\
\hline 63 & 2001Q3 & $\mathrm{NA}$ & 12111868 & 12108067 & 12115418 & 12087238 & 12071961 & 12113685 & 12107545 & 12112533 & 12054819 & 0.50 & $\checkmark$ \\
\hline 64 & 2001Q4 & $\mathrm{NA}$ & 12113236 & 12026339 & 12056467 & 12006479 & 12050550 & 12035185 & 12058109 & 12063885 & 12057046 & 0.88 & $\checkmark$ \\
\hline 65 & 2002Q1 & $\mathrm{NA}$ & $\mathrm{NA}$ & 12096445 & 11843077 & 12096997 & 12123007 & 11843907 & 11854858 & 11846743 & 12133368 & 2.45 & $\checkmark$ \\
\hline 66 & 2002Q2 & NA & NA & 12246474 & 12522584 & 12245260 & 12182728 & 12489210 & 12487220 & 12467664 & 12187914 & 2.78 & $\checkmark$ \\
\hline 67 & 2002Q3 & NA & NA & 12415062 & 12417101 & 12407272 & 12345789 & 12338094 & 12318168 & 12334697 & 12327750 & 0.80 & $\checkmark$ \\
\hline 68 & 2002Q4 & NA & NA & 12444199 & 12420053 & 12417811 & 12526491 & 12353810 & 12369179 & 12359836 & 12540003 & 1.50 & $\checkmark$ \\
\hline 69 & 2003Q1 & NA & NA & NA & 12552442 & 12049562 & 12229809 & 12472055 & 12567377 & 12551554 & 12233460 & 4.29 & $\boldsymbol{x}$ \\
\hline 70 & 2003Q2 & NA & NA & $\mathrm{NA}$ & 12783233 & 13154610 & 13087201 & 12746133 & 12913301 & 12899324 & 13157883 & 3.23 & $\boldsymbol{x}$ \\
\hline 71 & 2003Q3 & $\mathrm{NA}$ & $\mathrm{NA}$ & $\mathrm{NA}$ & 12958069 & 12802069 & 12770046 & 12884368 & 12988051 & 12990559 & 12768926 & 1.73 & $\checkmark$ \\
\hline 72 & 2003Q4 & $\mathrm{NA}$ & $\mathrm{NA}$ & NA & 12972644 & 12832633 & 12908260 & 12851482 & 12915938 & 12863632 & 12877043 & 1.09 & $\checkmark$ \\
\hline 73 & 2004Q1 & NA & $\mathrm{NA}$ & $\mathrm{NA}$ & NA & 13169059 & 13186441 & 12695471 & 12613040 & 12659483 & 13148514 & 4.54 & $\boldsymbol{x}$ \\
\hline 74 & 2004Q2 & $\mathrm{NA}$ & $\mathrm{NA}$ & $\mathrm{NA}$ & $\mathrm{NA}$ & 13624201 & 13449928 & 13922201 & 14161269 & 13899949 & 13386416 & 5.78 & $\boldsymbol{x}$ \\
\hline 75 & 2004Q3 & $\mathrm{NA}$ & $\mathrm{NA}$ & $\mathrm{NA}$ & $\mathrm{NA}$ & 13899616 & 13161207 & 13796879 & 13849123 & 13829283 & 13059808 & 6.43 & $\boldsymbol{x}$ \\
\hline 76 & $2004 \mathrm{Q} 4$ & $\mathrm{NA}$ & $\mathrm{NA}$ & $\mathrm{NA}$ & $\mathrm{NA}$ & 13767786 & 14107270 & 13807782 & 13733217 & 13845454 & 14471962 & 5.37 & $\boldsymbol{x}$ \\
\hline 77 & 2005Q1 & NA & NA & NA & NA & NA & 13899893 & 13529314 & 13857597 & 13468266 & 14063632 & 4.42 & $\boldsymbol{*}$ \\
\hline 78 & 2005Q2 & $\mathrm{NA}$ & $\mathrm{NA}$ & $\mathrm{NA}$ & $\mathrm{NA}$ & $\mathrm{NA}$ & 14238683 & 14797252 & 14374313 & 14787460 & 14256239 & 3.92 & $\boldsymbol{x}$ \\
\hline 79 & 2005Q3 & NA & NA & NA & NA & NA & 14540479 & 14511252 & 14671229 & 14562362 & 14472876 & 1.37 & $\checkmark$ \\
\hline 80 & 2005Q4 & $\mathrm{NA}$ & $\mathrm{NA}$ & $\mathrm{NA}$ & $\mathrm{NA}$ & $\mathrm{NA}$ & 14610021 & 14372986 & 14559261 & 14371039 & 14510670 & 1.66 & $\checkmark$ \\
\hline 81 & 2006Q1 & $\mathrm{NA}$ & $\mathrm{NA}$ & $\mathrm{NA}$ & NA & NA & $\mathrm{NA}$ & 14460995 & 14084117 & 14551946 & 14742313 & 4.67 & $\boldsymbol{x}$ \\
\hline 82 & 2006Q2 & $\mathrm{NA}$ & NA & NA & NA & NA & $\mathrm{NA}$ & 14846278 & 15503639 & 15035647 & 14951384 & 4.42 & $\boldsymbol{x}$ \\
\hline 83 & 2006Q3 & $\mathrm{NA}$ & $\mathrm{NA}$ & $\mathrm{NA}$ & $\mathrm{NA}$ & $\mathrm{NA}$ & $\mathrm{NA}$ & 15204136 & 15100976 & 15282114 & 15058873 & 1.48 & $\checkmark$ \\
\hline 84 & 2006Q4 & $\mathrm{NA}$ & $\mathrm{NA}$ & $\mathrm{NA}$ & $\mathrm{NA}$ & $\mathrm{NA}$ & $\mathrm{NA}$ & 15188311 & 15085307 & 15220383 & 15243691 & 1.04 & $\checkmark$ \\
\hline 85 & 2007Q1 & NA & NA & NA & NA & NA & $\mathrm{NA}$ & $\mathrm{NA}$ & 15357434 & 14861978 & 14896794 & 3.33 & $\boldsymbol{x}$ \\
\hline 86 & 2007Q2 & NA & NA & NA & NA & NA & NA & $\mathrm{NA}$ & 15653038 & 16234388 & 16135312 & 3.71 & $\boldsymbol{x}$ \\
\hline 87 & 2007Q3 & $\mathrm{NA}$ & $\mathrm{NA}$ & $\mathrm{NA}$ & $\mathrm{NA}$ & $\mathrm{NA}$ & $\mathrm{NA}$ & $\mathrm{NA}$ & 15867451 & 15754368 & 15543065 & 2.08 & $\checkmark$ \\
\hline \multirow[t]{3}{*}{88} & 2007Q4 & NA & NA & NA & $\mathrm{NA}$ & NA & $\mathrm{NA}$ & NA & 15791955 & 16010743 & 15757890 & 1.60 & $\checkmark$ \\
\hline & Median & - & - & - & - & - & - & - & - & - & - & 1.51 & - \\
\hline & Mean & - & - & - & - & - & - & - & - & - & - & 2.36 & $33 \%$ \\
\hline
\end{tabular}

Source: Author's elaboration. 
Table 16: Sliding spans of trend-cycle series (log), Aggregation 4

\begin{tabular}{|c|c|c|c|c|c|c|c|c|c|c|c|c|c|}
\hline No. Obs. & Date & $\mathrm{S}(1)$ & $\mathrm{S}(2)$ & $\mathrm{S}(3)$ & $\mathrm{S}(4)$ & $\mathrm{S}(5)$ & $\mathrm{S}(6)$ & $\mathrm{S}(7)$ & $\mathrm{S}(8)$ & $\mathrm{S}(9)$ & $\mathrm{S}(10)$ & $\mathrm{S}^{\max }$ & Score \\
\hline 40 & 1995Q4 & 9819331 & 9819252 & 9819312 & 9819341 & 9819183 & 9820605 & 9820627 & 9820628 & 9820627 & 9820627 & 0.01 & 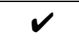 \\
\hline 41 & 1996Q1 & 10006963 & 10006830 & 10006967 & 10007021 & 10007148 & 10007883 & 10007879 & 10007892 & 10007882 & 10007884 & 0.01 & $\checkmark$ \\
\hline 42 & 1996Q2 & 10157765 & 10158470 & 10158341 & 10158171 & 10158496 & 10157458 & 10157378 & 10157386 & 10157391 & 10157391 & 0.01 & $\checkmark$ \\
\hline 43 & 1996Q3 & 10286493 & 10287316 & 10287228 & 10286820 & 10286786 & 10285530 & 10285407 & 10285393 & 10285406 & 10285401 & 0.01 & $\checkmark$ \\
\hline 44 & 1996Q4 & 10417829 & 10417114 & 10417358 & 10417140 & 10416937 & 10419065 & 10418955 & 10418946 & 10418943 & 10418940 & 0.02 & $\checkmark$ \\
\hline 45 & 1997Q1 & 10570504 & 10567780 & 10568060 & 10568028 & 10568344 & 10568752 & 10568670 & 10568659 & 10568647 & 10568647 & 0.02 & $\checkmark$ \\
\hline 46 & 1997Q2 & 10767589 & 10766869 & 10766467 & 10766333 & 10766860 & 10765237 & 10765145 & 10765166 & 10765175 & 10765178 & 0.02 & $\checkmark$ \\
\hline 47 & 1997Q3 & 11033265 & 11034040 & 11033763 & 11033687 & 11033046 & 11032246 & 11032302 & 11032339 & 11032347 & 11032348 & 0.01 & $\checkmark$ \\
\hline 48 & 1997Q4 & 11229141 & 11229844 & 11230165 & 11230438 & 11229237 & 11231040 & 11231156 & 11231140 & 11231135 & 11231129 & 0.01 & $\checkmark$ \\
\hline 49 & 1998Q1 & 11359183 & 11357350 & 11357903 & 11357747 & 11357859 & 11356757 & 11356593 & 11356523 & 11356548 & 11356548 & 0.02 & $\checkmark$ \\
\hline 50 & 1998Q2 & 11398761 & 11393102 & 11393402 & 11393438 & 11394426 & 11393655 & 11393544 & 11393545 & 11393521 & 11393522 & 0.04 & $\checkmark$ \\
\hline 51 & 1998Q3 & 11274174 & 11273737 & 11272831 & 11274023 & 11276733 & 11277918 & 11278106 & 11278177 & 11278074 & 11278077 & 0.04 & $\checkmark$ \\
\hline 52 & 1998Q4 & 11045550 & 11048454 & 11045874 & 11047276 & 11051180 & 11052329 & 11052723 & 11052661 & 11052599 & 11052604 & 0.06 & $\checkmark$ \\
\hline 53 & 1999Q1 & 10929135 & 10921467 & 10919949 & 10919607 & 10922979 & 10921934 & 10922135 & 10921928 & 10922012 & 10922021 & 0.08 & $\checkmark$ \\
\hline 54 & 1999Q2 & 11010690 & 11004012 & 11003176 & 11002199 & 11002006 & 11002021 & 11002114 & 11002130 & 11002163 & 11002160 & 0.07 & $\checkmark$ \\
\hline 55 & 1999Q3 & 11240461 & 11246839 & 11247163 & 11247592 & 11245091 & 11245738 & 11246175 & 11246398 & 11246261 & 11246262 & 0.06 & $\checkmark$ \\
\hline 56 & 1999Q4 & 11478246 & 11485537 & 11486199 & 11487028 & 11486604 & 11485095 & 11485530 & 11485619 & 11485574 & 11485583 & 0.07 & $\checkmark$ \\
\hline 57 & 2000Q1 & 11556174 & 11546103 & 11545931 & 11547872 & 11549791 & 11549528 & 11549803 & 11549153 & 11549288 & 11549254 & 0.08 & $\checkmark$ \\
\hline 58 & 2000Q2 & 11571389 & 11565618 & 11563644 & 11565673 & 11562087 & 11564428 & 11565083 & 11564197 & 11564137 & 11564038 & 0.08 & $\checkmark$ \\
\hline 59 & 2000Q3 & 11679509 & 11689407 & 11691522 & 11694491 & 11687196 & 11688019 & 11689420 & 11689379 & 11688721 & 11688676 & 0.12 & $\checkmark$ \\
\hline 60 & 2000Q4 & 11841783 & 11853557 & 11855391 & 11859506 & 11858431 & 11855601 & 11857592 & 11858032 & 11857813 & 11857904 & 0.14 & $\checkmark$ \\
\hline 61 & 2001Q1 & NA & 11990667 & 11983574 & 11984657 & 11990802 & 11990430 & 11990260 & 11990189 & 11990928 & 11990994 & 0.06 & $\checkmark$ \\
\hline 62 & 2001Q2 & $\mathrm{NA}$ & 12060911 & 12072863 & 12068565 & 12076370 & 12079142 & 12077486 & 12075592 & 12075927 & 12075857 & 0.15 & $\checkmark$ \\
\hline 63 & 2001Q3 & $\mathrm{NA}$ & 12074449 & 12109922 & 12112629 & 12115983 & 12118916 & 12119920 & 12117992 & 12116688 & 12116658 & 0.37 & $\checkmark$ \\
\hline 64 & 2001Q4 & $\mathrm{NA}$ & 12109244 & 12128835 & 12136155 & 12141800 & 12141710 & 12144828 & 12144648 & 12144112 & 12144415 & 0.29 & $\checkmark$ \\
\hline 65 & 2002Q1 & $\mathrm{NA}$ & $\mathrm{NA}$ & 12179708 & 12177353 & 12192037 & 12190896 & 12188886 & 12188213 & 12189629 & 12189547 & 0.12 & $\checkmark$ \\
\hline 66 & 2002Q2 & $\mathrm{NA}$ & $\mathrm{NA}$ & 12250047 & 12239359 & 12240527 & 12238884 & 12233159 & 12232864 & 12233889 & 12233570 & 0.14 & $\checkmark$ \\
\hline 67 & 2002Q3 & $\mathrm{NA}$ & $\mathrm{NA}$ & 12343827 & 12348047 & 12332606 & 12335168 & 12333108 & 12336271 & 12334827 & 12334946 & 0.12 & $\checkmark$ \\
\hline 68 & 2002Q4 & NA & NA & 12489643 & 12503441 & 12507300 & 12512107 & 12514201 & 12518537 & 12517989 & 12518812 & 0.23 & $\checkmark$ \\
\hline 69 & 2003Q1 & $\mathrm{NA}$ & $\mathrm{NA}$ & $\mathrm{NA}$ & 12649441 & 12679307 & 12679098 & 12673664 & 12671623 & 12673967 & 12673728 & 0.23 & $\checkmark$ \\
\hline 70 & 2003Q2 & $\mathrm{NA}$ & $\mathrm{NA}$ & NA & 12756992 & 12765098 & 12760373 & 12754422 & 12750558 & 12751650 & 12750905 & 0.11 & $\checkmark$ \\
\hline 71 & 2003Q3 & $\mathrm{NA}$ & $\mathrm{NA}$ & $\mathrm{NA}$ & 12853094 & 12802142 & 12803050 & 12808640 & 12808415 & 12807790 & 12807741 & 0.39 & $\checkmark$ \\
\hline 72 & 2003Q4 & $\mathrm{NA}$ & $\mathrm{NA}$ & $\mathrm{NA}$ & 12993177 & 12920743 & 12929379 & 12938566 & 12951569 & 12942414 & 12943007 & 0.56 & $\checkmark$ \\
\hline 73 & 2004Q1 & NA & $\mathrm{NA}$ & $\mathrm{NA}$ & NA & 13144119 & 13148419 & 13165885 & 13182427 & 13165674 & 13168181 & 0.29 & $\checkmark$ \\
\hline 74 & 2004Q2 & $\mathrm{NA}$ & $\mathrm{NA}$ & $\mathrm{NA}$ & $\mathrm{NA}$ & 13434318 & 13430303 & 13463353 & 13473369 & 13463203 & 13465164 & 0.32 & $\checkmark$ \\
\hline 75 & 2004Q3 & $\mathrm{NA}$ & $\mathrm{NA}$ & $\mathrm{NA}$ & $\mathrm{NA}$ & 13701433 & 13704231 & 13736645 & 13745107 & 13745479 & 13744780 & 0.32 & $\checkmark$ \\
\hline 76 & 2004Q4 & $\mathrm{NA}$ & $\mathrm{NA}$ & $\mathrm{NA}$ & $\mathrm{NA}$ & 13882085 & 13906842 & 13919657 & 13917000 & 13920361 & 13919969 & 0.27 & $\checkmark$ \\
\hline 77 & 2005Q1 & NA & $\mathrm{NA}$ & $\mathrm{NA}$ & NA & NA & 14064076 & 14056856 & 14037151 & 14044503 & 14042500 & 0.19 & $\checkmark$ \\
\hline 78 & 2005Q2 & $\mathrm{NA}$ & $\mathrm{NA}$ & $\mathrm{NA}$ & $\mathrm{NA}$ & $\mathrm{NA}$ & 14250453 & 14248997 & 14247247 & 14248356 & 14243861 & 0.04 & $\checkmark$ \\
\hline 79 & 2005Q3 & NA & $\mathrm{NA}$ & NA & NA & NA & 14414893 & 14440608 & 14467474 & 14457903 & 14455743 & 0.36 & $\checkmark$ \\
\hline 80 & 2005Q4 & $\mathrm{NA}$ & $\mathrm{NA}$ & $\mathrm{NA}$ & $\mathrm{NA}$ & $\mathrm{NA}$ & 14559786 & 14579465 & 14600078 & 14597436 & 14599483 & 0.27 & $\checkmark$ \\
\hline 81 & 2006Q1 & $\mathrm{NA}$ & $\mathrm{NA}$ & $\mathrm{NA}$ & NA & $\mathrm{NA}$ & $\mathrm{NA}$ & 14741733 & 14727694 & 14737843 & 14741885 & 0.09 & $\checkmark$ \\
\hline 82 & 2006Q2 & $\mathrm{NA}$ & $\mathrm{NA}$ & $\mathrm{NA}$ & NA & NA & NA & 14891341 & 14870111 & 14868909 & 14872149 & 0.15 & $\checkmark$ \\
\hline 83 & 2006Q3 & $\mathrm{NA}$ & $\mathrm{NA}$ & $\mathrm{NA}$ & NA & NA & NA & 15030415 & 15036552 & 15021195 & 15018311 & 0.12 & $\checkmark$ \\
\hline 84 & 2006Q4 & NA & $\mathrm{NA}$ & NA & NA & NA & $\mathrm{NA}$ & 15257763 & 15281505 & 15280486 & 15275079 & 0.15 & $\checkmark$ \\
\hline 85 & 2007Q1 & NA & $\mathrm{NA}$ & NA & NA & NA & NA & $\mathrm{NA}$ & 15521933 & 15526250 & 15541755 & 0.12 & $\checkmark$ \\
\hline 86 & 2007Q2 & NA & $\mathrm{NA}$ & NA & NA & NA & $\mathrm{NA}$ & $\mathrm{NA}$ & 15632343 & 15620505 & 15649737 & 0.18 & $\checkmark$ \\
\hline 87 & 2007Q3 & $\mathrm{NA}$ & $\mathrm{NA}$ & $\mathrm{NA}$ & $\mathrm{NA}$ & $\mathrm{NA}$ & $\mathrm{NA}$ & $\mathrm{NA}$ & 15708419 & 15693603 & 15701783 & 0.09 & $\checkmark$ \\
\hline \multirow[t]{3}{*}{88} & 2007Q4 & $\mathrm{NA}$ & $\mathrm{NA}$ & $\mathrm{NA}$ & $\mathrm{NA}$ & $\mathrm{NA}$ & $\mathrm{NA}$ & $\mathrm{NA}$ & 15884912 & 15887098 & 15883123 & 0.02 & $\checkmark$ \\
\hline & Median & - & - & - & - & - & - & - & - & - & - & 0.11 & - \\
\hline & Mean & - & - & - & - & - & - & - & - & - & - & 0.14 & $0 \%$ \\
\hline
\end{tabular}

Source: Author's elaboration. 
Table 17: Sliding spans of trend-cycle series (log), Aggregation 5

\begin{tabular}{|c|c|c|c|c|c|c|c|c|c|c|c|c|c|}
\hline No. Obs. & Date & $\mathrm{S}(1)$ & $\mathrm{S}(2)$ & $\mathrm{S}(3)$ & $\mathrm{S}(4)$ & $\mathrm{S}(5)$ & $\mathrm{S}(6)$ & $\mathrm{S}(7)$ & $\mathrm{S}(8)$ & $\mathrm{S}(9)$ & $\mathrm{S}(10)$ & $\mathrm{S}^{\max }$ & Score \\
\hline 40 & 1995Q4 & 9837548 & 9840904 & 9834768 & 9838670 & 9835301 & 9823056 & 9822867 & 9822870 & 9822954 & 9839089 & 0.05 & $V$ \\
\hline 41 & 1996Q1 & 10017532 & 10018840 & 10013451 & 10019467 & 10014484 & 10038008 & 10037800 & 10037702 & 10037695 & 10015871 & 0.11 & $\checkmark$ \\
\hline 42 & 1996Q2 & 10128307 & 10127346 & 10129760 & 10129953 & 10131056 & 10130491 & 10130399 & 10130372 & 10130792 & 10127914 & 0.03 & $\checkmark$ \\
\hline 43 & 1996Q3 & 10233136 & 10233302 & 10235839 & 10234957 & 10236553 & 10232956 & 10233023 & 10233027 & 10233227 & 10236116 & 0.14 & $\checkmark$ \\
\hline 44 & 1996Q4 & 10386163 & 10387235 & 10385202 & 10387086 & 10385261 & 10386432 & 10386497 & 10386504 & 10386058 & 10387686 & 0.08 & $\checkmark$ \\
\hline 45 & 1997Q1 & 10562435 & 10563204 & 10559231 & 10560587 & 10559171 & 10561754 & 10561712 & 10561705 & 10561457 & 10560103 & 0.15 & $\checkmark$ \\
\hline 46 & 1997Q2 & 10758399 & 10759566 & 10759971 & 10757514 & 10760543 & 10759759 & 10759674 & 10759671 & 10760230 & 10759041 & 0.14 & $\checkmark$ \\
\hline 47 & 1997Q3 & 10998960 & 11001073 & 11003073 & 11002189 & 11003879 & 11001447 & 11001437 & 11001459 & 11001833 & 11002567 & 0.08 & $v$ \\
\hline 48 & 1997Q4 & 11185951 & 11188912 & 11187347 & 11189544 & 11185800 & 11186088 & 11186242 & 11186224 & 11185319 & 11186248 & 0.07 & $\checkmark$ \\
\hline 49 & 1998Q1 & 11299612 & 11298269 & 11293328 & 11298064 & 11291664 & 11295974 & 11296163 & 11296048 & 11294344 & 11294898 & 0.11 & $\checkmark$ \\
\hline 50 & 1998Q2 & 11328256 & 11321607 & 11323184 & 11321464 & 11322850 & 11324365 & 11324421 & 11324285 & 11325103 & 11323684 & 0.15 & $\checkmark$ \\
\hline 51 & 1998Q3 & 11215715 & 11210163 & 11237725 & 11208705 & 11238204 & 11211438 & 11211540 & 11211699 & 11220758 & 11219613 & 0.10 & $\checkmark$ \\
\hline 52 & 1998Q4 & 11047900 & 11044187 & 11013487 & 11044935 & 11015370 & 11041335 & 11041508 & 11041517 & 11034633 & 11035765 & 0.22 & $\checkmark$ \\
\hline 53 & 1999Q1 & 10953229 & 10945874 & 10942204 & 10948059 & 10944421 & 10946024 & 10945960 & 10945995 & 10945400 & 10947771 & 0.10 & $\checkmark$ \\
\hline 54 & 1999Q2 & 11028428 & 11028058 & 11031033 & 11028735 & 11031798 & 11030614 & 11030401 & 11030275 & 11031244 & 11028949 & 0.14 & $\checkmark$ \\
\hline 55 & 1999Q3 & 11224049 & 11234742 & 11238105 & 11238346 & 11240989 & 11237378 & 11237522 & 11237491 & 11237968 & 11235946 & 0.25 & $\checkmark$ \\
\hline 56 & 1999Q4 & 11449704 & 11462755 & 11457552 & 11461808 & 11460854 & 11455711 & 11456050 & 11456176 & 11455784 & 11457440 & 0.16 & $v$ \\
\hline 57 & 2000Q1 & 11547968 & 11546614 & 11539284 & 11536000 & 11536916 & 11535429 & 11535323 & 11535207 & 11534766 & 11538113 & 0.26 & $\checkmark$ \\
\hline 58 & 2000Q2 & 11577984 & 11571366 & 11577405 & 11570443 & 11576713 & 11575500 & 11575248 & 11574971 & 11575684 & 11576118 & 0.18 & $\checkmark$ \\
\hline 59 & 2000Q3 & 11671126 & 11680011 & 11694374 & 11684145 & 11701794 & 11697210 & 11697801 & 11697932 & 11698508 & 11679543 & 0.34 & $\checkmark$ \\
\hline 60 & 2000Q4 & 11818756 & 11851856 & 11852143 & 11866005 & 11858723 & 11852734 & 11853521 & 11854218 & 11853937 & 11871041 & 0.21 & $\checkmark$ \\
\hline 61 & 2001Q1 & NA & 11989245 & 11978979 & 11975444 & 11975812 & 11968916 & 11968862 & 11968903 & 11968871 & 11965599 & 0.36 & $\checkmark$ \\
\hline 62 & 2001Q2 & $\mathrm{NA}$ & 12055874 & 12057616 & 12054457 & 12045941 & 12036133 & 12035965 & 12035543 & 12034082 & 12029506 & 0.18 & $\checkmark$ \\
\hline 63 & 2001Q3 & $\mathrm{NA}$ & 12054859 & 12096754 & 12103825 & 12077364 & 12081519 & 12083305 & 12083583 & 12080483 & 12081242 & 0.28 & $\checkmark$ \\
\hline 64 & 2001Q4 & $\mathrm{NA}$ & 12127540 & 12124625 & 12124764 & 12131933 & 12109595 & 12111520 & 12113298 & 12110882 & 12114232 & 0.17 & $\checkmark$ \\
\hline 65 & 2002Q1 & $\mathrm{NA}$ & NA & 12180638 & 12166045 & 12160993 & 12155817 & 12154382 & 12155086 & 12154801 & 12154072 & 0.14 & $\checkmark$ \\
\hline 66 & 2002Q2 & $\mathrm{NA}$ & $\mathrm{NA}$ & 12244343 & 12232286 & 12233543 & 12230950 & 12228187 & 12227017 & 12227606 & 12221744 & 0.27 & $\checkmark$ \\
\hline 67 & 2002Q3 & $\mathrm{NA}$ & $\mathrm{NA}$ & 12328533 & 12345842 & 12358792 & 12356263 & 12357740 & 12357883 & 12358297 & 12362645 & 0.17 & $\checkmark$ \\
\hline 68 & 2002Q4 & $\mathrm{NA}$ & $\mathrm{NA}$ & 12446732 & 12506818 & 12528653 & 12571390 & 12576720 & 12581207 & 12581632 & 12549321 & 0.18 & $\checkmark$ \\
\hline 69 & 2003Q1 & $\mathrm{NA}$ & $\mathrm{NA}$ & NA & 12666423 & 12704555 & 12709739 & 12710530 & 12710710 & 12710291 & 12703200 & 0.09 & $\checkmark$ \\
\hline 70 & 2003Q2 & $\mathrm{NA}$ & $\mathrm{NA}$ & $\mathrm{NA}$ & 12757565 & 12794008 & 12769747 & 12766639 & 12764688 & 12764608 & 12768019 & 0.31 & $\checkmark$ \\
\hline 71 & 2003Q3 & $\mathrm{NA}$ & $\mathrm{NA}$ & $\mathrm{NA}$ & 12825018 & 12821115 & 12795697 & 12793343 & 12791879 & 12791710 & 12789393 & 0.30 & $\checkmark$ \\
\hline 72 & 2003Q4 & NA & NA & NA & 12962752 & 12955517 & 12941283 & 12936296 & 12930248 & 12930217 & 12919302 & 0.12 & $\checkmark$ \\
\hline 73 & 2004Q1 & $\mathrm{NA}$ & NA & $\mathrm{NA}$ & $\mathrm{NA}$ & 13168527 & 13169909 & 13160795 & 13153338 & 13152854 & 13141491 & 0.10 & $\checkmark$ \\
\hline 74 & 2004Q2 & $\mathrm{NA}$ & $\mathrm{NA}$ & $\mathrm{NA}$ & $\mathrm{NA}$ & 13377335 & 13426147 & 13427044 & 13430797 & 13428618 & 13424487 & 0.30 & $\checkmark$ \\
\hline 75 & 2004Q3 & $\mathrm{NA}$ & $\mathrm{NA}$ & $\mathrm{NA}$ & $\mathrm{NA}$ & 13727190 & 13678487 & 13692966 & 13706195 & 13704587 & 13704732 & 0.38 & $\checkmark$ \\
\hline 76 & 2004Q4 & $\mathrm{NA}$ & $\mathrm{NA}$ & $\mathrm{NA}$ & $\mathrm{NA}$ & 13890924 & 13900538 & 13908022 & 13908415 & 13909794 & 13907038 & 0.25 & $\checkmark$ \\
\hline 77 & 2005Q1 & $\mathrm{NA}$ & $\mathrm{NA}$ & $\mathrm{NA}$ & $\mathrm{NA}$ & $\mathrm{NA}$ & 14093957 & 14080431 & 14058786 & 14055918 & 14051420 & 0.22 & $\checkmark$ \\
\hline 78 & 2005Q2 & $\mathrm{NA}$ & $\mathrm{NA}$ & $\mathrm{NA}$ & $\mathrm{NA}$ & $\mathrm{NA}$ & 14275744 & 14276099 & 14259702 & 14250728 & 14248954 & 0.45 & $\checkmark$ \\
\hline 79 & 2005Q3 & $\mathrm{NA}$ & $\mathrm{NA}$ & $\mathrm{NA}$ & $\mathrm{NA}$ & $\mathrm{NA}$ & 14427738 & 14451102 & 14462847 & 14457486 & 14457559 & 0.53 & $\checkmark$ \\
\hline 80 & 2005Q4 & $\mathrm{NA}$ & $\mathrm{NA}$ & $\mathrm{NA}$ & NA & NA & 14570041 & 14588974 & 14601944 & 14607443 & 14605560 & 0.31 & $\checkmark$ \\
\hline 81 & 2006Q1 & NA & NA & NA & NA & NA & $\mathrm{NA}$ & 14759792 & 14733277 & 14739737 & 14743815 & 0.13 & $\checkmark$ \\
\hline 82 & 2006Q2 & $\mathrm{NA}$ & $\mathrm{NA}$ & $\mathrm{NA}$ & $\mathrm{NA}$ & $\mathrm{NA}$ & $\mathrm{NA}$ & 14896428 & 14872733 & 14863721 & 14866575 & 0.40 & $\checkmark$ \\
\hline 83 & 2006Q3 & $\mathrm{NA}$ & $\mathrm{NA}$ & $\mathrm{NA}$ & $\mathrm{NA}$ & $\mathrm{NA}$ & $\mathrm{NA}$ & 15032478 & 15040300 & 15032843 & 15025761 & 0.47 & $\checkmark$ \\
\hline 84 & 2006Q4 & $\mathrm{NA}$ & $\mathrm{NA}$ & $\mathrm{NA}$ & $\mathrm{NA}$ & $\mathrm{NA}$ & $\mathrm{NA}$ & 15255056 & 15280259 & 15298116 & 15290439 & 0.20 & $v$ \\
\hline 85 & 2007Q1 & $\mathrm{NA}$ & $\mathrm{NA}$ & $\mathrm{NA}$ & $\mathrm{NA}$ & $\mathrm{NA}$ & NA & $\mathrm{NA}$ & 15522820 & 15545012 & 15549212 & 0.13 & $\checkmark$ \\
\hline 86 & 2007Q2 & $\mathrm{NA}$ & $\mathrm{NA}$ & $\mathrm{NA}$ & $\mathrm{NA}$ & $\mathrm{NA}$ & NA & NA & 15620085 & 15616434 & 15621838 & 0.15 & $\checkmark$ \\
\hline 87 & 2007Q3 & $\mathrm{NA}$ & $\mathrm{NA}$ & $\mathrm{NA}$ & $\mathrm{NA}$ & $\mathrm{NA}$ & $\mathrm{NA}$ & $\mathrm{NA}$ & 15683815 & 15667351 & 15662339 & 0.18 & $\checkmark$ \\
\hline \multirow[t]{3}{*}{88} & 2007Q4 & $\mathrm{NA}$ & $\mathrm{NA}$ & $\mathrm{NA}$ & $\mathrm{NA}$ & $\mathrm{NA}$ & $\mathrm{NA}$ & $\mathrm{NA}$ & 15850902 & 15888758 & 15883117 & 0.19 & $\checkmark$ \\
\hline & Median & - & - & - & - & - & - & - & - & - & - & 0.19 & - \\
\hline & Mean & - & - & - & - & - & - & - & - & - & - & 0.21 & $0 \%$ \\
\hline
\end{tabular}

Source: Author's elaboration. 
Table 18: Sliding spans of trend-cycle series (log), Aggregation 6

\begin{tabular}{|c|c|c|c|c|c|c|c|c|c|c|c|c|c|}
\hline No. Obs. & Date & $\mathrm{S}(1)$ & $\mathrm{S}(2)$ & $\mathrm{S}(3)$ & $\mathrm{S}(4)$ & $\mathrm{S}(5)$ & $\mathrm{S}(6)$ & $\mathrm{S}(7)$ & $\mathrm{S}(8)$ & $\mathrm{S}(9)$ & $\mathrm{S}(10)$ & $\mathrm{S}^{\max }$ & Score \\
\hline 40 & 1995Q4 & 9781679 & 9781741 & 9781734 & 9781715 & 9781709 & 9781682 & 9781710 & 9781710 & 9781708 & 9781708 & 0.00 & $V$ \\
\hline 41 & 1996Q1 & 9973168 & 9973210 & 9973201 & 9973182 & 9973170 & 9973308 & 9973199 & 9973197 & 9973206 & 9973206 & 0.00 & $\checkmark$ \\
\hline 42 & 1996Q2 & 10119721 & 10119654 & 10119652 & 10119625 & 10119612 & 10119574 & 10119613 & 10119614 & 10119612 & 10119612 & 0.00 & $\checkmark$ \\
\hline 43 & 1996Q3 & 10283549 & 10283741 & 10283720 & 10283677 & 10283630 & 10283342 & 10283593 & 10283612 & 10283594 & 10283593 & 0.00 & $\checkmark$ \\
\hline 44 & 1996Q4 & 10403202 & 10402920 & 10403089 & 10403447 & 10403640 & 10404005 & 10403608 & 10403575 & 10403601 & 10403602 & 0.01 & $\checkmark$ \\
\hline 45 & 1997Q1 & 10519363 & 10517814 & 10518193 & 10518954 & 10519398 & 10520566 & 10519385 & 10519301 & 10519381 & 10519385 & 0.02 & $\checkmark$ \\
\hline 46 & 1997Q2 & 10739540 & 10738330 & 10738568 & 10738912 & 10739092 & 10739428 & 10739058 & 10739027 & 10739052 & 10739053 & 0.01 & $\checkmark$ \\
\hline 47 & 1997Q3 & 11035736 & 11036967 & 11036983 & 11036837 & 11036628 & 11035942 & 11036581 & 11036636 & 11036593 & 11036589 & 0.01 & $\checkmark$ \\
\hline 48 & 1997Q4 & 11241351 & 11241907 & 11241775 & 11242017 & 11242104 & 11241984 & 11242006 & 11242044 & 11242042 & 11242040 & 0.00 & $\checkmark$ \\
\hline 49 & 1998Q1 & 11362724 & 11358517 & 11358411 & 11358850 & 11359438 & 11360252 & 11359363 & 11359274 & 11359339 & 11359348 & 0.03 & $\checkmark$ \\
\hline 50 & 1998Q2 & 11385590 & 11381724 & 11381970 & 11382642 & 11382871 & 11384232 & 11382827 & 11382818 & 11382917 & 11382915 & 0.03 & $\checkmark$ \\
\hline 51 & 1998Q3 & 11238409 & 11240686 & 11241135 & 11242085 & 11241815 & 11243084 & 11241808 & 11241978 & 11242069 & 11242053 & 0.04 & $\checkmark$ \\
\hline 52 & 1998Q4 & 11011644 & 11015910 & 11015972 & 11016848 & 11016953 & 11017966 & 11017016 & 11017155 & 11017226 & 11017218 & 0.05 & $\checkmark$ \\
\hline 53 & 1999Q1 & 10903976 & 10898887 & 10898646 & 10898886 & 10899862 & 10901959 & 10900043 & 10899809 & 10899931 & 10899952 & 0.04 & $\checkmark$ \\
\hline 54 & 1999Q2 & 10994521 & 10989857 & 10990396 & 10989617 & 10989374 & 10989061 & 10989289 & 10989100 & 10989078 & 10989081 & 0.04 & $\checkmark$ \\
\hline 55 & 1999Q3 & 11227261 & 11233021 & 11232854 & 11232256 & 11230860 & 11228160 & 11230651 & 11230878 & 11230716 & 11230690 & 0.05 & $\checkmark$ \\
\hline 56 & 1999Q4 & 11455668 & 11464880 & 11464641 & 11465937 & 11465950 & 11465437 & 11466060 & 11466509 & 11466484 & 11466470 & 0.09 & $\checkmark$ \\
\hline 57 & 2000Q1 & 11531493 & 11521798 & 11521321 & 11522711 & 11525219 & 11529546 & 11525556 & 11525332 & 11525594 & 11525636 & 0.08 & $\checkmark$ \\
\hline 58 & 2000Q2 & 11565476 & 11557279 & 11558444 & 11555832 & 11555105 & 11554232 & 11554710 & 11554035 & 11553994 & 11554006 & 0.09 & $\checkmark$ \\
\hline 59 & 2000Q3 & 11679952 & 11689084 & 11688453 & 11686214 & 11683118 & 11678974 & 11682835 & 11682685 & 11682395 & 11682352 & 0.08 & $\checkmark$ \\
\hline 60 & 2000Q4 & 11834588 & 11848856 & 11849523 & 11853624 & 11853177 & 11852888 & 11853720 & 11855312 & 11855276 & 11855230 & 0.17 & $\checkmark$ \\
\hline 61 & 2001Q1 & NA & 11978720 & 11977640 & 11980978 & 11984995 & 11988091 & 11985039 & 11985600 & 11985808 & 11985844 & 0.08 & $\checkmark$ \\
\hline 62 & 2001Q2 & $\mathrm{NA}$ & 12042448 & 12043624 & 12038371 & 12044478 & 12054583 & 12044815 & 12040932 & 12041870 & 12042080 & 0.13 & $\checkmark$ \\
\hline 63 & 2001Q3 & $\mathrm{NA}$ & 12052780 & 12051583 & 12049316 & 12055171 & 12072410 & 12057653 & 12052445 & 12053747 & 12053957 & 0.19 & $\checkmark$ \\
\hline 64 & 2001Q4 & $\mathrm{NA}$ & 12085762 & 12088118 & 12098626 & 12103342 & 12115902 & 12106604 & 12108191 & 12109123 & 12109185 & 0.24 & $\checkmark$ \\
\hline 65 & 2002Q1 & NA & NA & 12163649 & 12170248 & 12180129 & 12181260 & 12180281 & 12181381 & 12181894 & 12182010 & 0.15 & $\checkmark$ \\
\hline 66 & 2002Q2 & $\mathrm{NA}$ & $\mathrm{NA}$ & 12228167 & 12215792 & 12215819 & 12225514 & 12212184 & 12208827 & 12208746 & 12208842 & 0.15 & $\checkmark$ \\
\hline 67 & 2002Q3 & $\mathrm{NA}$ & $\mathrm{NA}$ & 12334077 & 12325457 & 12312981 & 12331416 & 12311755 & 12309056 & 12308122 & 12307926 & 0.21 & $\checkmark$ \\
\hline 68 & 2002Q4 & $\mathrm{NA}$ & $\mathrm{NA}$ & 12467425 & 12482425 & 12479715 & 12496342 & 12484775 & 12491791 & 12491972 & 12491824 & 0.23 & $\checkmark$ \\
\hline 69 & 2003Q1 & $\mathrm{NA}$ & $\mathrm{NA}$ & NA & 12630629 & 12650761 & 12656527 & 12650453 & 12651291 & 12652511 & 12652805 & 0.20 & $\checkmark$ \\
\hline 70 & 2003Q2 & $\mathrm{NA}$ & $\mathrm{NA}$ & $\mathrm{NA}$ & 12768263 & 12773052 & 12767286 & 12766357 & 12760213 & 12759764 & 12759957 & 0.10 & $\checkmark$ \\
\hline 71 & 2003Q3 & $\mathrm{NA}$ & $\mathrm{NA}$ & $\mathrm{NA}$ & 12884107 & 12841595 & 12828502 & 12838169 & 12834569 & 12832879 & 12832435 & 0.43 & $\checkmark$ \\
\hline 72 & 2003Q4 & NA & NA & NA & 12976536 & 12933984 & 12934633 & 12939228 & 12944433 & 12945123 & 12944946 & 0.32 & $\checkmark$ \\
\hline 73 & 2004Q1 & $\mathrm{NA}$ & NA & $\mathrm{NA}$ & NA & 13137649 & 13145182 & 13131604 & 13158445 & 13160667 & 13160617 & 0.22 & $\checkmark$ \\
\hline 74 & 2004Q2 & NA & $\mathrm{NA}$ & $\mathrm{NA}$ & NA & 13439297 & 13430657 & 13426174 & 13465924 & 13467192 & 13466673 & 0.30 & $\checkmark$ \\
\hline 75 & 2004Q3 & $\mathrm{NA}$ & $\mathrm{NA}$ & $\mathrm{NA}$ & $\mathrm{NA}$ & 13719558 & 13710981 & 13724159 & 13752172 & 13753792 & 13752730 & 0.31 & $\checkmark$ \\
\hline 76 & 2004Q4 & $\mathrm{NA}$ & $\mathrm{NA}$ & $\mathrm{NA}$ & $\mathrm{NA}$ & 13921765 & 13929709 & 13933303 & 13920344 & 13921575 & 13919704 & 0.09 & $\checkmark$ \\
\hline 77 & 2005Q1 & $\mathrm{NA}$ & $\mathrm{NA}$ & $\mathrm{NA}$ & $\mathrm{NA}$ & $\mathrm{NA}$ & 14097821 & 14076543 & 14025767 & 14024886 & 14024583 & 0.52 & $\checkmark$ \\
\hline 78 & 2005Q2 & $\mathrm{NA}$ & $\mathrm{NA}$ & $\mathrm{NA}$ & $\mathrm{NA}$ & $\mathrm{NA}$ & 14279001 & 14276122 & 14235226 & 14227539 & 14228648 & 0.36 & $\checkmark$ \\
\hline 79 & 2005Q3 & $\mathrm{NA}$ & $\mathrm{NA}$ & $\mathrm{NA}$ & $\mathrm{NA}$ & $\mathrm{NA}$ & 14430429 & 14454822 & 14462177 & 14454318 & 14452333 & 0.22 & $\checkmark$ \\
\hline 80 & 2005Q4 & NA & $\mathrm{NA}$ & NA & NA & NA & 14554349 & 14571756 & 14596829 & 14601868 & 14597302 & 0.32 & $\checkmark$ \\
\hline 81 & 2006Q1 & NA & NA & NA & NA & NA & $\mathrm{NA}$ & 14723221 & 14727334 & 14739885 & 14743673 & 0.13 & $\checkmark$ \\
\hline 82 & 2006Q2 & $\mathrm{NA}$ & $\mathrm{NA}$ & $\mathrm{NA}$ & NA & $\mathrm{NA}$ & $\mathrm{NA}$ & 14866168 & 14872740 & 14864875 & 14871410 & 0.05 & $\checkmark$ \\
\hline 83 & 2006Q3 & NA & $\mathrm{NA}$ & $\mathrm{NA}$ & NA & NA & NA & 15012129 & 15035157 & 15019695 & 15015018 & 0.15 & $\checkmark$ \\
\hline 84 & 2006Q4 & $\mathrm{NA}$ & $\mathrm{NA}$ & $\mathrm{NA}$ & $\mathrm{NA}$ & $\mathrm{NA}$ & $\mathrm{NA}$ & 15241362 & 15276449 & 15284931 & 15273097 & 0.28 & $\checkmark$ \\
\hline 85 & 2007Q1 & $\mathrm{NA}$ & $\mathrm{NA}$ & $\mathrm{NA}$ & $\mathrm{NA}$ & $\mathrm{NA}$ & $\mathrm{NA}$ & $\mathrm{NA}$ & 15527560 & 15544436 & 15551391 & 0.15 & $\checkmark$ \\
\hline 86 & 2007Q2 & $\mathrm{NA}$ & $\mathrm{NA}$ & $\mathrm{NA}$ & $\mathrm{NA}$ & $\mathrm{NA}$ & $\mathrm{NA}$ & $\mathrm{NA}$ & 15640410 & 15639643 & 15659785 & 0.12 & $\checkmark$ \\
\hline 87 & 2007Q3 & $\mathrm{NA}$ & $\mathrm{NA}$ & $\mathrm{NA}$ & $\mathrm{NA}$ & $\mathrm{NA}$ & $\mathrm{NA}$ & $\mathrm{NA}$ & 15712632 & 15712635 & 15713739 & 0.00 & $\checkmark$ \\
\hline \multirow[t]{3}{*}{88} & 2007Q4 & $\mathrm{NA}$ & $\mathrm{NA}$ & $\mathrm{NA}$ & $\mathrm{NA}$ & $\mathrm{NA}$ & $\mathrm{NA}$ & $\mathrm{NA}$ & 15875506 & 15900422 & 15884213 & 0.15 & $\checkmark$ \\
\hline & Median & - & - & - & - & - & - & - & - & - & - & 0.10 & - \\
\hline & Mean & - & - & - & - & - & - & - & - & - & - & 0.14 & $0 \%$ \\
\hline
\end{tabular}

Source: Author's elaboration. 